San Jose State University

SJSU ScholarWorks

Master's Theses

Master's Theses and Graduate Research

1989

\title{
Modeling the movement of a wetting front in the vadose zone beneath the drainage retention basin, Lawrence Livermore National Laboratory site
}

Richard Kurt Landgraf

San Jose State University

Follow this and additional works at: https://scholarworks.sjsu.edu/etd_theses

\section{Recommended Citation}

Landgraf, Richard Kurt, "Modeling the movement of a wetting front in the vadose zone beneath the drainage retention basin, Lawrence Livermore National Laboratory site" (1989). Master's Theses. 3152. DOI: https://doi.org/10.31979/etd.47ur-nc5c

https://scholarworks.sjsu.edu/etd_theses/3152

This Thesis is brought to you for free and open access by the Master's Theses and Graduate Research at SJSU ScholarWorks. It has been accepted for inclusion in Master's Theses by an authorized administrator of SJSU ScholarWorks. For more information, please contact scholarworks@sjsu.edu. 


\section{INFORMATION TO USERS}

The most advanced technology has been used to photograph and reproduce this manuscript from the microfilm master. UMI films the text directly from the original or copy submitted. Thus, some thesis and dissertation copies are in typewriter face, while others may be from any type of computer printer.

The quality of this reproduction is dependent upon the quality of the copy submitted. Broken or indistinct print, colored or poor quality illustrations and photographs, print bleedthrough, substandard margins, and improper alignment can adversely affect reproduction.

In the unlikely event that the author did not sent UMI a complete manuscript and there are missing pages, these will be noted. Also, if unauthorized copyright material had to be removed, a note will indicate the deletion.

Oversize materials (e.g., maps, drawings, charts) are reproduced by sectioning the original, beginning at the upper left-hand corner and continuing from left to right in photographed in one exposure and is included in reduced form at the back of the book.

Photographs included in the original manuscript have been reproduced xerographically in this copy. Higher quality 6" x 9" black and white photographic prints are available for any photographs or illustrations appearing in this copy for an additional charge. Contact UMI directly to order. 
Order Number 1338705

Modeling the movement of a wetting front in the vadose zone beneath the drainage retention basin, Lawrence I,ivermore National Laboratory site

Landgraf, Richard Kurt, M.S.

San Jose State University, 1989

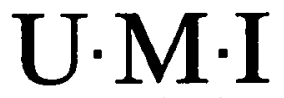





\title{
MODELING THE MOVEMENT OE A WETTING FRONT IN THE VADOSE ZONE BENEATH THE DRAINAGE RETENTION BASIN
}

\section{LAWRENCE LIVERMORE NATIONAL LABORATORY SITE}

\author{
A Thesis \\ Presented to \\ The Faculty of the Department of Geology \\ San Jose State University \\ In Partial Fulfillment \\ of the Requirements for the Degree \\ Master of Science
}

By

Richard Kurt Landgraf

August 1989 
APPROVED FOR THE DEPARTMENT OF GEOLOGY

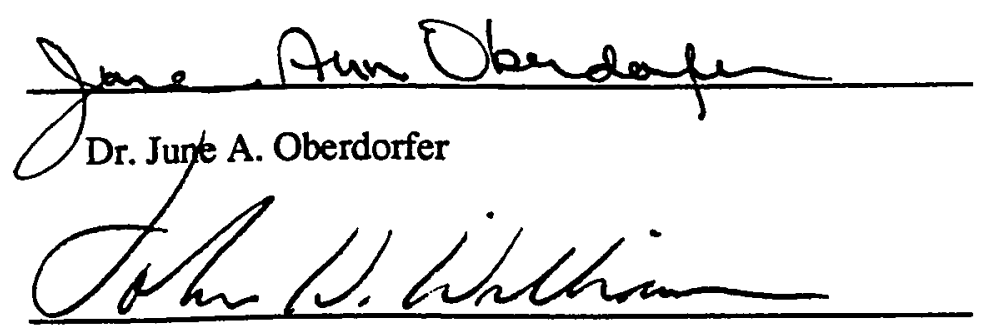

Dr. John W. Williams

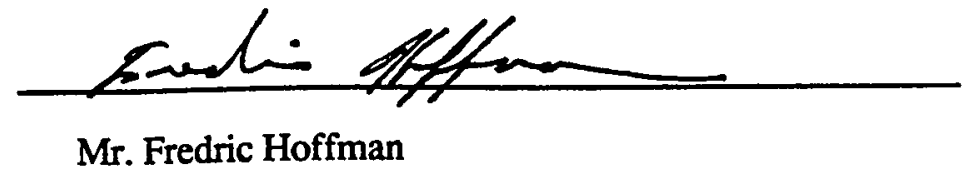

APPROVED FOR THE UNIVERSITY

Th. Lou Sewandoush. 


\section{ACKNOWLEDGEMENTS}

I am deeply indebted to Lawrence Livermore National Laboratory's Environmental Restoration Division for providing the resources, opportunity, and funding for this research project. I would like to thank my thesis committee, Dr. June Oberdorfer and Dr. John Williams, of San Jose State University, and Mr. Fredric Hoffman, of Lawrence Livermore National Laboratory, for all their time and efforts in reviewing my thesis and providing valuable insight. I am also indebted to Kenneth Toney for supplying much of the geologic data and February 1986 storm data for this thesis study.

I would also like to thank June Cramer and Pat Boyd for their work in typing this thesis and typesetting the equations. Their work is greatly appreciated.

Last, I would like to thank my parents, Mr. and Mrs. William C. Landgraf, my family, and my wife, Sheri, for all their love and support throughout this project. 


\section{TABLE OF CONTENTS}

\section{Page}

ABSTRACT xii

INTRODUCTION . .1

Objectives of Thesis Study..............................................5

Unsaturated Flow in the Vadose Zone.....................................5

BACKGROUND AND PREVIOUS STUDIES .............................. 12

Basin Lithology ........................................................ 14

Infiltrometer and Permeameter Test Results..................................... 16

Previous Vadose Zone Modeling Efforts.................................. 17

Variably Saturated Flow Simulation ...................................... 24

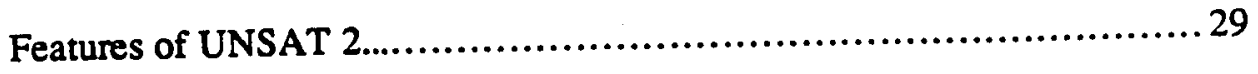

MODEL INPUT AND CALIBRATION ...................................... 35

Modeling the February 1986 Storm......................................4 42

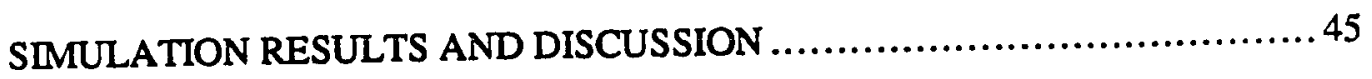

Sensitivity Analysis ................................................. 45

Results and Discussion .............................................. 46

February 1986 Storm Simulation....................................4 47

Lateral Flow Simulation ........................................6 69

Deep Ponding Simulation ...................................... 79

January 1988 Storm Simulation .................................. 93

Discussion on Adjusted Hydrogeologic Parameters .......................101

CONCLUSIONS ......................................................... 103

REFERENCES CITED.................................................... 107 
APPENDIX A. Geologic Logs of Borings ...............................111

APPENDIX B. Soil Material Characteristic Curves ............................117

APPENDIX C. Measured and Extrapolated Surface Node Pressure Heads .........128

APPENDIX D. Computer Input File used for the February 1986

Storm Simulation ..........................................137

APPENDIX E. Relative Moisture Content Plots.............................. 182

APPENDIX F. Table Comparing Saturated Hydraulic Conductivities...............198 


\section{LIST OF ILLUSTRATIONS}

Figure

Page

1. Location Map of Lawrence Livermore National Laboratory.........................2

2. Location Map of Lawrence Livermore National Laboratory, the Drainage

Retention Basin, the Arroyo Seco, and the Arroyo Las Positas. .................4

3. Menisci at various stages of saturation...................................

4. Dependence of conductivity on suction in soils of different textures..............9

5. Characteristic curves relating hydraulic conductivity and moisture

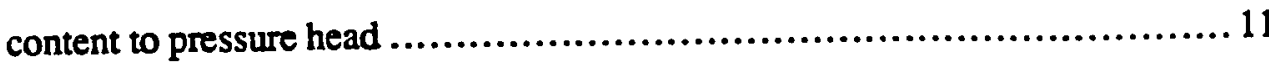

6. Map of drainage retention basin and locations of the LR-Series and

D-Series boreholes ..................................................... 13

7. Generalized geologic cross-section of the portion modeled beneath the drainage retention basin................................................. 15

8. Contour map of basin surface infiltration rates.................................. 18

9. Moisture content vs depth plot of homogeneous material...........................220

10. Elemental control volume...............................................27

11. Angle between the principal hydraulic conductivity and the $\mathrm{X}$ coordinate........33

12. Generalized geologic cross-section through drainage retention basin, showing the various materials used ...................................... 37

13. Finite element grid of drainage retention basin............................. 38

14. Cross-section of drainage retention basin displaying nodes and materials........ 39

15. Initially saturated zone beneath LR-3-R........................................4 41

16. Wetting front movement in the vadose zone produced by the February 1986 storm................................................... 44 
17. February 1986 storm initial conditions..........................................48

18. Saturated zone and wetting front after 1 day of simulation ....................49

19. Saturated zone and wetting front after 2 days of simulation...................50

20. Saturated zone and wetting front after 3 days of simulation...................51

21. Saturated zone and wetting front after 4 days of simulation..................5 52

22. Saturated zone, wetting front and transmission zone after 5 days of simulation........................................................... 53

23. Saturated zone, wetting front and transmission zone after 6 days of simulation.............................................................5 54

24. Saturated zone, wetting front and transmission zone after 7 days of simulation..............................................................55

25. Saturated zone, wetting front and transmission zone after 8 days of simulation...............................................................5 56

26. Saturated zone, wetting front and transmission zone after 9 days of simulation..............................................................5 57

27. Saturated zone, weting front and transmission zone after 10 days of simulation................................................................58

28. Saturated zone, wetting front and transmission zone after 11 days of simulation ............................................................ 59

29. Saturated zone, wetting front and transmission zone after 12 days of simulation.

30. Saturated zone, wetting front and transmission zone after 13 days of simulation.

31. Saturated zone, wetting front and transmission zone after 14 days of simulation 
32. Initial conditions for the lateral flow simulation...................................70

33. Wetting front and saturated zone after 2 days of lateral flow simulation.........71

34. Wetting front and saturated zone after 4 days of lateral flow simulation........72

35. Wetting front and saturated zone after 6 days of lateral flow simulation.........73

36. Wetting front and saturated zone after 8 days of lateral flow simulation..........74

37. Wetting front and saturated zone after 10 days of lateral flow simulation ........75

38. Wetting front and saturated zone after 12 days of lateral flow simulation ........76

39. Initial conditions for the deep ponding simulation........................... 80

40. Wetting front and saturated zone after 2 days of deep ponding simulation ........81

41. Wetting front and saturated zone after 4 days of deep ponding simulation .......82

42. Wetting front and saturated zone after 6 days of deep ponding simulation .......83

43. Wetting front and saturated zone after 8 days of deep ponding simulation .......84

44. Wetting front and saturated zone after 10 days of deep ponding simulation...... 85

45. Wetting front and saturated zone after 12 days of deep ponding simulation...... 86

46. Wetting front and saturated zone after 14 days of deep ponding simulation...... 87

47. Wetting front and saturated zone after 16 days of deep ponding simulation...... 88

48. Wetting front and saturated zone after 18 days of deep ponding simulation...... 89

49. Wetting front and saturated zone after 20 days of deep ponding simulation...... 90

50. Initial conditions of the January 1988 storm ............................... 95

51. Wetting front and saturated zone after 2 days of simulation of the January 1988 storm ..................................................... 96

52. Wetting front and saturated zone after 4 days of simulation of the January 1988 storm ..................................................... 97

53. Weiting front, saturated zone and transmission zone after 6 days of the

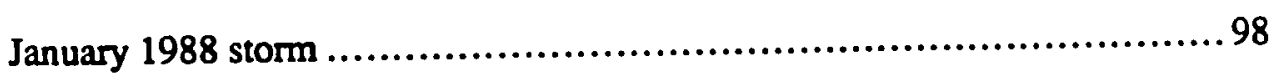


54. Wetting front, saturated zone and transmission zone after 8 days of the January 1988 storm .................................................. 99

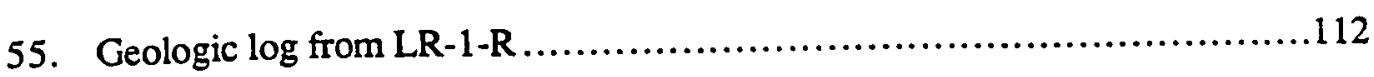

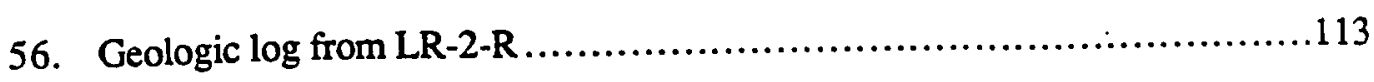

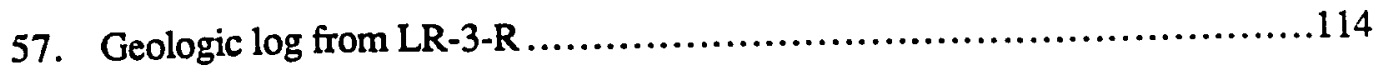

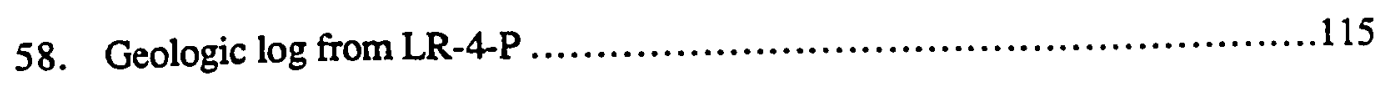

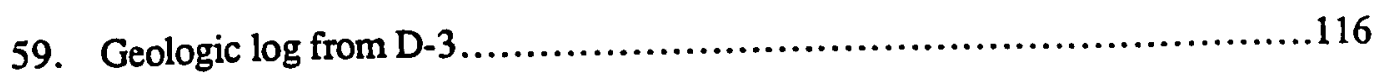

60. Soil material 1 pressure head vs moisture content characteristic curve..........118

61. Soil material 1 relative conductivity vs moisture content characteristic curve ...119

62. Soil material 2 pressure head vs moisture content characteristic curve...........120

63. Soil material 2 relative conductivity vs moisture content characteristic curve ...121

64. Soil material 3 pressure head vs moisture content characteristic curve..........122

65. Soil material 3 relative conductivity vs moisture content characteristic curve $\ldots 123$

66. Soil material 4 pressure head vs moisture content characteristic curve............124

67. Soil material 4 relative conductivity vs moisture content characteristic curve $\ldots 125$

68. Soil material 5 pressure head vs moisture content characteristic curve..........126

69. Soil material 5 relative conductivity vs moisture content characteristic curve ...127

70. Initial relative moisture content plot of the February 1986 storm ...............183

71. Relative moisture content plot of the February 1986 storm after 1 day ..........184

72. Relative moisture content plot of the February 1986 storm after 2 days .........185

73. Relative moisture content plot of the February 1986 storm after 3 days .........186

74. Relative moisture content plot of the February 1986 storm after 4 days.........187

75. Relative moisture content plot of the February $1986 \mathrm{storm}$ after 5 days.........188

76. Relative moisture content plot of the February 1986 storm after 6 days .........189

77. Relative moisture content plot of the February 1986 storm after 7 days .........190 
78. Relative moisture content plot of the February $1986 \mathrm{storm}$ after 8 days ........191

79 Relative moisture content plot of the February 1986 storm after 9 days .........192

80. Relative moisture content plot of the February 1986 storm after 10 days........193

81. Relative moisture content plot of the February 1986 storm after 11 days.........194

82. Relative moisture content plot of the February 1986 storm after 12 days.........195

83. Relative moisture content plot of the February 1986 storm after 13 days........196

84. Relative moisture content plot of the February 1986 storm after 14 days.........197 


\section{LIST OF TABLES}

Table Page

1. Saturated hydraulic conductivity values from basin core samples ..............17

2. Measured and extrapolated surface node pressure heads ......................129

3. Input data for the February 1986 storm simulation...........................138

4. Table comparing the saturated hydraulic conductivities..........................199 


\begin{abstract}
MODELING THE MOVEMENT OF A WETTING FRONT IN THE VADOSE ZONE BENEATH THE DRAINAGE RETENTION BASIN, LAWRENCE LIVERMORE NATIONAL LABORATORY SITE
\end{abstract}

by Richard K. Landgraf

A two-dimensional, variably saturated, finite element numerical model was used to model a 260 foot $(79 \mathrm{~m}) \times 55.3$ foot $(16.9 \mathrm{~m}) \mathrm{NW}-\mathrm{SE}$ transect through the heterogeneous vadose zone beneath Lawrence Livermore National Laboratory's (LLNL) 28 acre foot (3.5 $\mathrm{x} 10^{4}$ cubic meter) basin retention basin. The model was calibrated using the spatial and temporal wetting front patterns generated by an extensive network of basin vadose resistance cells during a severe mid-February 1986 storm.

The vadose zone model was used to study the wetting front movements produced during four simulations: the February 1986 storm, a deep ponding simulation, a lateral flow simulation, and a January 1988 storm. Wetting front migration was found to be dependent upon site geology, depth of ponded water, and surface moisture conditions.

The development of a moisture transmission zone at a silt/sand interface at 28 feet ( 8 $\mathrm{m}$ ) below the basin surface was predicted by the model during each of the four simulations. In addition, the model helped to confirm the existence of a permeable zone in the southeast portion of the basin (not modeled). 


\section{INTRODUCTION}

The purpose of this thesis project was to furnish Lawrence Livermore National Laboratory (LLNL) with a detailed simulation study of the movement of a wetting front in the heterogeneous vadose zone beneath the drainage retention basin at LLNL and to simulate the effect of ground water recharge beneath the basin. The two-dimensional numerical model UNSAT2 was used in this vadose zone study. The model was calibrated, spatially and temporally, using wetting front patterns generated by field vadose zone resistance cells during a severe mid-February 1986 storm. Four simulations are discussed in this paper. They are: the February 1986 storm simulation, a deep ponding simulation, a lateral flow simulation, and a January 1988 storm simulation.

Lawrence Livermore National Laboratory (LLNL) is located in the southeastern portion of the Livermore Valley, approximately 40 miles $(65 \mathrm{~km})$ east of San Francisco (figure 1). The Livermore Valley was created by the late Mesozoic-late Tertiary uplift of the Diablo Range. Valley sediments consist predominantly of detrital alluvial deposits of late Tertiary-Quaternary age which were deposited as a result of a "complex pattern of regional deformation, uplift, erosion, and deposition" (Carpenter et al., 1984). Sediment thicknesses may locally exceed 0.6 miles $(1 \mathrm{~km})$ in the valley. Age dating techniques performed on LLNL soils indicate that the upper 69 feet (21 meters) were deposited in the last 300,000 years.

Site geology consists of complexly interbedded and interlensed, Quaternary and Late Tertiary clays, silts, sands and gravels, deposited by a number of meandering streams and rivers which drained the Livermore Valley (Stone et al., 1982, and Carpenter et al., 1984). Ground water elevations fluctuate seasonally due to the influence of precipitation, local agricultural pumpage, and recharge from the drainage retention basin, the Arroyo 


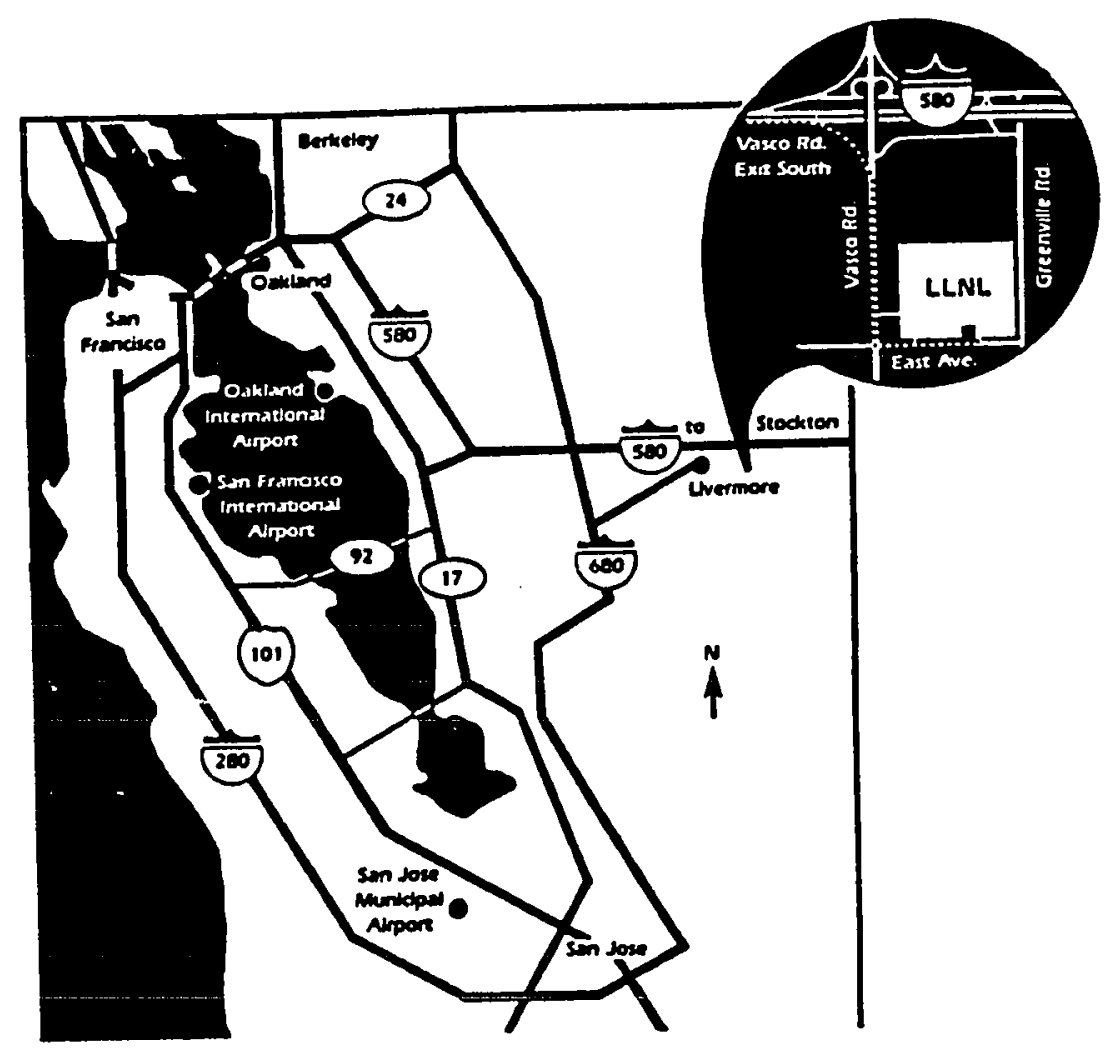

Figure 1. Location map of Lawrence Livermore National Laboratory (from Stone et al., 1982). 
Seco, and the Arroyo Las Positas (figure 2). Ground water mounding beneath the drainage retention basin resulting from the percolation of ponded runoff water has been documented by authors Toney and Oberdorfer (1986) during their 1985-1986 hydrogeologic investigation of the drainage retention basin.

During their hydrogeologic investigation of the drainage retention basin, Oberdorfer and Toney (1986) installed three strings of paired resistance cells in a NW - SE transect across the drainage retention basin. Cells were installed at eight depths varying from 2 to 55 feet $(61-1,680 \mathrm{~cm})$ beneath the basin floor and were wired to a Campbell Scientific datalogger. Soil resistance readings are measured every 10 minutes, averaged each hour and magnetically recorded on a cassette tape. Through extensive monitoring of precipitation, basin water levels, basin soil resistance, and nearby ground water levels, the movement of a wetting front through the basin vadose zone was tracked, and ground water recharge was quantified.

In mid-February 1986, a severe storm hit the Livermore Valley, precipitating 4.89 inches $(12.42 \mathrm{~cm})$ of rain, most of which occurred over a six day period. The storm caused the 28 acre-foot ( $3.5 \times 10^{4}$ cubic meters) drainage retention basin to fill to its maximum level of 10 feet $(3 \mathrm{~m})$ and overflow for two days at its northern edge. As the ponded water percolated into the vadose zone, the resistance data generated a good record of the migration of the wetting front from the surface to the water table.

The wetting front generated by this storm was modeled using a two-dimensional, Galerkin finite element, numerical model, UNSAT2. The numerical model was calibrated using the wetting front field data to develop a useful model for future predictive wetting front analysis. Four percolation simulations were performed by the calibrated model: the February 1986 storm, a lateral flow simulation, a deep ponding simulation, and a January 


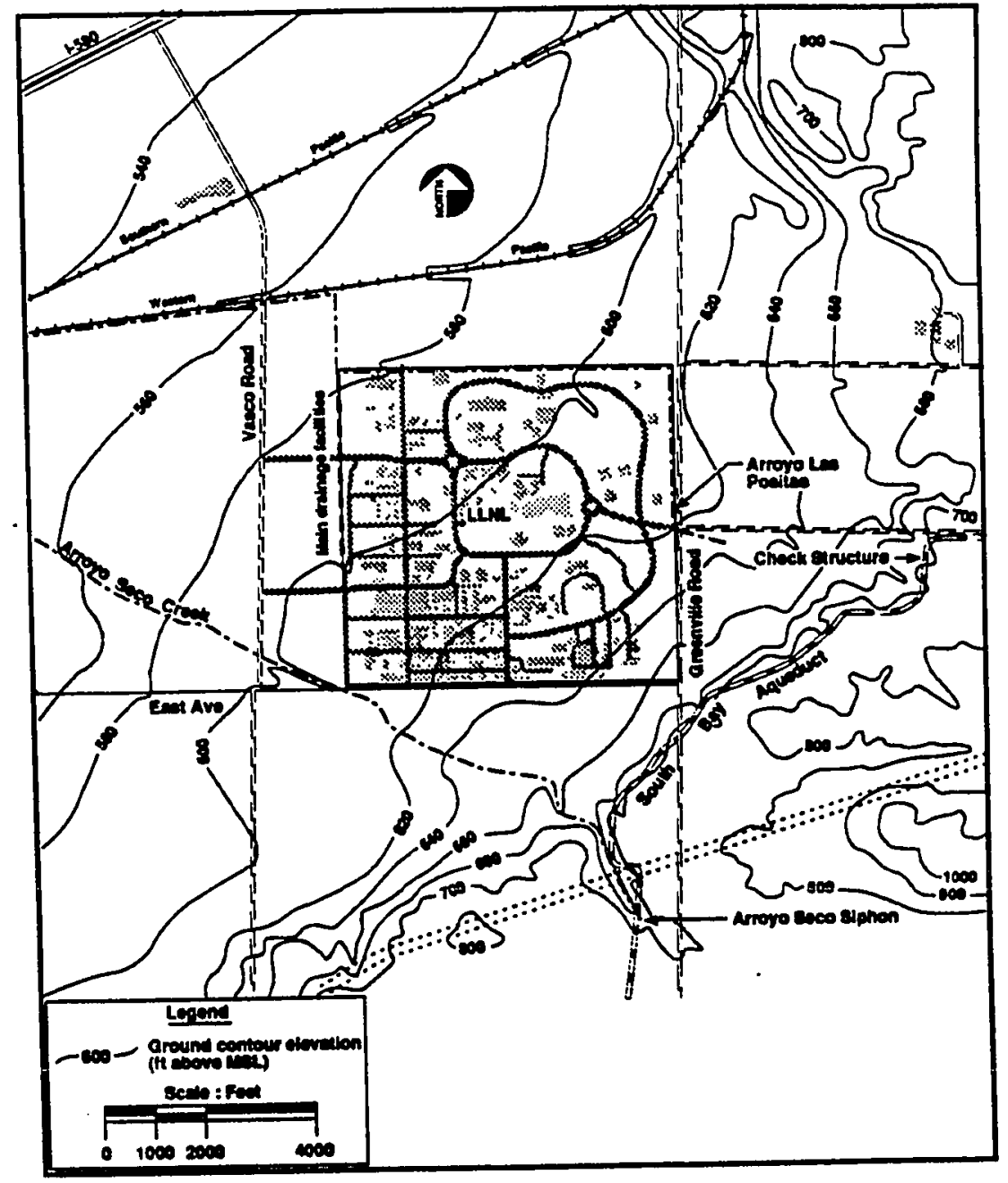

Figure 2. Location map of Lawrence Livermore National Laboratory, the drainage retention basin, the Arroyo Seco, and the Arroyo Las Positas (adapted from Carpenter et al., 1984). 
1988 storm simulation. The results of these simulations are discussed in detail in this paper.

\section{Obiectives of Thesis Study}

The purpose of this project was to furnish Lawrence Livermore National Laboratory with a detailed simulation study of infiltration into the vadose zone beneath the drainage retention basin at Lawrence Livermore National Laboratory. To complete this study, six objectives were established.

First, working soil parameters/properties were to be developed to calibrate the model and duplicate the known resistance data. Second, a sensitivity analysis of the model was to be performed to establish how the input parameters affect the model's performance. Third, the movement of the wetting front produced by the infiltration of ponded runoff water resulting from a severe mid-February, 1986, storm was to be simulated and used to calibrate the model. Fourth, once the computer model had been calibrated, it was to be studied at intermediate time steps to determine how, specifically, the wetting front migrates and how moisture patterns change in the vadose zone. Fifth, the simulation was to be used to study the effects heterogeneous alluvium have on the migration of the wetting front. Last, the calibrated soil characteristics/properties were to be used to determine the relative hydrogeologic conditions that prevail in the vadose zone under various scenarios.

\section{Unsaturated Flow in the Vadose Zone}

The purpose of this section is to familiarize the reader with some of the fundamental concepts of unsaturated flow in the vadose zone. For a more detailed discussion on the 
physics of unsaturated flow, the author suggests Freeze and Cherry (1979), Bear (1979), Baver et al. (1972), Kirkham and Powers (1972), Hillel (1971), and Childs (1969).

Unsaturated flow in the vadose zone is a complex phenomenon, which may involve soil hystersis, variable hydraulic conductivity, variable moisture content, variable pressure head/suction, water uptake by plants, infiltration and/or evaporation, and a general dependence upon antecedent soil moisture content. Hydrogeologists typically define the vadose zone as the zone of soil/rock between the ground surface and the water table (saturated zone). For this reason, and the fact that saturated regions may occur in the vadose zone (i.e., a perched water table) the term "vadose zone" is preferred over the term "unsaturated zone."

In saturated soils, the water table represents the zero pressure head boundary $(\psi=0)$, so that below the water table $\psi>0$ and above the water table $\psi<0$. The negative pressure head $(\Psi)$, or suction, is due to the physical affinity of the water to the soil-particle surfaces and capillary pores. Flow in the vadose zone is the result of gravitational forces and of pressure gradients, as in the saturated zone. However, in the vadose zone, the pressure gradients are due to contrasting matric suction (negative pressure heads) and, as a result of the suction gradients overcoming gravitational forces, water tends to flow from low suction zones to high suction zones (Hillel, 1971).

The affinity of the water to the soil particle (i.e., matric suction) is created by soil pore surface-tension forces. "A microscopic inspection would reveal a concave meniscus extending from grain to grain across each pore channel," (Freeze and Cherry, 1979) during unsaturated soil conditions (figure 3). The radius of curvature of the concave meniscus is a function of matric suction, grain size, and water content. The lower the water content, the higher the matric suction, and smaller the radius of curvature of each grain to grain 


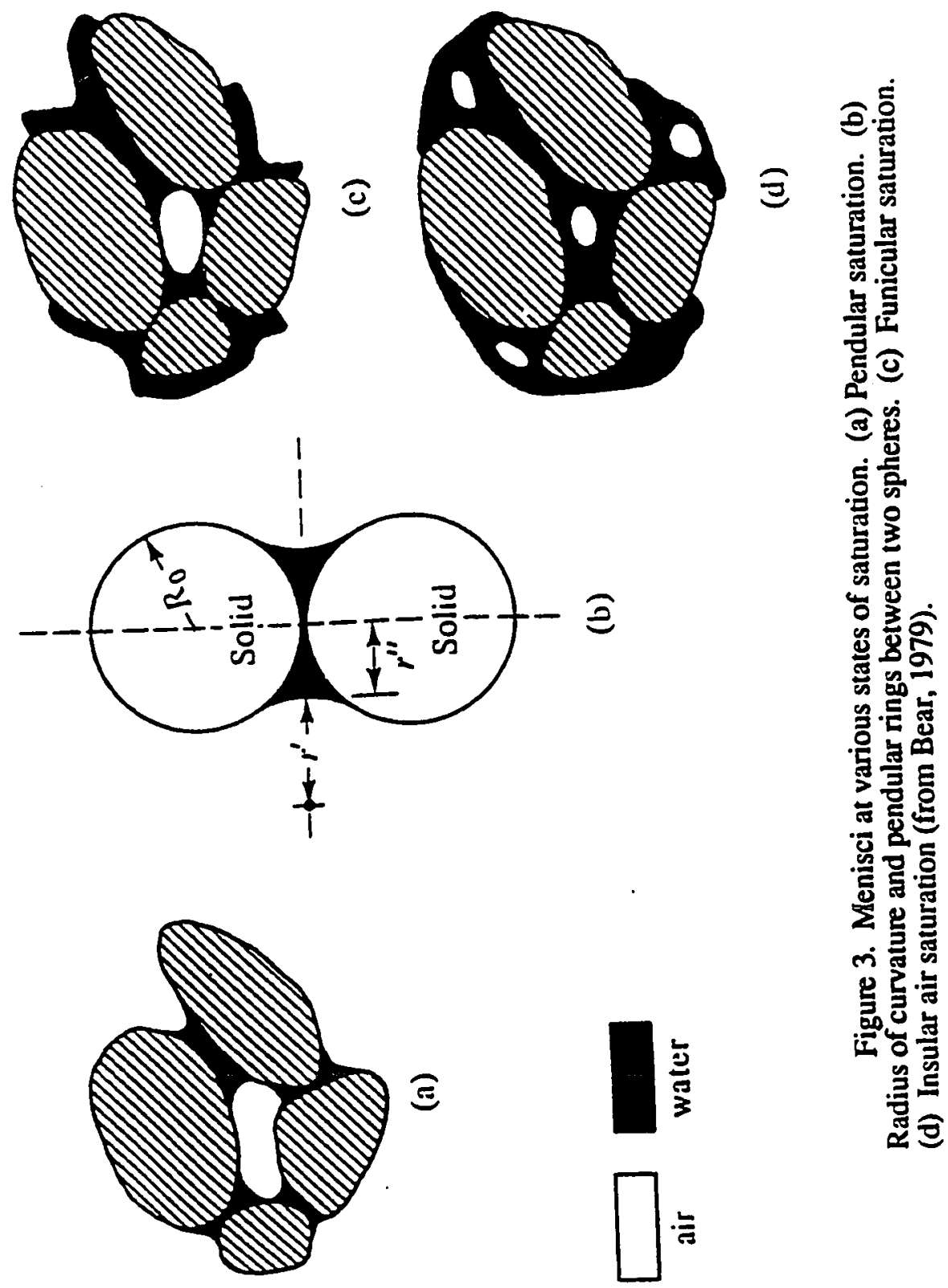


meniscus. Smaller grained soils, such as clays and silts, can support smaller radii of curvature and therefore sustain much larger matric suction values than larger grained soils, such as coarse sands and gravels.

There are two primary driving forces which control unsaturated flow in the vadose zone. First, as mentioned above, the matric suction gradient acts as a moisture migrating force by pulling (or sucking) moisture from low suction zones to high suction zones. Second, in soils displaying uniform negative pressure heads (matric suction) throughout a vertical profile (i.e., no suction gradient exists), the moving force may be driven by gravitational forces, provided the gravitational forces can overcome the initial soil matric suction forces. This is what is otherwise known as drainage. Often, these two forces will act together during the passing of a wetting front through the vadose zone.

While the hydraulic conductivity of a homogeneous, isotropic saturated soil remains constant, the hydraulic conductivity of a homogeneous, isotropic unsaturated soil varies with respect to pressure head and moisture content. In saturated soils, all connecting pores are full and capable of transmitting water at a maximum conductivity. However, in unsaturated soils, some pores become filled with air, which blocks the flow of water, therefore a smaller number of pores can transmit water and the conductivity decreases. Typically, the larger the soil grain (and pore size) the faster the soil desaturates and the faster the unsaturated hydraulic conductivity decreases. Conversely, finer grained soils tend to retain moisture longer, under larger negative pressure heads, and do not desaturate as quickly. As a result, the unsaturated hydraulic conductivity of finer grained soils decreases more gradually than that of larger/coarser grained soils (figure 4). The hydraulic conductivity/moisture content and pressure head/moisture content relationships are known as soil characteristics. 


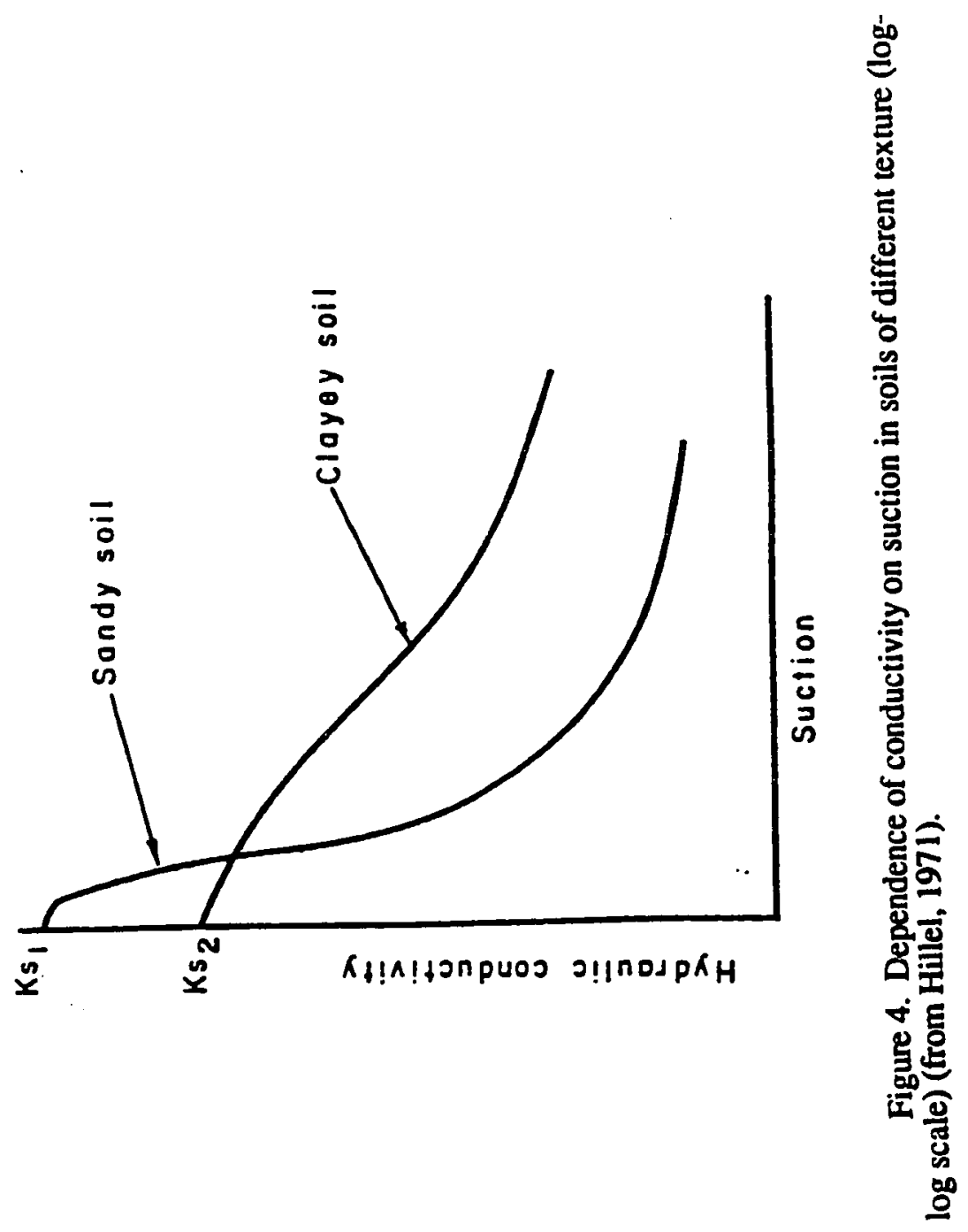


It is well known that in the saturated zone, soils with larger and more conductive pores (say, gravels) have higher hydraulic conductivity values than do soils with smaller and more restrictive pores (say, silts). However, in the vadose zone, as pressure heads decrease, gravels or other coarser grained soils will desaturate much more rapidly than soils with smaller pores (silts). Many of the silt pores will remain full and more conductive and, as the vadose zone desaturates, may become more conductive than the gravel. As a result, the gravel may actually impede flow of moisture, while greater moisture flux develops in the silt.

Since in the field the soil is unsaturated most of the time, it often happens that flow is more appreciable and persists longer in clayey than in sandy soils. For this reason, the occurrence of a layer of sand in a fine-textured profile, far from enhancing flow, may actually impede unsaturated water movement until water accumulates above the sand and suction decreases sufficiently for water to enter the large pores of the sand (Hillel, 1971).

The unsaturated soil characteristics may have complex relationships with respect to antecedent moisture conditions and whether the soil is wetting or drying. In other words, soil characteristic curves may have different shapes depending if they are measured during the wetting or drying of the soil. This is known as soil hystersis (figure 5). An infinite number of scanning curves may exist between the wetting or drying curves. They describe the moisture content vs pressure head or hydraulic conductivity relationships during partial wetting or drying. Soil hysteresis is typically the result of trapped air in pore spaces during wetting, moisture contact angle ("the raindrop effect"), the increased suction required as water reenters smaller pores ("the ink-bottle effect") (Bear, 1979), and/or the shrink/swell potential of the soil. In some soils, the difference between the wetting and drying curves is minimal and often ignored. Since UNSAT2 assumes no soil hystersis, only single (nonhysteretic) characteristic curves were used. 

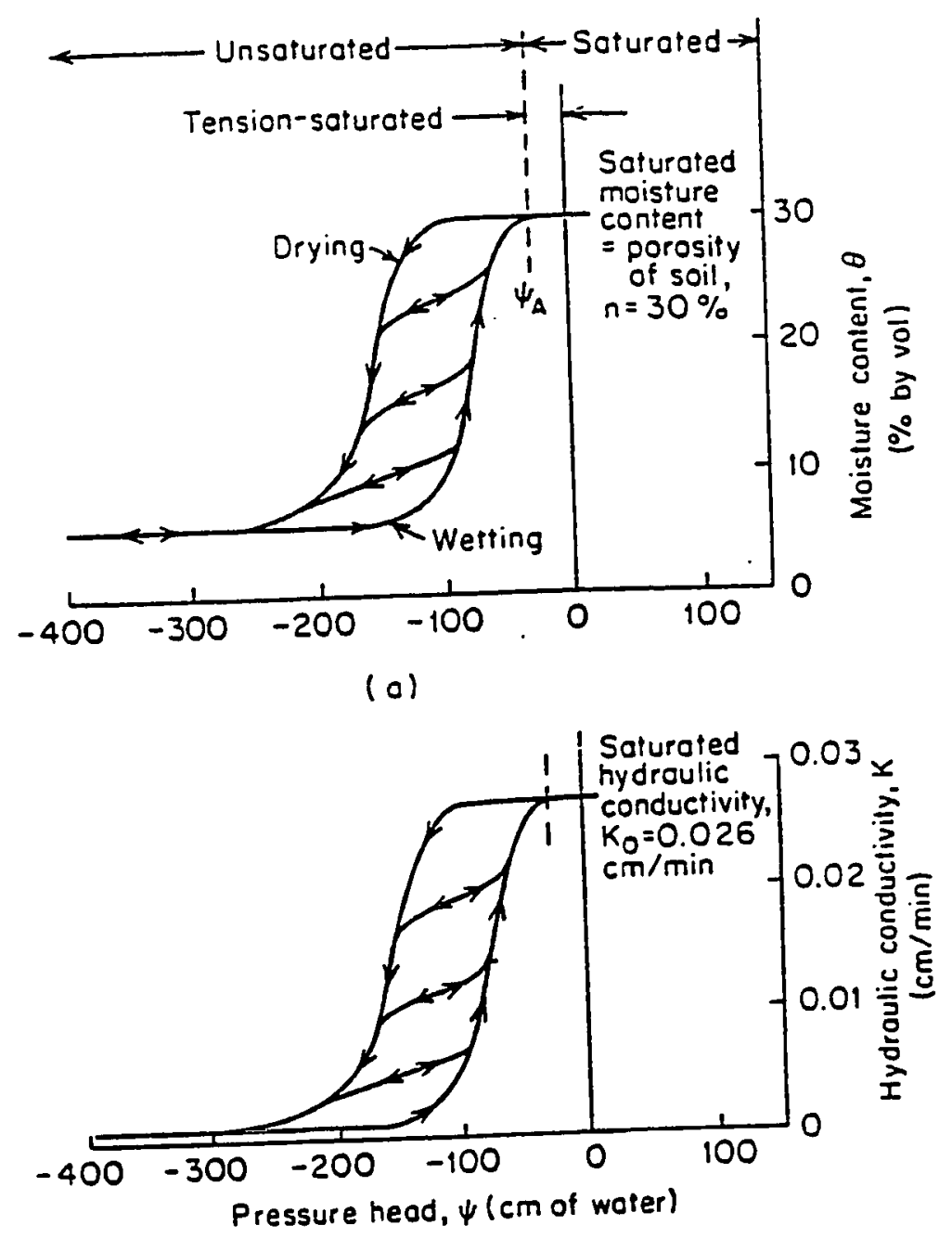

(b)

Figure 5. Characteristic curves relating hydraulic conductivity and moisture content to pressure head for a naturally occurring sand soil. Note soil hysteresis and scanning curves (from Freeze and Cherry, 1979). 


\section{BACKGROUND AND PREVIOUS STUDIES}

A major portion of the background data used in this study was accumulated by San Jose State University graduate student Kenneth Toney as part of his drainage retention basin monitoring, from August 1985 to December 1986. Toney conducted a hydrogeologic investigation of ground water recharge near the drainage retention basin at LLNL (Toney, Thesis Draft 1988). His work included the drilling and logging of four bore holes (LR-1-R, LR-2-R, LR-3-R, and LR-4-P, (see figure 6 for location and Appendix A for logs) in the floor of the drainage retention basin; the construction of one piezometer (LR-4-P) and three paired resistance cell strings (LR-1-R, LR-2-R, and LR-3R); the monitoring of vadose zone soil resistance, precipitation, basin water levels, and ground water levels in the vicinity of the basin; and performing infiltrometer and triaxial permeameter tests on some basin soils and core samples.

The three paired resistance cell strings were constructed by boring three approximately 50 foot $(15 \mathrm{~m})$ deep holes in the basin floor and installing eight pairs of Soiltest resistance cells at various depths in each hole. Each cell was embedded in 6 inches $(15 \mathrm{~cm})$ of electrically neutral, 200 mesh silica flour and sealed above and below with 1 foot $(0.3 \mathrm{~m})$ of bentonite pellets at approximately $2,5,10,15,20,30,40$, and 50 foot $(0.6,1.5,3,4,6,9,12$, and 15 meters) depths in each boring (LR-1-R, LR-2-R, and LR3-R) (Toney, Thesis draft, 1988). Depths of paired resistance cells are known specifically for each cell, but vary between each of the strings. Soil resistance at each cell is measured every 10 minutes, averaged each hour, and magnetically recorded on a cassette tape by a Campbell Scientific $21 \mathrm{X}$ datalogger. The soil resistance values yield, both spatially and temporally, a relative indication of the soil moisture and the pattem of the wetting front as it moves 


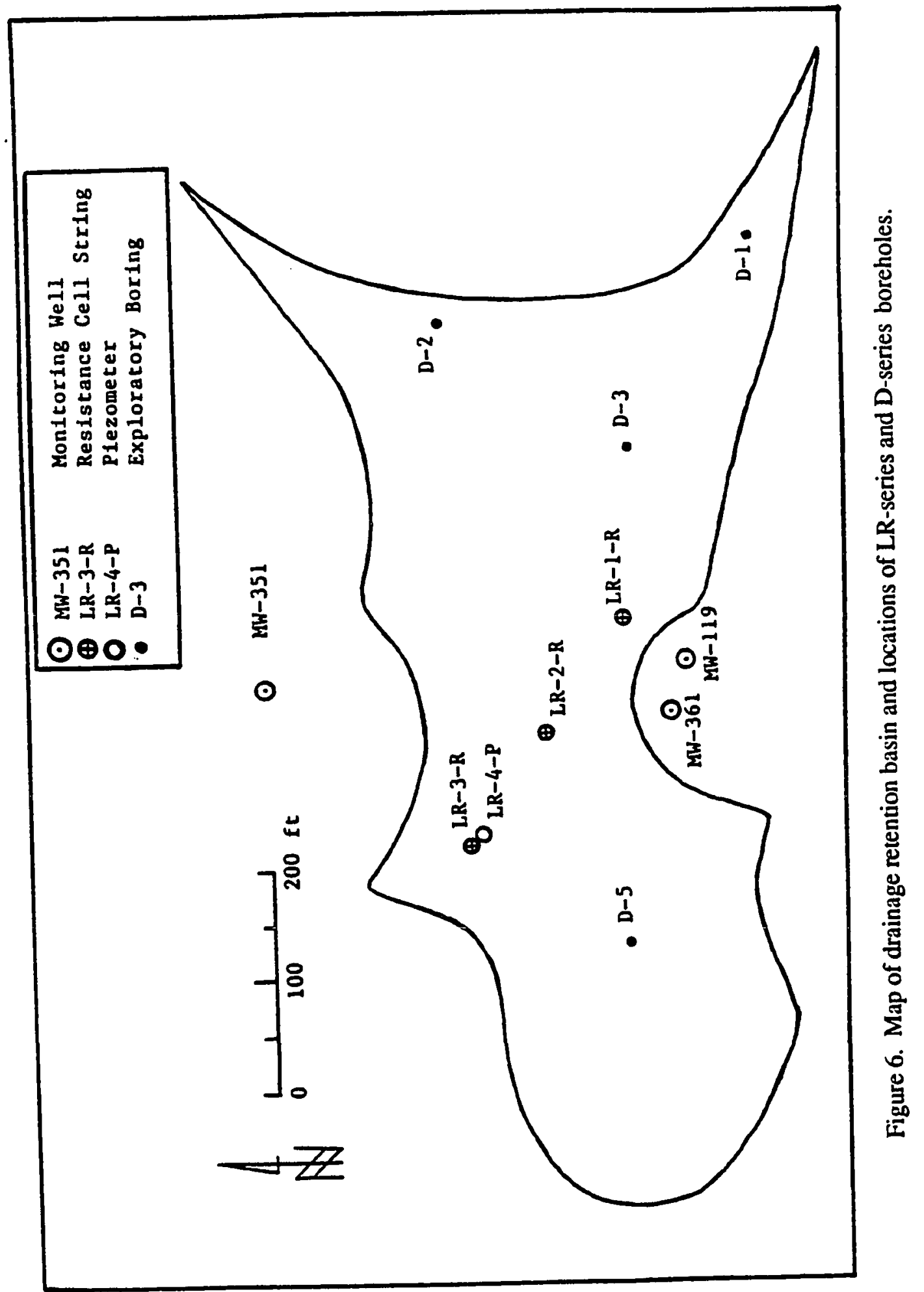


downward through the vadose zone during recharge events (an increase in soil moisture results in lower resistance values).

One particular recharge event occurred in 1986, between February 11 and February 19. During this storm, 4.89 inches $(12.42 \mathrm{~cm})$ of rain fell, causing the 28 acrefoot (3.5 $\times 10^{4}$ cubic meters) drainage retention basin at LLNL to fill to its maximum depth of 10 feet $(3.0 \mathrm{~m})$ and eventually overflow at its northern edge. Vadose zone soil resistance, basin water level, precipitation, and nearby monitoring well water levels were monitored extensively during the storm. The modeling of the migration of the wetting front created by this storm is the focus of this thesis study.

\section{Basin Lithology}

The 4 acre ( $1.6 \times 10^{4}$ square meters) drainage retention basin is underlain by heterogeneous alluvial sediments consisting of interbedded and interlensed clays, silts, sands, and gravels. Several borehole logs (LR-1-R, LR-2-R, LR-3-R, LR-4-P, D-1, D-2, D-3, and D-5) (fig. 6) and three nearby monitoring well logs (MW-119, MW-361, and MW-351) (fig. 6) were used to determine subsurface basin lithology and geologic properties. Based upon the above geologic information, a generalized NW-SE trending geologic cross section (fig. 7) was drafted through the three logged borings (LR-1-R, LR2-R, and LR-4-P). The cross section lithology was simplified for modeling purposes by combining adjacent geologic materials with similar hydrogeologic properties and characterizing them by their dominant constituents (as is commonly done when interpreting borehole data for alluvial sediments). The reason for creating a generalized cross section of the basin is that the individual heterogeneities characteristic of valley alluvium would be 


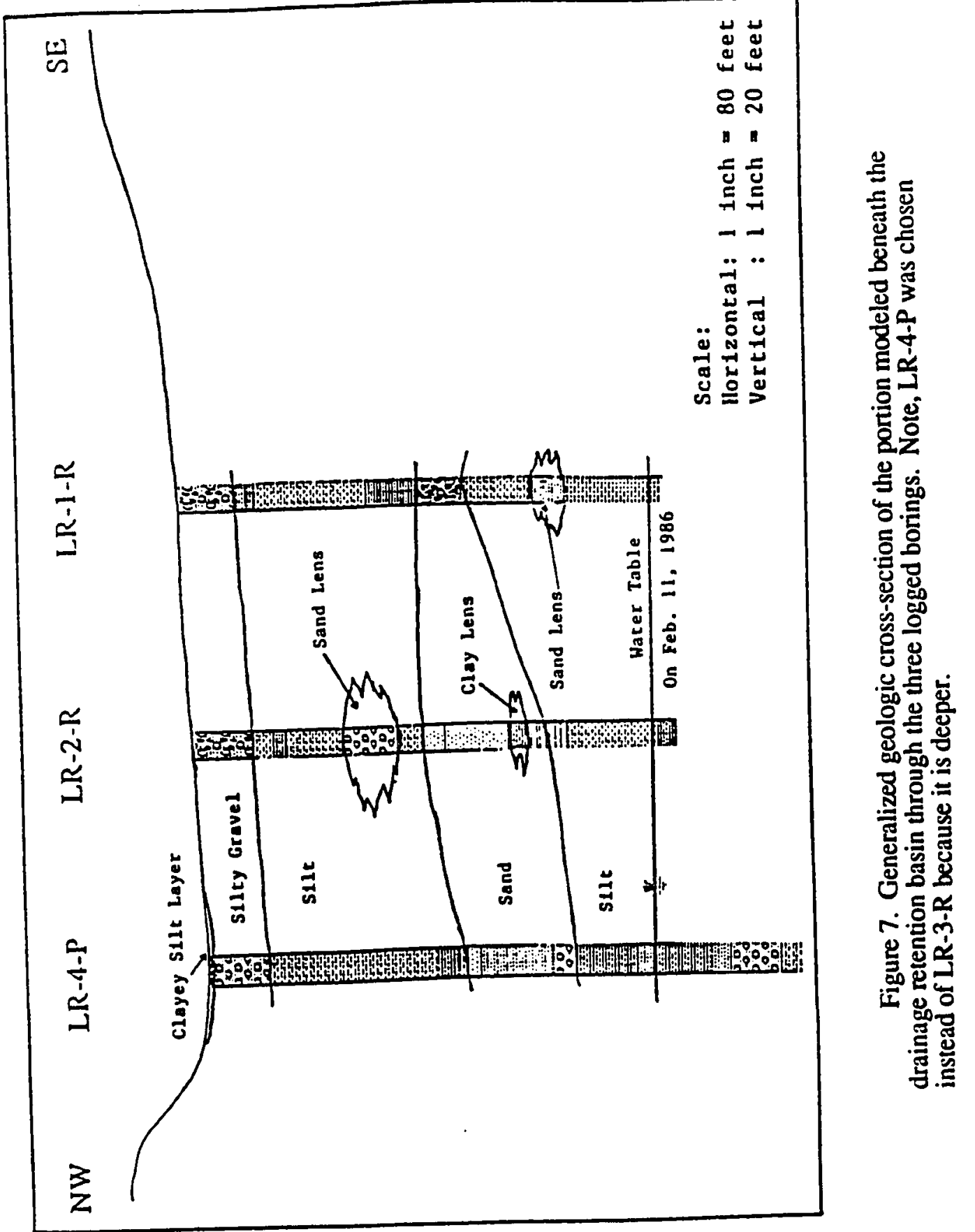


extremely difficult (if not impossible) to model because they are typically small and unknown between boreholes.

The basin lithology between the LR-series boreholes at the center of the basin and the D-series boreholes (Carpenter, 1984) (primarily D-3, see Appendix A) does not correlate very well. The D-series boreholes (not used in the cross-section) indicate that a fairly thick , 20 to 30 foot ( $6-9 \mathrm{~m}$ ) layer of moderate to high permeability silty-sandy, gravel exists under the southeast portion of the basin. In addition, high rates of infiltration are known to occur in the southeast corner of the drainage retention basin (Toney, Thesis Draft, 1988). The southeastern zone of moderate-high permeability is likely to affect local ground water recharge; it does not, however, seem to affect the migration of the wetting front between the resistance cell strings. In other words, the wetting front is not seen to migrate any faster at $L R-1-R$ (closest to $D-3$ ) than at LR-3-R (furthest from D-3). For these reasons and because the resistance data modeled is known only for LR-3-R, LR-2-R, and $L R-1-R$, the basin cross section used in the simulation exists from LR-3-R to LR-1-R.

Infiltrometer and Permeameter Test Results

Double-ring infiltrometer tests were performed on the drainage retention basin floor between February and September, 1986. Infiltration rates were found to be dependent upon antecedent moisture conditions and lithology. In the deeper portions of the basin (near LR-3-R and LR-4-P), a 6 -inch (15-cm) silt layer has been deposited over the 8-foot (2.4-m) thick silty gravel layer (basin floor) as a result of the deposition of silt sized particles transported into the basin by local runoff water. As a result, infiltration rates were found to be quite low, on the order of $0.01 \mathrm{ft} /$ day $(0.3 \mathrm{~cm} /$ day $)$. Moving outward from the NW low spot, infiltration values began to increase, as a result of decreased silt deposition 
on the basin floor. Infiltration rates reached a maximum value of nearly $1.9 \mathrm{ft} / \mathrm{day}$ (58 $\mathrm{cm} /$ day) along the outer edge of the drainage retention basin, where much of the silty gravel layer is exposed. Figure 8 is a contour map of the double-ring infiltrometer data from the drainage retention basin.

Triaxial permeameter tests were performed on three cores taken from the boreholes drilled in the basin floor. Table 1 summarizes the results from the permeameter tests. Steady-state hydraulic conductivity values obtained from the double-ring infiltrometer and the triaxial permeameter tests were found to be consistent (within an order of magnitude) with hydraulic conductivity values for similar soils listed in Freeze and Cherry (1979) (Toney, personal communication, 1987).

Table 1. Saturated hydraulic conductivity values from basin core samples. Conductivities determined by triaxial permeameter (Toney, Thesis Draft, 1988).

\begin{tabular}{lll}
\hline $\begin{array}{l}\text { Sample } \\
\text { Name }\end{array}$ & $\begin{array}{l}\text { Soil } \\
\text { Type }\end{array}$ & $\begin{array}{l}\text { Saturated } \\
\text { Conductivity } \\
\text { (cm/day) }\end{array}$ \\
\hline LR4P-55 & Sandy Silt & $5.5 \times 10^{-4}$ \\
LR1R-40 & Sandy Silt & $1.8 \times 10^{-3}$ \\
LR2R-30 & Sand & 680 \\
\hline
\end{tabular}

\section{Brevious Vadose Zone Modeling Efforts}

A number of one-dimensional, saturated-unsaturated flow programs have been written over the past 20 years (Freeze, 1969; Bhuiyan et al., 1971; Bond et al., 1982; Kunze and Nielson, 1982; Ragab et al., 1982; Kirby, 1985; and U.S. EPA, 1986). The one-dimensional models have been typically used to compare theoretical simulation results 


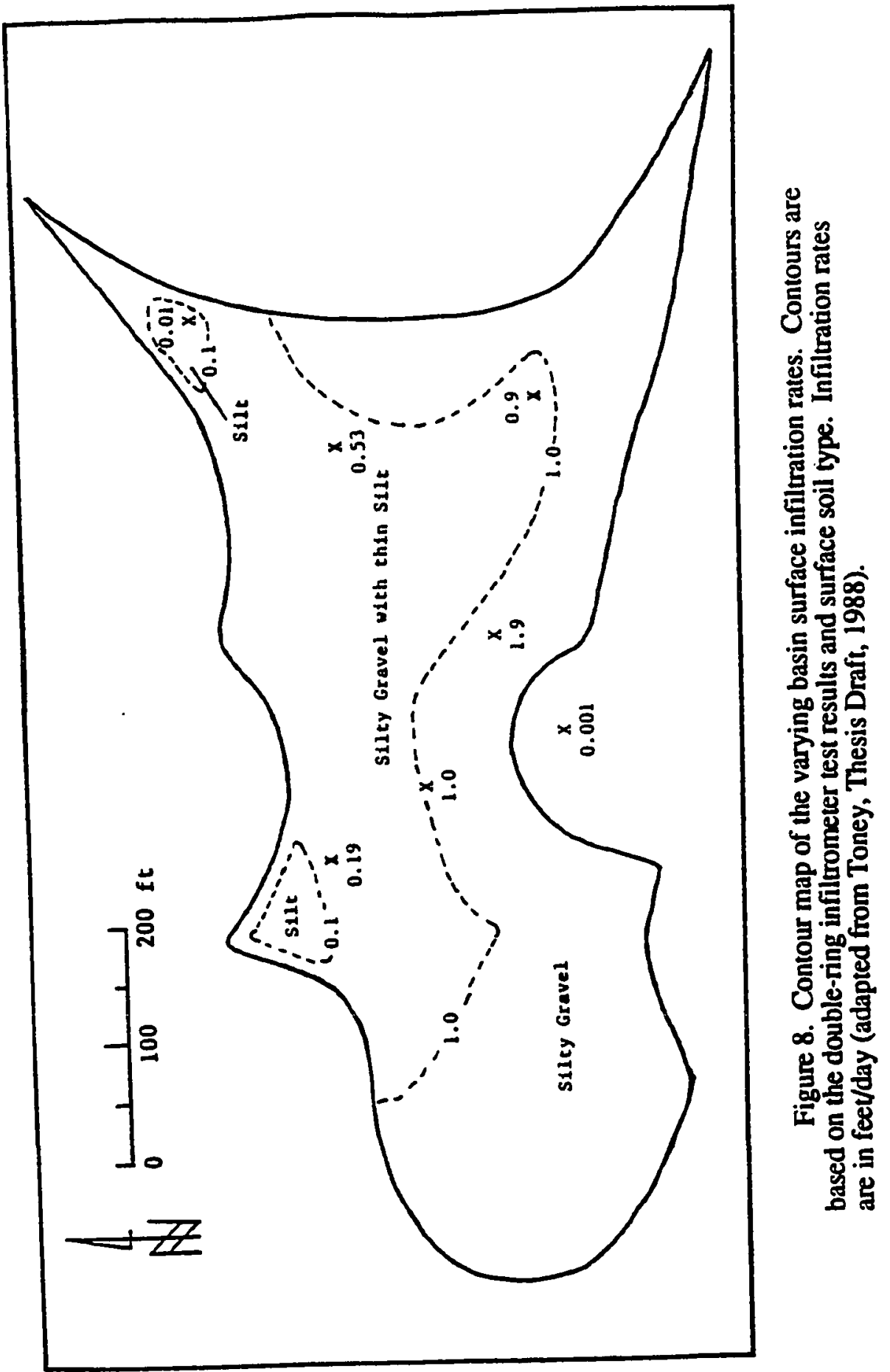


with laboratory column infiltration results to verify or validate the unsaturated flow. programs, simulate vertical infiltration in homogeneous, istotropic materials, and simulate vertical infiltration at surface liquid impoundment facilities. Figure 9 is a typical moisture content vs depth plot of a homogeneous, isotropic material generated from a onedimensional, variably saturated flow model. Unfortunately, the simplicity of the onedimensional models prevents them from adequately describing the actual flow system in the field due to the anisotropies and heterogeneities inherent in a true field situation (Yeh et al., 1985).

One of the first multidimensional models was a three-dimensional, finite difference model, developed to describe saturated-unsaturated, transient flow in small nonhomogeneous, anisotropic geologic basins (maximum grid size: a few miles by 1000 feet deep). The model was useful in determining regional hydrologic responses of a ground water basin to pumping and infiltration (Freeze, 1971). The results of this model are commonly studied by undergraduate and graduate hydrogeology students in Freeze and Cherry's (1979) text, Groundwater.

At the same time Freeze's regional, three-dimensional, finite difference model was published, Neuman and Whitherspoon (1971) developed a two-dimensional, finite element model capable of describing the local, saturated-unsaturated vadose zone responses to infiltration, evaportranspiration, axisymmetric flow to a well, and the adjustment of the free surface within a dam due to the sudden lowering of the reservoir level in anisotropic, heterogeneous materials. The Neuman/Whitherspoon program, through a series of refinements, eventually became UNSAT2, which the writer has used for this study.

Two other multidimensional models have been used to simulate infiltration into the vadose zone. Authors Vauclin, Khanji, and Vachaud (1979) developed a threedimensional saturated-unsaturated, finite difference model to simulate the response of a slab 


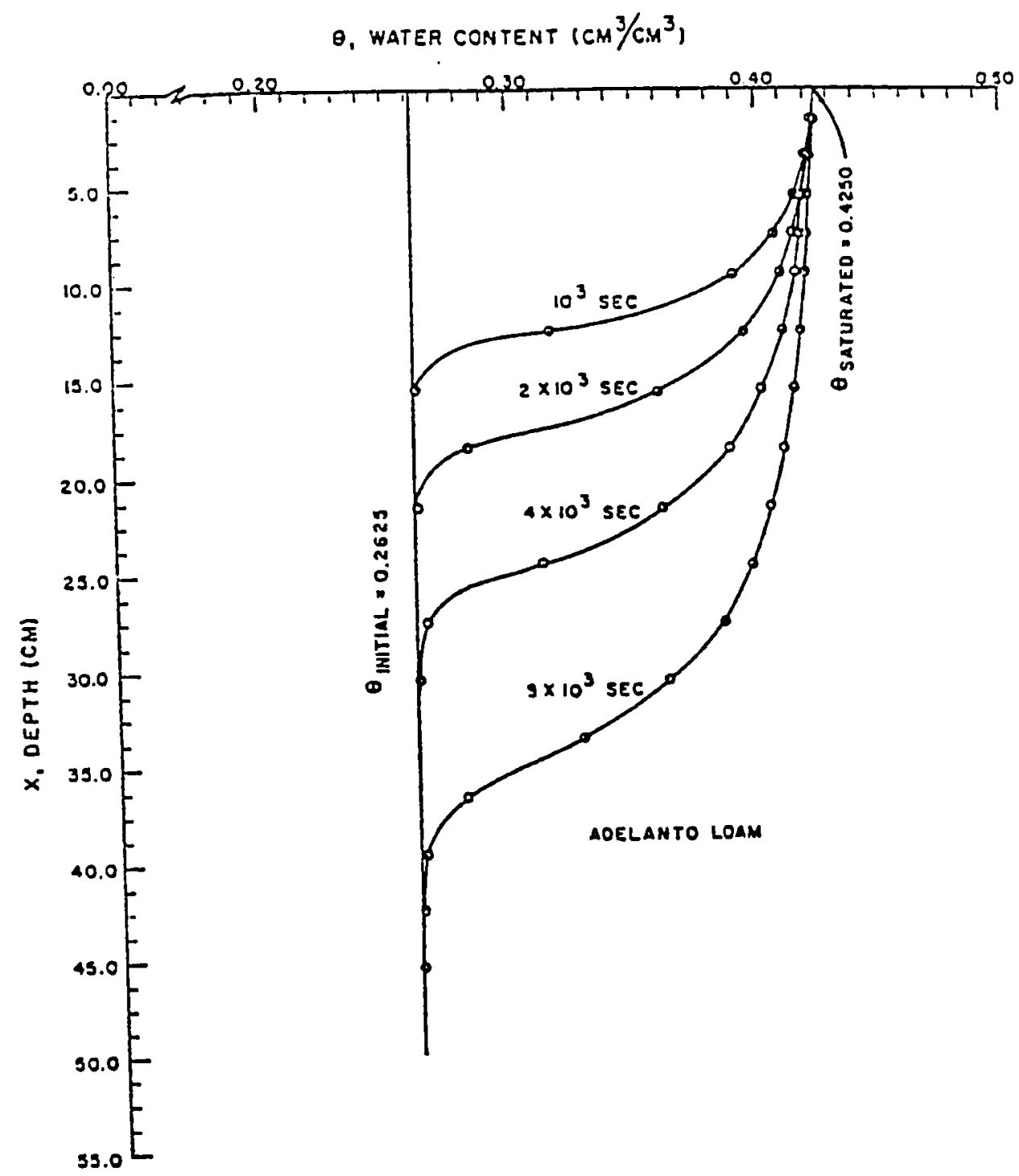

Figure 9. Typical moisture content vs. depth plot of a homogeneous material (Adelanto Loam), generated from a 1-D variably saturated flow model (from Bhuiyan et al., 1971). 
of homogeneous soil to constant infiltration. The flow system was constructed in the laboratory and fitted with several pressure transducers and tensiometers to quantify the system's response to constant infiltration. The numerical model's simulation of the shape and advance of the wetting front, water content profiles, and water table mounding were all in excellent agreement with measured laboratory data. Unfortunately the model's program code and finite difference scheme prevented it from modeling heterogeneous materials with complex geometry/structure, such as the geology at the LLNL site.

Winter (1978) performed several numerical simulations of infiltration due to a variety of hypothetical, large-scale, lake configurations with a three-dimensional, finite difference code. The model only simulated general hydrogeologic changes in lake-ground water systems from surface infiltration and is not suitable for simulating infiltration in complex hydrogeologic settings.

A more recent modeling approach to unsaturated flow in heterogeneous soils is that of stochastic analysis. Stochastic analysis is based upon a statistical analysis of the three dimensionality of field heterogeneity and anisotropy. The overall goals are to determine the mean or effective large-scale behavior of the heterogeneous system and the degree of variation about the mean (Yeh et al., 1985). This approach is primarily for predicting large-scale flow characteristics of regional ground water systems and would not be suitable for the local vadose response to the infiltration of ponded runoff waters at $L L N L$, which is modeled in this study. For a more detailed discussion of stochastic modeling see Yeh et al. (1985), and Mantoglou and Gelhar (1987).

UNSAT 2 has been used to successfully simulate one-dimensional and twodimensional infiltration through a sand column and a sand flume system, respectively (Davis and Neuman, 1983). Both tests duplicated laboratory results, with a reasonable amount of agreement. In an earlier two-dimensional simulation of the nonsteady buildup of 
a ground water mound due to infiltration, Neuman and Witherspoon (1971) found that their model's (i.e., UNSAT 2 's) results compared favorably with both the analytical results of another modeler and laboratory experiments.

In 1983, the Illinois State Geological Survey used UNSAT2 to simulate infiltration into several hypothetical, layered covers for a low level radioactive trench to evaluate their effectiveness at isolating the buried waste. The model predicted pressure head and moisture content distributions that were in close agreement with laboratory soil column tests. The two-dimensional study enabled the Illinois State Geological Survey to study the vertical and lateral response to gravel and loess layers encountered in the trench cover, and to study the effects of moisture buildup and breakthrough in a layered system.

After several laboratory and computer simulations, it was concluded that "a layer of coarse textured, unsaturated material overlain by fine-grained material serves as a barrier to moisture movement. The effectiveness of the barrier is related to the contrast in saturated hydraulic conductivity and texture between the two layers" (Johnson et al., 1983). The barrier (or "wick effect") as predicted by UNSAT2 is consistent with the findings of other researchers studying the affects of moisture migration in layered soils with contrasting texture (Hillel, 1971; and Rojstaczer, 1981).

A fairly extensive field study and computer simulation (UNSAT2) of water flow through unsaturated soil beneath a 48 acre ( $1.9 \times 10^{5}$ square meters) liquid waste disposal pond was conducted by Trautwein et al. (1983). UNSAT2 was used to model a onedimensional 400 foot $(122 \mathrm{~m})$ deep profile beneath the center of the pond to predict present and future wetting front migration, and the impact of contamination on an aquifer 390 feet $(119 \mathrm{~m}$ ) below the pond. The model accurately predicted the present wetting front location within 30 feet $(9 \mathrm{~m})$ (i.e., $8 \%$ error). Given the hydrogeologic simplifications required for simulation and the large number of uncertanties that exist in some of the input parameters 
(i.e., limited permeability and soil characteristic data), the vadose simulation produced results that were realistic and very useful in determining the future propagation of the contaminated wetting front under a variety of corrective actions. The model was also useful in providing a background for a more complex multi-dimensional flow simulation of the site to be performed in the future.

Authors McMahon and Dennehy (1985) of the U.S. Geological Survey, South Carolina, successfully applied UNSAT2 to qualitatively simulate variably saturated flow in the vadose zone at two experimental waste-burial trenches. The model accurately predicted the hydraulic head distributions seen in field data and was useful in analyzing the complex flow patterns in and around the trenches due to the infiltration of runoff waters. It was found that UNSAT2 was very sensitive to the initial conditions of the three material, $10 \mathrm{x}$ 12 meter ( $32.8 \times 39.4$ foot), finite element grid and by adjusting the initial conditions the model's accuracy could have been increased. The simulation was also useful in explaining the complex tracer distribution patterns found in field scale experiments.

UNSAT2 is presently available from Dr. Shlomo Neuman (at the University of Arizona) or the U.S. Nuclear Regulatory Commission in Cyber or CDC Fortran 77 forms. A few more variably saturated flow programs are also currently available. TRUST, a three-dimensional, finite difference model developed by Dr. Narasimhan at the University of California, Berkeley is available in a variety of altered forms, as the result of continued modification by his graduate students. VS2D is a two-dimensional, finite difference program which was recently made available by the USGS. The Geotrans company has produced two variably saturated flow models, Saturn and Flaminco. Both programs are capable of modeling variably saturated flow and contaminant transport with finite elements in two- and three-dimensions respectively. 


\section{Variably Saturated Flow Simulation}

UNSAT 2 uses the following general equation to govern the flow of water in variably saturated porous media (Davis and Neuman, 1983). The first term on the right side is advection, the second drainage, the third storage, and the last term, $S$, represents a source or sink.

$$
\begin{aligned}
\mathrm{L}(\psi)=\sum_{\mathrm{i}=1}^{3} \sum_{\mathrm{j}=1}^{3} \frac{\partial}{\partial \mathrm{x}_{\mathrm{i}}}\left[\mathrm{K}^{\mathrm{r}}(\psi) \mathrm{K}_{\mathrm{ij}}^{\mathrm{s}} \frac{\partial \psi}{\partial \mathrm{x}_{\mathrm{j}}}\right] & \\
& +\sum_{\mathrm{i}=1}^{3} \frac{\partial}{\partial \mathrm{x}_{\mathrm{i}}} \mathrm{K}^{\mathrm{r}}(\psi) \mathrm{K}_{\mathrm{i} 3}^{\mathrm{s}}-\left[\mathrm{C}(\psi)+\beta \mathrm{S}_{\mathrm{s}}\right] \frac{\partial \mathrm{h}}{\partial \mathrm{t}}-\mathrm{S}=0,
\end{aligned}
$$

where $\mathrm{L}=$ quasilinear differential operator defined in the flow region (1/T),

$x_{i}=$ spatial coordinates $\left(i=1,2,3\right.$ with $x_{3}$ the vertical) $(L)$,

$\mathrm{K}^{\mathrm{r}} \quad$ = relative hydraulic conductivity $\left(0 \leq \mathrm{K}^{\mathrm{r}} \leq 1\right)$ (dimensionless),

$\mathrm{K}_{\mathrm{i} j}^{\mathrm{s}}=$ hydraulic conductivity tensor at saturation $(\mathrm{L} / \mathrm{T})$,

$\psi=$ pressure head, positive in saturated zones, negative in unsaturated zones, and zero at a phreatic surface $(\mathrm{L})$,

C = specific moisture capacity $=\mathrm{d} \theta / \mathrm{d} \psi(1 / \mathrm{L})$,

$\theta \quad=$ volumetric moisture content (dimensionless),

$\beta=0$ in unsaturated zone and 1 in saturated zone (dimensionless),

$\mathrm{S}_{\mathrm{S}} \quad$ specific storage $(1 / \mathrm{L})$,

$\mathrm{t} \quad=$ time $(\mathrm{T})$,

$S \quad=\operatorname{sink} \operatorname{term}(1 / T)$,

$\mathrm{h} \quad=$ hydraulic head (L).

The specific storage, $S_{S}$, is allowed to drop out of Eq.(1) for unsaturated soils as the result of $\beta=0$ (see above). The reasoning behind this is fairly simple. In unsaturated soils, "storage is controlled much more by moisture content than by compressibility 
effects" (Davis and Neuman, 1983); as a result, the specific storage can be neglected and the specific moisture capacity, $\mathrm{C}$, becomes the dominant storage term.

The general transient flow equation for saturated and unsaturated flow (Eq. 1) consists of equations describing advection, drainage, storage, and the influence of a source or sink. It is derived from Darcy's law in the following manner:

$$
Q=-K \frac{d h}{d x} A \quad, \quad \text { (Darcy's law in 1-D) }
$$

or

$$
V=\frac{Q}{A}=\cdot K \frac{d h}{d x} \text {. }
$$

where

$$
Q=\text { flow rate }\left(\mathrm{L}^{3 / T}\right) \text {, }
$$

$\mathrm{K}=$ hydraulic conductivity $(\mathrm{L} / \mathrm{T})$,

A = cross-sectional area $\left(L^{2}\right)$,

$\frac{\mathrm{dh}}{\mathrm{dx}}=$ hydraulic gradient (dimensionless),

$V \quad=$ specific discharge $(L / T)$.

In 3-D, Darcy's law [Eq. (3)] may be written:

$$
\begin{aligned}
& V_{x}=-K_{x x} \frac{\partial h}{\partial x}-K_{x y} \frac{\partial h}{\partial y}-K_{x z} \frac{\partial h}{\partial z}, \\
& V_{y}=-K_{y x} \frac{\partial h}{\partial x}-K_{y y} \frac{\partial h}{\partial y}-K_{y z} \frac{\partial h}{\partial z}, \\
& V_{z}=-K_{z x} \frac{\partial h}{\partial x}-K_{z y} \frac{\partial h}{\partial y}-K_{z z} \frac{\partial h}{\partial z}, \\
& V(x, y, z)=V_{x}+V_{y}+V_{z}
\end{aligned}
$$

or as

$$
V(x, y, z)=-\sum_{i=1}^{3} \sum_{j=1}^{3} K_{i j} \frac{\partial h}{\partial x_{i}},
$$

where $x_{i}$ represents three orthogonal spacial coordinates $\left(i=1,2,3\right.$; with $x_{3}=$ vertical). 
The law of conservation of mass and the equation of continuity describe flow through an elemental control volume (figure 10). They may be reduced to:

$$
-\frac{\partial V_{x}}{\partial x}-\frac{\partial V_{y}}{\partial y}-\frac{\partial V_{z}}{\partial z}=0, \quad \text { (Steady-state) }
$$

or

$$
-\sum_{i=1}^{3} \frac{\partial}{\partial x_{i}} v_{i}=0 \quad \text { (Steady-state) }
$$

Substituting in Darcy's law, the general steady-state flow equation may be obtained:

$$
\begin{aligned}
& \frac{\partial}{\partial x}\left(K_{x x} \frac{\partial h}{\partial x}+K_{x y} \frac{\partial h}{\partial y}+K_{x z} \frac{\partial h}{\partial z}\right)+\frac{\partial}{\partial y}\left(K_{y x} \frac{\partial h}{\partial x}+K_{y y} \frac{\partial h}{\partial y}+K_{y z} \frac{\partial h}{\partial z}\right) \\
& +\frac{\partial}{\partial z}\left(K_{z x} \frac{\partial h}{\partial h}+K_{z y} \frac{\partial h}{\partial y}+K_{z z} \frac{\partial h}{\partial z}\right)=0 . \\
& \text { or } \quad \sum_{i=1}^{3} \sum_{j=1}^{3} \frac{\partial}{\partial x_{i}}\left[K_{i j} \frac{\partial h}{\partial x_{j}}\right]=0 .
\end{aligned}
$$

In the case of transient flow, the right-hand side of the steady-state flow equation does not equal zero; instead it equals the time rate of change of fluid storage:

$$
\begin{aligned}
& \sum_{i=1}^{3} \sum_{j=1}^{3} \frac{\partial}{\partial x_{i}}\left[K_{i j} \frac{\partial h}{\partial x_{j}}\right]=S_{s} \frac{\partial h}{\partial t}, \\
& \text { where } S_{s} \frac{\partial h}{\partial t}=\text { time rate of change of fluid storage }(1 / T) \text {. }
\end{aligned}
$$

The above term is also seen in the storage equation in Eq. (1).

For steady-state, unsaturated flow, the hydraulic conductivity is a function of the pressure head $(\Psi)$ of the soil. The general steady-state flow equation (Eq. 9) may be rewritten to include unsaturated flow: 


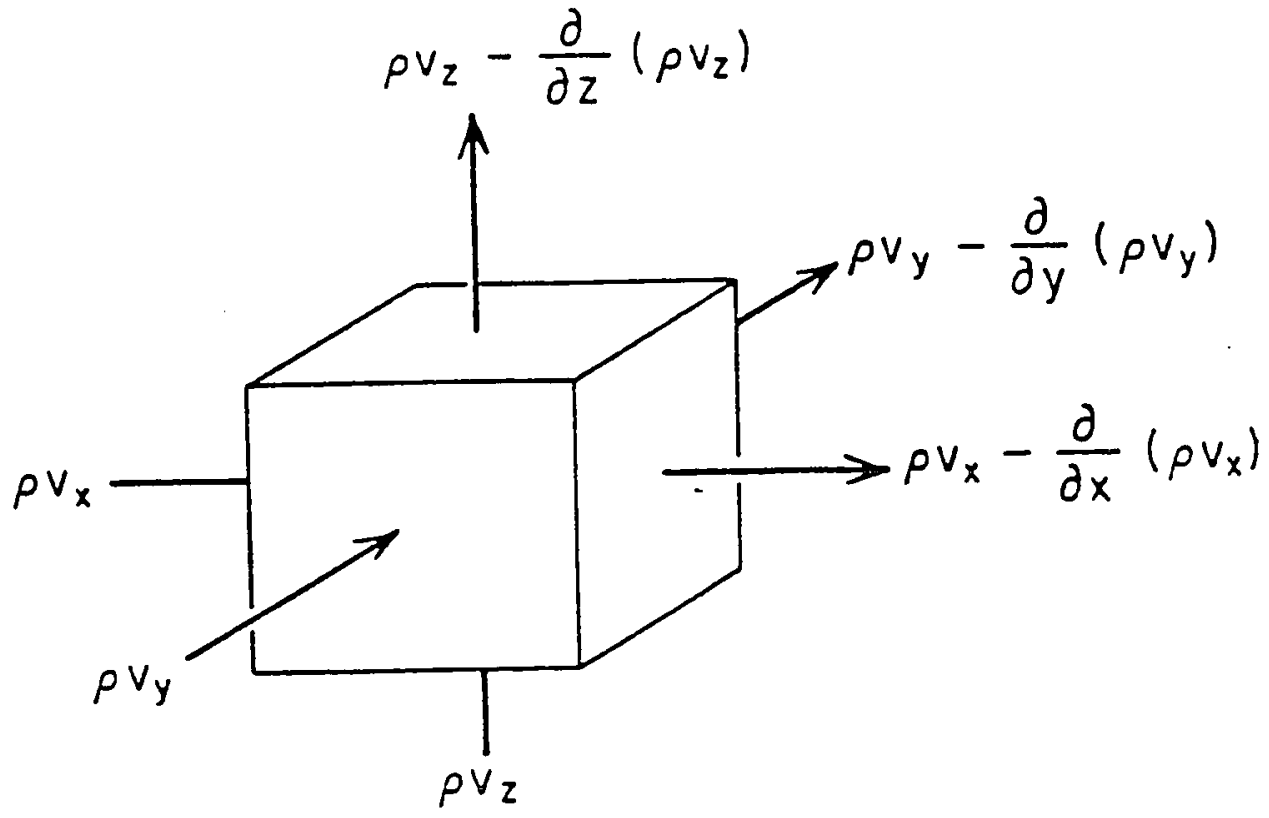

Figure 10. Elemental control volume for flow through porous media (from Freeze and Cherry, 1979). 


$$
\sum_{i=1}^{3} \sum_{j=1}^{3} \frac{\partial}{\partial x_{i}}\left[K^{r}(\psi) K_{i j}^{s} \frac{\partial h}{\partial x_{j}}\right]=0
$$

where

$\mathrm{K}_{\mathrm{ij}}^{\mathrm{s}}=$ hydraulic conductivity tensor at saturation $(\mathrm{L} / \mathrm{T})$,

$\mathbf{K}^{\mathrm{r}}(\psi)=$ relative hydraulic conductivity $\left(0 \leq \mathbf{K}^{\mathrm{T}} \leq 1\right)$ where $\mathbf{K}^{\mathrm{r}}(\psi)=1$ at saturation (dimensionless).

For transient, unsaturated flow, Eq. 11 is written:

$$
\begin{aligned}
& \sum_{i=1}^{3} \sum_{j=1}^{3} \frac{\partial}{\partial x_{i}}\left[K^{r}(\psi) K_{i j}^{s} \frac{\partial h}{\partial x_{j}}\right]=\frac{\partial \theta}{\partial t}, \\
& \text { where } \frac{\partial \theta}{\partial t}=\text { the time rate of change in moisture }(1 / T) \text {. }
\end{aligned}
$$

Combining the transient saturated and unsaturated flow equations (Eqs. 10 and 12) yields a more general flow equation:

$$
\sum_{i=1}^{3} \sum_{j=1}^{3} \frac{\partial}{\partial x_{i}}\left[K^{T}(\psi) K_{i j}^{s} \frac{\partial h}{\partial x_{j}}\right]=S_{s} \frac{\partial h}{\partial t}+\frac{\partial \theta}{\partial t},
$$

Adding a vertical drainage term and a source/sink term completes the generalized, transient, variably saturated flow equation:

$$
\begin{aligned}
& \sum_{i=1}^{3} \sum_{j=1}^{3} \frac{\partial}{\partial x_{i}}\left[K^{r}(\psi) K_{i j}^{3} \frac{\partial \psi}{\partial x_{j}}\right]+\sum_{i=1}^{3} \frac{\partial}{\partial x_{i}} K^{s}(\psi) K_{i 3}^{s}-\frac{\partial \theta}{\partial t}-S_{s} \frac{\partial h}{\partial t}-S=0 \\
& \text { where } \sum_{i=1}^{3} \frac{\partial}{\partial x_{i}} K^{r}(\psi) K_{i 3}^{s}=\text { vertical drainage term and } S=\text { source/sink term. }
\end{aligned}
$$

The vertical drainage term is used to account for gravity drainage during a vertical plane simulation. For a more complete derivation of the transient variably saturated flow equation see Neuman (1973, 1975), Neuman et al. (1975), and Freeze and Cherry (1979). 
UNSAT2 uses the Galerkin finite element method of weighted residuals to solve Equation 1. "A rather large number of articles on the applications of the finite element method, and especially of the Galerkin method, to the solution of two- and threedimensional flow problems has been published in the literature of water resources and presented in special symposia, especially since the late 1960's" (Bear, 1979). As a result, the finite element method and the Galerkin method will not be further discussed. For a detailed discussion on the Galerkin method, the author suggests Pinder and Gray (1977), Bear (1979), and Wang and Anderson (1982).

\section{Features of UNSAT2}

UNSAT2 contains a variety of special features useful to the modeler. The special features include quadrilateral and triangular elements, variable flow direction, various boundaries (prescribed flux, seepage faces, evaporation or infiltration), the ability to handle water uptake by plant roots (various species), pumping wells (fully screened, partially screened, and/or variable pumping rates), steady-state or transient flow, non-linear soil properties, and the ability to model non-homogeneous anisotropic porous media. Three main assumptions are made by UNSAT2: no soil hysteresis, no soil deformation, and flow to a well (if used) is axisymmetric. If used with highly hysteretic or deformable soils, UNSAT2 may yield questionable results due to the model's assumptions.

Input parameters are divided into 19 "input groups" (which range from Group A the Problem Title, to Group $S$ - the Execution Terminator) to simplify the input process. Below is a complete list and explanation of the input parameters. The parameters marked with a "*" are required input for all problems. The parameters marked with a "+" are required for all unsaturated flow problems (Davis and Neuman, 1983). 
Input Group:

* A: Problem Title - problem header or title, used to identify the problem's input and output.

* B: General Control Data - this group primarily consists of the cross-section data, such as number of nodal points, number of materials, type of flow system (horizontal, axisymmetric, or vertical), number of seepage faces, and maximum number of nodes along the seepage faces.

+ C: Special Control Data - this group allows the user to access the various special functions of UNSAT2, such as well analysis, evaporation or infiltration, and plant transpiration.

* D: Material Control Data - the user must specify the number of paired entries of relative hydraulic conductivity vs moisture content, and pressure head vs moisture content for each discretized characteristic curve, corresponding to each unsaturated material.

E: Seepage Face Data - this group records the corresponding nodes for each seepage face.

F: Atmospheric Control Data - input required for this group is the maximum rate of infiltration or evaporation at the soil surface for each node that applies. 
G: Soil Surface Geometric Data - the width of each evaporation or infiltration element at the surface must be specified in this input group to allow UNSAT2 to compute the flux through the evaporation or infiltration elements.

H: Root Zone Grid Data - data input for this input group is required only for the plant transpiration function. Input includes the number of vertical nodal columns and the number of nodes in each root zone column. Input must be repeated for each plant species.

I: Plant Species Data - data for this group are as required in Group H. Input consists of the wilting pressure head and maximum allowable rate of transpiration for each plant species.

J: Root Zone Data - data for this group are as required in group H. Input includes the width of each root zone, the sequential node numbers of each top and bottom node of each vertical root zone column, root-effectiveness coefficient for each plant species, and the soil material within each root zone.

K: Well Descriptive Date - input into this group requires that axisymmetric flow is specified in the General Control Data (Group B) and that the well lie along the left hand boundary of the finite element grid. Input consists of the nodal numbers of those nodes located at the bottom of the well, and of the seepage face nodes along the well casing (particularly if a well is partially screened or if it is partially penetrating the aquifer). 
L: Well Control Data - this input group specifies the well parameters, such as the effective radius of the pumping well, radius of the well production tubing, discharge rate from the well, initial water level in the well, and an underrelaxation factor for iterative treatment of the well (default relaxation factor $=$ 0.8 ).

* M: Time Step Data - for this input group, the user must specify the initial time step, maximum time step, initial time, multiplication factor for the time steps, maximum iteration time, and pressure head convergence criterion.

* N: Unit Conversion Factors - these parameters allow the user to input non-consistent unit data. UNSAT2 will convert the input data to consistent units, perform the calculations, and output in consistent or non-consistent units, depending upon the user's selection.

* O: Material Constant Properties - input data for this group are required for all problems. Input for this group supplies UNSAT2 with the constant hydraulic properties of each material. Input must include the first and second principal, saturated hydraulic conductivities $\left(K^{s} 11\right.$ and $\mathrm{K}^{s_{22}}$, see figure 11$)$, porosity, and specific storage of each material. For unsaturated flow, the specific storage is set equal to zero. Group $O$ is repeated for each material.

P: Unsaturated Material Properties - data required for this input group consist of the paired relative hydraulic conductivity vs moisture content values and the paired pressure head vs moisture content values that discretize each characteristic curve for each unsaturated material. Group $P$ is repeated for each material. 


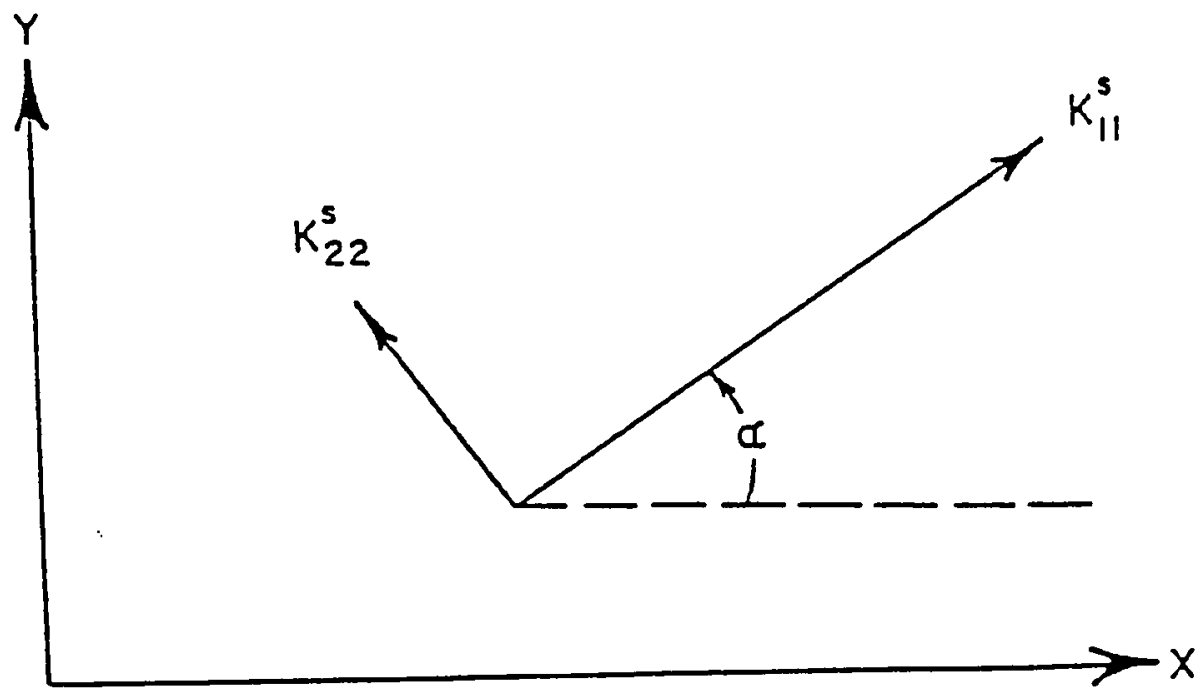

Figure 11. Angle $\alpha$ between the principal hydraulic conductivity and the $\mathrm{X}$ coordinate (from Davis and Neuman, 1983). 
* Q. Nodal Point Data - data input of this group requires the user to specify the spacial coordinates ( $\mathrm{X}$ and $\mathrm{Y}$ ), boundary codes (no-flow, seepage face, etc.), initial pressure head values, boundary head values, boundary fluxes and/or source/sink terms for each nodal point.

R: Element Data - input required for each element consists of the element number, the corner nodes of the element ( $i, j, k, l$; for triangular elements $k=1$ ), the material assigned to the element, and the angle (in degrees) between the first principal hydraulic conductivity and the horizontal axis (fig. 11) used in the element.

RA-RG: Restart Feature - this input group enables the user to change a few input parameters/data and retain all the unchanged input data, thus only entering the changed parameters/data. This feature is useful in modeling transient situations, such as the changing pond level at LLNL's drainage retention basin.

* S: Execution Terminator - this function ends the program after the maximum program time (TMAX) has expired. 


\section{MODEL INPUT AND CALIBRATION}

The following steps were used in configuring and calibrating UNSAT2 to simulate variably saturated flow in the vadose zone beneath the drainage retention basin of LLNL:

1. Define vadose zone lithology beneath the basin.

2. Construct the finite element grid.

3. Establish grid boundary conditions.

4. Estimate soil properties.

5. Estimate initial conditions.

6. Allow system to reach an equilibrium by simulating drainage to find relative steady-state initial condition values for nodes.

7. Perform computer simulation and compare results with field observations (i.e., resistance data).

8. Calibrate model - repeat steps 4-7 until strong correlation between computer simulation and field data develops.

UNSAT2 requires the input of a detailed finite element grid to simulate a specific flow region. The grid must be hydrogeologically accurate for proper simulation.

The development of the finite element grid for LLNL's drainage retention basin was a relatively detriled process. First, an accurate, scaled cross-section of the drainage retention basin, transecting LR-3-R, LR-4-P, LR-2-R, and LR-1-R, was drafted (figure 7). As previously mentioned, the basin lithology was simplified for modeling purposes by 
combining adjacent geologic materials with similar hydrogeologic properties and characterizing them by their dominant constituents and by using simple lens shapes. A total of five different materials were grouped. They are: the upper clayey silt layer (material 1), the silty gravel unit (material 2), the upper silt unit (material 3), the upper sand lens (material 4), the lower sand unit (material 4), the lower silt unit (material 3), and the lower clay lens (material 5) (figure 12).

Second, a scaled finite element grid (55.3 feet x 260 feet; $1,680 \mathrm{~cm} \times 7,920 \mathrm{~cm}$ ) was created from the generalized geologic cross-section (figures 13 and 14). Element size was based on a number of contributing factors, such as lithology, anticipated pressure head changes and computer memory limitations. Smaller elements were used in areas where high hydraulic gradients were expected and in areas where lithology and resistance data were better known (i.e., in the vicinity of the borings). Larger elements were used in areas where lower hydraulic gradients were expected and where lithology and resistance data had to be interpolated (i.e., between boreholes). A strong effort was made to maintain fairly equidimensional element sizes, so as not to introduce additional numerical error into the flow problem.

The author chose boundary conditions according to node location and boundary function. The bottom nodes simulate the top of the water table and have been set as a no flow boundary to simulate the effect of a rising water table. The nodes along the right and left boundaries of the cross-section were set as no flow boundaries, permitting only vertical flow along those boundaries. Any other boundary (i.e., seepage face or constant head) would have been hydraulically incorrect and prevented vertical flow along the sides of the cross-section. Also, since the cross-section modeled does not extend to the basin margin, it is hydraulically "isolated" from the lateral flow effects that occur at the basin perimeter. As a result, these effects were not modeled. This type of boundary definition is consistent 


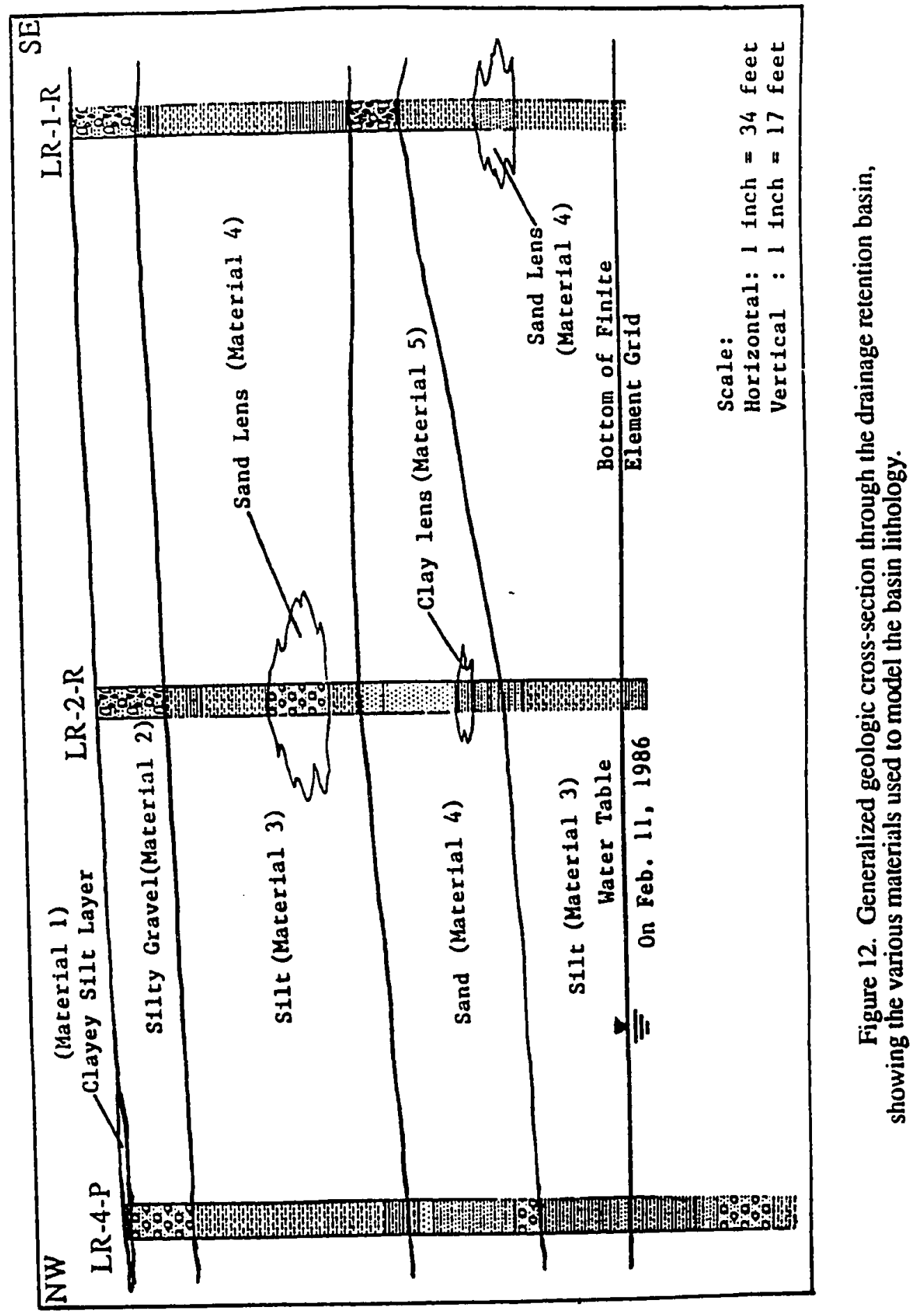




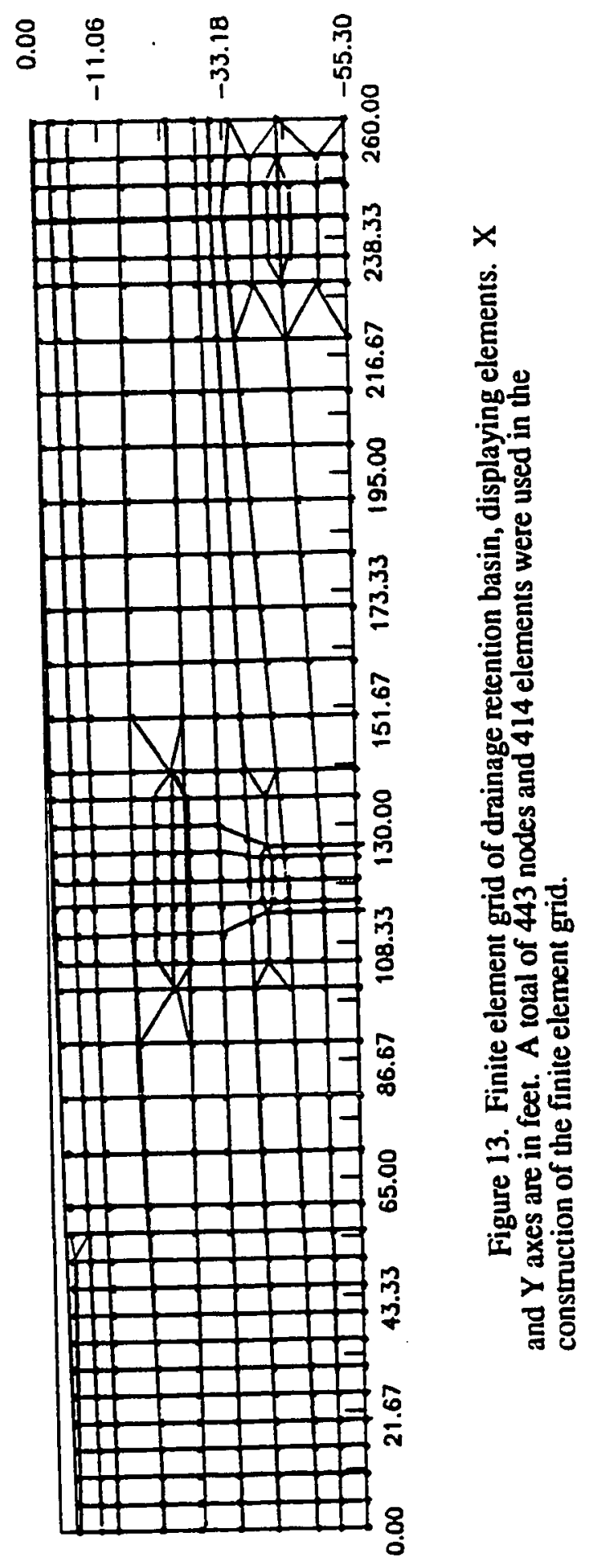




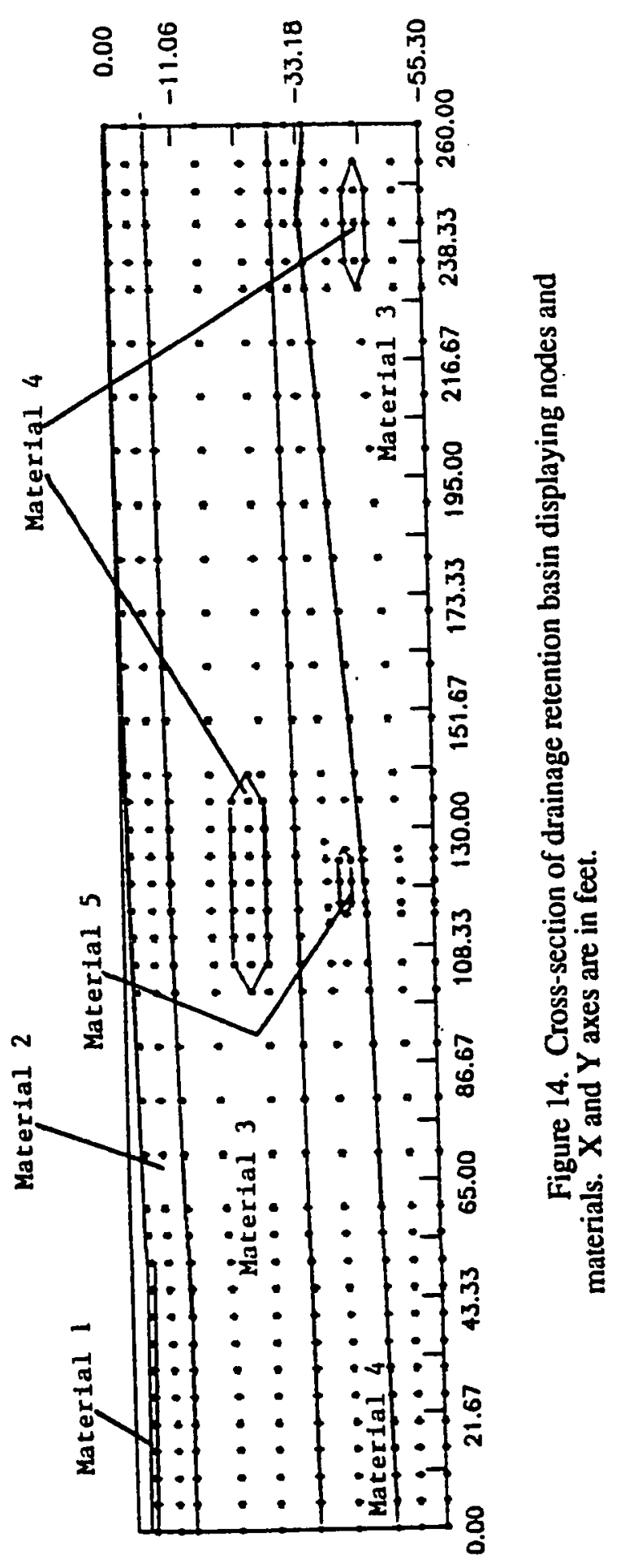


with those of other researchers (Johnson et al., 1983; Trautwein et al., 1983; and McMahon and Dennehy, 1985) for simulating infiltration into the vadose zone. The primary purpose for this configuration is to isolate the modeled cross-section, to enable the model to simulate the ground water recharge contribution from only this section of the basin.

The surface nodes were set as constant head boundaries, signifying a constant pond level. For surface nodes where no ponded water was present, the nodes were treated as a boundary with no infiltration taking place.

Vadose zone resistance data were used to determine initial subsurface conditions. Figure 15 displays an initially saturated zone beneath the thin silt layer in the northwest portion of the basin. Past resistance data also indicates that this zone remains fairly moist throughout the fall, winter, and spring months. This is due to the fact that water is almost always ponded on the surface at this location. The permeability of the silt in the northwest comer is quite low and, as a result, runoff water will pond and slowly infiltrate into the vadose zone, keeping the soil beneath the silt layer in near saturated conditions throughout the rainy season.

To simulate the effects of intermittent precipitation, the non-ponded portion of the basin surface was initially assumed to be saturated for half a day, due to effects of the previous day's precipitation. This is consistent with the author's own recent observations and those of Toney (personal communication, 1988).

Unsaturated soil characteristic curves (pressure head vs moisture content and relative hydraulic conductivity vs moisture content) were chosen from Mualem (1976). Five soils were chosen, based upon their lithologic classification, constituent analysis, and measured hydraulic parameters to represent the site soil's hydrogeologic response to infiltration. All five soils chosen closely matched the descriptions and characteristics of the 


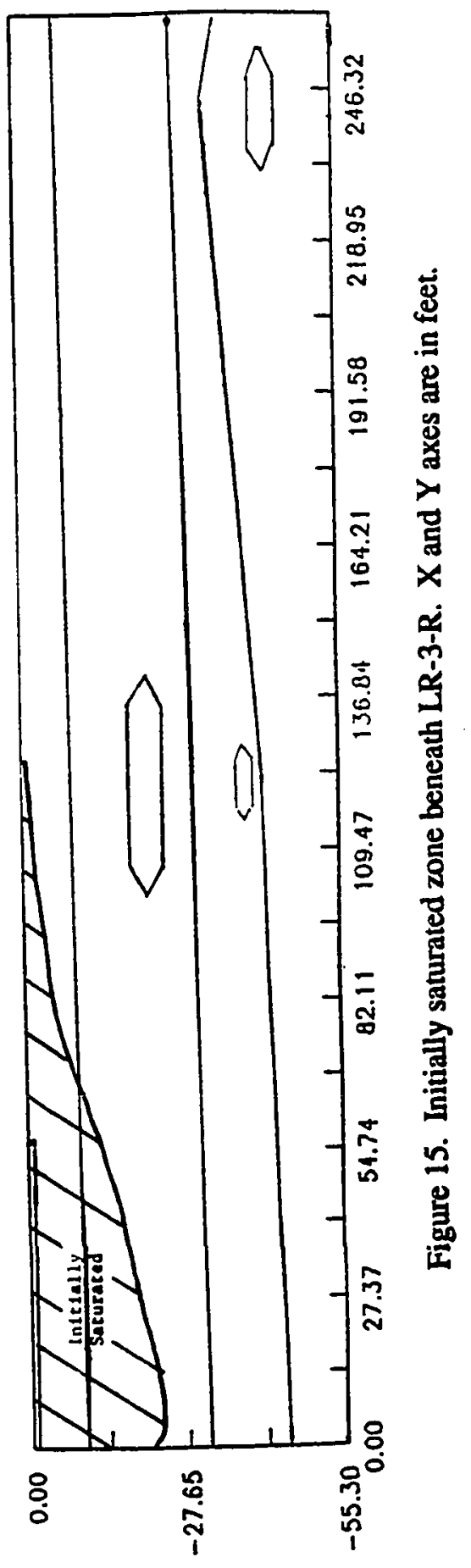


LLNL soils. When possible, drying curves were ignored and wetting curves were used, because the model does not incorporate hysteresis. If a wetting curve for the matching soil material had not been developed, then the drying curve was used for the soil. Appendix B contains the characteristic curves of the five soil materials used to simulate the LLNL site soils.

The reasoning behind choosing known soil characteristic curves to represent site soils instead of developing them for the site is three fold. First, it was not the focus of this study to develop soil characteristic curves for the site soils. Second, the process of measuring soil characteristics is a very long one, and would be extremely time consuming for this project. Last, soil characteristic curves from core samples at the site would not truly represent the site soils due to the heterogeneous nature of the site soils as indicated by the geologic well logs.

Qualitative initial soil moisture values were obtained by analyzing the soil resistance values on February 11, 1986, and the lowest resistance values obtained during the storm (for modeling purposes, these were assumed to indicate saturation). From this information, the author was able to calculate a relative change in moisture content, back calculate from the chosen characteristic curves, and obtain an initial moisture content value and therefore initial pressure head value for each material. These were only rough initial estimates and required several recalibrations to obtain proper initial conditions for a working simulation model, as discussed in the Simulation Results and Discussion section.

\section{Modeling the February 1986 Storm}

As previously mentioned, the significant storm used to calibrate the model occurred between February 11 and 19, 1986. Toney (personal communication, 1988) monitored the 
hydrogeologic response to the storm by monitoring drainage retention basin water levels, local monitoring well water level responses, precipitation, and basin soil resistance. The basin water levels and finite element grid dimensions were converted into centimeters (for computer model unit consistency) and unknown water levels were extrapolated between known days, see Appendix C. The water levels (in centimeters) were used as surface node pressure heads, corresponding to the pond level at the particular time step. The surface nodes where no ponded water was initially present were set with an initial constant pressure head of zero for every other time step (time step = half day), signifying surface soil saturation from intermittent precipitation. This was repeated until the fourth day of simulation, when the entire modeled cross-section surface was submerged. Resistance data were used to develop the qualitative conceptual model of the downward propagation of the wetting front through the vadose zone. Figure 16 shows the spatial and temporal wetting front pattern (developed from the resistance data) to which the computer simulation was compared for calibration purposes for the February $1986 \mathrm{stom}$. By calibrating the computer model to simulate the propagation of the wetting front for this known set of data (i.e., February 1986 storm data), it was hoped to gain valuable knowledge as to how the wetting front migrates, to determine what effects the lithology might have on the migration pattem and the type of hydrogeologic conditions that prevail in the vadose zone beneath LLNL's drainage retention basin under severe storm conditions, and to develop a predictive tool to simulate other situations. Appendix D contains a complete copy of the February 1986 storm input data required by UNSAT2. 


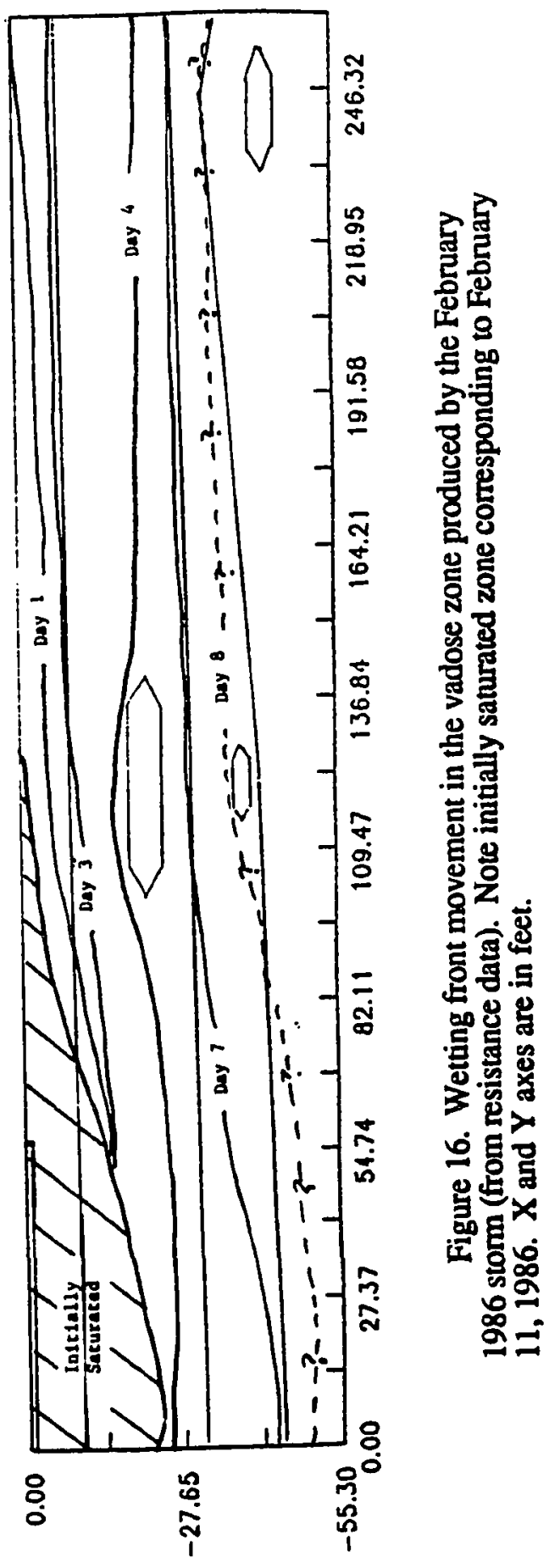




\section{SIMULATION RESULTS AND DISCUSSION}

\section{Sensitivity Analysis}

During the iterative model calibration process, a sensitivity analysis was performed on UNSAT2 to determine the model's sensitivity to the numerical and hydrogeologic parameters required for input into the model. The sensitivity of the model to a particular input variable was obtained by consecutively running the model, slightly changing the input variable after each iteration, while holding all other variables constant, and noting the change in model output created by the change in input. The following is a description of the results of the sensitivity analysis.

First, the model was found to be the most sensitive to the saturated hydraulic conductivity of each soil material. Major changes in the movement of the wetting front could be obtained by relatively small changes in the saturated hydraulic conductivity of a material. This was concluded after varying the saturated hydraulic conductivity of soil materials 2,3, and 4, over several orders of magnitude, and observing the effects of the three separate analyses. This finding was consistent with that of Trautwein et al. (1983).

Second, by changing the unsaturated soil characteristic curves of one soil for those of a similar description, it was revealed that the characteristic curves are of significant importance. For example, a moisture content vs pressure head characteristic curve displaying a high air entry pressure caused the material to become effectively saturated at relatively high suction (i.e., negative pressure head). Due to the high suction and corresponding low relative hydraulic conductivity, a noticeable pressure head build up in 
the soil occurred. It was important that the correct unsaturated characteristic curves were chosen to properly simulate the hydrogeologic effects of the LLNL soils.

Third, the model was found to be only moderately sensitive to the initial soil suction values, unless they were chosen to be excessively dry or excessively moist. This was concluded after varying the initial soil suction values from $-400 \mathrm{~cm}$ to $0 \mathrm{~cm}$, during the calibration process. If the initial soil suction values were chosen to be excessively moist relative to equilibrium or steady-state values, the model would allow the corresponding nodes to "drain" until relative steady-state values were obtained. The excess moisture drained from the moist nodes would eventually migrate to the bottom no-flow boundary and simulate a significant premature rise in the ground water table.

Last, element size was found to be an important factor in the model's accuracy. Large, less dense, elements tended to produce slightly less reasonable results. This is most likely the result of the model having to average soil material's hydrogeologic properties and pressure heads over a larger element area, therefore creating a less accurate average over the area. Generally, the averaging effect of the larger elements is small. However, in the event of significant changes in pressure heads (i.e., large moisture or pressure gradients) over one time step, the effect can be noticeable. This effect can be seen on the fourteenth day of simulation of the February 1986 storm near the bottom no-flow boundary at LR-1-R, when the water table "bows" a slight amount in the larger elements. Conversely, smaller elements and more densely spaced elements tended to produce more reasonable responses.

\section{Results and Discussion}

The following section contains a comprehensive discussion of the vadose zone computer simulation results. Four simulations were run with the calibrated model: the 
February 1986 storm, a lateral flow simulation, a deep ponding simulation, and a January 1988 storm simulation. A list of figures is given at the beginning of each simulation discussion. The figures are to be followed during the discussion to enhance the reader's conception of the movement of the wetting front in the vadose zone created by these four modeled situations.

February 1986 Storm Simulation

On February 11, 1986, a severe storm hit the Livermore Valley, precipitating 4.89 inches $(12.42 \mathrm{~cm})$ of rain over a 9 day period, most of which was precipitated between February $15-20,1986$. As a result of the severe storm, LLNL's drainage retention basin filled to its 10 foot $(304.8 \mathrm{~cm}$ ) maximum level and overflowed for 2 days. Figures 17 through 31 contain scaled contour plots of the simulated wetting front propagation through the vadose zone during the severe February 11-20, 1986, storm at LLNL. The discussion below refers to these figures. For more detailed nodal point moisture content plots for the February 1986 storm, see Appendix E.

As previously mentioned, the spatial and temporal characteristics of the wetting front produced by the February 1986 storm were determined by soil resistance data. The resistance data was used to calibrate the model initially, and at $1,3,4$, and 7 days after the onset of the storm (February 11, 1986). The resistance data for the intermediate time steps is fairly inconclusive; hence the need for computer simulation.

The initial subsurface pressure head values were determined through an iterative process consisting of approximating node pressure head values and allowing the model to drain for about 30 days (simulated), until a relative equilibrium had been reached. This procedure is consistent with modeling efforts of Trautwein et al. (1983). The "equilibrium" or steady-state pressure head values were used as approximate initial 


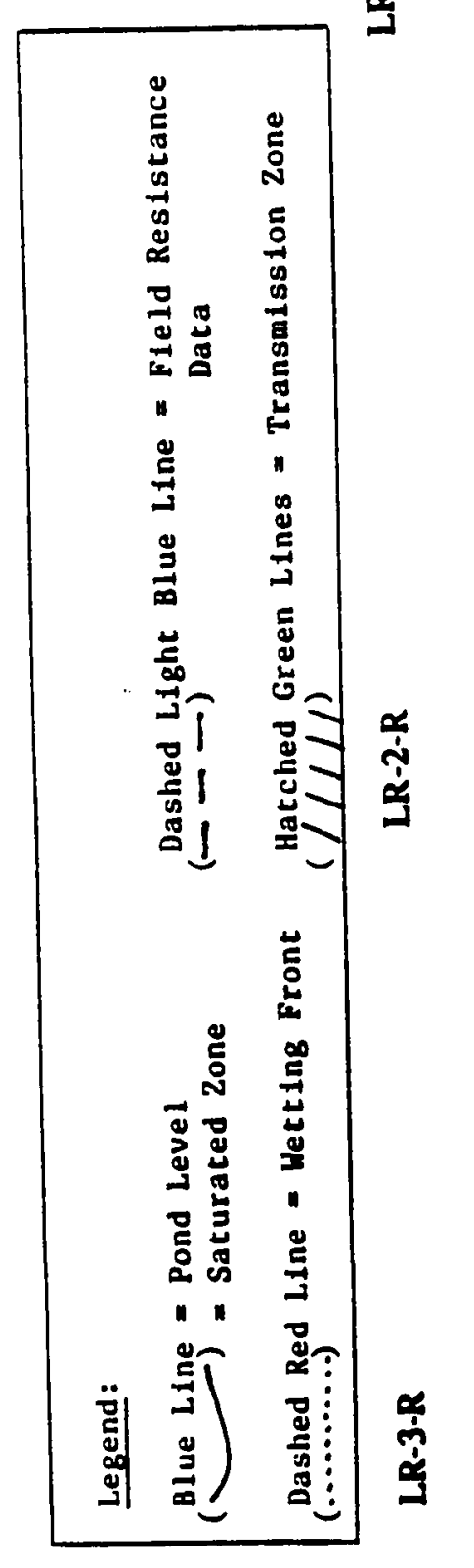

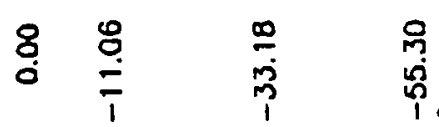

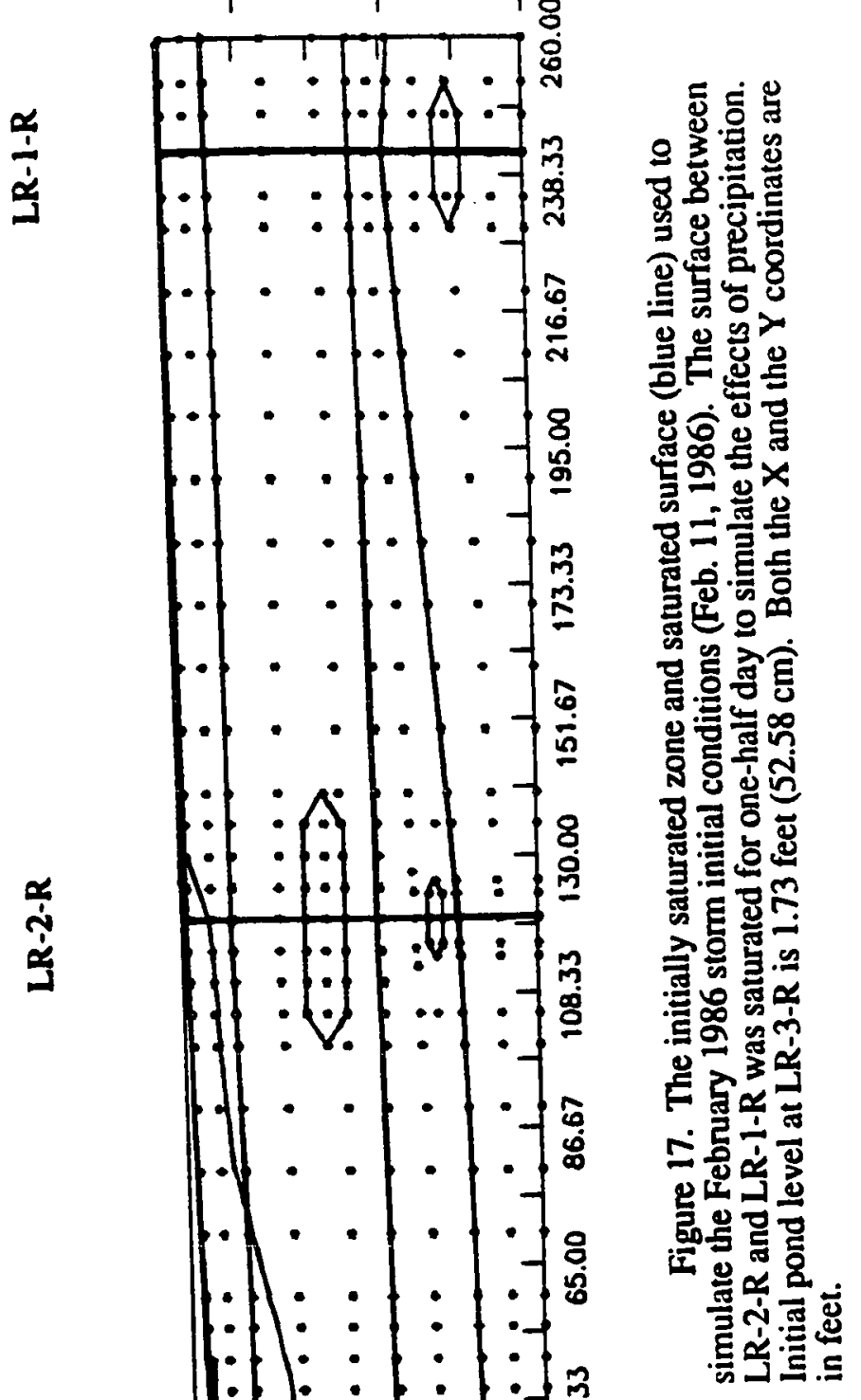




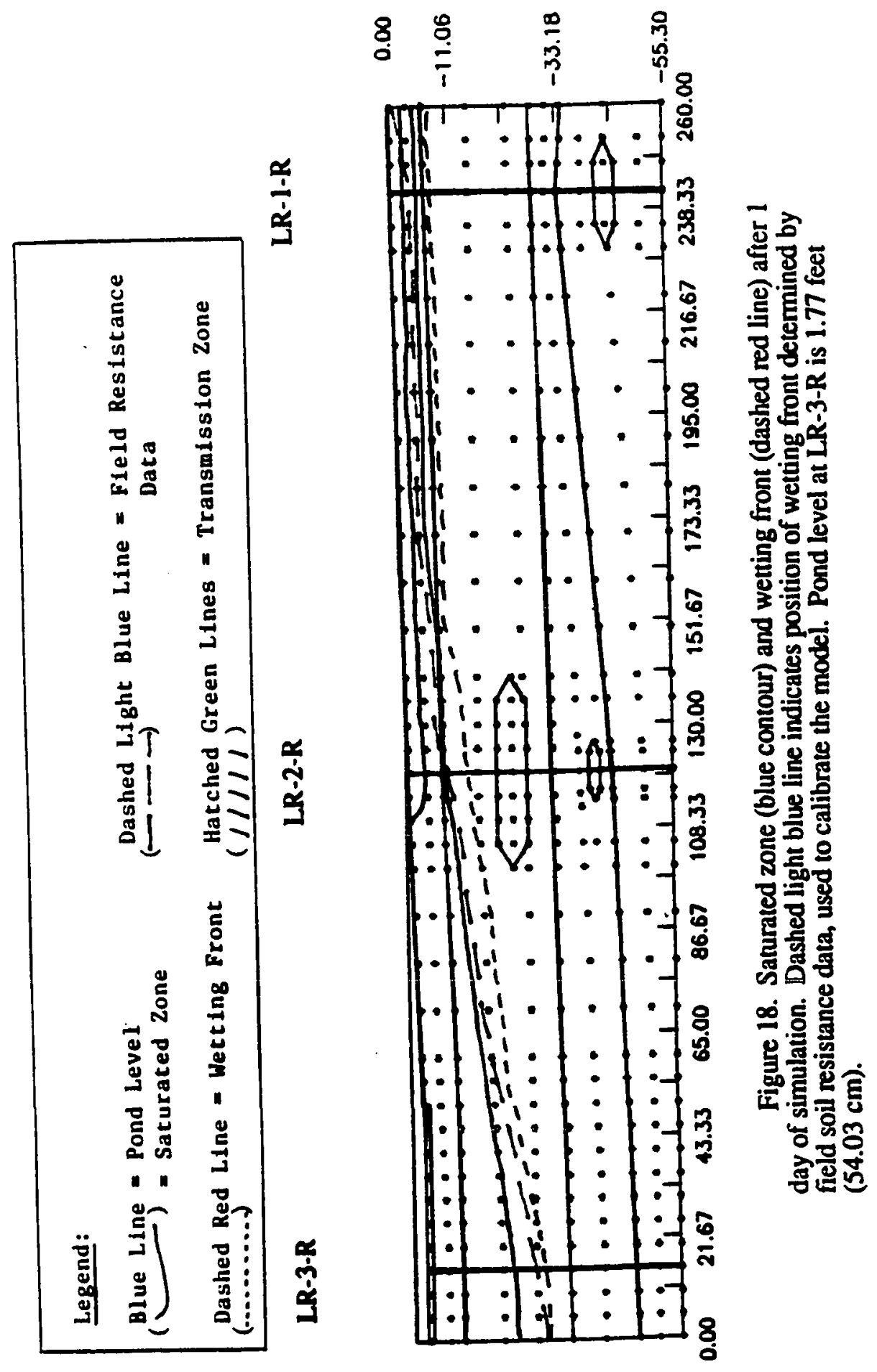




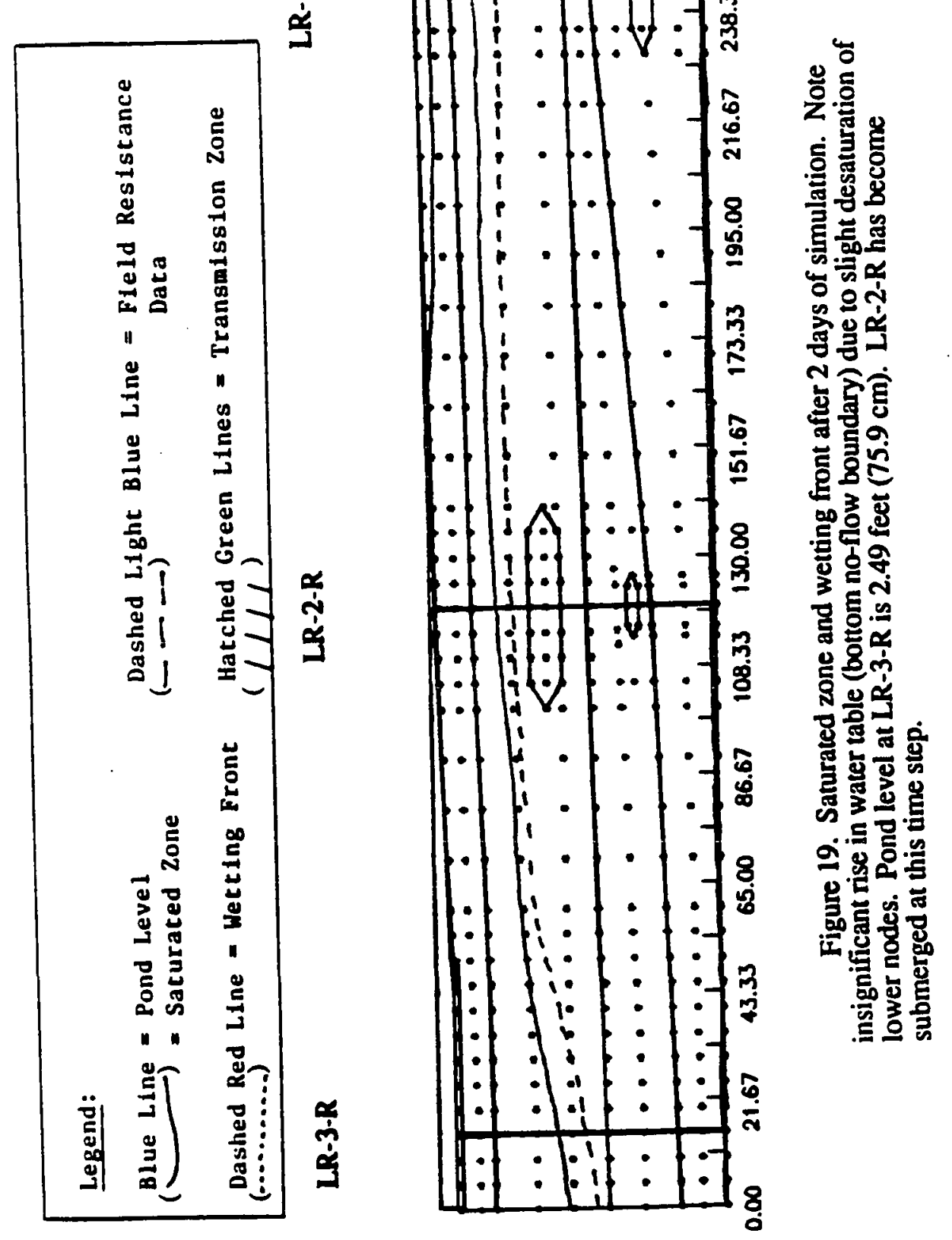




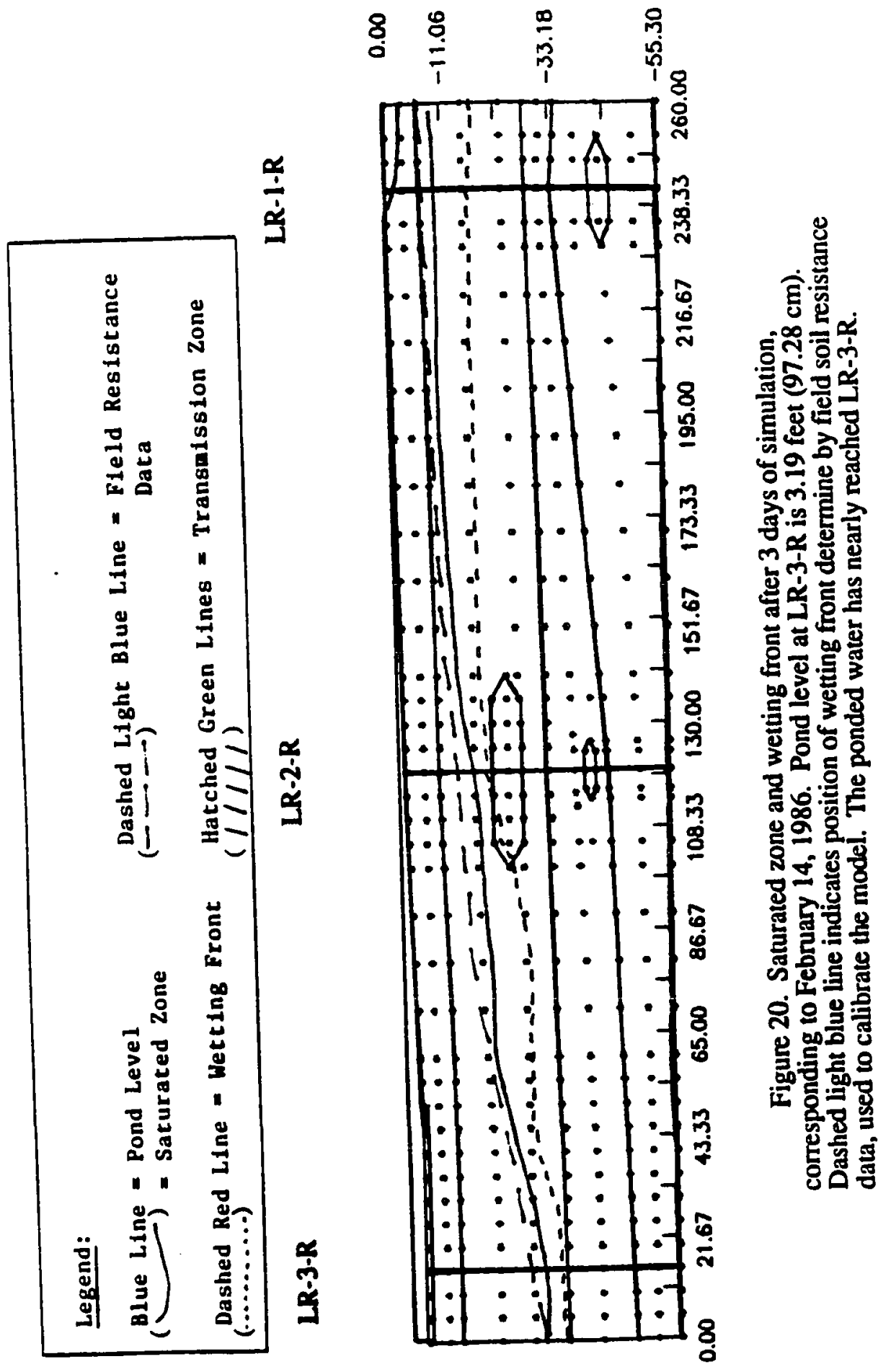




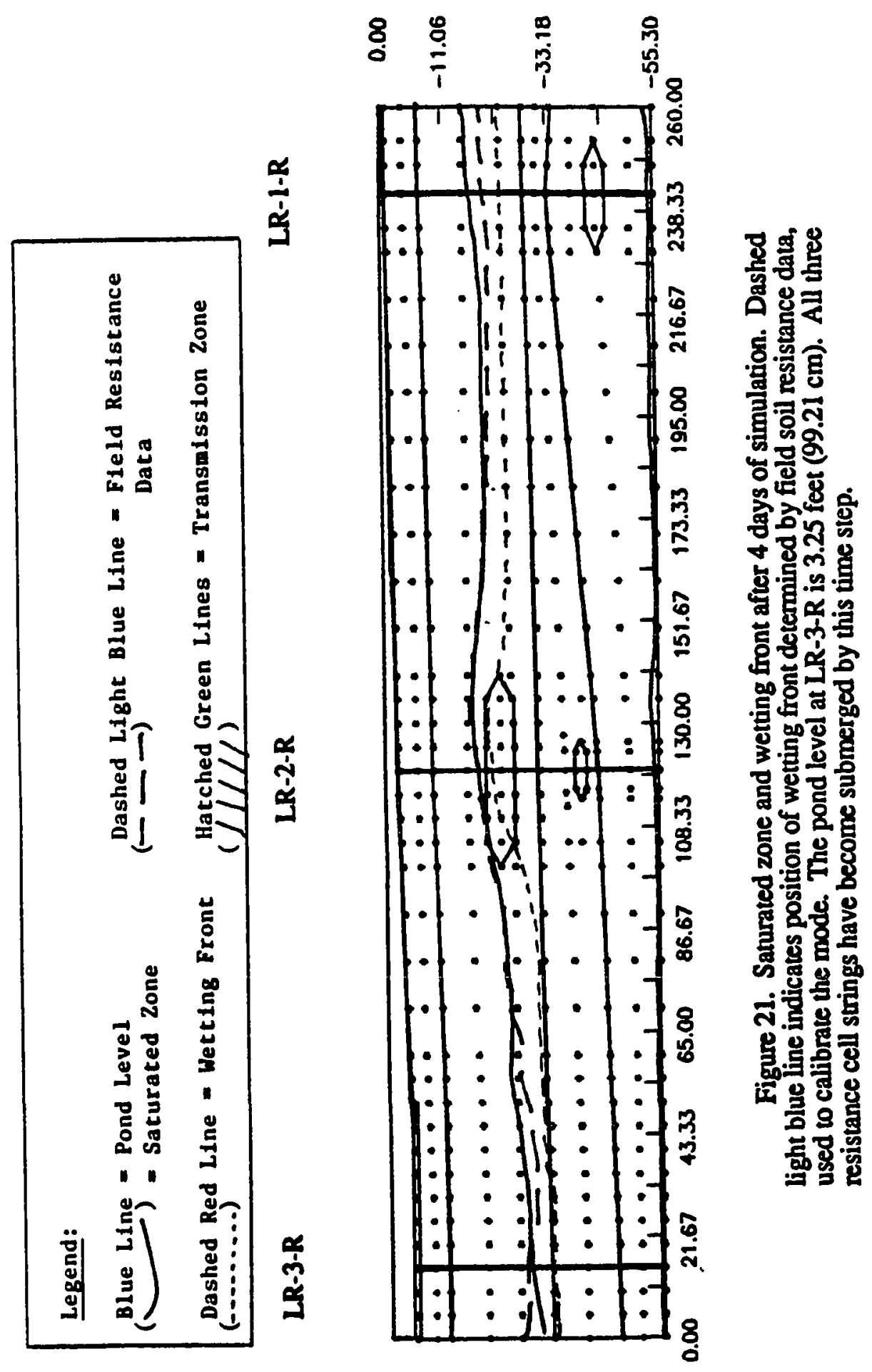




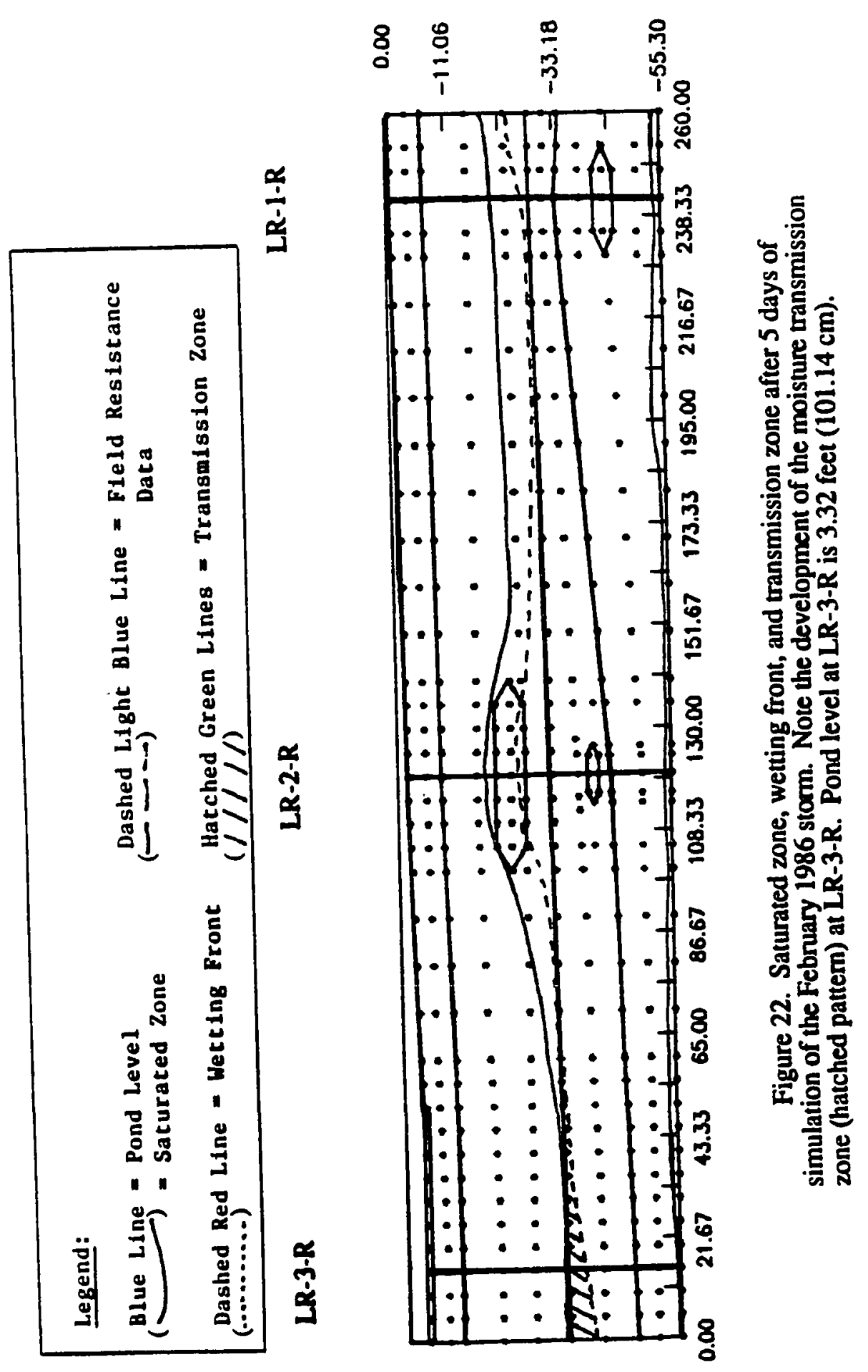




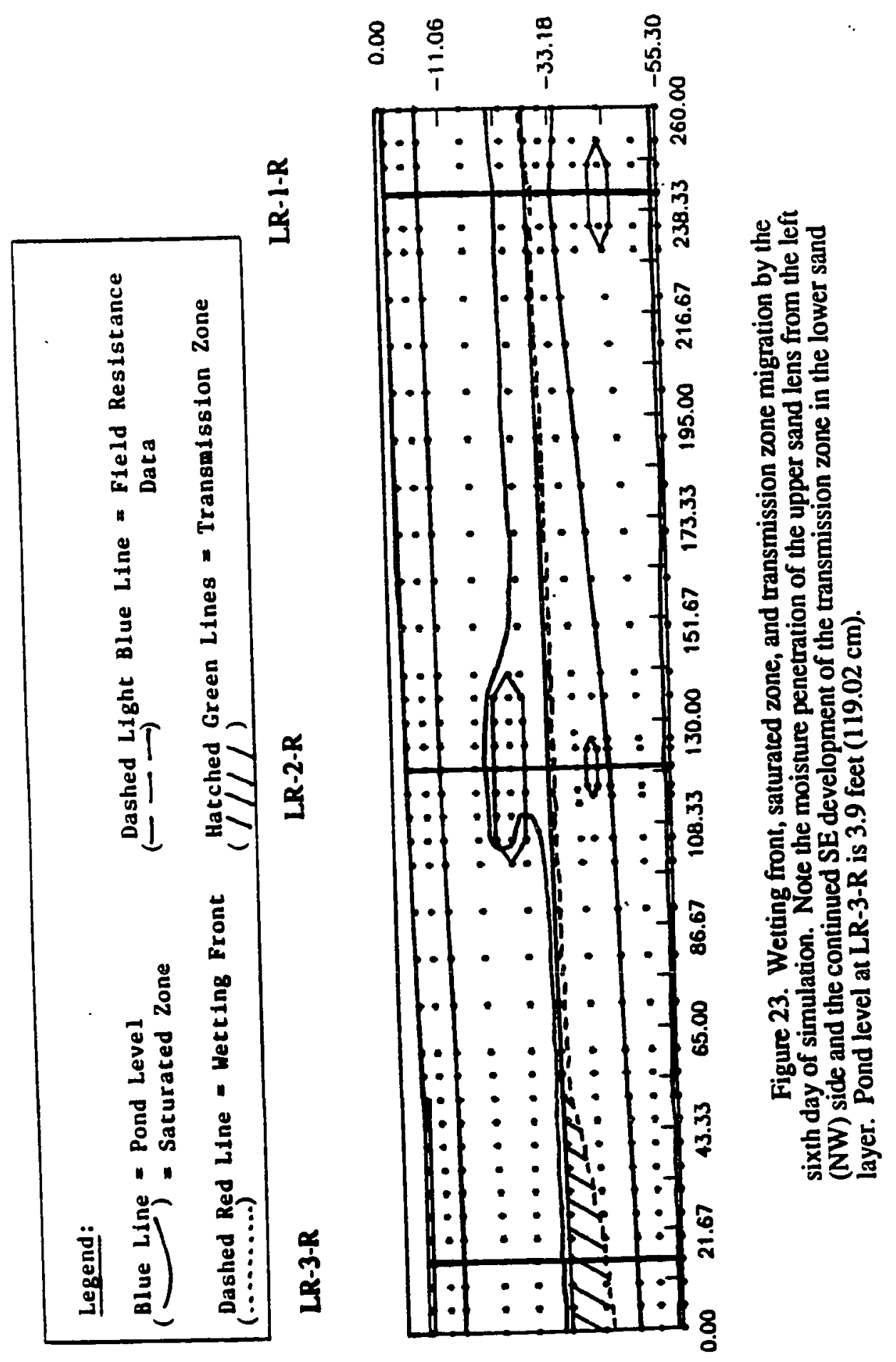




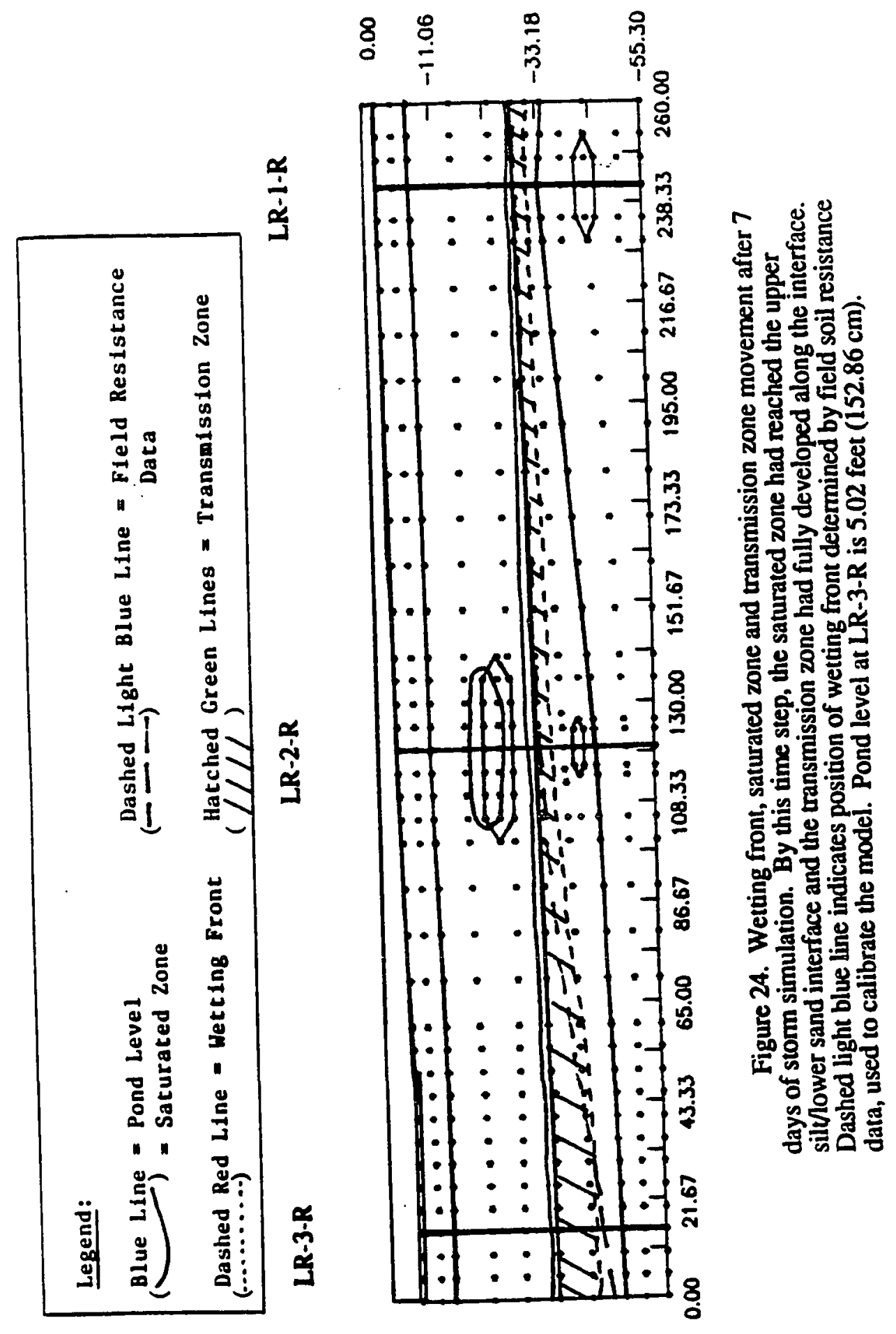




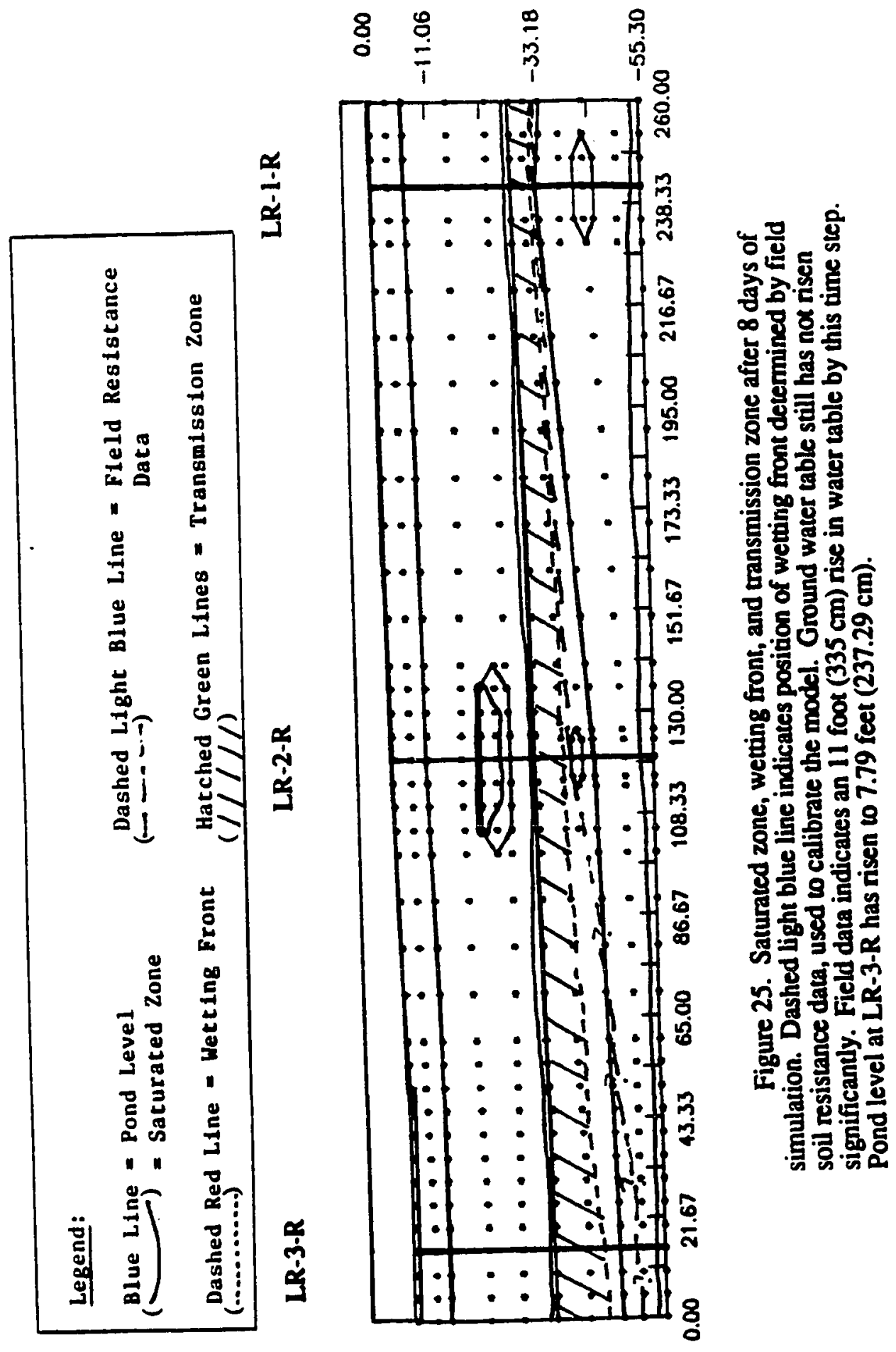




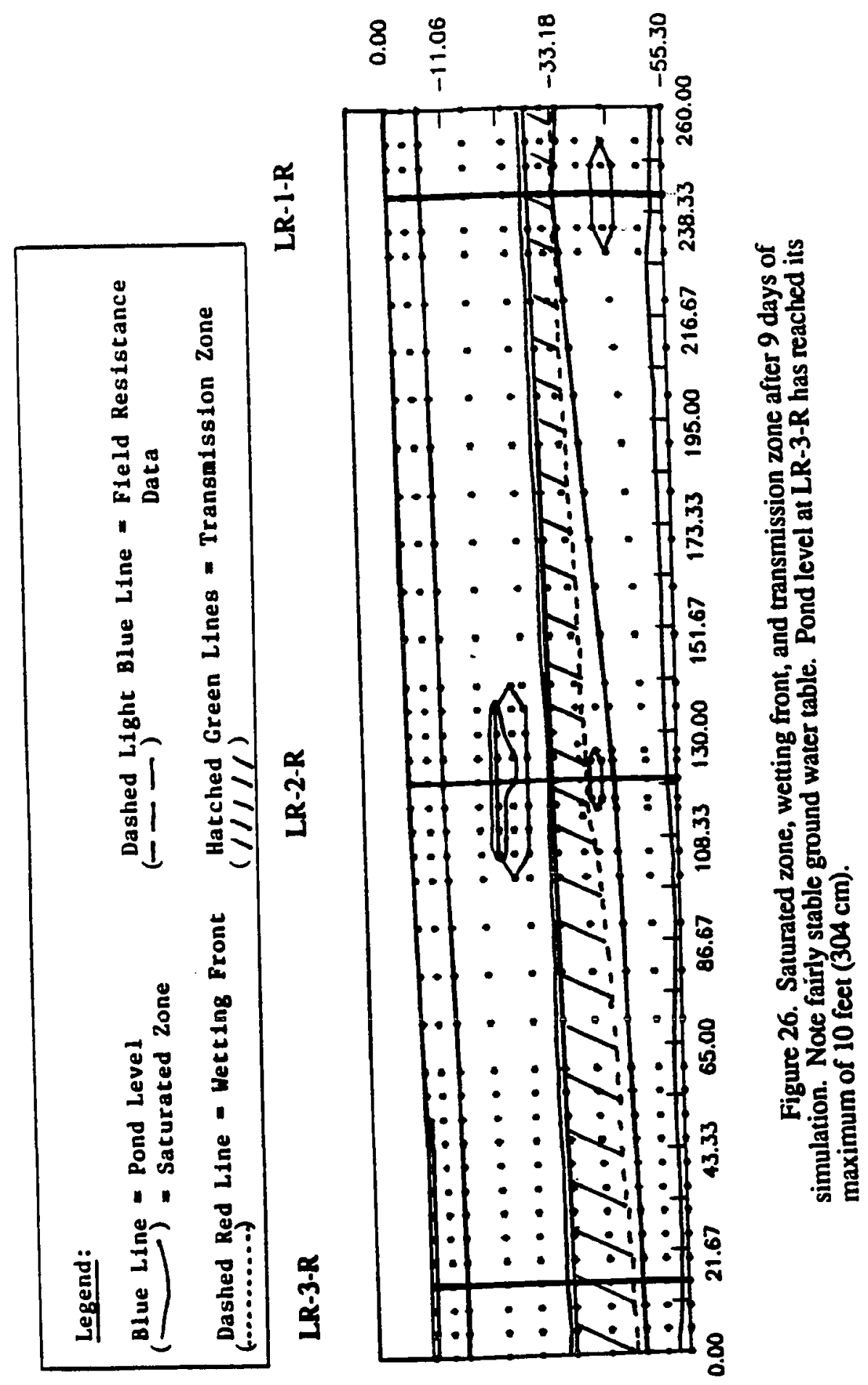




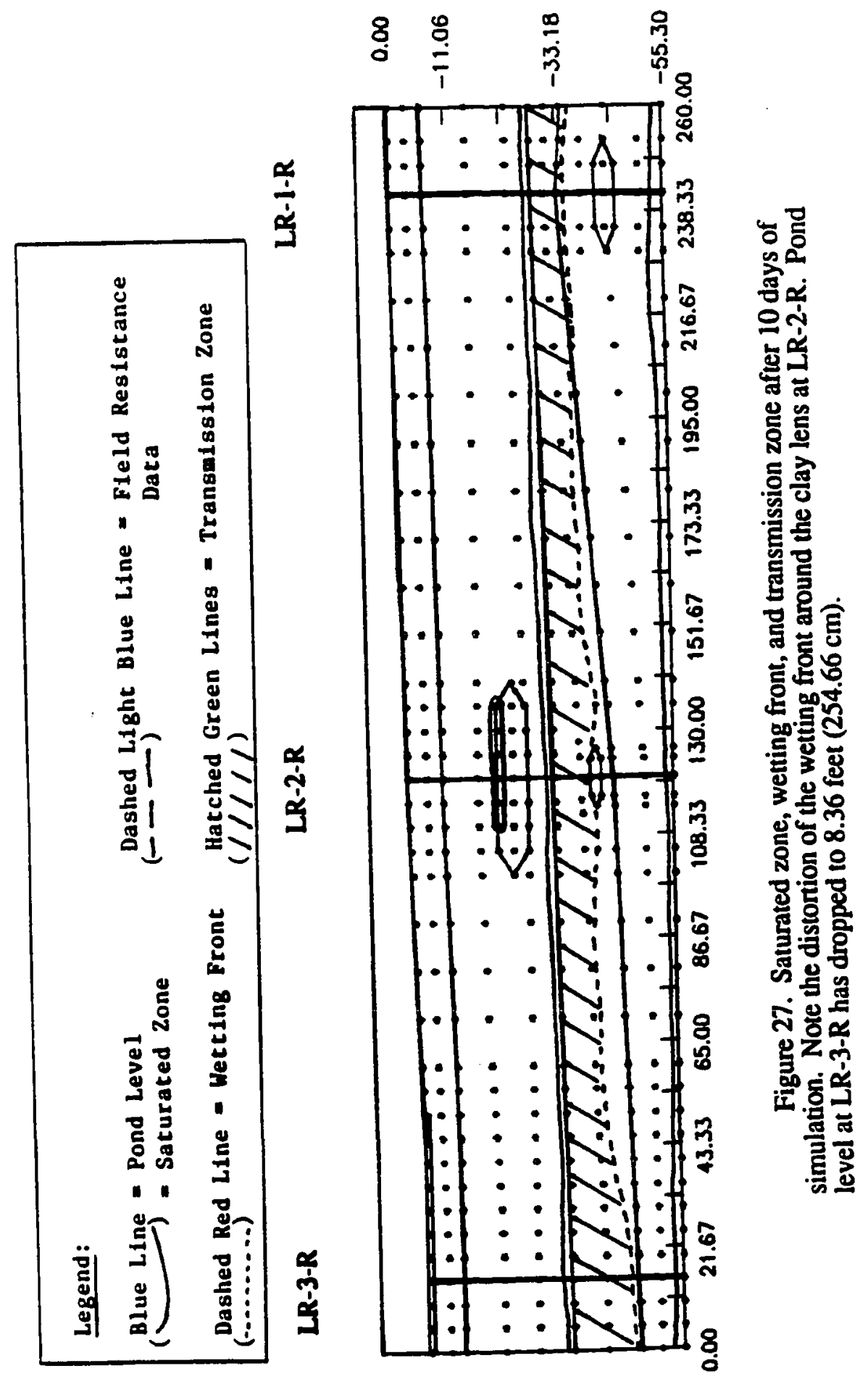




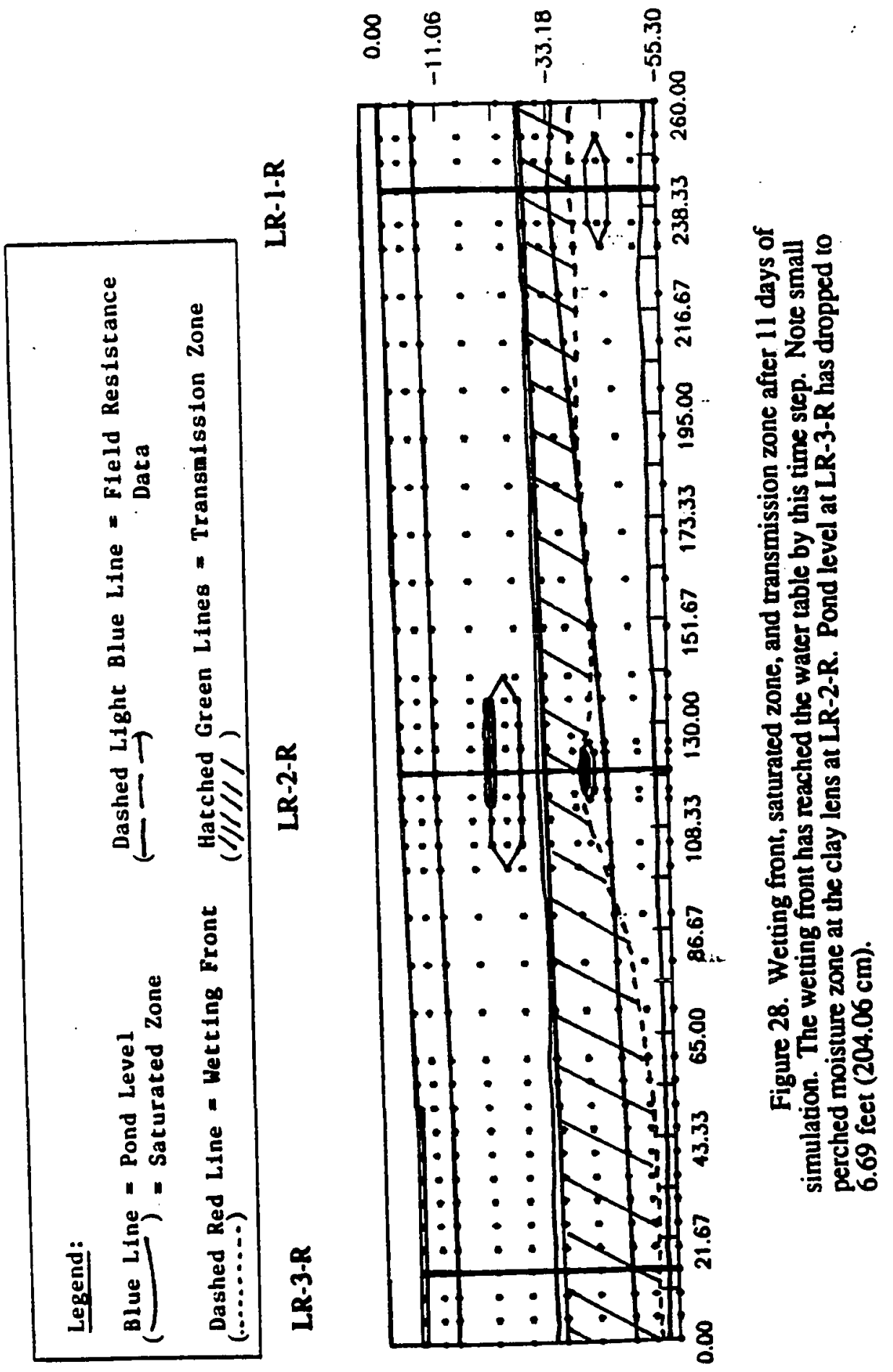




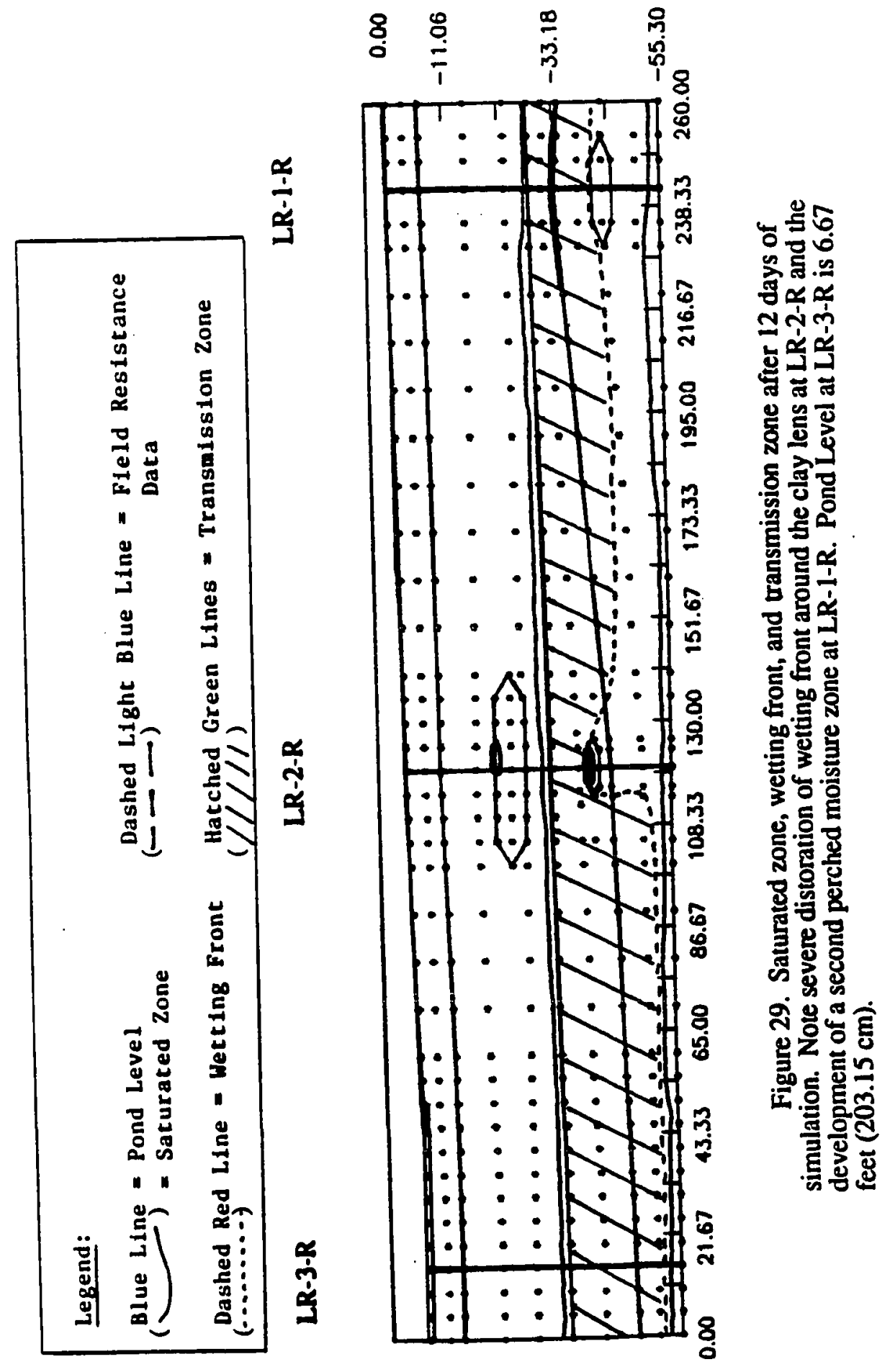




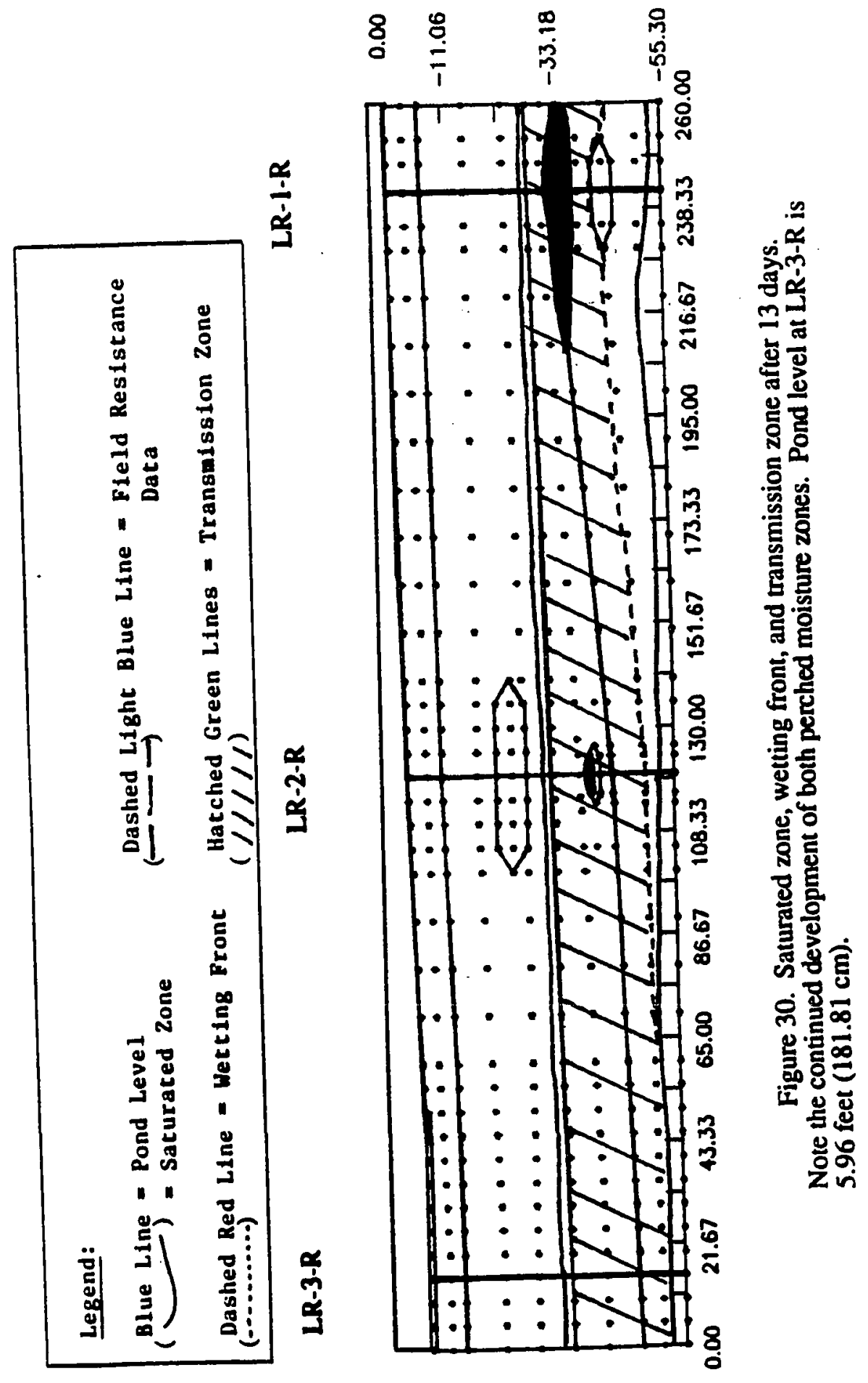




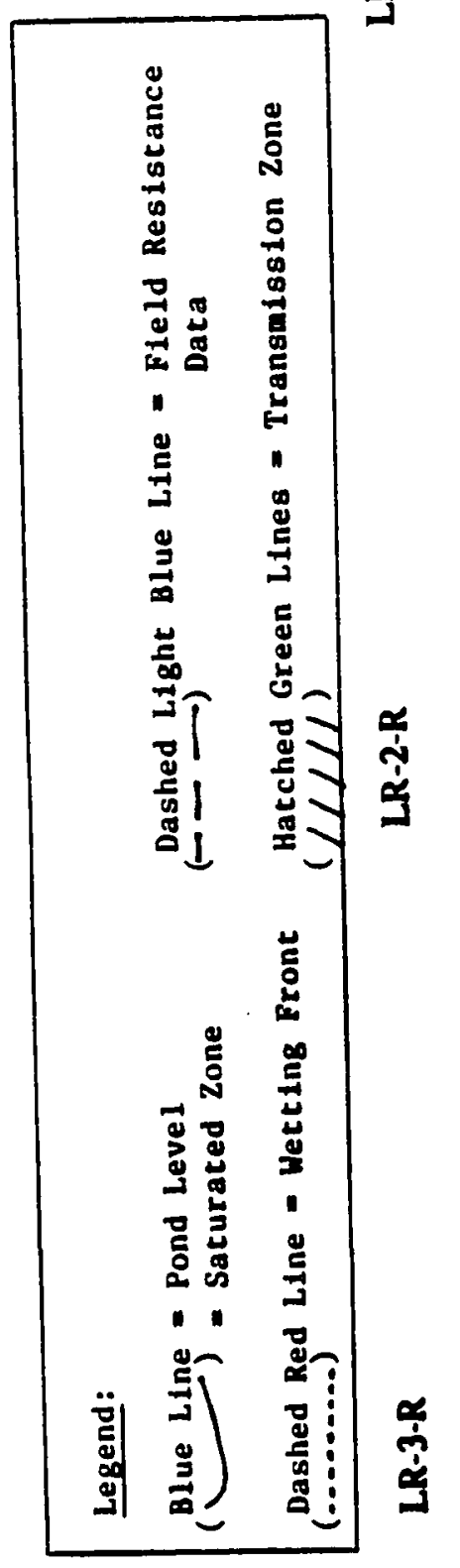

$8 \stackrel{9}{0} \quad \frac{0}{p}$ po 8 范

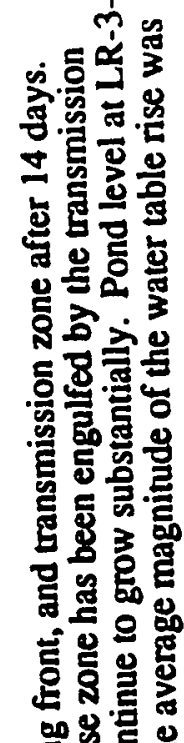

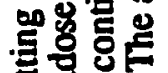

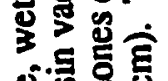

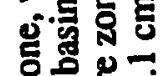

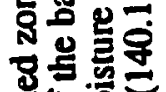

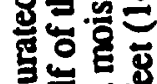
를

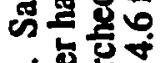

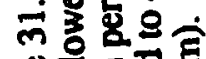
을웅

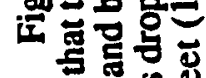

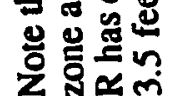


conditions, which were slightly adjusted to properly simulate the initial soil conditions preceding the February 1986 storm. This technique prevented the input of erroneously moist conditions which would have lead to premature drainage during the wetting front simulation and lead to a significant false rise in the ground water table.

Initially, the surface nodes were set equal to the depth of the ponded water, on February 11, 1986, at the specific node location (for example $1.75 \mathrm{ft}(52.58 \mathrm{~cm})$ at LR-3-R). Surface nodes between $L R-2-R$ and $L R-1-R$ were set at $\psi=0 \mathrm{~cm}$ to simulate saturated surface conditions due to precipitation on February 11, 1986. The bottom nodes (no-flow boundary) were initially set at $\psi=-10 \mathrm{~cm}$, to simulate the capillary fringe at the top of the water table and to enable the model to simulate the ground water recharge contribution of this specific cross-section of the drainage retention basin. At each half day time step, the surface node pressure heads were reset to either the extrapolated or field measured pond level corresponding to the time step.

After one day of simulation, the wetting front (defined by a $5 \%$ increase in moisture content) had moved through the silty gravel and into the upper silt unit. The saturated zone (defined by a zero pressure head contour) had spread out in the silty gravel unit, as the result of the simulated precipitation. The saturated zone seemed to propagate as a slug, or body, of water through the upper silty gravel unit (soil material 2) between LR-2-R and LR-1-R. This pattem is consistent with the resistance data and is probably the result of the initial precipitation conditions. As expected, the pressure head and moisture content values in the upper silty gravel significantly increased, resulting in a pressure head and moisture build up above the silty gravel/upper silt layer contact. This was caused by the contrast in hydraulic conductivities between the upper silty gravel and the upper silt layer, and the location of the wetting front. The low conductivity of the silt impeded the downward propagating moisture, and created a pressure head build up in the silty gravel unit. A very 
small water table response (approximately $0.1 \mathrm{feet}, 3 \mathrm{~cm}$ ) is seen after the first day of simulation. This is due to minor drainage from the lower silt layer, which produced saturated conditions at some of the bottom nodes at the bottom no-flow boundary.

By the second day of simulation, the wetting front had moved only a few feet downward in the upper silt unit. The silty gravel unit had become more saturated as the result of increased surface ponding of storm runoff water. Pressure heads in the upper silty gravel (material 2) had begun to augment as a result of the increased surface pressure heads (i.e., increasing pond level). The minor rise in the water table continued as a result of the slight subsurface draining and the effects of the bottom no-flow boundary. On the third day of simulation, the NW side of the wetting front (closest to LR-3-R) continued to propagate deeper into the vadose zone, more so than the SE portion (closest to LR-1-R). The differential wetting front penetration was most likely created as a result of the higher initial moisture content in the NW portion of the basin from the initial ponding, and due to the higher surface pressure head values at the NW pond surface.

A notable effect created by the contrasting, unsaturated hydrogeologic properties of the upper sand lens and the upper silt layer on the wetting front and saturated zone is predicted by the fourth day of simulation. The pressure head difference between the silt (sanurated portion) and the sand lens (unsaturated) created a hydraulic conductivity contrast between the two materials, which caused the sand lens to act as a moisture barrier. The higher conductivity of the saturated portion of the silt layer and higher suction values lower in the silt layer caused the wetting front to become impeded at the top of the sand lens and to flow around it. The fine grained texture of the silt allowed the moisture to flow laterally and vertically around the coarse grained sand lens. This phenomenon is known as the "wick effect." The phenomenon of impeding moisture migration by contrasting soil material properties and causing the moisture to flow around the coarse grained "barrier" 
(i.e., "wick effect") has been only recently understood and is now being used in the design of hazardous waste burial trenches (Mercer et al., 1983, and Yeh et al., 1985).

On the fifth day, pressure heads along the upper silt/lower sand unit interface began to build up in the $\mathrm{NW}$ portion of the cross-section. The moisture build up created a "moisture transmission zone" or moisture flux zone in the lower sand unit as the percolating water broke through the upper silt unit/lower sand unit interface. The moisture transmission zone developed as a result of the upper silt unit/lower sand unit contrast in hydrogeologic properties. The lower sand unit drains moisture at a faster rate (sand: high hydraulic conductivity) from the interface than the moisture arrives (silt: low hydraulic conductivity), resulting in the development of a zone which transmits moisture, but never really becomes saturated itself, unless the water table rises and submerges the zone. The transmission zone is a moisture flux zone defined by the saturated zone (above) and the wetting front (below). Pressure heads in the upper portion of the upper sand lens started to decrease, indicating that a critical interfacial pressure $\left(h_{c}\right)$ had been reached, allowing the wetting front to pass through the upper silt/sand lens boundary. The water table had nearly stabilized by this time step (at approximately $1.5 \mathrm{feet}, 45 \mathrm{~cm}$ ), due to the fact that most of the nodes in the lower silt unit have finally reached more stable moisture contents/pressure heads.

By the sixth day of simulation, the wetting front had moved into the NW side of the upper sand lens and soil suction values at the base of the sand lens had decreased significantly (i.e., increased moisture content). The infiltrating water had penetrated the side of the lens and had progressed around the lens. The transmission zone continued to grow in a southeasterly direction, between LR-3-R and LR-2-R, as a result of the continued downward propagation of the wetting front. At this time step, moisture contents and pressure heads at and above the wetting front have increased significantly, while 
suction in the lower sand unit remains relatively high. The continued moisture buildup in the silt layer will lead to continued moisture breakthrough into the lower sand unit and lateral growth of the transmission zone. This phenomenon is fairly characteristic of a silt texture above a sand or gravel texture.

Moisture breakthrough occurs when the fine grained material (silt) above the fine grained/coarse grained (i.e., silt/sand) interface undergoes a significant moisture and pressure head buildup. At some critical interfacial pressure $\left(h_{c}\right)$, moisture breaks through the fine grained/coarse grained interface and rapidly flows into the lower coarse grained material (lower sand unit). This phenomenon occurs between the fifth and seventh days of simulation, where the moisture contents in the silt at the interface built up to approximately $95 \%$ of saturation.

By the seventh day, the transmission zone was fully developed and moisture penetrated the lower sand layer along the entire silt/sand interface. Also, the saturated zone had passed around the upper sand lens, leaving some of the lens still unsaturated, and became impeded at the upper silt unit/ower sand unit interface. This is the result of the contrasting hydrogeologic properties of the silt and sand, as mentioned above.

The author has found that the moisture breakthrough is highly influenced by the hydrogeologic properties of the fine-grained material (i.e., silt) and, therefore, the shape of the material's characteristic curves. By interchanging various shaped characteristic curves for soil material 3 (silt) during the sensitivity analysis, it was found that a larger pressure head (i.e., moisture) buildup is required for fine textured soils with high negative air entry pressure heads in order to achieve breakthrough into the underlying coarse textured material. The high negative air entry pressure heads are created as a result of the fine textured material becoming effectively saturated at a relatively high suction value, to which the corresponding hydraulic conductivity value is quite low (say, $0.5 \times \mathrm{KSAT}$ ). The low 
hydraulic conductivity impedes downward flow, and as a result, moisture is built up above the wetring front and may even flow laterally away from beneath the source.

At the eighth day, the model and the contoured resistance data, again, matched fairly well. Both indicate the the wetting front had advanced through much of the lower sand unit. However, field data indicated that the ground water level beneath the basin should have risen nearly 11 feet $(335 \mathrm{~cm})$ by this time step. The model only simulated a 2 3 foot $(61-91 \mathrm{~cm})$ rise in ground water level at this time step, some of which was due to the desaturation of some initially moist nodes. By comparing the recharge contribution of the simulated cross-section and ground water field data, the author has concluded that the fairly thick (approximately 20-30 feet, 6-9 m) permeable sandy gravel zone in the southeast portion of the basin (not modeled) is a major source of ground water recharge at the drainage retention basin. As previously mentioned, this thick permeable zone was originally suggested by the geologic log of the D-3 (Appendix A) boring in the floor of the drainage retention basin (see figure 6 for location).

Originally, the existence of the thick permeable sandy gravel in the SE basin was disputed because of extremely poor geologic correlation between D-3 and other borings in and around the basin. However, the discrepancy between the field ground water data and the recharge contribution from the simulated cross-section is cited as further evidence supporting the existence of a thick permeable zone in the southeastern portion of the basin. Finally, the reason why the recharge contribution from the SE basin could not be noted prior to the eighth day of simulation is that a minimum pond level of $4-4.5$ feet (1.2-1.4 $m$ ), as measured at LR-3-R, is required for the SE portion of the basin to become covered with ponded water and for measurable amounts of recharge to begin to occur.

From the eighth to the tenth days of simulation, the transmission zone and wetting front slowly progressed downward through the lower sand unit. The upper sand lens 
became increasingly saturated as moisture continued to fill the remaining unsaturated sand pores. The saturated zone remained stagnant at the upper silt unit/lower sand unit interface, for reasons discussed above.

By the eleventh day of simulation, the transmission zone began to penetrate the lower silt unit in the NW basin, near LR-3-R, and finally reach the water table. Moisture began to become perched on the clay lens (soil material 5) within the lower sand unit as the wetting front/transmission zone became slightly distorted around the clay lens. This is the result of the contrasting hydrogeologic properties between the more permeable sand and the less permeable clay lens, which acted as a barrier and impeded the downward propagating moisture under these relatively moist conditions.

During the twelfth day of the storm, moisture was rapidly pulled into the lower silt unit, causing the wetting front to become more distorted around the low conductivity clay lens. The author believes this was the result of the silt's "wick effect" and higher affinity for moisture. At this time step, moisture had also become perched at the lower sand unit/lower silt unit interface, near LR-1-R. This may be the effect of the no-flow boundary along the right (southeast) side of the finite element grid, and/or the simplified soil/material contact along that portion of the sand/silt interface, required for modeling purposes. At LR-1-R, the contact between the lower sand and lower silt may actually be more gradational and not as sharp as modeled. A more gradational contact at this location may allow moisture to pass more readily through the interface without becoming perched along the "contact." Unfortunately, limited geologic knowledge of the heterogeneous subsurface and model simplifications make gradational contacts difficult to model. Also, the lack of any quantitative field moisture content data makes it impossible to verify the existence of the perched moisture zone at this contact. However, perched moisture zones have been encountered in the vadose zone during the drilling of a few of the ground water monitoring 
wells at the LLNL site (Dresen, personal communication, 1988). This evidence indicates that the perching of moisture in the vadose zone beneath the LLNL site is a realistic phenomenon, and, therefore, may not be a result created by the model's boundary conditions or soil contact assumptions (i.e., abrupt change in grain size across the contact).

Between the thirteenth and fourteenth days of the February 1986 storm simulation, the perched moisture zone at LR-1-R continued to grow laterally, nearly 65 feet $(20 \mathrm{~m})$, and to slightly thicken. By the fourteenth, and last, day of simulation, the transmission zone had expanded from the lower sand unit/upper silt unit interface down to the water table, making the entire lower portion of the vadose zone a moisture transmission zone. The water table had risen a total of 3.5 feet $(107 \mathrm{~cm})$ by the fourteenth day of simulation. Nearly 2 feet $(61 \mathrm{~cm})$ of the total water table rise may be attributed to the recharge effects of the transmission zone and 1.5 feet $(45 \mathrm{~cm})$ may be attributed to the earlier draining of the lower nodes, indicating that the modeled cross-section contributes only a minor amount to local ground water recharge.

\section{Lateral Flow Simulation}

To use the calibrated model as a predictive tool, a hypothetical lateral flow simulation was designed to evaluate any lateral flow components in the basin vadose zone that might be created by soil material interfaces or soil material hydrogeologic properties. To simulate the lateral flow components, the author continuously simulated 10 feet $(304.8 \mathrm{~cm})$ of ponded water over the northwest portion of the basin, between LR-3-R and LR-2-R, and allowed the model to run for 12 simulated days. Figures 32 through 38 display the contoured results from the lateral flow simulation. In keeping with realistic initial subsurface moisture conditions, initial subsurface moisture/pressure head conditions were assumed to be the same as the initial conditions of the February 1986 storm. 


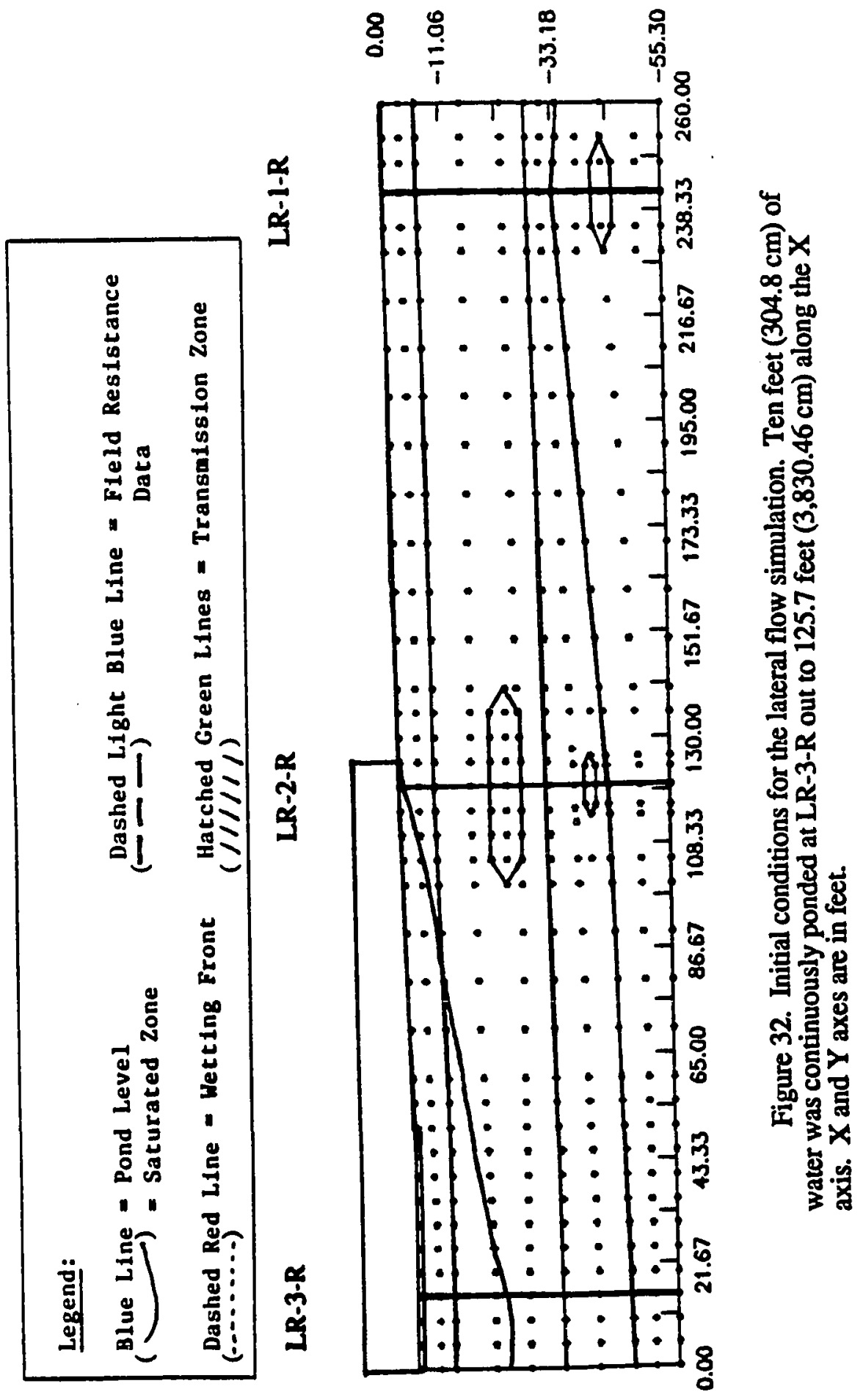




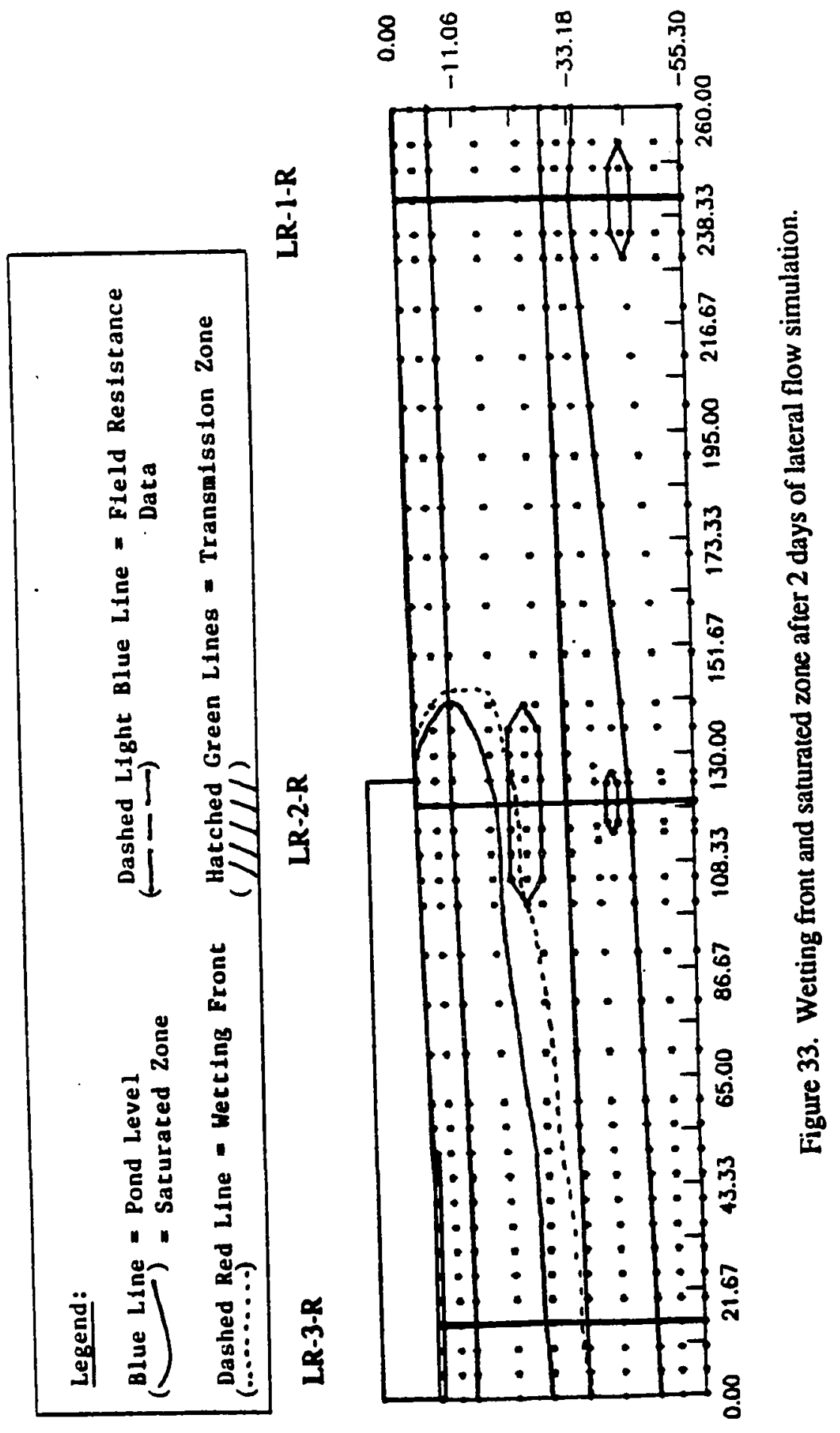




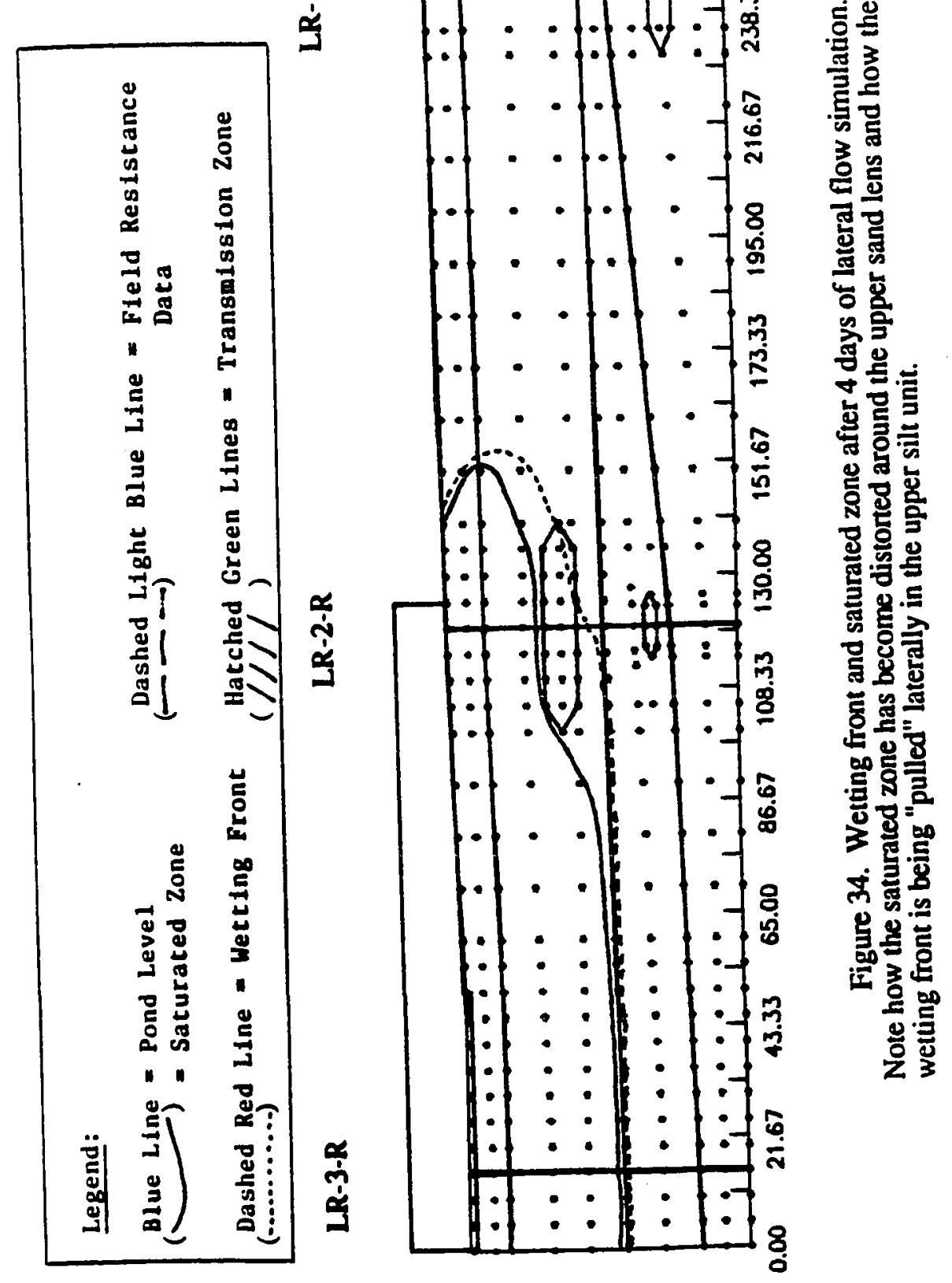




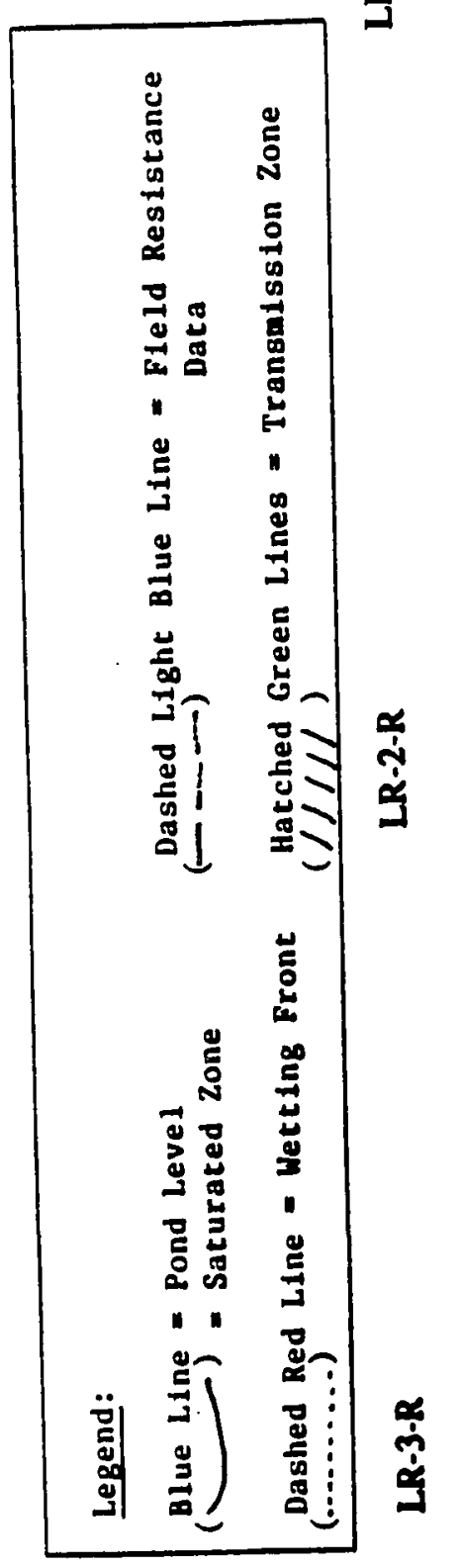

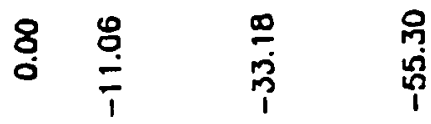

.1.T.T.1.

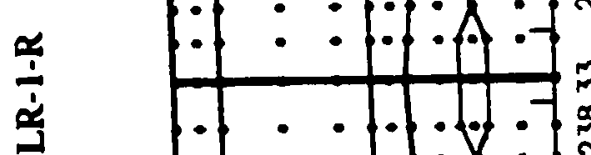

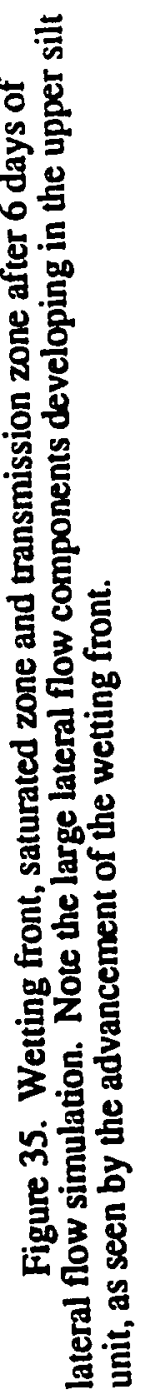




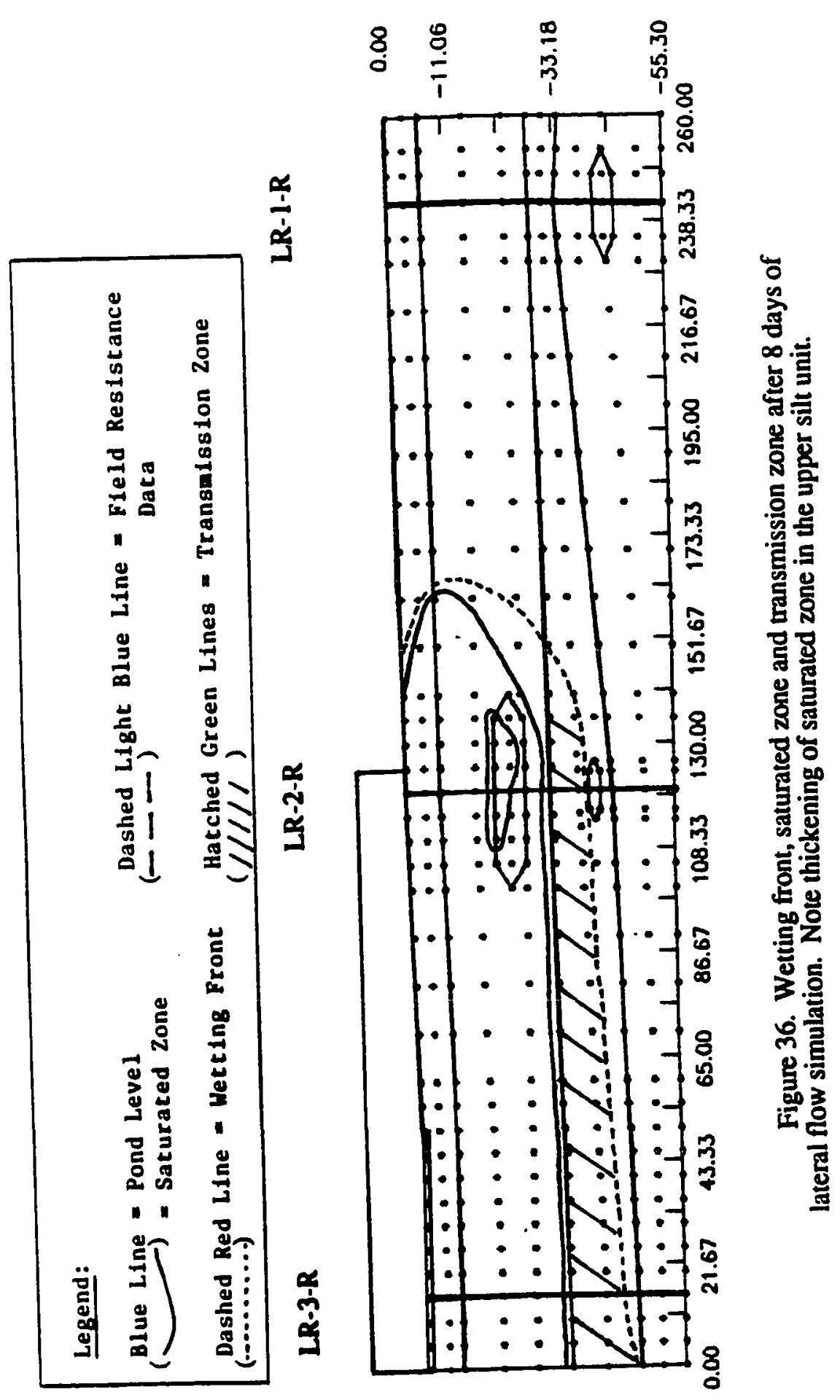




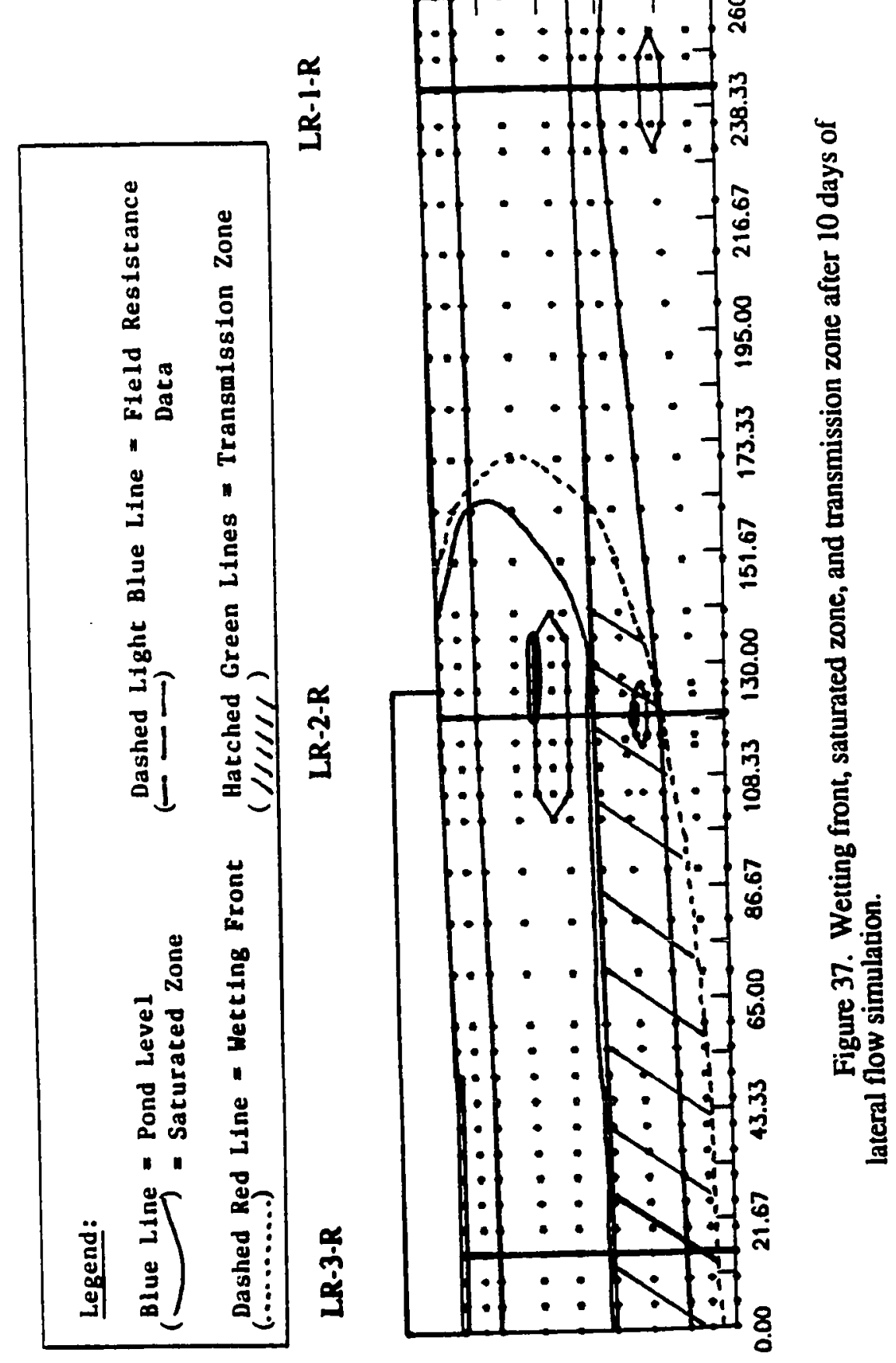

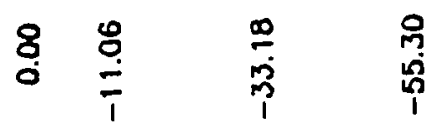

18 


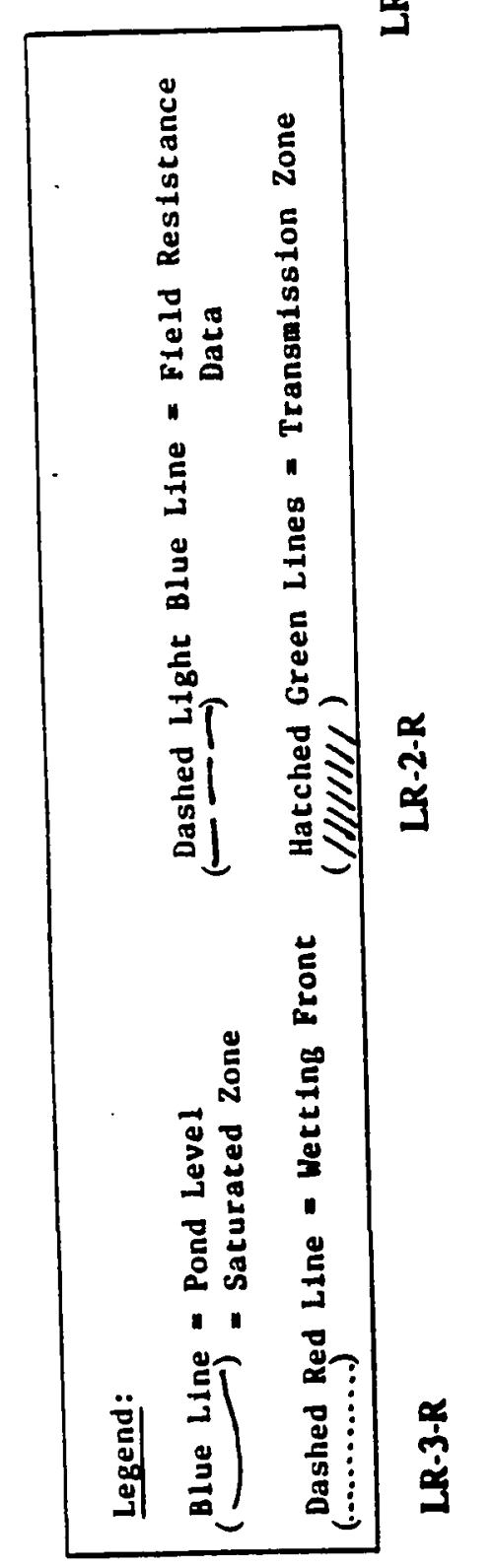

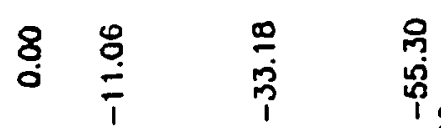
18

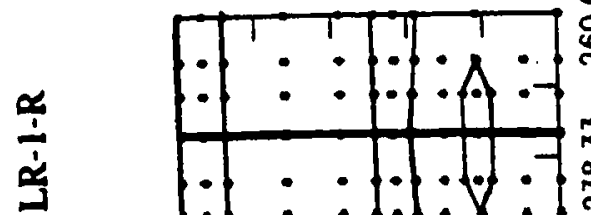

m

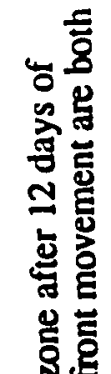

.댈

है

范

응홍을

흥 동를

응.

웡

胥导

范导

苍专总

을

들

븜

舟䓃

늘 氙

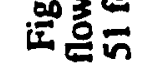

르른

코 욜 
After two days of simulation, the wetting front and saturated zone had moved a maximum of nearly 18 feet $(5.5 \mathrm{~m})$ laterally in the silty gravel and upper silt units. As expected, the wetting front and saturated zone moved further downward, a maximum of approximately 20 feet $(6.1 \mathrm{~m})$, due to the initially saturated zone at LR-3-R.

By the fourth day of simulation, the wetting front had begun to move out (laterally) a few feet ahead of the saturated zone in the upper silt unit, while they remained fairly close together in the silty gravel. Overall, the wetting front had progressed about 28 feet $(8.5 \mathrm{~m})$ laterally by this time step. As predicted in the February 1986 storm, the wetting front and saturated zone have become distorted by the upper sand lens and have become slightly impeded at the upper silt unit/lower sand unit interface.

The lateral flow components of the silt become evident by the sixth day of simulation. By this time step, the lateral component of the wetting front had grown to nearly 43 feet $(13 \mathrm{~m})$ in the upper silt unit, while the lateral flow component of the silty gravel, above, remained a bit smaller. The author believes that the "wick effect" of the fine grained texture of the silt is actually pulling the moisture laterally in the upper silt unit. Since the silty gravel (material 2) has a much coarser grained texture, the ability of the gravel to "pull" the moisture laterally is much smaller and therefore its lateral component is smaller. In addition, the author concludes that most of the lateral flow component predicted in the gravel is most likely created as a result of the hydraulic conductivity contrast between the silty gravel and the upper silt unit.

The wetting front still remained a few feet ahead of the saturated zone in the upper silt unit by the eighth day of lateral flow simulation. The saturated zone and the wetting zone (defined by the wetting front) began to thicken by this time step. In addition, it appears that the lateral flow component in the silt began to slow down, as indicated by the minimal advancement of the wetting front at this time step. 
By the tenth day, the wetting front had advanced a total of 46 feet $(14 \mathrm{~m})$, approximately 15 feet $(4.6 \mathrm{~m})$ laterally ahead of the saturated zone. The wetting front and saturated zone still remain quite close together in the silty gravel unit, a consequence of the coarse grained texture of the silty gravel unit. Again, the lateral flow component in the upper silt unit may be attributed to the "wick effect," created by the fine grained silt.

At the twelfth and final day of lateral flow simulation, the wetting front appeared to have grown, both laterally and vertically, about 51 feet $(16 \mathrm{~m})$. This simulation indicates that a fairly significant lateral flow component exists in the silt unit, more so than in any other simulated material. As previously mentioned, the author believes that the lateral fiow is created by the fine grained texture of the silt and the affinity of the silt sized particles for moisture, both responsible for the "wick effect," which causes moisture to move further in the silt than in other materials. In the event of a severe storm, causing the basin to fill for a number of days, the author believes that a significant amount of lateral flow (saturated and unsaturated) away from the basin (radially) would also occur in addition to large vertical flow components.

Both the lateral and vertical flow components of the wetting front moved a maximum of $4 \mathrm{feet} /$ day $(1.2 \mathrm{~m} / \mathrm{day})$. However, the individual components moved at varying rates during the simulation. The vertical flow component was primarily controlled by lithology, since the surface pressure head was constant. The lateral flow component was controlled by lithology and lateral distance away from the source, however. As the wetting front progressed laterally outward, the rate of movement decreased. The fastest lateral flow occurred at the first time step ( $9 \mathrm{feet} /$ day, $2.7 \mathrm{~m} /$ day) and progressively decreased to 2.1 feet/day $(0.6 \mathrm{~m} /$ day $)$, due to dominate effects of the vertical flow component laterally away from the source. 
After a thorough analysis of the lateral flow simulation results, it was found that the lateral flow components beneath the ponded water vary with respect to time. Initially, the extent to which lateral flow affects moisture movement directly beneath the ponded water was 9.5 feet $(2.9 \mathrm{~m})$, due to the initially dry subsurface conditions. By the twelfth day of simulation, subsurface moisture conditions beneath the ponded water were less transient. As a result, the extent to which lateral flow affects moisture movement beneath the ponded water decreased to 5 feet $(1.5 \mathrm{~m})$. It can be concluded from this analysis that the right and left no-flow boundaries do not adversely affect the moisture gradients along the right and left boundaries and are correct boundary conditions for the model. This is due to the fact that the lateral flow components have a very small effect beneath the ponded water simulated.

\section{Deep Ponding Simulation}

In another predictive, hypothetical simulation, the author simulated the flooding of the basin with 10 feet $(304.8 \mathrm{~cm})$ of ponded water for 20 days to predict the effects of the wetting front migration in the vadose zone. Initial subsurface moisture/pressure head conditions were assumed to be the same as for the February 1986 storm. Figures 39 through 49 display the initial conditions and the simulated results for the deep ponding simulation. Initial surface pressure heads were set at 10 feet $(304.8 \mathrm{~cm})$ in the deepest (northwest) portion of the basin, near LR-3-R, and decreased to 6.8 feet $(207.26 \mathrm{~cm})$ in the shallowest (southeast) portion of the basin, near LR-1-R, due to the slope in the basin floor. These surface pressure heads were set as a constant pressure head boundary (i.e., constant pond level) throughout the entire deep ponding simulation.

After two days of simulation, the wetting front and saturated zone had propagated downward, about halfway into the upper silt unit, much faster than the February 1986 


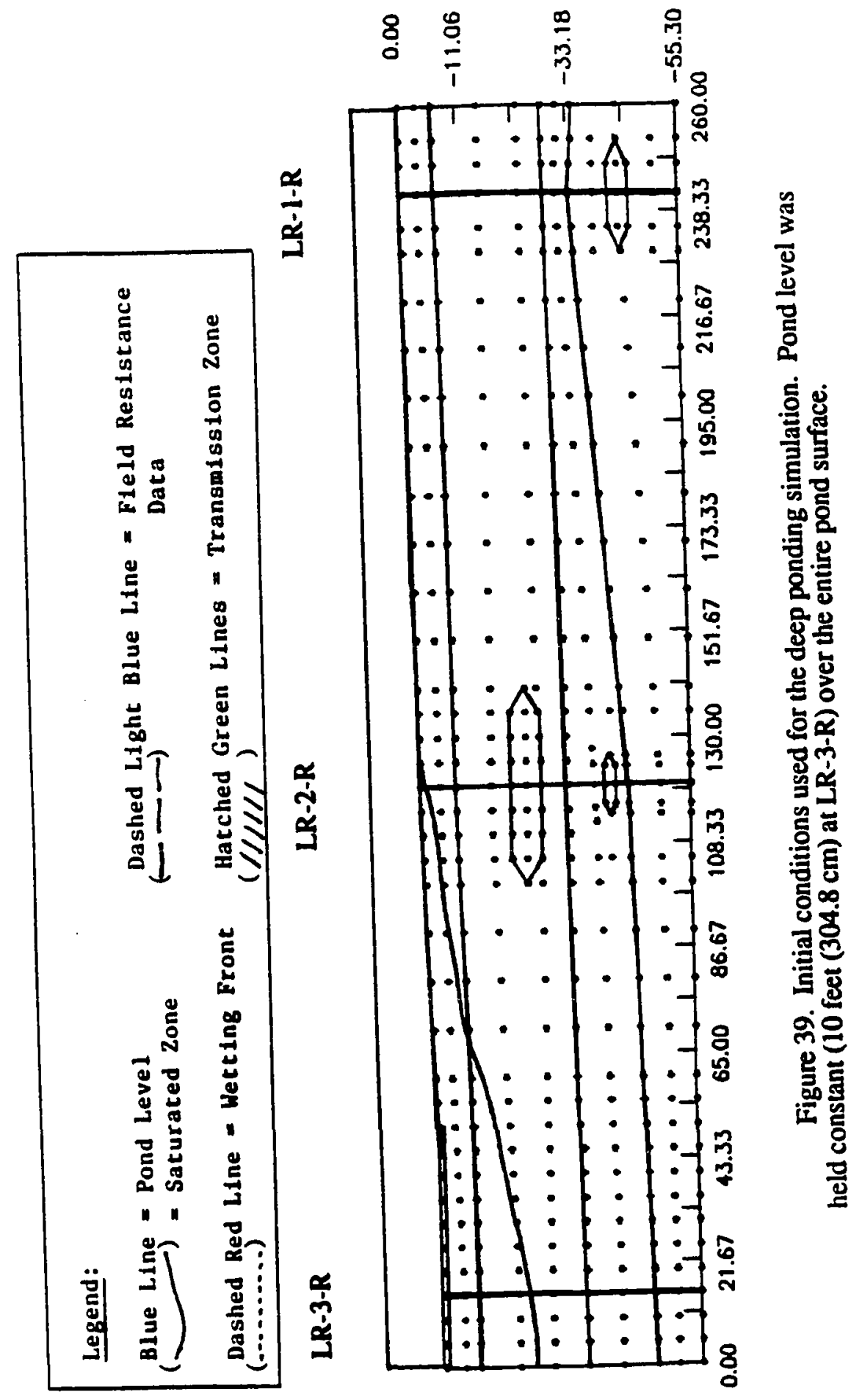




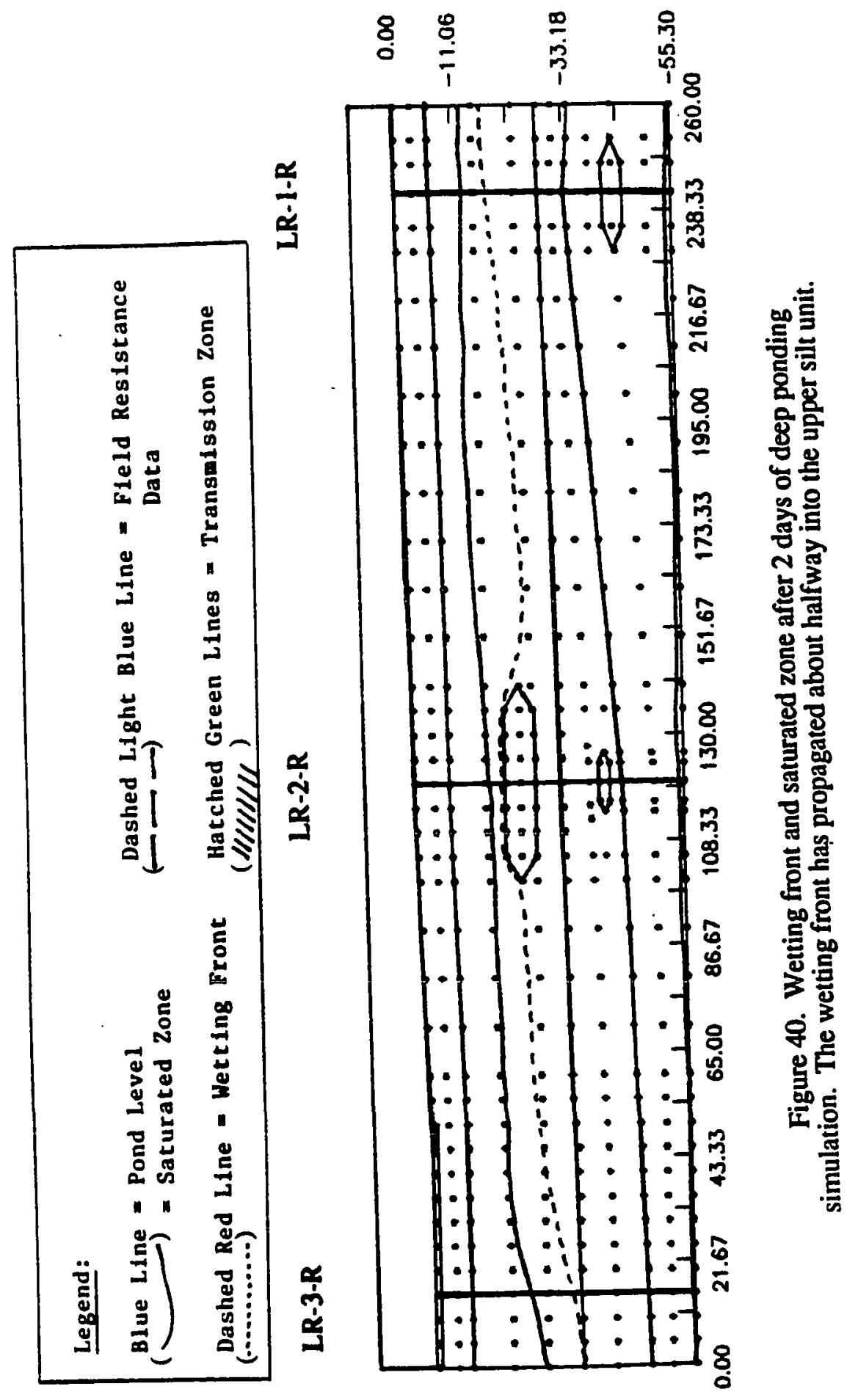




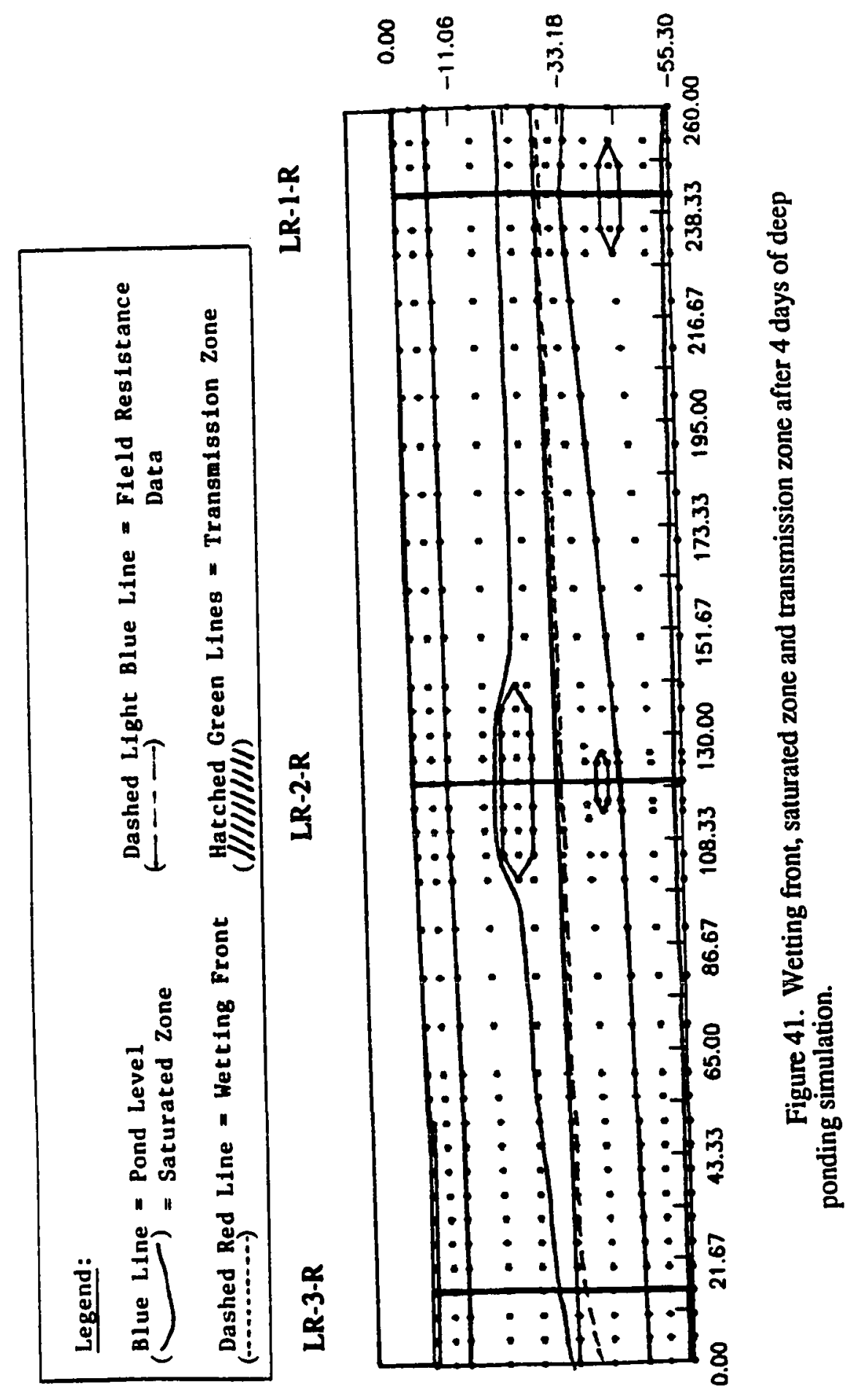




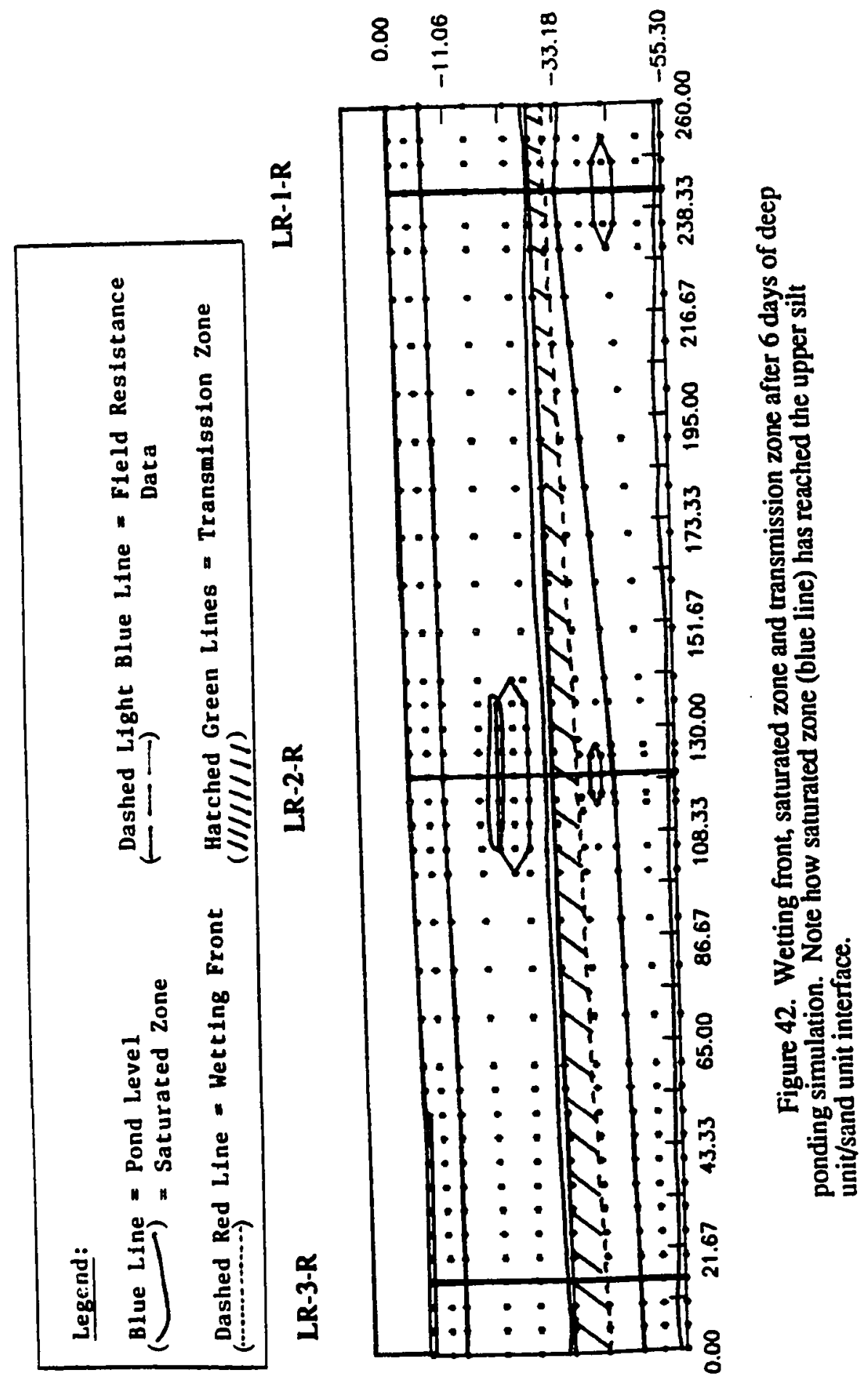




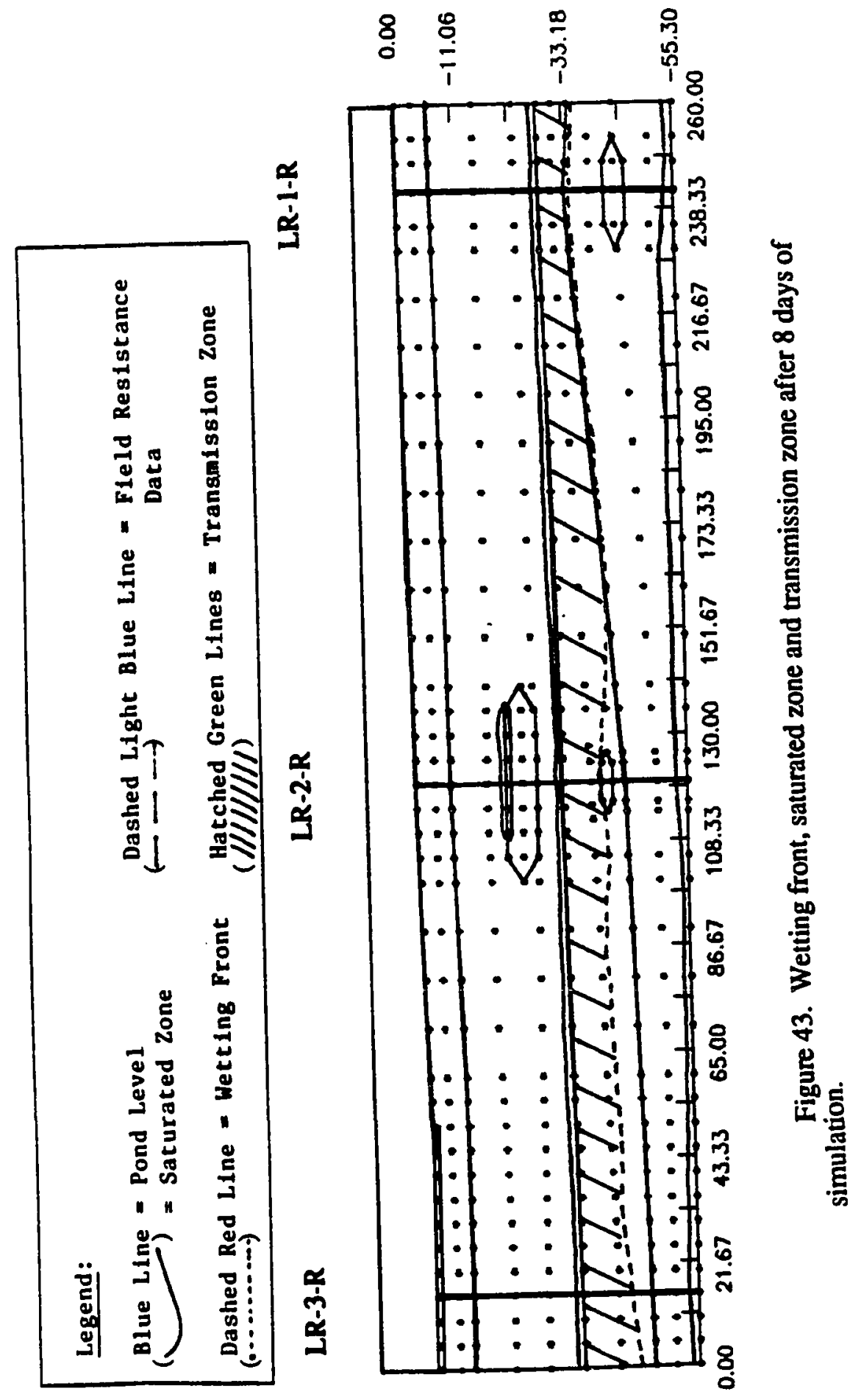




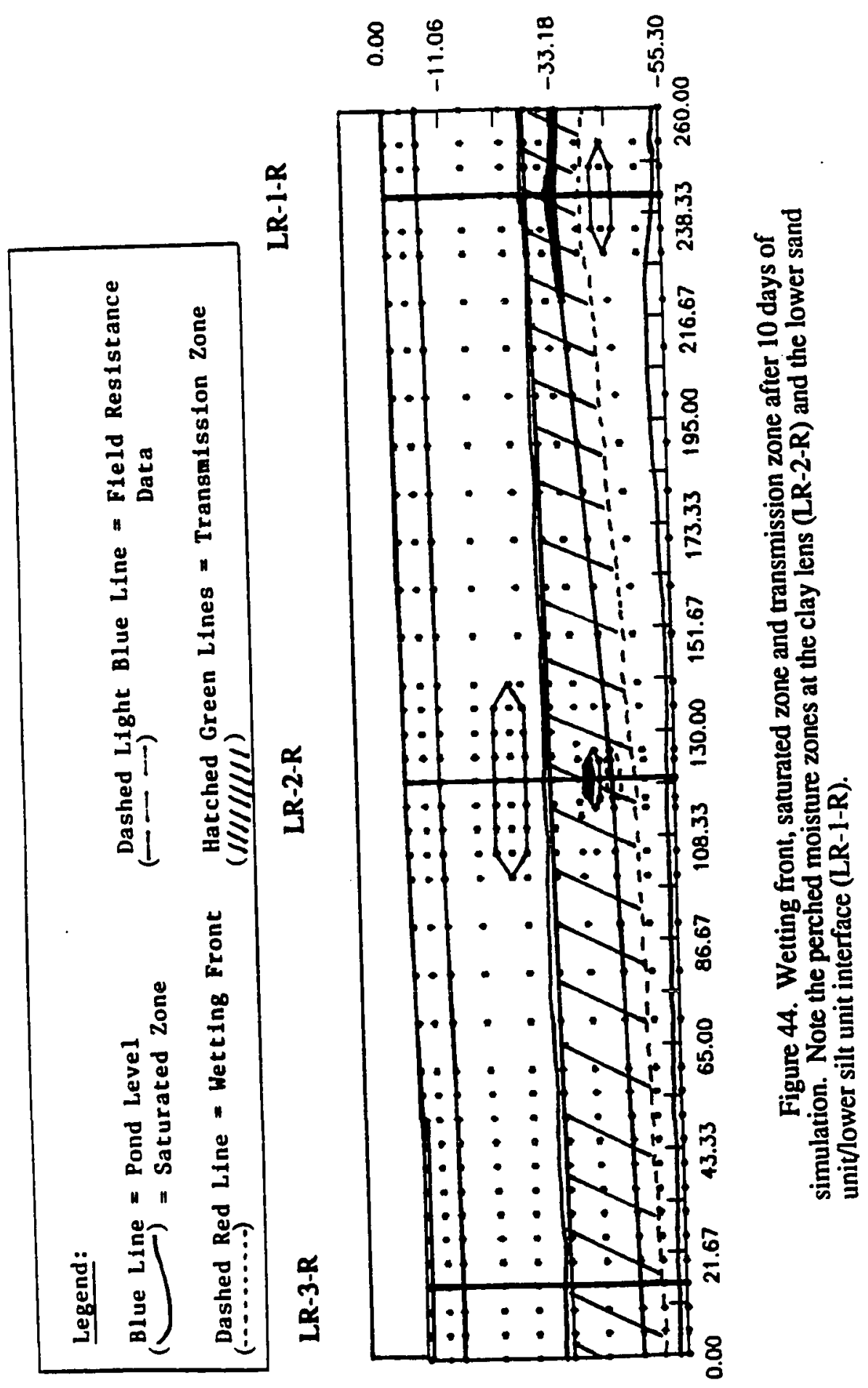




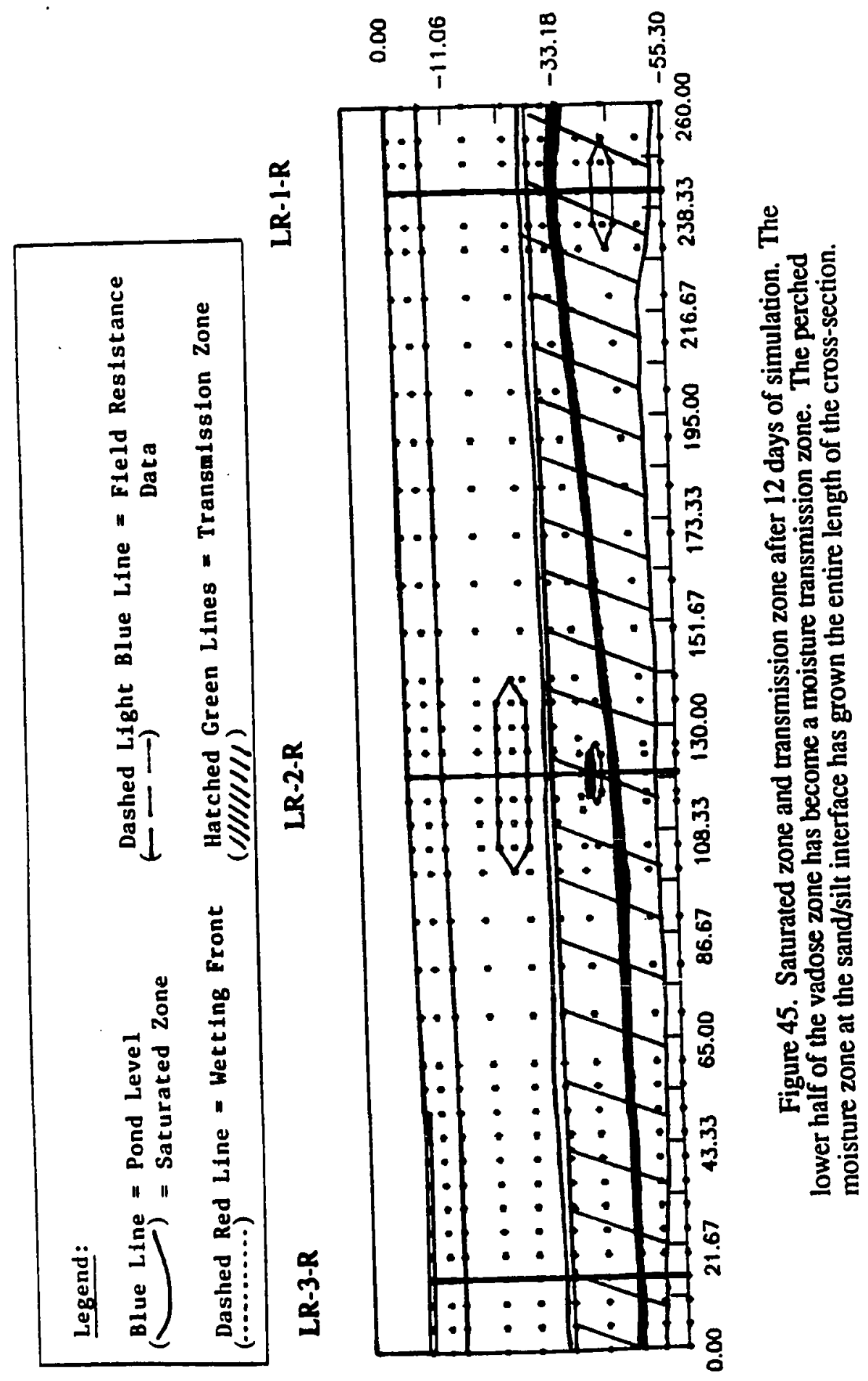




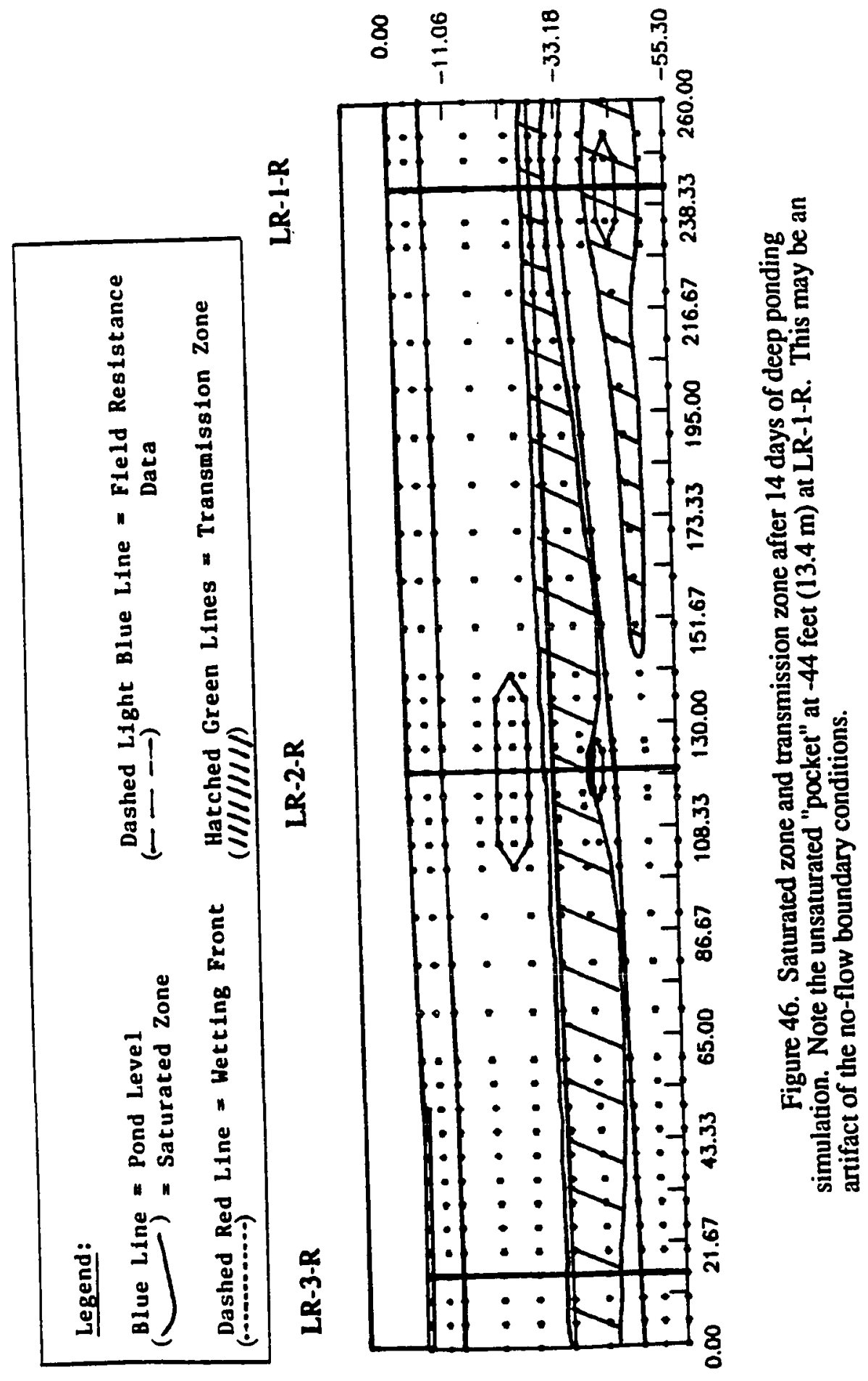




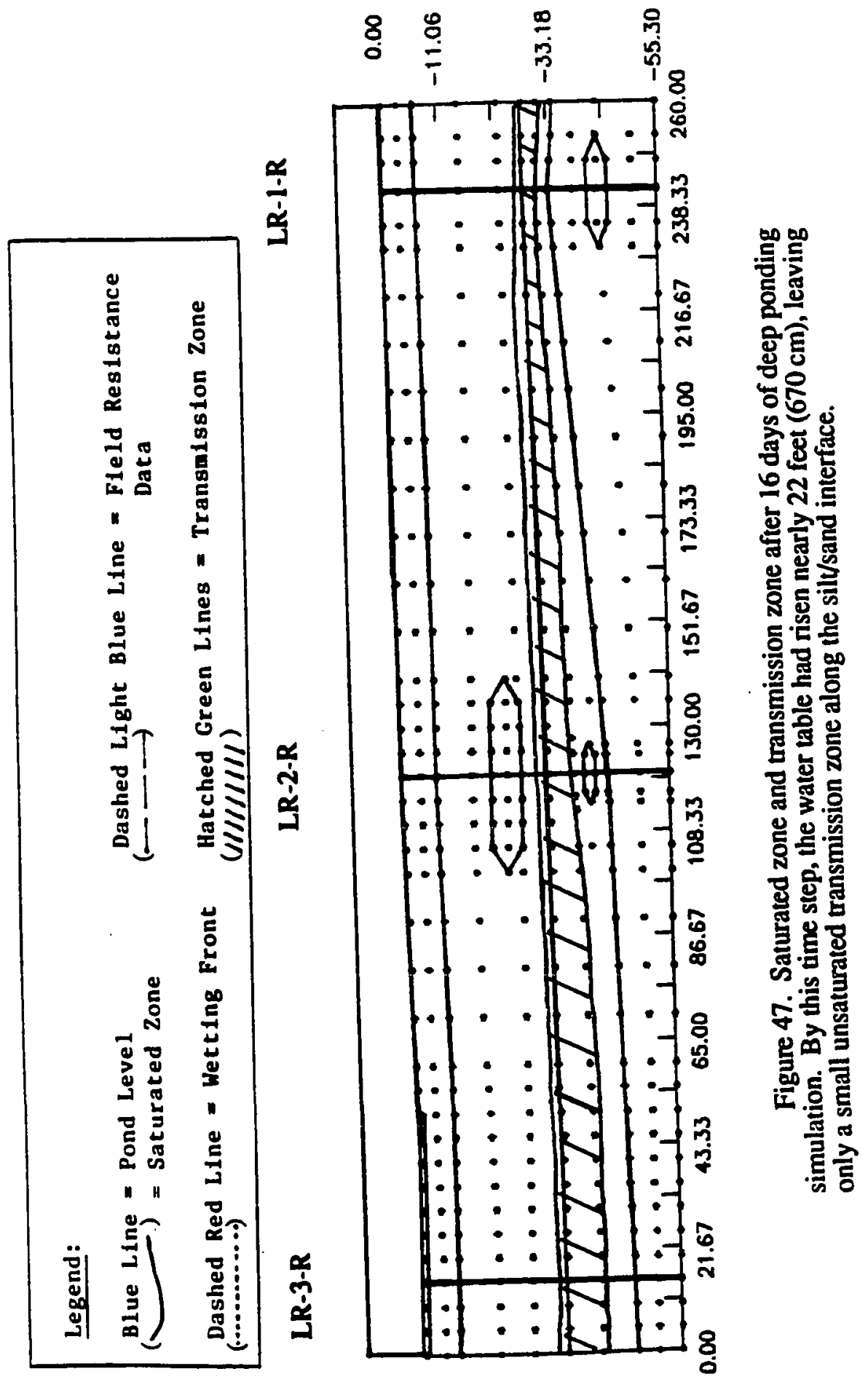




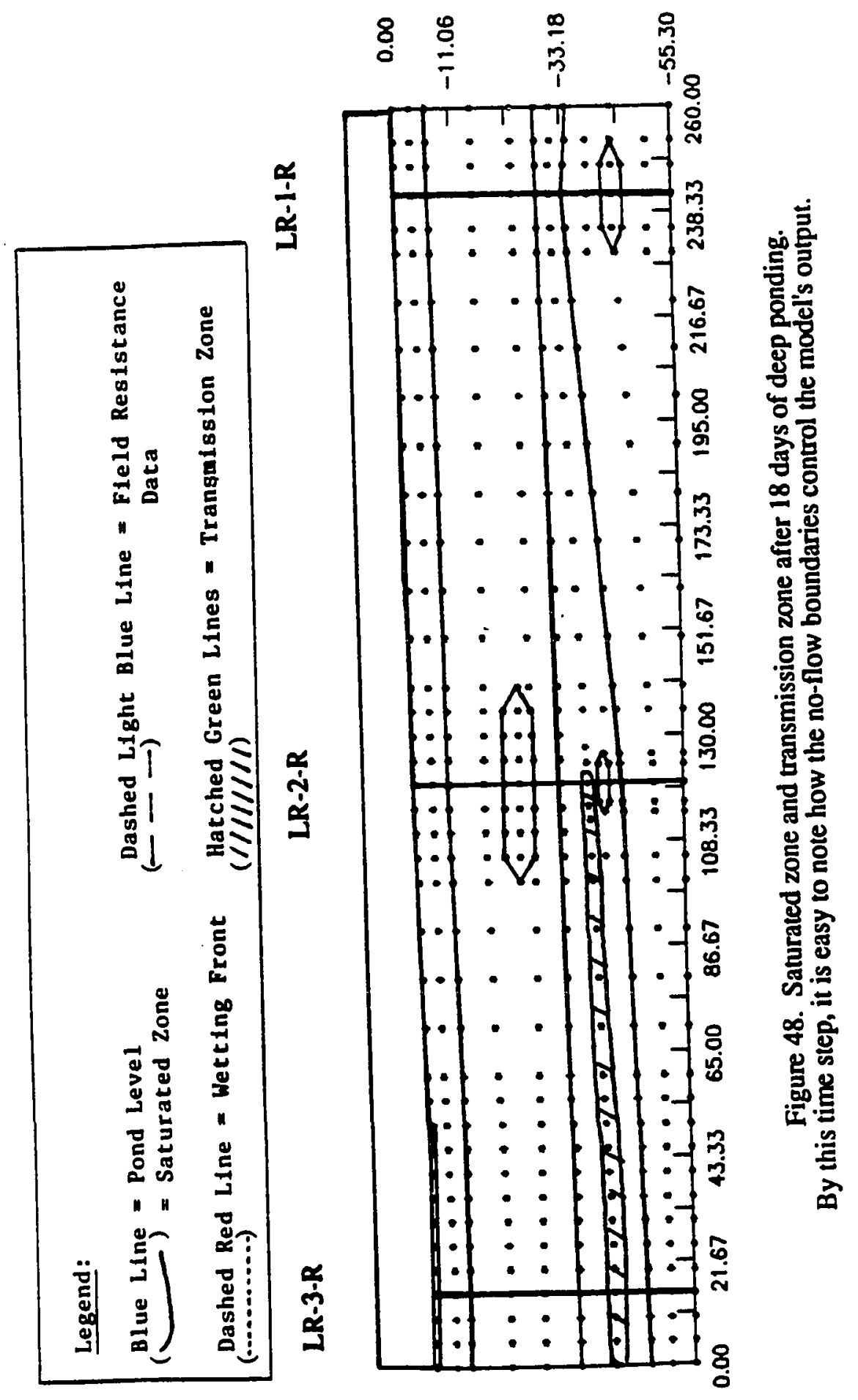




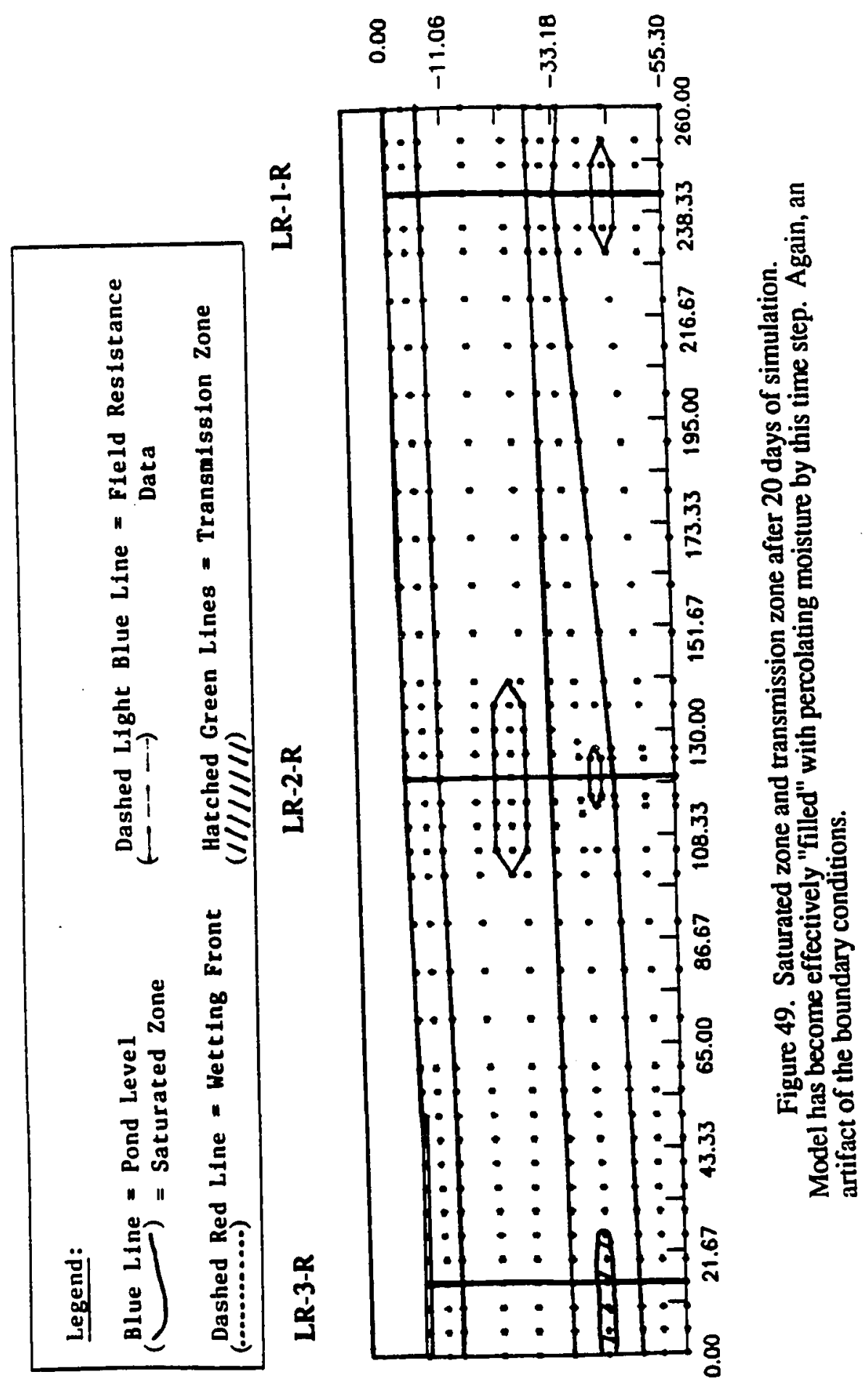


storm simulation. This is the result of the initial and constant deep pond level, covering the entire pond surface.

The wetting front had reached the upper silt unit/lower sand unit interface by the fourth day, nearly 7.5 feet $(2.3 \mathrm{~m})$ ahead of the saturated zone. As predicted by the February 1986 storm simulation, the saturated zone became impeded at the upper sand lens and began to flow around it.

By the sixth day, the model predicted that the saturated zone would become impeded at the upper silt unit/lower sand unit interface, and the transmission zone would fully develop across the lower sand unit. Only a small portion of the upper sand lens is left unsaturated by the sixth day of simulation. It is interesting to note how much faster the wetting front has moved as compared with the February $1986 \mathrm{storm}$. This is an obvious artifact resulting from the high surface pressure heads (i.e., deep surface ponding). Nearly the entire lower sand unit has been engulfed by the transmission zone by the eighth day. Moisture has become perched on the clay lens in the lower sand unit, an effect of the hydraulic conductivity contrasts between the sand (soil material 4) and the clay (soil material 5).

On the tenth day of deep ponding, the wetting front penetrated the lower silt unit and the upper sand lens became fully saturated, an effect not seen in the February 1986 storm simulation until the thirteenth day. In addition, a minor perched moisture zone began to develop in the southeastern portion of the cross-section at the lower sand/lower silt unit interface. Again, this may be a product of the sand/silt interface and right no-flow boundary.

By the twelfth day, the entire lower portion of the modeled vadose zone had become engulfed by the transmission zone and direct ground water recharge began to take place. The entire lower sand unit/lower silt unit interface had become a perched moisture 
zone by this time step. Again, this is the result of the hydraulic conductivity contrast between the higher conductivity sand and the lower conductivity silt. The ground water recharge contribution by this time step is almost 5 feet $(1.5 \mathrm{~m})$, significantly more than the 2 feet $(0.6 \mathrm{~m})$ contribution by the twelfth day of the February 1986 storm simulation. This leads the author to conclude that the depth of ponded water has a significant influence upon the rate and, obviously, the amount by which the ground water table is recharged.

At the fourteenth day of simulation, the ground water table has risen significantly more and the perched moisture zone at the sand/silt interface has thickened quite a bit and reached the ground water table between the left no-flow boundary and LR-2-R. A long, thin zone in the lower silt unit remains unsaturated in the southeast portion of the crosssection. This unsaturated "pocket" is caused by the increased thickness of the low conductivity lower silt and the presence of the unsaturated sand lens, which acts as a moisture barrier until its moisture content increases. It is apparent by this time step that the boundary conditions (i.e, right, left, and bottom no-flow boundaries) are affecting the modeled results. The purpose of the no-flow boundaries is to isolate the cross-section to simulate the contribution to ground water recharge from the cross-section. However, the no-flow boundaries also tend to create a "glass box" effect by not allowing moisture to naturally flow outward and away from the basin. As a result of the boundary conditions, downward percolating moisture is trapped in the "glass box" and the cross-section (or box) begins to fill up during a severe ponding event, such as during this simulation.

By the sixteenth day, the simulated ground water table has risen 22 feet $(6.7 \mathrm{~m})$ from its initial conditions, saturating the lower portion of the basin vadose zone. The transmission zone had significantly decreased in thickness as a result of the rising ground water table. Only a very small section of the lower sand unit, 33 feet $(10 \mathrm{~m})$ below the surface, remains unsaturated. 
Nearly the entire vadose zone became fully saturated by the twentieth day of deep ponding. As mentioned above, the simulated results after 12 days are highly influenced by the bottom, left and right no-flow boundary conditions, which create a "glass box" effect on the deep ponding simulation. It is difficult to simulate such a large scale event with a small, localized model, such as this drainage retention basin model. Proper simulation of the effects of deep ponding would require linking this simulated cross-section to a regional ground water model.

In a field situation, the author believes that a definite ground water mound would develop beneath the flooded recharge basin. However, lateral flow components in the vadose zone and regional ground water flow gradients would attenuate the mounding effect, decreasing its size and preventing the mound from "filling up" (i.e., saturating) the entire 55 foot $(16.8 \mathrm{~m})$ thick vadose zone.

\section{January 1988 Storm Simulation}

During the summer months of 1987 , a drainage outlet was added to the northeastern portion of the drainage retention basin. This outlet now limits the basin capacity to 3.5 feet $(106.7 \mathrm{~cm})$ maximum depth. As a result, the volume of water available for percolation has been significantly reduced from the 28 acre-feet ( $3.4 \times 10^{4}$ cubic meters) available in 1986 when the pond was filled to its 10 foot $(3 \mathrm{~m})$ capacity. The purpose for modeling the January 1988 storm pond data was to predict the effects of the new drainage outlet on the movement of the wetting front in the basin vadose zone. The simulation was run for a total of 8 days. Field observations indicated that evapotranspiration had a dominant influence on the pond level after the eighth day. As a result, field pond level data after the eighth day was not indicative of the infiltration taking place. Unfortunately, the resistance data for the January 1988 storm is fairly inconclusive in that no wetting front movement could be 
could be tracked. As a result, no qualitative field wetting front data may be used to verify the model's output for this simulation.

Prior to the onset of the storm, the basin had approximately 1.5 feet $(45.7 \mathrm{~cm})$ of water ponded in its deepest (northwestern) portion, near LR-3-R, as it typically does throughout the winter months. Again, to simulate initial subsurface moisture conditions, the initial February 1986 storm subsurface moisture conditions were assumed to hold true for this simulation. A heavy weekend storm (January 15, 16, and 17, 1988) filled the basin with $3.2 \mathrm{feet}(97.54 \mathrm{~cm})$ of runoff water. The author used the 3.2 feet $(97.54 \mathrm{~cm})$ of ponded water as the initial (January 19,1988 ) surface pressure head conditions. At each half day time step, an extrapolated value or field pressure head value was used to simulate the falling pond level. Figures 50 through 54 display the contoured computer model output for the January 1988 storm simulation.

As the pond level fell, the model predicted that the wetting front would move into the upper silt unit by the second day of simulation. The saturated zone had filled most of the silty gravel unit and penetrated the upper silt unit in the northwestem portion of the basin, near LR-3-R.

After four days of simulated percolation, the saturated zone had moved laterally, saturating the silty gravel/upper silt unit interface along the entire length of the crosssection. As a result of the falling pond level exposing the southeastern basin surface and significantly reducing the surface recharge at this location, the author concludes that both the drainage of earlier infiltrated water and the upper silt unit's "wick effect" resulted in the lateral movement of moisture in the vadose zone, causing the entire silty gravel/upper silt interface to become saturated. The model, again, predicts the moisture impeding effects of the upper sand lens on the saturated zone and the wetting front by the fourth day. 


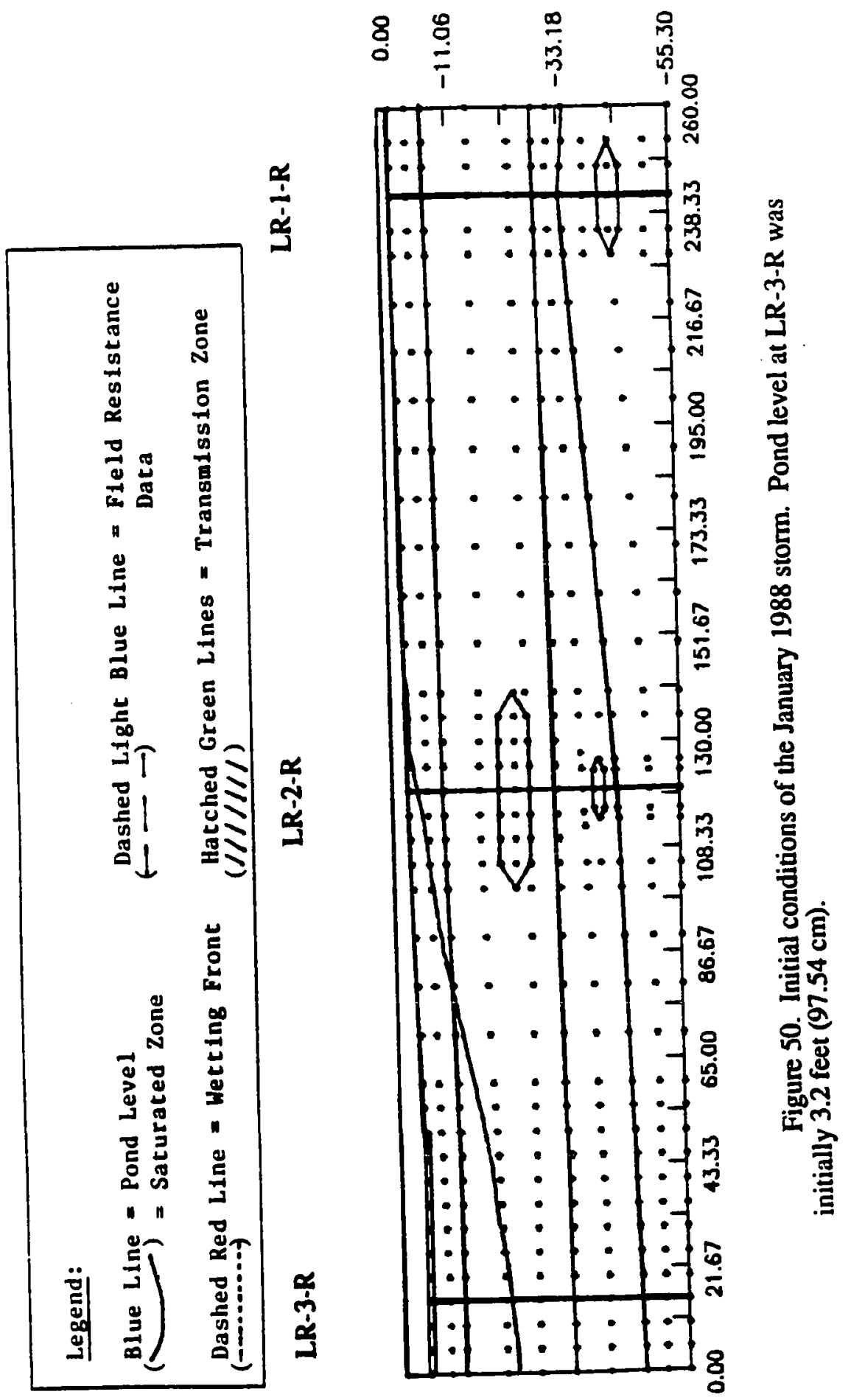




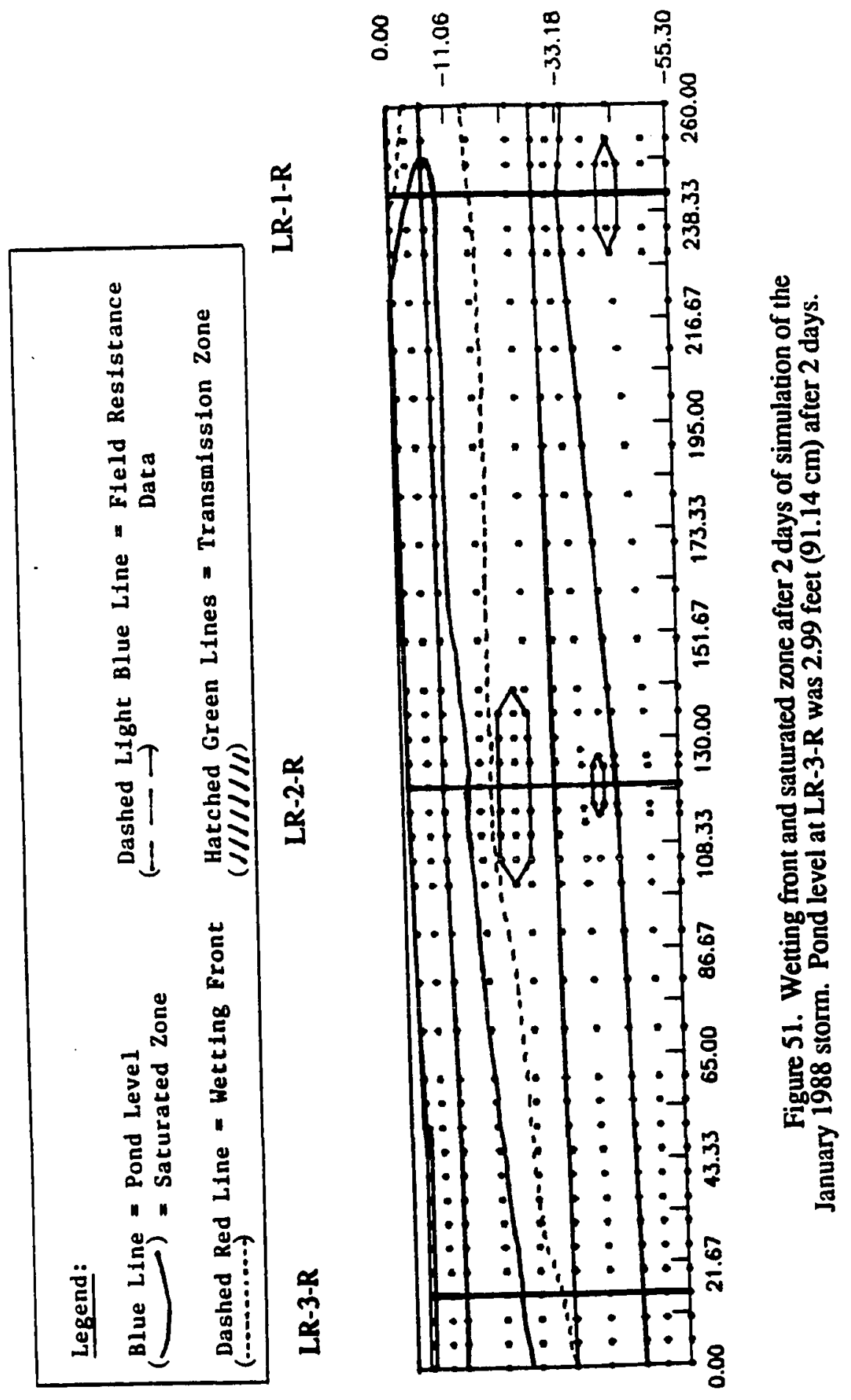




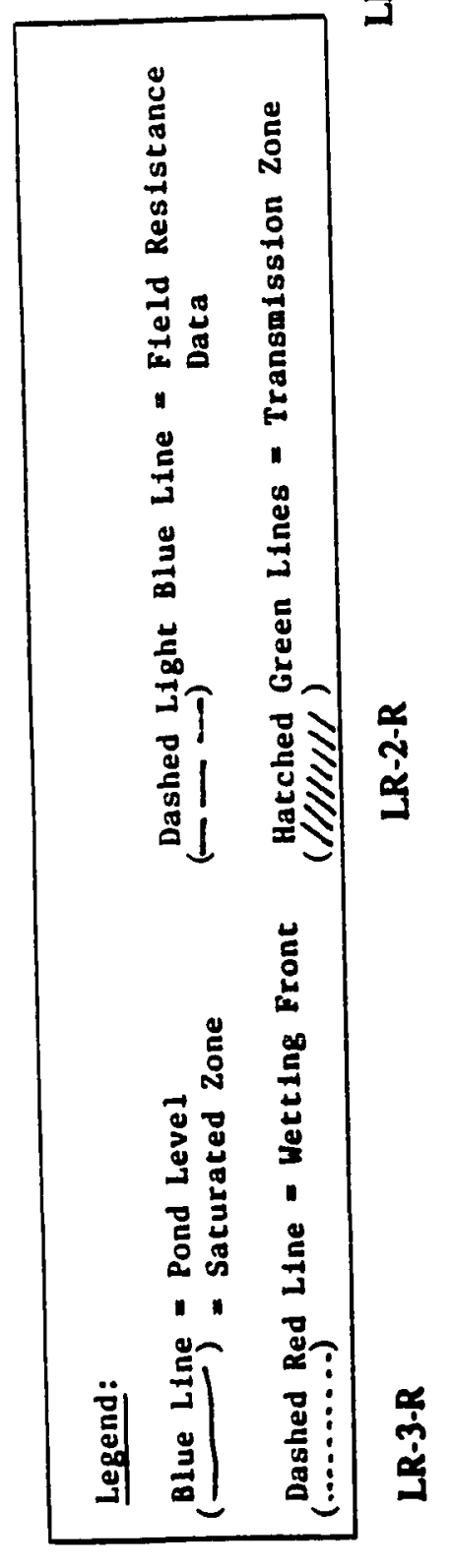

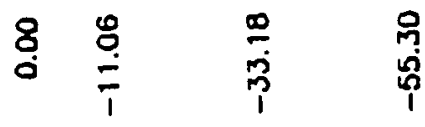

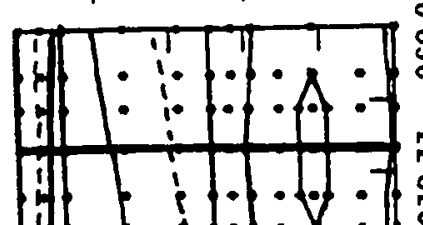

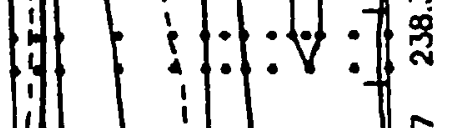

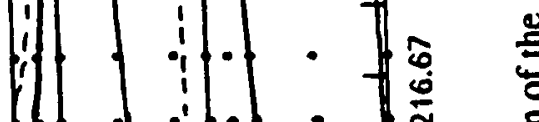

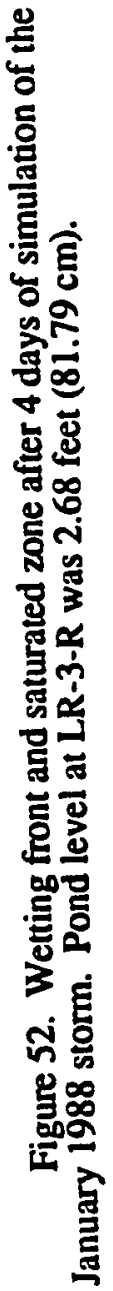




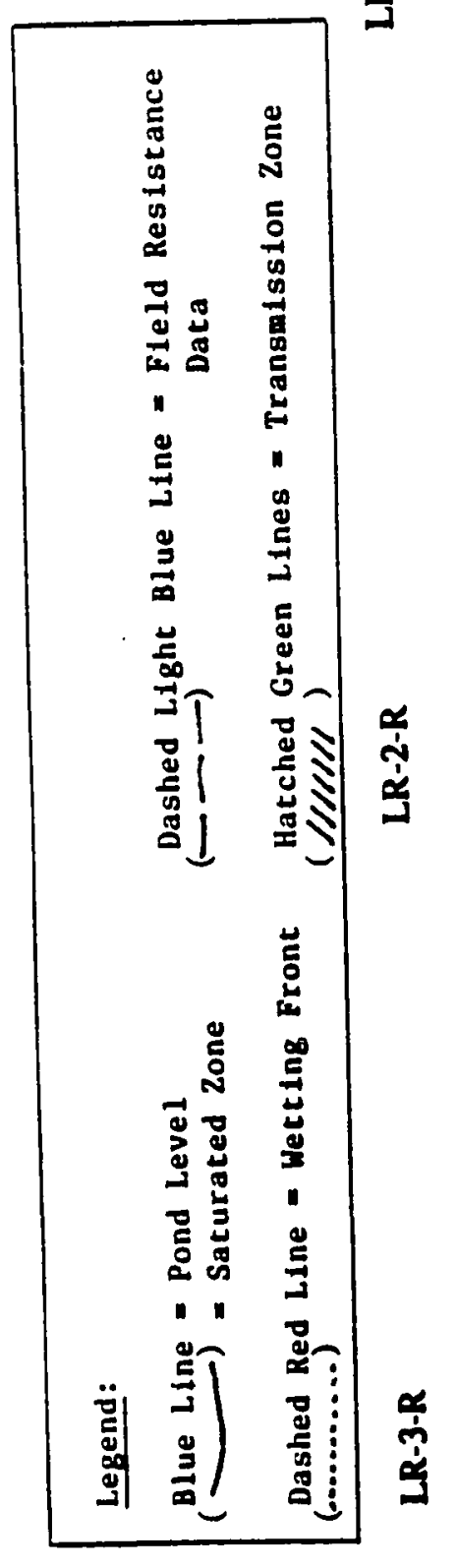

$8 \stackrel{8}{0} \quad \frac{\infty}{p}$ p

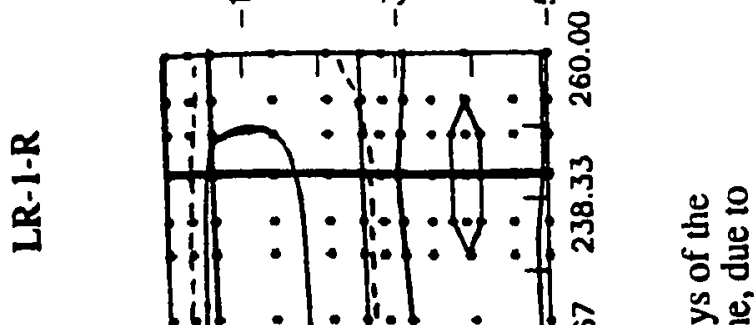

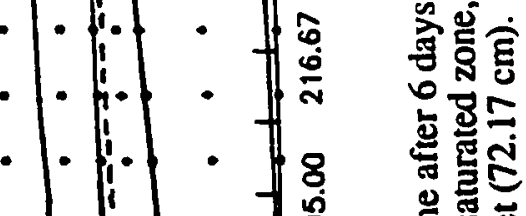

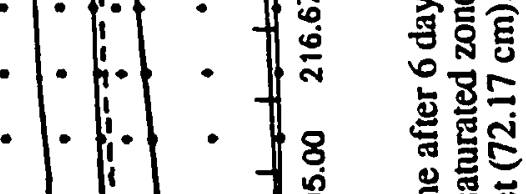

.

- . . -

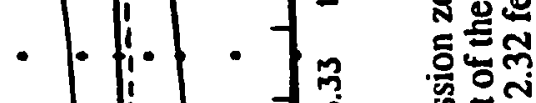

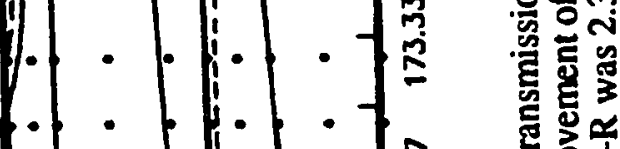

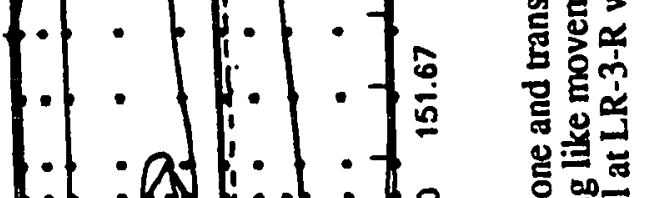

- : 1 :

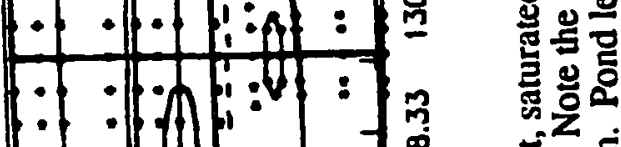

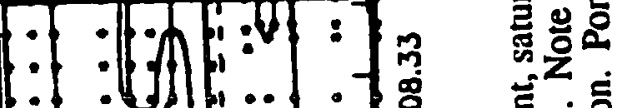

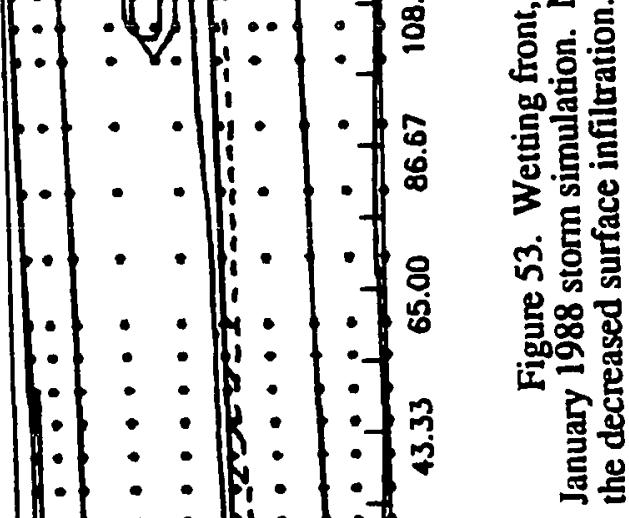

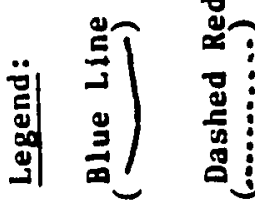

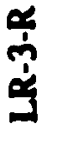

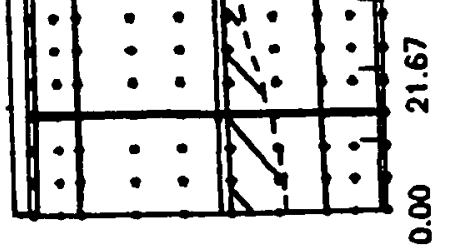




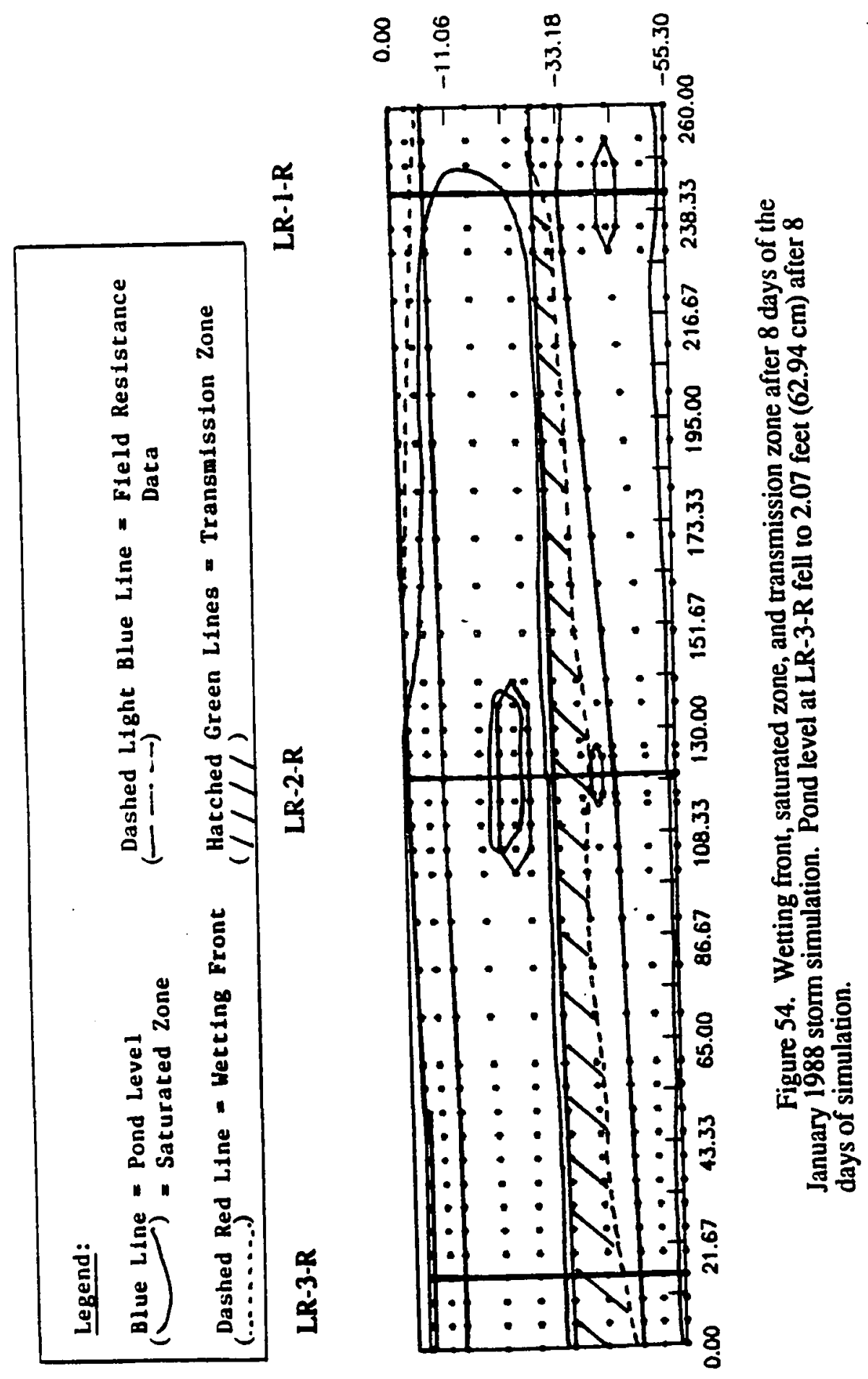


On the sixth day of simulation, the model predicted a "slug" type movement of the saturated zone in the vadose zone. At this time step, the saturated zone basically moved downward, under the force of gravity, and since infiltration in the southeastem portion of the basin has significantly diminished, the saturated zone moved downward, like a body or slug of water. As a result of the low surface pressure heads, the saturated zone slowly began to surround the upper sand lens and saturated it from its sides and bottoms. The wetting front had penetrated the northwest section of the lower sand unit, resulting in the development of a transmission zone in that region.

By the eighth and final day of predictive simulation, the saturated zone moved downward and thickened to engulf the upper silt unit. The southeastern upper portion of the saturated zone moved downward, out of the silty gravel. Again, the result of the decreased pond level and surface coverage near LR-1-R. By this time step, the transmission zone had progressed southeasterly along the upper silt unit/lower sand unit interface. However, the transmission zone failed to develop along the entire length of the cross-section. As mentioned above, this is the result of the decreased pond level, decreased surface coverage, and decreased volume of water available for percolation. Also, the "slug" of water (i.e., saturated zone) beneath the portion of the basin no longer ponded continued to travel downward and to broaden with time and distance traveled.

It is interesting to note that in spite of the decreasing pond level of the January 1988 storm, the pattern and timing of the progression of the wetting front between LR-3-R and LR-2-R is very similar to that produced by the February 1986 storm, through the eighth day of simulation. This is most likely due to the fact that over the first 6 days of both simulations, the average pond level was nearly the same (approximately $2.8 \mathrm{feet}, 86 \mathrm{~cm}$ ). As a result of the similar average pond levels, similar wetting front patterns between LR-3-R and LR-2-R developed for the first 8 days of simulation of both storms. 
However, a comparison of the field ground water data for the first eight days of the February 1986 storm and the January 1988 storm indicated that the water table rose 11 feet $(3.4 \mathrm{~m})$ and 1.2 feet $(0.4 \mathrm{~m})$, respectively. The author believes that the difference in recharge between the two storms is due to the limited surface coverage, reduced pond volume, and lower pressure heads created by the NE drain outlet.

\section{Discussion on Adjusted Hydrogeologic Parameters}

Appendix F contains a comparison between the computer model saturated hydraulic conductivity for each soil material and field values, laboratory values and expected ranges for the various conductivity values. The adjusted model parameters for soil materials 1-4 all lie within the expected ranges, as catalogued by Freeze and Cherry (1979). The saturated hydraulic conductivity for soil material 5 (clay) had to be set two orders of magnitude higher to prevent model convergence problems. Minor differences (silty gravel) and major differences (silt) exist between the laboratory (permeameter) hydraulic conductivity values and the model values required to develop strong correlations with actual field behavior. However, instrument problems developed with the laboratory permeameter during core sample testing, and therefore values determined by that technique should be given less importance (Toney, personal communication, 1987). In addition, Trautwein et al. (1983) found that laboratory saturated hydraulic conductivity measurements tend to be less than those measured in the field and typically a wide range of values are obtained. This is because "laboratory tests fail to account for microscopic effects such as cracks and root holes that naturally occur in the field." Trautwein et al. also found that laboratory saturated hydraulic conductivity measurements of a clay unit at their test site ranged over five orders of magnitude! With this in mind, the calibrated computer model hydraulic 
conductivity values were primarily determined by the overall model's correlation with true field behavior (soil resistance/wetting front behavior) and less so by laboratory and field conductivity values.

Trautwein et al. (1983) also firmly state that "the importance of calibrating a model cannot be over emphasized." The author has found this also to be true in his computer modeling experiences. If only laboratory values were to be used, the model would have inaccurately predicted the movement of the wetting front, because the saturated hydraulic conductivity values for the silty gravel and especially for the silt would have been much to low. It is important to keep in mind that the primary objective of this type of model is to simulate and predict the overall field effects of percolating moisture into the vadose zone. Therefore, model calibration and parameter adjustment are an extremely important process in the development of an accurate predictive model. 


\section{CONCLUSIONS}

After a time consuming iterative calibration process, the model's calibrated output from the February 1986 storm developed a strong correlation with the field resistance data. By calibrating the model spatially and temporally with well-known field wetting front data, the author was able to develop a reliable predictive tool not only capable of simulating a known event, the February 1986 storm, but also useful in predicting the effects of other field type situations.

The author found that the wetting front migration was dependent upon site geology, depth of ponded water, and simulated surface conditions. The site geology had a dominant effect on the movement of the wetting front. Contrasting material/geologic properties tended to control the wetting front, for example, by causing it to distort around the upper sand lens or develop into a transmission zone at the upper silt unit/lower sand unit contact. After comparing the results of the February 1986 stom with those of the January 1988 storm, it is easy to observe the effects of depth of ponded water on migration of the wetting front. Shallow pond depths translate into smaller surface pressure heads, smaller surface coverage and a reduced volume of water available for percolation, which reduce the horizontal and vertical movement of the wetting front and reduce the effective recharge capabilities of the drainage retention basin. Last, simulated surface conditions had an important effect on the movement of the wetting front. Simulating the effects of precipitation, during the initial conditions of the February 1986 storm, on the basin surface not covered by pond water allowed the wetting front and saturation zone to develop in the southeastern section of the basin. Had the effects of precipitation not been modeled, the 
model would not have properly simulated the growth of the wetting front and saturated zone by the first day of simulation.

The model predicted the development of the moisture transmission zone at the upper silt unit/lower sand unit interface. The soil resistance data were useful in determining the weting front location, but could not be used to delineate the development of the transmission zone. The model also predicted that the saturated zone would become perched (or impeded) at the upper silt unit/lower sand unit interface. Again, the use of the resistance data was limited in that it could not be used to evaluate the occurrence of this phenomenon.

The calibrated model helped confirm the hydraulic behavior of the thick permeable sandy gravel zone in the southeast portion of the basin (not modeled). By comparing the model's output for the February 1986 storm with the contoured field resistance data and field measured ground water levels, it was concluded that the cross-section modeled was not a major source of ground water recharge. This information, field observations (high infiltration rates) and the noted lack of correlation between the D-3 boring were cited as evidence to conclude that the southeast portion of the drainage retention basin is a major site of ground water recharge.

Thorough analysis of the lateral flow simulation indicates that a significant lateral flow component exists in the upper silt unit. After 12 days of simulated percolation, the lateral movement of the wetting front in the upper silt unit nearly equaled that of the vertical component through the entire vadose zone $(51$ feet, $15.5 \mathrm{~m})$. The author believes that the fine grained texture of the silt creates a strong affinity for moisture, hence the "wick effect," resulting in significant amounts of moisture being "pulled" (or sucked) laterally in the silt, away from the source. In addition, it was found that the lateral flow effects directly 
beneath the ponded water were small and that the right and left no-flow boundaries would not adversely affect flow gradients along the finite element grid boundaries.

Upon modeling the January 1988 storm, it was concluded that the new drainage outlet in the northeast portion of the basin has a significant impact on the movement of the wetting front through the vadose zone. The drain was found to limit the depth of ponded water to 3.5 feet $(1.1 \mathrm{~m})$, as compared with the 10 foot $(3.0 \mathrm{~m})$ maximum limit in 1986. The drain also limited the pond surface coverage and the volume of ponded water available for percolation. As a result of the new drainage outlet, the model predicted that the saturated zone would move like a slug of water, in the vadose zone below the area no longer ponded, as the pond level and surface infiltration decreased, and that the sarurated zone would be limited in both its vertical and horizontal extent. In addition, the development of the transmission zone was significantly reduced by the limited percolating moisture. As a result, the transmission zone failed to reach the full length of the crosssection. A comparison of the field ground water data for the first 8 days of the February 1986 storm and the January 1988 storm indicated that the water table rose 11 feet $(3.4 \mathrm{~m})$ and 1.2 feet $(0.4 \mathrm{~m})$, respectively. This recharge difference is primarily the result of the limited pond surface coverage, the decrease in volume of available water and lower pressure heads associated with shallow ponding created by the NE drain outlet.

Last, it was determined that the boundary conditions had a profound impact upon the wetting front movement and ground water table rise during the deep ponding simulation. The right, left, and bottom no-flow boundaries basically create a "glass box" (or sealed box) effect, and as a consequence, moisture may not leave the system. After nearly 12 days of deep ponding simulation, the model began to predict strange patterns of vadose zone saturation. By the twentieth day, nearly the entire cross-section was saturated, due to the "glass box" effect. To more accurately simulate a deep ponding, or extreme 
flooding, this localized vadose zone model should be linked to a regional ground water model. As the present model is configured, it is not possible to accurately simulate the migration of the wetting front during deep ponding after 12 days. 


\section{REFERENCES CITED}

Baver, L.D., Gardner, W. H., and Gardner, W.R., 1972, Soil Physics, Fourth Edition: John Wiley and Sons, Inc., New York, N.Y., 498 p.

Bear, J., 1979, Hydraulics of Groundwater, McGraw-Hill Series in Water Resources and Environmental Engineering: McGraw-Hill, Israel, 567 p.

Bhuiyan, S. I., Hiler, E.A., Van Bavel, C.H.M., and Aston, A.R., 1971, Dynamic Simulation of Vertical Infiltration into Unsaturated Soils: Water Resources Research, v. 7, No. 6, p. 1597-1606.

Bond, F.W., Cole, C.R., and Gutknecht, P.J., 1982, Unsaturated Groundwater Flow Model (UNSAT1D) Computer Code Manual, Report CS-2434-CCM: Prepared by Battelle Northwest Laboratories for the Electric Power Research Institute, Palo Alto, California, 194 p.

Carpenter, D.W., 1984, Assessment of Contamination in Soils and Groundwater at Lawrence Livermore National Laboratory, Sandia National Laboratory, and Adjacent Properties, Lawrence Livermore National Laboratory, Livermore, CA, UCAR-10181, $206 \mathrm{p}$.

Carpenter, D.W., Sweeny, J.J., Kasameyer, P.W., Burkhard, N.R., Knauss, K.G., and Shlemon, R.J., i984, Geology of the Lawrence Livermore National Laboratory Site and Adjacent Areas: National Technical Information Service, U.S. Department of Commerce, Springfield, VA, 150 p.

Childs, E.C., 1969, An Introduction to the Physical Basis of Soil Water Phenomena: John Wiley and Sons, Inc., Interscience Division, New York, N.Y., 379 p.

Davis, L.A., and Neuman, S.P., 1983, Documentation and User's Guide, UNSAT2 Variably Saturated Flow Model: Division of Waste Management, Office of Nuclear Material Safety and Safeguards, U.S. Nuclear Regulatory Commission, Washington, D.C., 203 p.

Everett, L.G., Wilson, L.G., and Hoylman. E.W., 1983, Vadose Zone Monitoring for Hazardous Waste Sites: Environmental Monitoring Systems Laboratory, Office of Research and Development, U.S. Environmental Protection Agency, Las Vegas, Nevada, 358 p.

Freeze, Allen R., 1969, The Mechanism of Natural Ground-Water Recharge and Discharge: 1. One-Dimensional, Vertical, Unsteady, Unsaturated Flow Above a Recharging or Discharging Ground-Water Flow System: Water Resources Research, v. 5, no. 1, p. 153-171.

Freeze, Allen R., 1971, Three-Dimensional, Transient, Saturated- Unsaturated Flow in a Groundwater Basin: Water Resources Research, v. 7, no. 2, p. 347-365. 
Freeze, Allen R., and Cherry, John A., 1979, Groundwater: Prentice-Hall, Inc., Englewood Cliffs, New Jersey, 604 p.

Hillel, D., 1971, Soil and Water, Physical Principles and Processes: Academic Press, San Francisco, California, 288 p.

Johnson, T.M., Cartwright, K., Herzog, B. L., and Larson, T.H., 1983, Modeling of Moisture Movement Through Layered Trench Covers, in Mercer, James W., Rao, P.S.C., and Marine, I. Wendell, eds., Role of the Unsaturated Zone in Radioactive and Hazardous Waste Disposal: Ann Arbor Science, Ann Arbor, Michigan, p. 1126.

Kirby, J.M., 1985, A Note on the Use of a Simple Numerical Model for Vertical, Unsaturated Fluid Flow: Soil Science, v. 139, no. 5, p. 462-467.

Kirkham, Don, and Powers, W.L., 1972, Advanced Soil Physics: John Wiley and Sons, Inc., Interscience Division, New York, N.Y., 534 p.

Kunze, R.J., and Nelson, D.R., 1982, Finite-Difference Solutions of the Infiltration Equation: Soil Science, v. 134, no. 2, p. 81-88. Mantoglou, Aristotelis, and Gelhar, Lynn W., 1987a, Stochastic Modeling of Large-Scale Transient Unsaturated Flow System: Water Resources Research, vol. 23, no. 1, p. 37-46.

Mantoglou, Aristotelis, and Gelhar, Lynn W., 1987, Capillary Tension Head Variance, Mean Soil Moisture Content, and Effective Specific Soil Moisture Capacity of Transient Unsaturated Flow in Stratified Soils: Water Resources Research, vol. 23, no. 1 , p. 47-56.

McMahon, Peter, B., and Dennehy, Kevin, F., 1985, Water Movement in the Vadose Zone at Two Experimental Waste-Burial Trenches in South Carolina, in Proceedings of the NWWA Conference on Characterization and Monitoring of the Vadose (Unsaturated) Zone, National Water Well Publishing Co., Dublin, Ohio, p. 34-54.

Mercer, James W., Rao, P.S.C., and Marine, I., Wendell, eds., 1983, Role of the Unsaturated Zone in Radioactive and Hazardous Waste Disposal: Ann Arbor Science, Ann Arbor, Michigan, 339 p.

Maulem, Y., 1976, A Catalogue of the Hydraulic Properties of Unsaturated Soils, Development of Methods, Tools, and Solutions for Unsaturated Flow with Application to Watershed Hydrology and Other Fields, Research Project 442: Technion - Israel Institute of Technology, Hiafa, Israel, 100 p.

Neuman, Shlomo P., and Whitherspoon, Paul A., 1971, Analysis of Nonsteady Flow with a Free Surface Using the Finite Element Method: Water Resources Research, v. 7 , no. 3 , p. $611-623$.

Neuman, Shlomo P., 1973, Saturated-Unsaturated Seepage by Finite Elements: Proceedings from the ASCE, Journal of Hydraulics Division 99, (HY12), p. 22332250. 
Neuman, Shlomo P., 1975, Galerkin Approach to Saturated-Unsaturated Flow in Porous Media, in Gallagher, J.T., Oden, C. Taylor, and Zienkiewicz, O.C., eds., Finite Elements in Fluids, Volume I: Viscous Flow and Hydrodynamics: John Wiley and Sons, Inc., London, p. 201-217.

Neuman, Shlomo P., Feddes, Reinder A., and Bresler, 1975, Finite Element Analysis of Two-Dimensional Flow in Soils Considering Water Update by Plant Roots: I. Theory: Soil Science, v. 39, no. 2, p. 224-230.

Oberdorfer, June A. and Toney, Kenneth, 1986, Water Transport in the Vadose Zone Beneath a Drainage Retention Basin: EOS., v. 67, no. 44, p. 944.

Pinder, G.F., and Gray, W.G., 1977, Finite Element Simulation in Surface and Subsurface Hydrology: Academic Press, New York, N.Y. 295 p.

Ragab, R., Feyen. J., and Hillel, D., 1982, Comparison of Experimental and Simulated Infiltration Profiles in Sand: Soil Science, v. 133, no. 1, p. 61-64.

Rojstaczer, S.A., 1981, Moisture Movement Through Layered Soils of Highly Contrasting Texture (Unpublished M.S. Thesis): University of Illinois, 86 p.

Stone, R., Ruggieri, M.R., Rogers, L.L., Emerson, D.O., and Buddemeier, R.W., 1982 , Potential for Saturated Ground-Water System Contamination at the Lawrence Livermore National Laboratory: National Technical Information Service, U.S. Department of Commerce, Springfield, VA, 105 p.

Toney, Kenneth, and Oberdorfer, June A., 1986, Quantifying Groundwater Recharge Under a Drainage Retention Basin: EOS, v. 67, no. 44, p. 944.

Toney, Kenneth, 1988, A Hydrogeological Investigation of Groundwater Recharge Near the Drainage Retention Basin, Lawrence Livermore National Laboratory, Livermore, California (Unpublished M.S. Thesis Draft): San Jose State University.

Trautwein, Steven, J., Daniel, David E., and Cooper, Michael W., 1983, Case History Study of Water Flow Through Unsaturated Soil, in Mercer, James W., Rao, P.S.C., and Marine, I. Wendell, eds., Role of the Unsaturated Zone in Radioactive and Hazardous Waste Disposal, Ann Arbor Science, Ann Arbor, Michigan, p. 229-253.

U.S. EPA, 1986, Soiliner Model - Documentation and User's Guide (Version 1): Environmental Protection Agency, Cincinnati, Ohio, 85 p.

Vauclin, M., Khanji, D., and Vachaud, G., 1979, Experimental and Numerical Study of a Transient, Two-Dimensional Unsaturated-Saturated Water Table Recharge Problem: Water Resources Research, v. 15, no. 5, p. 1089-1101.

Wang, H.F., and Anderson, M.P., 1982, Introduction to Groundwater Modeling, Finite Difference and Finite Element Methods, W.H. Freeman and Company, San Francisco, CA, 237 p. 
Winter, Thomas C., 1978, Numerical Simulation of Steady Three-Dimensional

Groundwater Flow Near Lakes: Water Resources Research v. 14, no. 2, p. 245254.

. Yeh, Jim T.C., Gelhar, Lynn W., and Gutjahr, Allen L., 1985, Stochastic Analysis of Unsaturated Flow in Heterogeneous Soils: 1. Statistically Isotropic Media: Water Resources Research, v. 21, no. 4, p. 447-456. 


\section{APPENDIX A}

Geologic Logs of Borings 
Figure 55. Geologic log for LR-1-R.

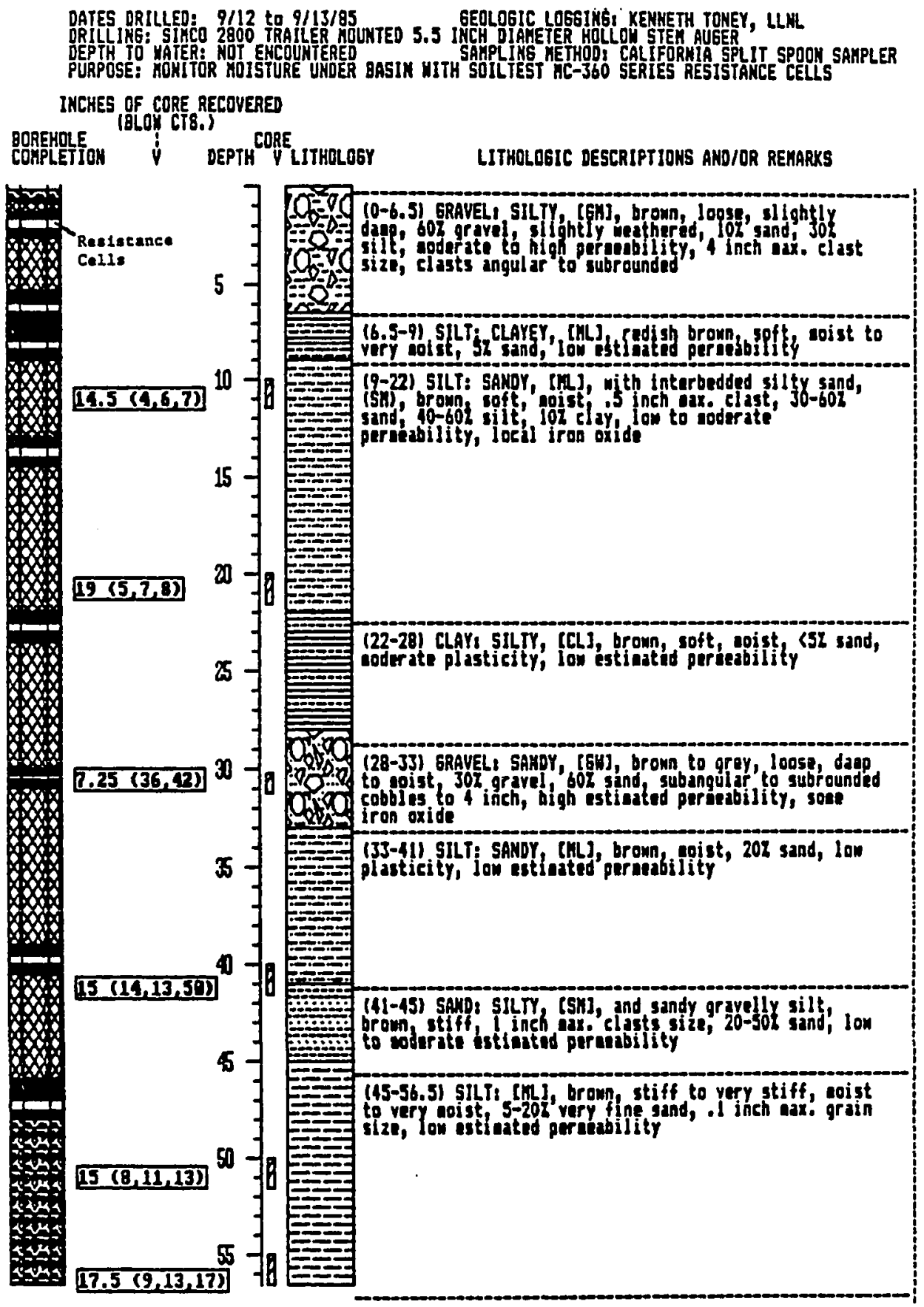

(from Toney, Thesis Draft, 1988) 
Figure 56. Geologic log for LR-2-R.

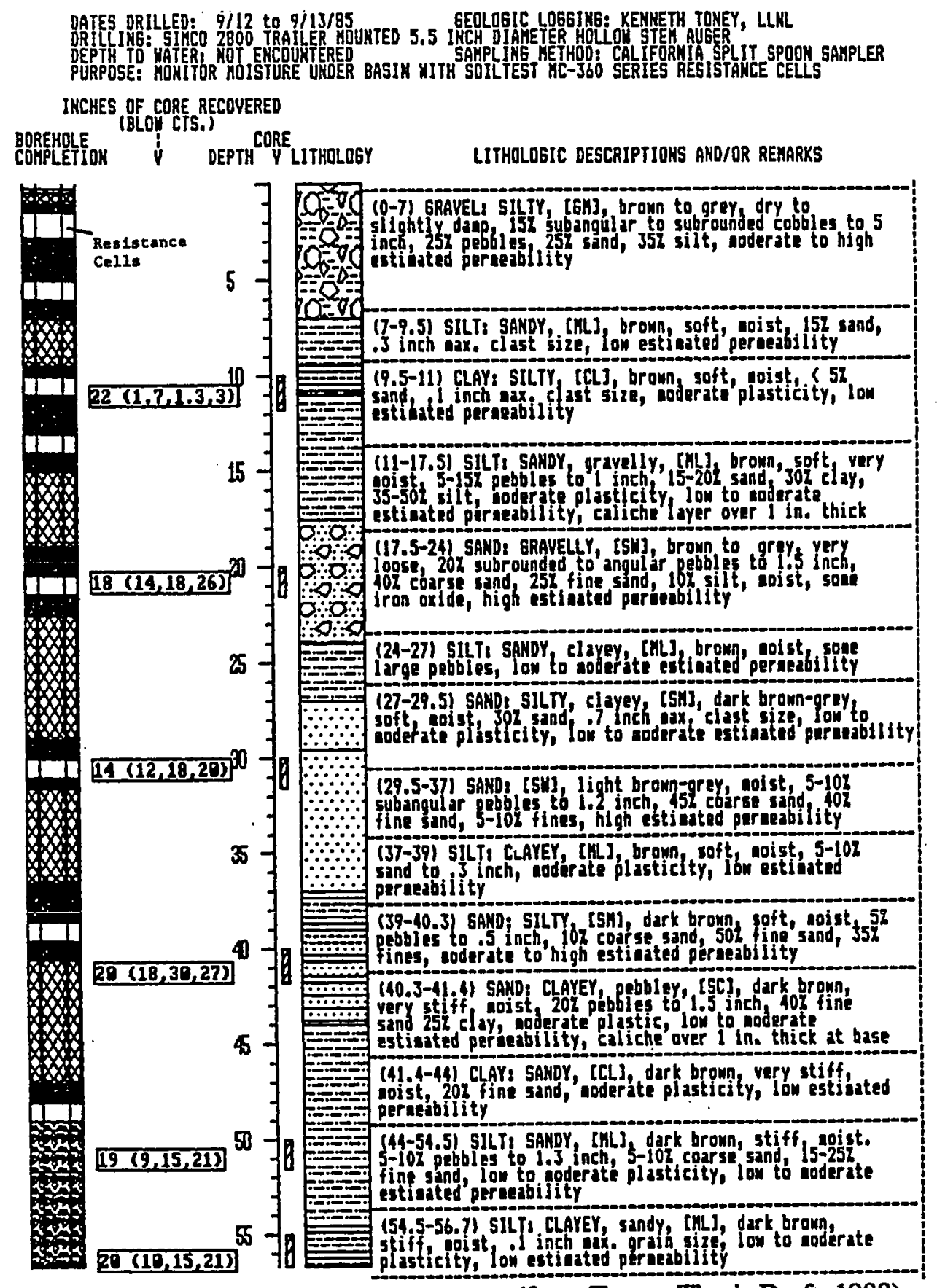

(from Toney, Thesis Draft, 1988) 
Figure 57. Geologic $\log$ for LR-3-R.

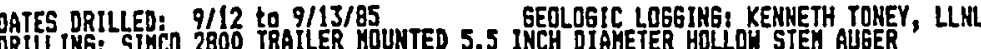

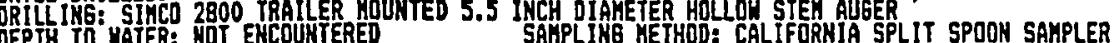
PURPOSE: MOHITOR HOISTURE UHDER BASIN WITH SOLLTEST HC-360 SERIES RESISTAKCE CELLS

LOREHOLE
Resiscance

(from Toney, Thesis Draft, 1988) 
Figure 58. Geologic log from LR-4-P.

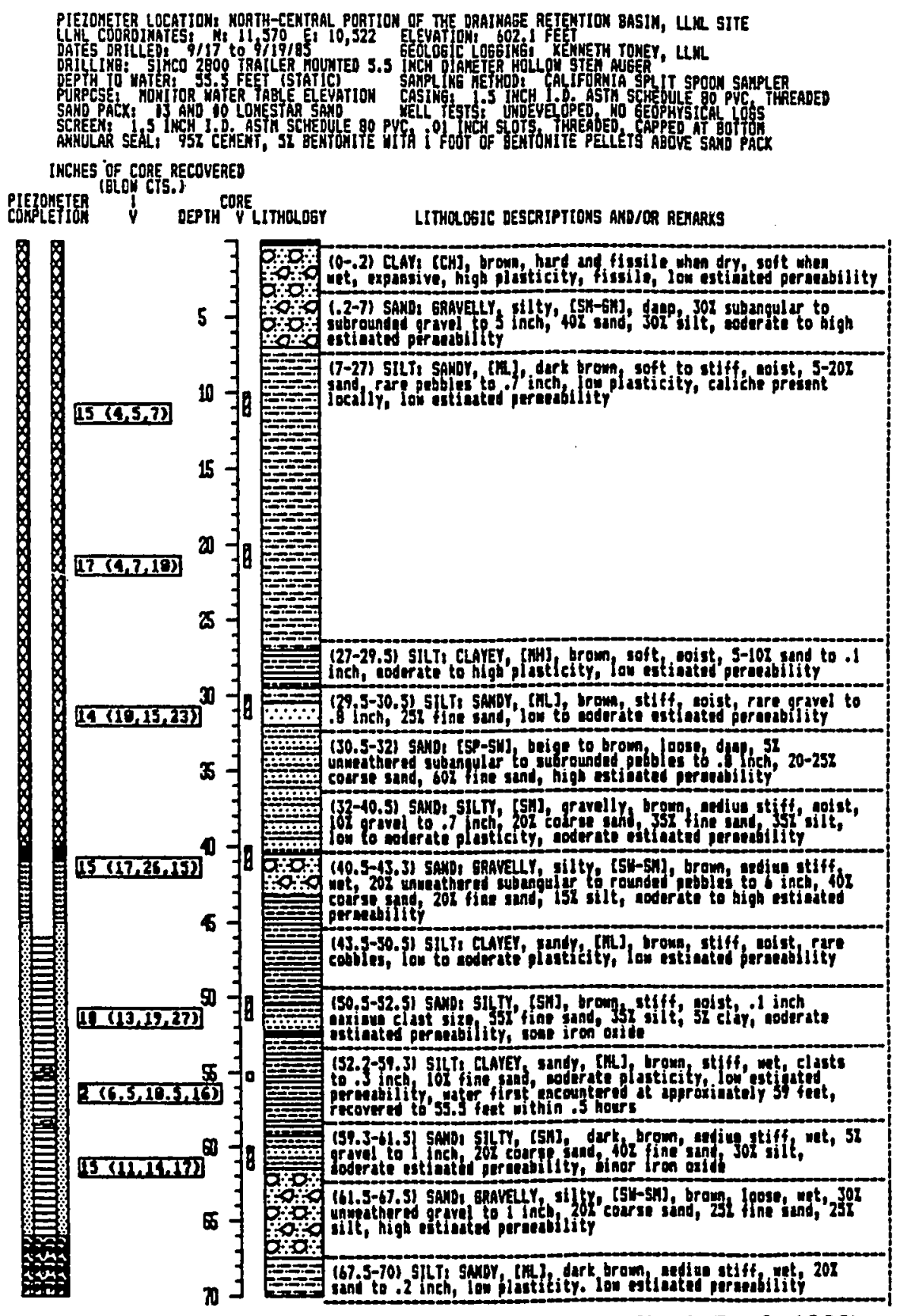

(from Toney, Thesis Draft, 1988) 
Figure 59. Geologic log from D-3.

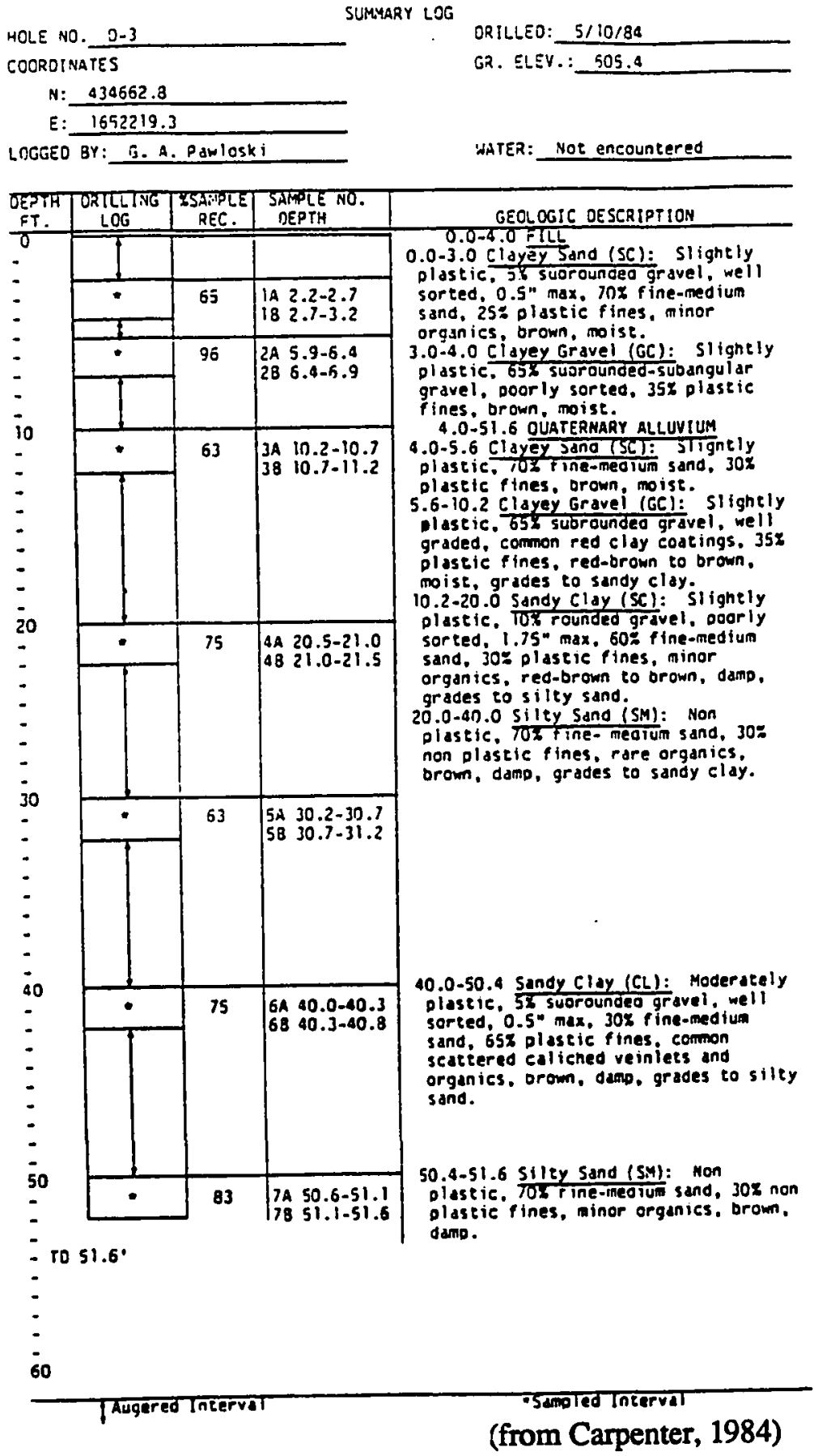




\section{APPENDIX B}

Soil Material Characteristic Curves 


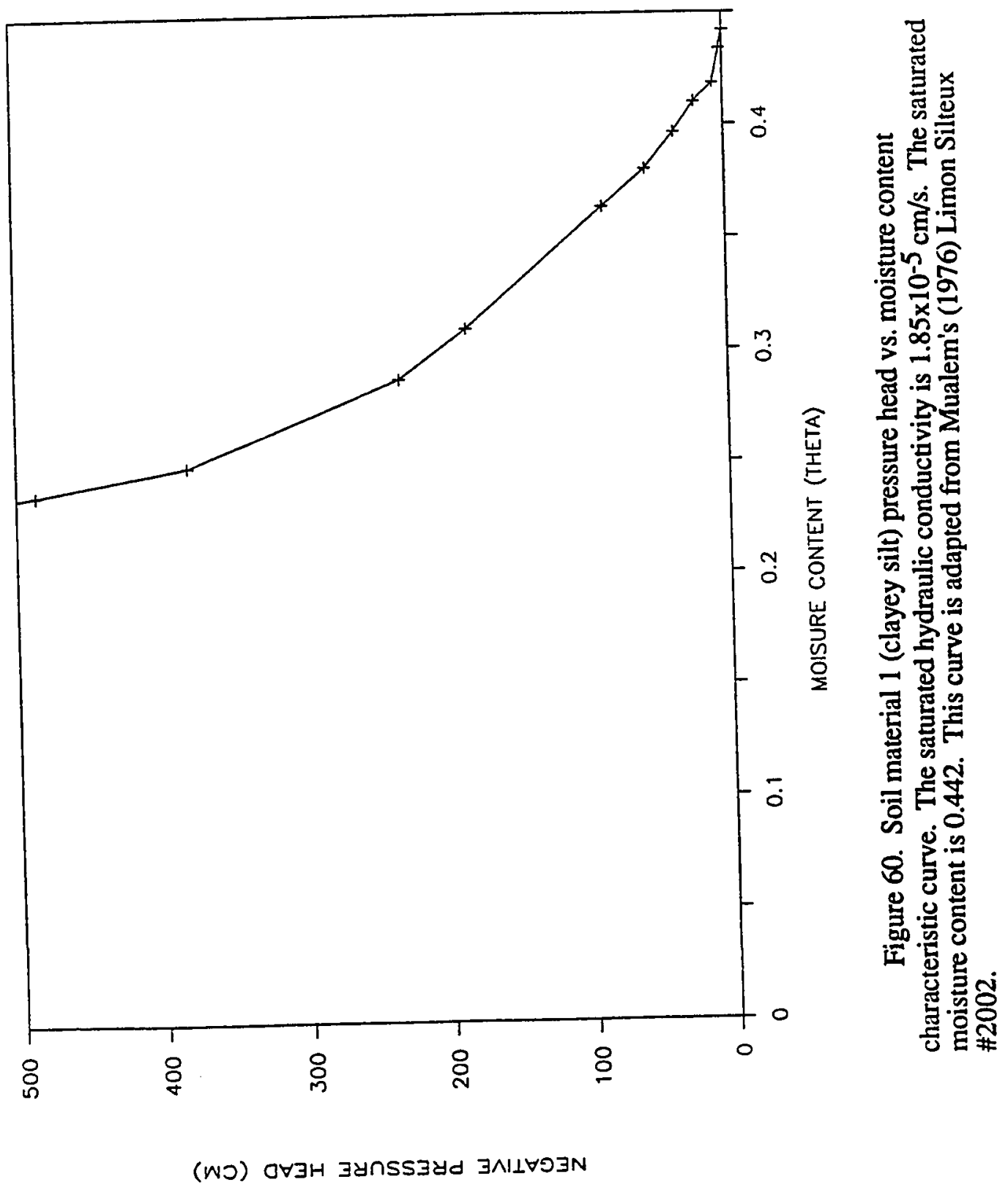




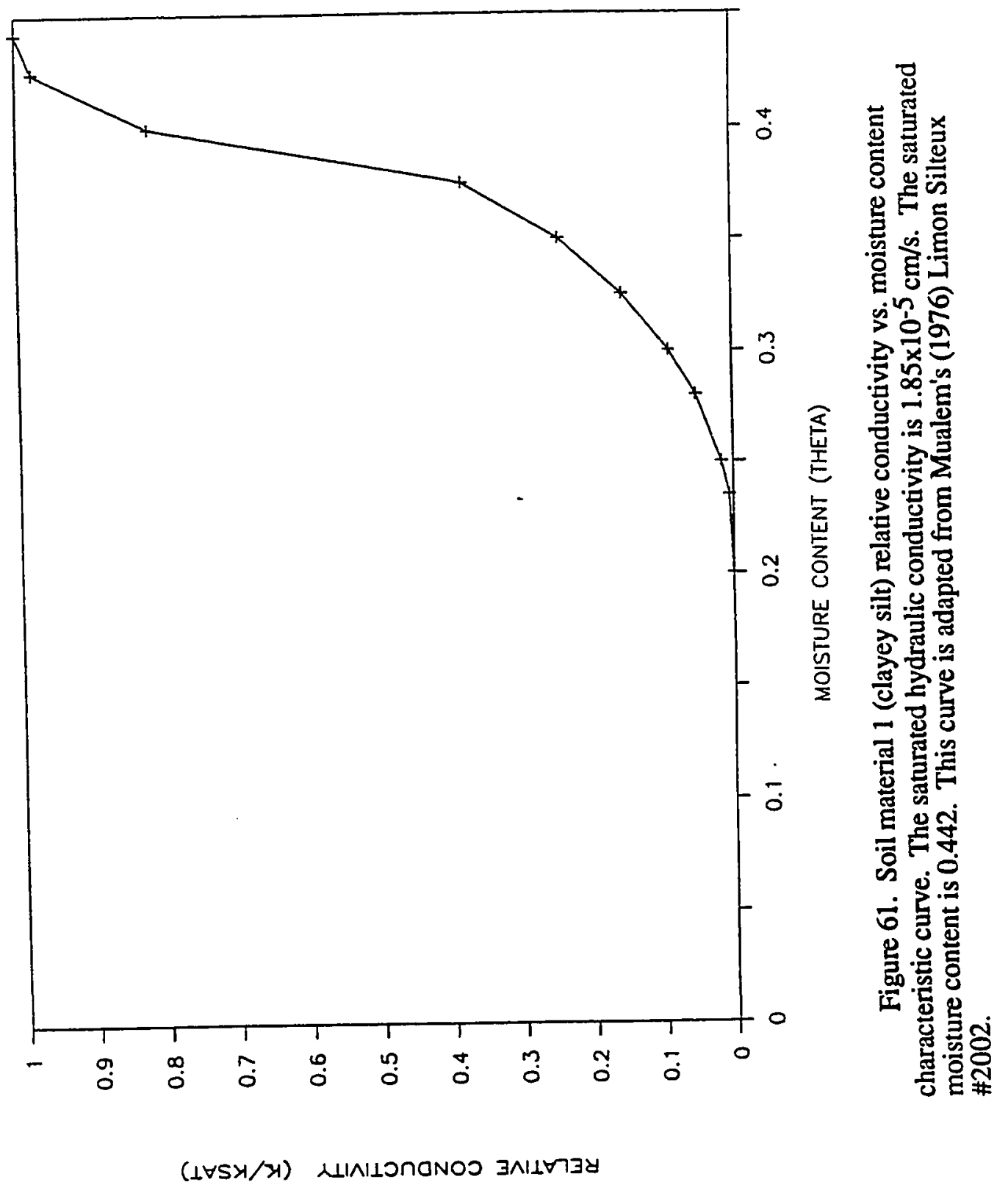




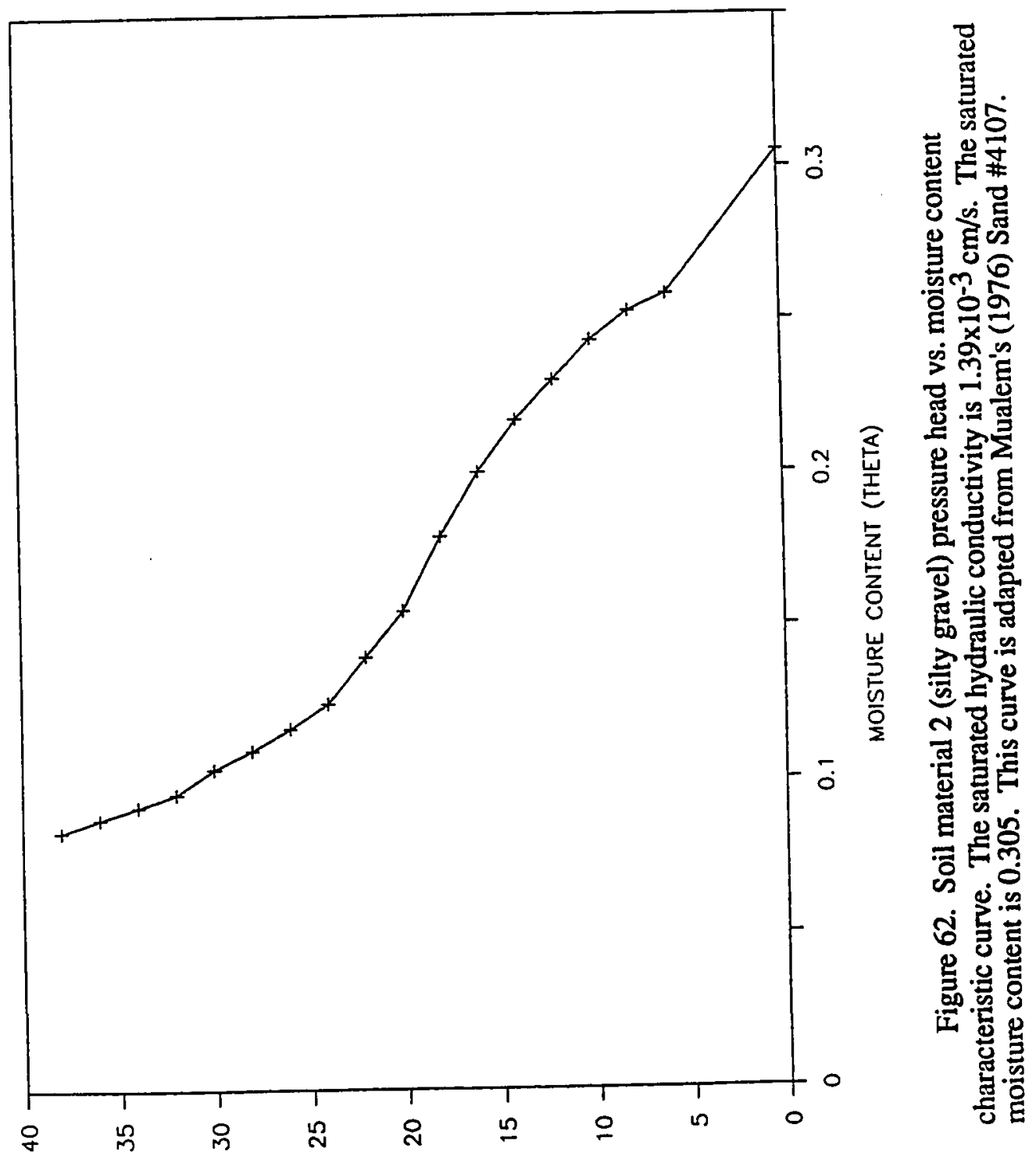

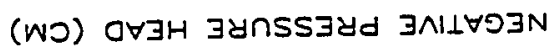




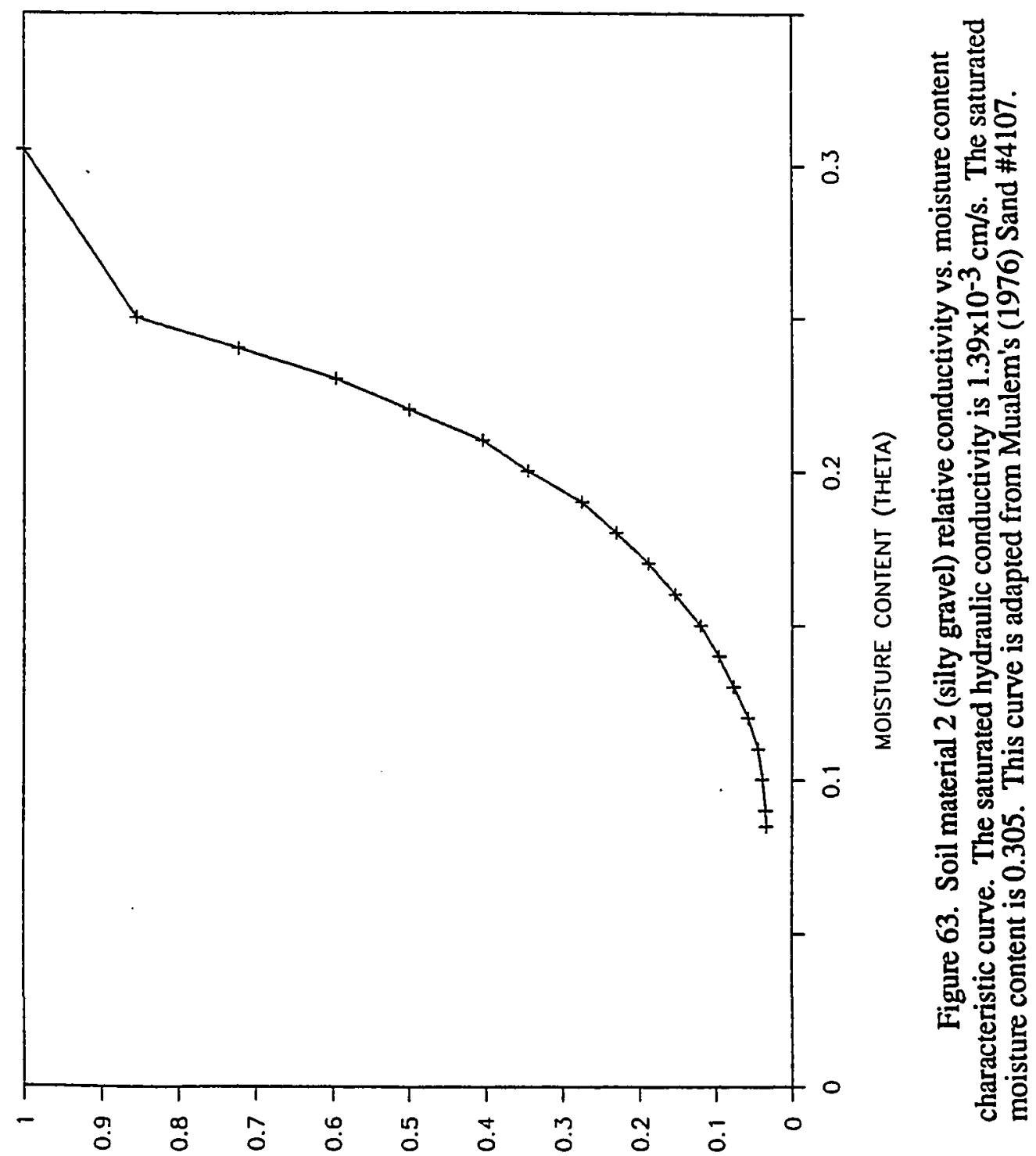

( 


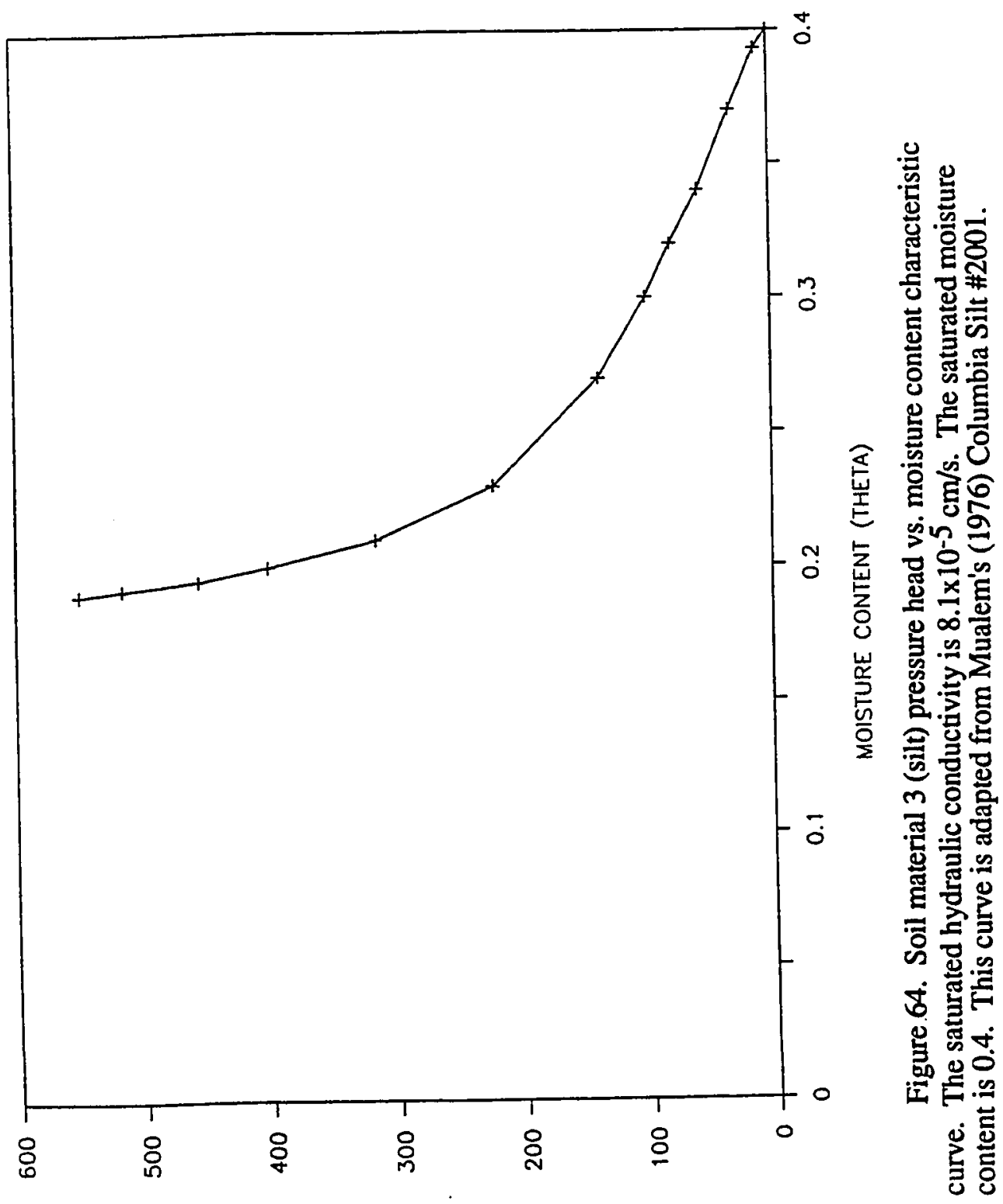

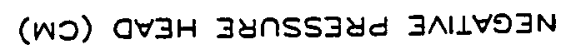




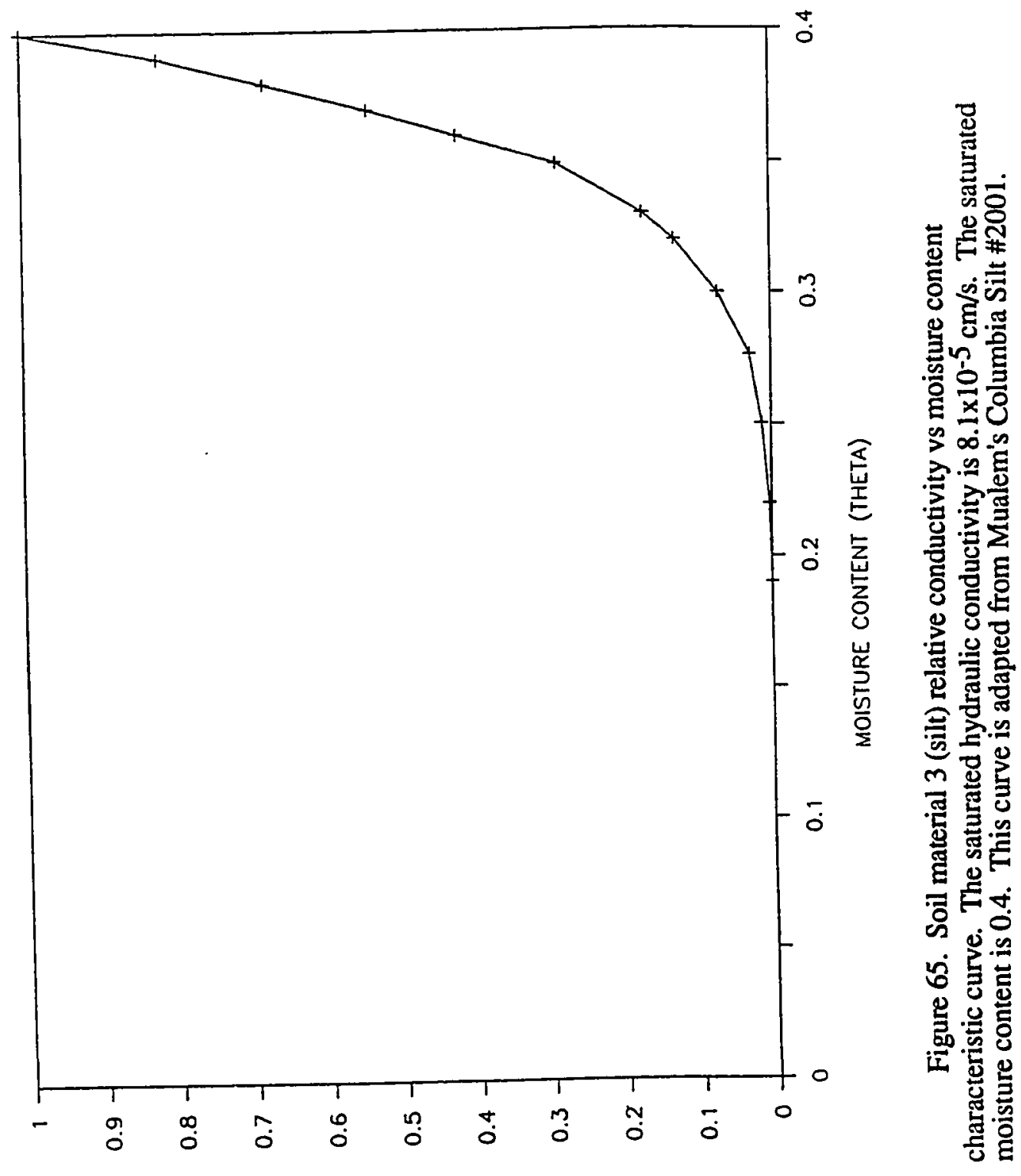

(LVSX/X) UINILOกONOJ JINILVIJע 


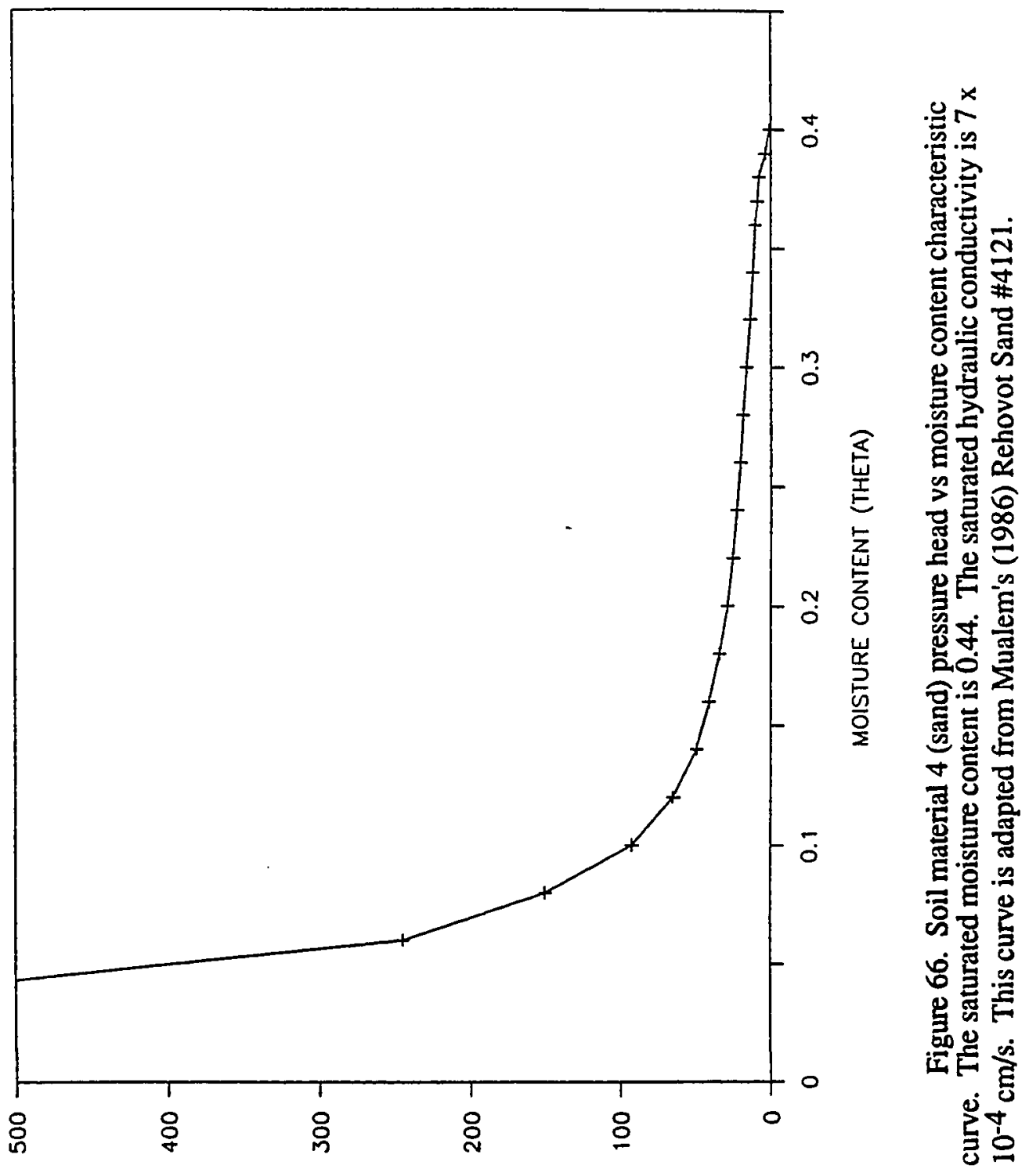

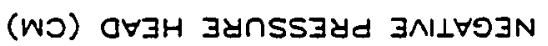




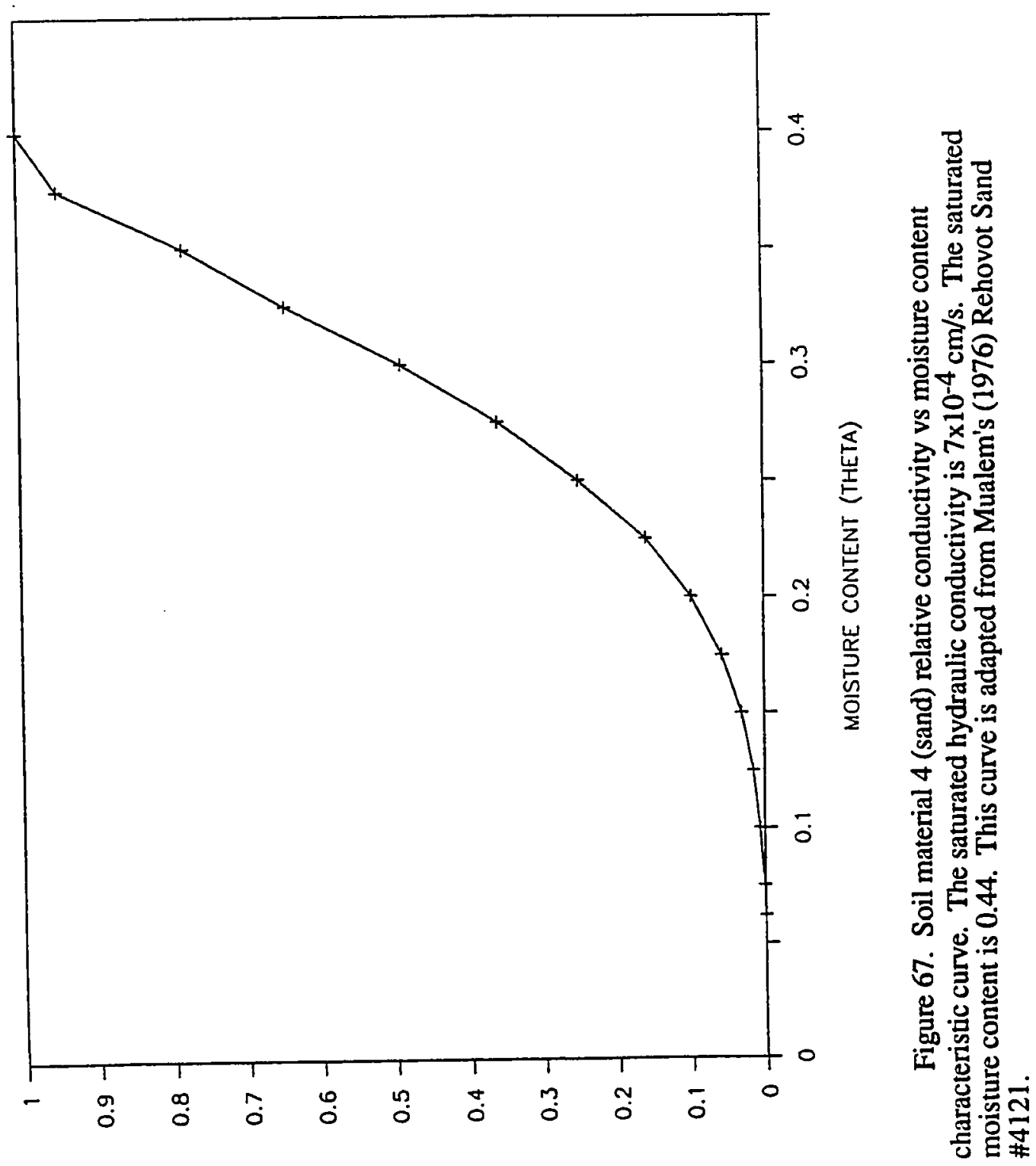

$(\perp \forall S Y / X)$ LIAILONONOS JAILVIJY 


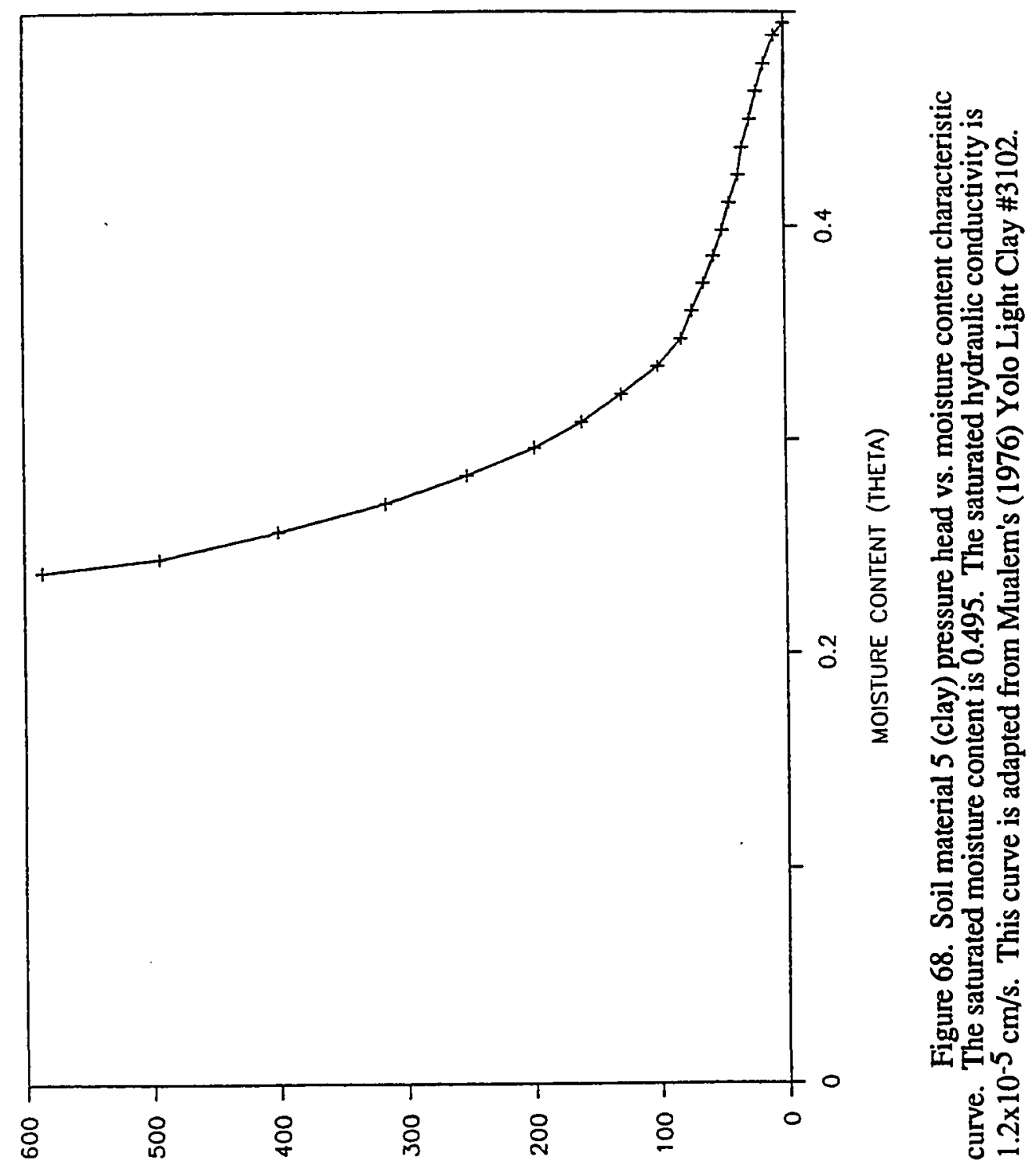

(wכ) ดช 3 H 


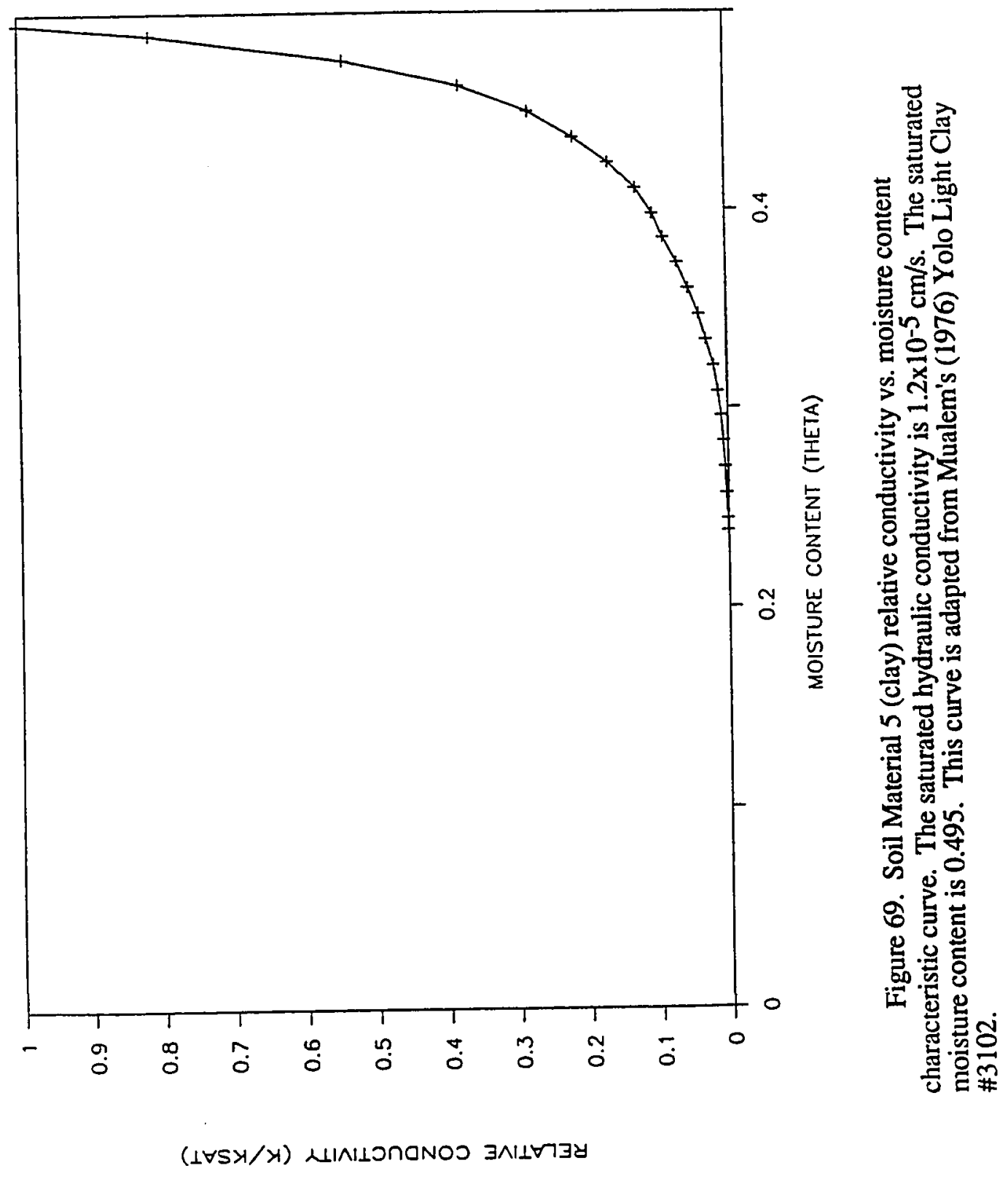




\section{APPENDIX C}

Measured and Extrapolated Surface Node Pressure Heads 
Table 2. Measured and extrapolated surface node pressure heads in centimeters, used in the February 1986 storm simulation and calibration.

\begin{tabular}{|c|c|c|c|c|c|c|}
\hline \multirow{3}{*}{$\begin{array}{l}\text { SIMULATION } \\
\text { DAY }\end{array}$} & \multirow[b]{3}{*}{ DATE } & \multicolumn{5}{|c|}{ NOOE NUKBER } \\
\hline & & \multirow[b]{2}{*}{11} & \multirow[b]{2}{*}{22} & \multirow{3}{*}{33} & \multirow{3}{*}{44} & \multirow{3}{*}{55} \\
\hline & & & & & & \\
\hline$\cdots$ & $\cdots$ & & & & & \\
\hline & | FEB II & 52.58 & 52.58 & 52.58 & 52.58 & 52.58 \\
\hline \multirow[t]{2}{*}{ DAY 1} & FEB 11.5 & 54.03 & 54.03 & 54.03 & 54.03 & 54.03 \\
\hline & FEB 12 & 55.47 & 55.47 & 55.47 & 55.47 & 55.47 \\
\hline \multirow[t]{2}{*}{ DAY 2} & FEB 12.5 & 75.90 & 75.90 & 75.90 & 75.90 & 75.90 \\
\hline & - FEB 13 & 96.32 & 96.32 & 96.32 & 96.32 & 96.32 \\
\hline \multirow[t]{2}{*}{ DAY 3} & FEB 13.5 & 97.28 & 97.28 & 97.28 & 97.28 & 97.28 \\
\hline & FEB 14 & 98.25 & 98.25 & 98.25 & 98.25 & 98.25 \\
\hline \multirow[t]{2}{*}{ DAY 4} & FEB 14.5 & 99.21 & 99.21 & 99.21 & 99.21 & 99.21 \\
\hline & FEB 15 & 100.18 & 100.18 & 100.18 & 100.18 & 100.18 \\
\hline \multirow[t]{2}{*}{ DAY 5} & FEB15.5 & 101.14 & 101.14 & 101.14 & 101.14 & 101.14 \\
\hline & - FEB 16 & 102.11 & 102.11 & 102.11 & 102.11 & 102.11 \\
\hline \multirow[t]{2}{*}{ DAY 6} & FEB 16.5 & 119.02 & 119.02 & 119.02 & 119.02 & 119.02 \\
\hline & FEB 17 & 135.94 & 135.94 & 135.94 & 135.94 & 135.94 \\
\hline \multirow[t]{2}{*}{ DAY 7} & FEB 17.5 & 152.86 & 152.86 & 152.86 & 152.86 & 152.86 \\
\hline & - FEB 18 & 169.77 & 169.77 & 169.77 & 169.77 & 169.77 \\
\hline \multirow[t]{2}{*}{ DAY 8} & FEB 18.5 & 237.29 & 237.29 & 237.29 & 237.29 & 237.29 \\
\hline & - FEB 19 & 304.80 & 304.80 & 304.80 & 304.80 & 304.80 \\
\hline \multirow[t]{2}{*}{ DAY 9} & FEB 19.5 & 304.80 & 304.80 & 304.80 & 304.80 & 304.80 \\
\hline & - FEB 20 & 304.80 & 304.80 & 304.80 & 304.80 & 304.80 \\
\hline \multirow[t]{2}{*}{ DAY 10} & FEB 20.5 & 254.66 & 254.66 & 254.66 & 254.66 & 254.66 \\
\hline & - FEB 2I & 204.52 & 204.52 & 204.52 & 204.52 & 204.52 \\
\hline \multirow[t]{2}{*}{ DAY II } & FEB 21.5 & 204.06 & 204.06 & 204.06 & 204.06 & 204.06 \\
\hline & FEB 22 & 203.61 & 203.61 & 203.61 & 203.61 & 203.61 \\
\hline \multirow[t]{2}{*}{ DAY 12} & FEB 22.5 & 203.15 & 203.15 & 203.15 & 203.15 & 203.15 \\
\hline & - FEB 23 & 202.69 & 202.69 & 202.69 & 202.69 & 202.69 \\
\hline \multirow[t]{2}{*}{ DAY 13} & FEB 23.5 & 181.81 & 181.81 & 181.81 & 181.81 & 181.81 \\
\hline & FEB 24 & 160.93 & 160.93 & 160.93 & 160.93 & 160.93 \\
\hline \multirow[t]{2}{*}{ DAY 14} & FEB 24.5 & 140.06 & 140.06 & 140.06 & 140.06 & 140.06 \\
\hline & - FEB 25 & 119.18 & 119.18 & 119.18 & 119.18 & 119.18 \\
\hline
\end{tabular}

- heasured data point + value during sinulation 


\begin{tabular}{|c|c|c|c|c|c|c|}
\hline \multirow{2}{*}{ SIMULATION } & \multirow[b]{3}{*}{ DATE } & \multicolumn{5}{|c|}{ NODE NUKBER } \\
\hline & & \multirow[b]{2}{*}{66} & \multirow[b]{2}{*}{77} & \multirow{3}{*}{88} & \multirow{3}{*}{99} & \multirow{3}{*}{110} \\
\hline DAY & & & & & & \\
\hline-- & ---- & & & & & \\
\hline \multirow{3}{*}{ DAY 1} & + FEB II & 52.58 & 52.58 & 52.58 & 52.58 & 52.58 \\
\hline & FEB 11.5 & 54.03 & 54.03 & 54.03 & 54.03 & 54.03 \\
\hline & + FEB 12 & 55.47 & 55.47 & 55.47 & 55.47 & 55.47 \\
\hline \multirow[t]{2}{*}{ DAY 2} & FEB 12.5 & 75.90 & 75.90 & 75.90 & 75.90 & 75.90 \\
\hline & * FEB 13 & 96.32 & 96.32 & 96.32 & 96.32 & 96.32 \\
\hline \multirow[t]{2}{*}{ DAY $3^{\circ}$} & FEB 13.5 & 97.28 & 97.28 & 97.28 & 97.28 & 97.28 \\
\hline & FEB 14 & 98.25 & 98.25 & 98.25 & 98.25 & 98.25 \\
\hline \multirow[t]{2}{*}{ DAY 4} & FEB 14.5 & 99.21 & 99.21 & 99.21 & 99.21 & 99.21 \\
\hline & FEB 15 & 100.18 & 100.18 & 100.18 & 100.18 & 100.18 \\
\hline \multirow[t]{2}{*}{ DAY 5} & FEB15.5 & 101.14 & 101.14 & 101.14 & 101.14 & 101.14 \\
\hline & - FEB 16 & 102.11 & 102.11 & 102.11 & 102.11 & 102.11 \\
\hline \multirow[t]{2}{*}{ DAY 6} & FEB 16.5 & 119.02 & 119.02 & 119.02 & 119.02 & 119.02 \\
\hline & FEB 17 & 135.94 & 135.94 & 135.94 & 135.94 & 135.94 \\
\hline \multirow[t]{2}{*}{ DAY 7} & FEB 17.5 & 152.86 & 152.86 & 152.86 & 152.86 & 152.86 \\
\hline & - FEB 18 & 169.77 & 169.77 & 169.77 & 169.77 & 169.77 \\
\hline \multirow[t]{2}{*}{ DAY 8} & FEB 18.5 & 237.29 & 237.29 & 237.29 & 237.29 & 237.29 \\
\hline & + FEB 19 & 304.80 & 304.80 & 304.80 & 304.80 & 304.80 \\
\hline \multirow[t]{2}{*}{ DAY 9} & FEB 19.5 & 304.80 & 304.80 & 304.80 & 304.80 & 304.80 \\
\hline & - FEB 20 & 304.80 & 304.80 & 304.80 & 304.80 & 304.80 \\
\hline \multirow[t]{2}{*}{ DAY 10} & FEB 20.5 & 254.66 & 254.66 & 254.66 & 254.66 & 254.66 \\
\hline & - FEB 21 & 204.52 & 204.52 & 204.52 & 204.52 & 204.52 \\
\hline \multirow[t]{2}{*}{ DAY $I I$} & FEB 21.5 & 204.06 & 204.06 & 204.06 & 204.06 & 204.06 \\
\hline & FEB 22 & 203.61 & 203.61 & 203.61 & 203.61 & 203.61 \\
\hline \multirow[t]{2}{*}{ DAY 12} & FEB 22.5 & 203.15 & 203.15 & 203.15 & 203.15 & 203.15 \\
\hline & + FEB 23 & 202.69 & 202.69 & 202.69 & 202.69 & 202.69 \\
\hline \multirow[t]{2}{*}{ DAY 13} & FEB 23.5 & 181.81 & 181.81 & 181.81 & 181.81 & 181.81 \\
\hline & FEB 24 & 160.93 & 160.93 & 160.93 & 160.93 & 160.93 \\
\hline \multirow[t]{2}{*}{ DAY 14} & FEB 24.5 & 140.06 & 140.06 & 140.06 & 140.06 & 140.06 \\
\hline & - FEB 25 & 119.18 & 119.18 & 119.18 & 119.18 & 119.18 \\
\hline
\end{tabular}


NODE NUKBER

\begin{tabular}{|c|c|c|c|c|c|c|}
\hline \multicolumn{7}{|l|}{ SIMULATION } \\
\hline DAY & DATE & 121 & 131 & 141 & 151 & 161 \\
\hline \multirow[t]{2}{*}{--} & $\cdots$ & & & & & \\
\hline & I FEB II & 52.58 & 49.53 & 43.43 & 37.34 & 28.19 \\
\hline \multirow[t]{2}{*}{ DAY 1} & FEB 11.5 & 54.03 & 50.98 & 44.88 & 38.79 & 29.64 \\
\hline & - FEB 12 & 55.47 & 52.42 & 46.33 & 40.23 & 31.09 \\
\hline \multirow[t]{2}{*}{ DAY 2} & FEB 12.5 & 75.90 & 72.85 & 66.75 & 60.66 & 51.51 \\
\hline & - FEB 13 & 96.32 & 93.27 & 87.17 & 81.08 & 71.93 \\
\hline \multirow[t]{2}{*}{ DAY 3} & FEB 13.5 & 97.28 & 94.23 & 88.14 & 82.04 & 72.90 \\
\hline & FEB 14 & 98.25 & 95.20 & 89.10 & 83.01 & 73.86 \\
\hline \multirow[t]{2}{*}{ DAY 4} & FEB 14.5 & 99.21 & 96.16 & 90.07 & 83.97 & 74.83 \\
\hline & FEB 15 & 100.18 & 97.13 & 91.03 & 84.94 & 75.79 \\
\hline \multirow[t]{2}{*}{ DAY 5} & FEBI5.5 & 101.14 & 98.09 & 92.00 & 95.90 & 76.76 \\
\hline & 4 FEB 16 & 102.11 & 99.06 & 92.96 & 86.87 & 77.72 \\
\hline \multirow[t]{2}{*}{ DAY 6} & FEB 16.5 & 119.02 & 115.97 & 109.88 & 103.78 & 94.64 \\
\hline & FEB 17 & 135.94 & 132.89 & 126.80 & 120.70 & 111.56 \\
\hline \multirow[t]{2}{*}{ DAY 7} & FEB 17.5 & 152.86 & 149.81 & 143.71 & 137.62 & 128.47 \\
\hline & - FEB 18 & 169.77 & 166.72 & 160.63 & 154.53 & 145.39 \\
\hline \multirow[t]{2}{*}{ DAY 8} & FEB 18.5 & 237.29 & 234.24 & 228.14 & 222.05 & 212.90 \\
\hline & - FEB 19 & 304.80 & 301.75 & 295.66 & 289.56 & 280.42 \\
\hline \multirow[t]{2}{*}{ DAY 9} & FEB 19.5 & 304.80 & 301.75 & 295.66 & 289.56 & 280.42 \\
\hline & - EEB 20 & 304.80 & 301.75 & 295.66 & 289.56 & 280.42 \\
\hline \multirow[t]{2}{*}{ DAY 10} & FEB 20.5 & 254.66 & 251.61 & 245.32 & 239.42 & 230.28 \\
\hline & - FEB 2! & 204.52 & 201.47 & 195.38 & 189.28 & 180.14 \\
\hline \multirow[t]{2}{*}{ DAY II } & FEB 21.5 & 204.06 & 201.01 & 194.92 & 189.82 & 179.68 \\
\hline & FEB 22 & 203.61 & 200.56 & 194.46 & 188.37 & 179.22 \\
\hline \multirow[t]{2}{*}{ DAY 12} & FEB 22.5 & 203.15 & 200.10 & 194.01 & 187.91 & 178.77 \\
\hline & - FEB 23 & 202.69 & 199.64 & 193.55 & 187.45 & 178.31 \\
\hline \multirow[t]{2}{*}{ DAY 13} & $F E B \quad 23.5$ & 181.91 & 178.76 & 172.67 & 166.57 & 157.43 \\
\hline & FEB 24 & 160.93 & 157.88 & 151.79 & 145.69 & 136.55 \\
\hline \multirow[t]{2}{*}{ DAY 14} & FEA 24.5 & 140.06 & 137.01 & 130.91 & 124.82 & 115.67 \\
\hline & FEB 25 & 119.18 & 116.13 & 110.03 & 103.94 & 94.79 \\
\hline
\end{tabular}

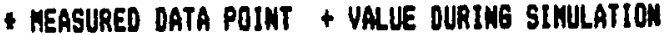


NODE NUABER

\begin{tabular}{|c|c|c|c|c|c|c|}
\hline & & & & & & \\
\hline NULATION & & & & & & \\
\hline DAY & DATE & $17 !$ & 182 & 195 & 208 & 222 \\
\hline-- & $\infty-\infty$ & & & & & \\
\hline & - FEB II & 19.05 & 11.43 & 6.86 & 0.00 & 0.00 \\
\hline DAY 1 & FEB 11.5 & 20.50 & 12.88 & 8.31 & 0.69 & + \\
\hline & I FEB 12 & 21.95 & 14.33 & 9.75 & 2.13 & 0.00 \\
\hline DAY 2 & FEB 12.5 & 42.37 & 34.75 & 30.18 & 22.56 & 17.98 \\
\hline & I FEB 13 & 62.79 & 55.17 & 50.60 & 42.98 & 38.40 \\
\hline DAY 3 & FEB 13.3 & 63.75 & 56.13 & 51.56 & 13.94 & 39.37 \\
\hline & FEB 14 & 64.72 & 57.10 & 52.53 & 44.91 & 40.34 \\
\hline DAY 4 & FED 14.5 & 65.68 & 58.06 & 53.49 & 45.87 & 41.30 \\
\hline & FEB 15 & 66.65 & 39.03 & 54.46 & 46.84 & 42.27 \\
\hline DAY 5 & FEB15.5 & 67.61 & 59.99 & 55.42 & 47.80 & 43.23 \\
\hline & t FEB if & 68.58 & 60.96 & 56.39 & 48.77 & 44.20 \\
\hline DAY 6 & FEB 16.5 & 85.50 & 77.88 & 73.30 & 65.68 & 61.11 \\
\hline & FEB 17 & 102.41 & 94.79 & 90.22 & 82.60 & 78.03 \\
\hline DAY 7 & FEB 17.5 & 119.33 & 111.71 & 107.14 & 99.52 & 94.95 \\
\hline & - FEB 18 & 136.25 & 128.63 & 124.05 & 116.43 & 111.86 \\
\hline DAY 8 & FEB 18.5 & 203.76 & 196.14 & 191.57 & 183.95 & 179.37 \\
\hline & - FEB 19 & 271.27 & 263.65 & 259.08 & 251.46 & 246.89 \\
\hline DAY 9 & FEB 19.5 & 271.27 & 263.65 & 259.08 & 231.46 & 246.89 \\
\hline & - FEB 20 & 271.27 & 263.65 & 259.08 & 251.46 & 246.89 \\
\hline DAY 10 & FEB 20.5 & 221.13 & 213.51 & 208.94 & 201.32 & 196.75 \\
\hline & - FEB 21 & 170.99 & 163.37 & 158.80 & 151.18 & 146.61 \\
\hline DAY 11 & FEB 21.5 & 170.54 & 162.92 & 158.34 & 150.72 & 146.15 \\
\hline & FEB 22 & 170.08 & 162.46 & 157.89 & 150.27 & 145.69 \\
\hline DAY 12 & FEB 22.5 & 169.62 & 162.00 & 157.43 & 149.81 & 145.24 \\
\hline & - FEB 23 & 169.16 & 161.54 & 156.97 & $\$ 49.35$ & 144.78 \\
\hline DAY IJ & FEB 23.5 & 148.29 & 140.67 & 136.09 & 128.47 & 123.90 \\
\hline & FEB 24 & 127.41 & 119.79 & 115.21 & 107.59 & 103.02 \\
\hline DAY 14 & FEB 24.5 & 106.53 & 98.91 & 94.34 & 86.72 & 82.14 \\
\hline & - FEB 25 & 85.65 & 78.03 & 73.46 & 65.84 & 61.26 \\
\hline
\end{tabular}

- heasureo oata poInt + value duRING sinulation 


\begin{tabular}{|c|c|c|c|c|c|c|}
\hline \multirow{2}{*}{ SIMULATION } & & \multicolumn{5}{|c|}{ NODE NUMBER } \\
\hline & & & & & & \\
\hline DAY & DATE & 236 & 250 & 263 & 276 & 287 \\
\hline \multirow{2}{*}{--} & $\cdots$ & & & & & \\
\hline & - FEB II & 0.00 & 0.00 & 0.00 & 0.00 & 0.00 \\
\hline \multirow{2}{*}{ DAY 1} & FEB 11.5 & + & + & + & + & + \\
\hline & - FEB 12 & 0.00 & 0.00 & 0.00 & 0.00 & 0.00 \\
\hline \multirow[t]{2}{*}{ DAY 2} & FEB 12.5 & 14.94 & 14.94 & 13.41 & 11.89 & 10.36 \\
\hline & - FEB 13 & 35.36 & 35.36 & 33.83 & 32.31 & 30.78 \\
\hline \multirow[t]{2}{*}{ DAY 3} & FEB 13.5 & 36.32 & 36.32 & 34.80 & 33.27 & 31.75 \\
\hline & FEB 14 & 37.29 & 37.29 & 35.76 & 34.24 & 32.72 \\
\hline \multirow[t]{2}{*}{ DAY 4} & FEB 14.5 & 38.25 & 38.25 & 36.73 & 35.20 & 33.68 \\
\hline & FEB 15 & 39.22 & 39.22 & 37.69 & 36.17 & 34.65 \\
\hline \multirow[t]{2}{*}{ DAY 5} & FEB15.5 & 40.18 & 40.18 & 38.66 & 37.13 & 35.61 \\
\hline & A FEB 16 & 41.15 & 41.15 & 39.62 & 38.10 & 36.58 \\
\hline \multirow[t]{2}{*}{ DAY 6} & FE8 16.5 & 58.06 & 58.06 & 56.54 & 55.02 & 53.49 \\
\hline & FEB 17 & 74.98 & 74.98 & 73.46 & 71.93 & 70.41 \\
\hline \multirow[t]{2}{*}{ DAY 7} & FEB 17.5 & 91.90 & 91.90 & 90.37 & 89.85 & 87.33 \\
\hline & - FEB 18 & 108.81 & 108.81 & 107.29 & 105.77 & 104.24 \\
\hline \multirow[t]{2}{*}{ DAY 8} & FEB 18.5 & 176.33 & 176.33 & 174.80 & 173.28 & 171.75 \\
\hline & - FEB 19 & 243.84 & 243.84 & 242.32 & 240.79 & 239.27 \\
\hline \multirow[t]{2}{*}{ DAY 9} & FEB 19.5 & 243.94 & 243.84 & 242.32 & 240.79 & 239.27 \\
\hline & - FEB 20 & 243.84 & 243.84 & 242.32 & 240.79 & 239.27 \\
\hline \multirow[t]{2}{*}{ DAY 10} & FEB 20.5 & 193.70 & 193.70 & 192.18 & 190.65 & 189.13 \\
\hline & - FEB 21 & 143.56 & 143.56 & 142.04 & 140.51 & 138.99 \\
\hline \multirow[t]{2}{*}{ DAY 11} & FEB 21.5 & 143.10 & 143.10 & 141.58 & 140.06 & 138.53 \\
\hline & FEB 22 & 142.65 & 142.65 & 141.12 & 139.60 & 138.07 \\
\hline \multirow[t]{2}{*}{ DAY 12} & FEB 22.5 & 142.19 & 142.19 & 140.67 & 139.14 & 137.62 \\
\hline & - FEB 23 & 141.73 & 141.73 & 140.21 & 138.68 & 137.1 \\
\hline \multirow[t]{2}{*}{ DAY 13} & FEB 23.5 & 120.85 & 120.85 & 119.33 & 117.81 & 116.2 \\
\hline & FEB 24 & 99.97 & 99.97 & 98.45 & 96.93 & 95.4 \\
\hline \multirow[t]{2}{*}{ DAY 14} & FEB 24.5 & 79.10 & 79.10 & 77.57 & 76.05 & 74.5 \\
\hline & - FEB 25 & 58.22 & 58.22 & 56.69 & 35.17 & 53.6 \\
\hline
\end{tabular}

- heasured data point + yalue during simLlation 


\begin{tabular}{|c|c|c|c|c|c|c|}
\hline \multirow[b]{2}{*}{ SIMULATION } & \multirow[b]{3}{*}{ DATE } & \multicolumn{5}{|c|}{ NODE NUKBER } \\
\hline & & \multirow[b]{2}{*}{297} & \multirow[b]{2}{*}{307} & \multirow[b]{2}{*}{317} & \multirow[b]{2}{*}{327} & \multirow[b]{2}{*}{337} \\
\hline DAY & & & & & & \\
\hline \multirow[t]{2}{*}{$\cdots$} & $-\pi$ & & & & & \\
\hline & - FEB II & 0.00 & 0.00 & 0.00 & 0.00 & 0.00 \\
\hline \multirow[t]{2}{*}{ DAY 1} & FEB 11.5 & + & + & + & + & + \\
\hline & - FEB 12 & 0.00 & 0.00 & 0.00 & 0.00 & 0.010 \\
\hline \multirow[t]{2}{*}{ DAY 2} & FEB 12.5 & 7.32 & 4.27 & 1.22 & + & + \\
\hline & - FEB 13 & 27.74 & 24.69 & 21.64 & 18.59 & 15.54 \\
\hline \multirow[t]{2}{*}{ DAY 3} & FEB 13.5 & 28.70 & 25.65 & 22.61 & 19.56 & 16.51 \\
\hline & FEB 14 & 29.67 & 26.62 & 23.57 & 20.52 & 17.48 \\
\hline \multirow[t]{2}{*}{ DAY 4} & FEB 14.5 & 30.63 & 27.58 & 24.54 & 21.49 & 18.44 \\
\hline & FEB 15 & 31.60 & 28.35 & 25.50 & 22.45 & 19.41 \\
\hline \multirow[t]{2}{*}{ DAY 5} & FEB15.5 & 32.56 & 29.51 & 26.47 & 23.42 & 20.37 \\
\hline & + FEB 16 & 33.53 & 30.48 & 27.43 & 24.38 & 21.34 \\
\hline \multirow[t]{2}{*}{ DAY 6} & FEB 16.3 & 50.44 & 47.40 & 44.35 & 41.30 & 38.25 \\
\hline & FEB 17 & 67.36 & 64.31 & 61.26 & 58.22 & 55.17 \\
\hline \multirow[t]{2}{*}{ DAY 7} & FEB 17.5 & 84.28 & 84.23 & 78.18 & 75.13 & 72.09 \\
\hline & - FEB 18 & 101.19 & 98.15 & 95.10 & 92.05 & 89.00 \\
\hline \multirow[t]{2}{*}{ DAY 8} & FEB 18.3 & 168.71 & 165.66 & 162.61 & 159.56 & 156.51 \\
\hline & - FEB 19 & 236.22 & 233.17 & 230.12 & 227.08 & 224.03 \\
\hline \multirow[t]{2}{*}{ DAY 9} & FEB 19.5 & 236.22 & 233.17 & 230.12 & 227.08 & 224.03 \\
\hline & - FEB 20 & 236.22 & 233.17 & 230.12 & 227.08 & 224.03 \\
\hline \multirow[t]{2}{*}{ DAY 10} & FEB 20.5 & 186.08 & 183.03 & 179.98 & 176.94 & 173.89 \\
\hline & - FEB 21 & 135.94 & 132.89 & 129.84 & 126.80 & 123.75 \\
\hline \multirow[t]{2}{*}{ DAY II } & FEB 21.5 & 135.48 & 132.44 & 129.39 & 126.34 & 123.29 \\
\hline & FEB 22 & 135.03 & 131.98 & 128.93 & 125.88 & 122.83 \\
\hline \multirow[t]{2}{*}{ DAY 12} & FEB 22.5 & 134.57 & 131.52 & 128.47 & 125.43 & 122.38 \\
\hline & - FEB 23 & 134.11 & 131.06 & 128.02 & 124.97 & 121.92 \\
\hline \multirow[t]{2}{*}{ DAY 13} & FEB 23.5 & 113.23 & 110.19 & 107.14 & 104.09 & 101.04 \\
\hline & FEB 24 & 92.35 & 89.31 & 86.26 & 83.21 & 80.16 \\
\hline \multirow[t]{2}{*}{ DAY 14} & FEB 24.5 & 71.48 & 68.43 & 65.38 & 62.33 & 59.28 \\
\hline & - FEB 25 & 50.60 & 17.55 & 44.50 & 41.45 & 38.40 \\
\hline
\end{tabular}

- measured data point + value ouring sinulation 
NODE NUMBER

\begin{tabular}{|c|c|c|c|c|c|c|}
\hline \multicolumn{7}{|l|}{ SIMULATION } \\
\hline DAY & DATE & 347 & 357 & 367 & 379 & 393 \\
\hline-- & - - & & & & & \\
\hline & - FEB II & 0.00 & 0.00 & 0.00 & 0.00 & 0.00 \\
\hline DAY 1 & FEB 11.5 & + & + & + & + & + \\
\hline & - FEB 12 & 0.00 & 0.00 & 0.00 & 0.00 & 0.00 \\
\hline DAY 2 & FEB 12.5 & + & + & + & + & + \\
\hline & - FEB 13 & 12.50 & 9.45 & 6.40 & 3.35 & 1.83 \\
\hline DAY 3 & FEB 13.5 & 13.46 & 10.41 & 7.37 & 4.32 & 2.79 \\
\hline & FEB 14 & 14.43 & 11.38 & 8.33 & 5.28 & 3.76 \\
\hline DAY 4 & FEB 14.5 & 15.39 & 12.34 & 9.30 & 6.25 & 4.72 \\
\hline & FEB 15 & 16.36 & 13.31 & 10.26 & 7.21 & 5.69 \\
\hline DAY 5 & FEB15.5 & 17.32 & 14.27 & 11.23 & 8.18 & 6.65 \\
\hline & - FEB 16 & 18.29 & 15.24 & 12.19 & 9.14 & 7.62 \\
\hline DAY 6 & FEB 16.5 & 35.20 & 32.16 & 29.11 & 26.06 & 24.54 \\
\hline & FEB 17 & 52.12 & 49.07 & 46.02 & 42.98 & 41.45 \\
\hline DAY 7 & FEB 17.5 & 69.04 & 65.99 & 62.94 & 59.89 & 59.37 \\
\hline & - FEB 18 & 85.95 & 82.91 & 79.86 & 76.81 & 75.29 \\
\hline DAY 8 & FEB 18.5 & 153.47 & 150.42 & 147.37 & 144.32 & 142.80 \\
\hline & - FEB 19 & 220.98 & 217.93 & 214.88 & 211.84 & 210.31 \\
\hline DAY 9 & FEB 19.5 & 220.98 & 217.93 & 214.88 & 211.84 & 210.31 \\
\hline & - FEB 20 & 220.98 & 217.93 & 214.88 & 211.84 & 210.31 \\
\hline DAY 10 & FEB 20.5 & 170.84 & 167.79 & 164.74 & 161.70 & 160.17 \\
\hline & - FEB 21 & 120.70 & 117.65 & 114.60 & 111.56 & 110.03 \\
\hline DAY II & FEB 21.5 & 120.24 & 117.20 & 114.15 & 111.10 & 109.58 \\
\hline & FEB 22 & 119.79 & 116.74 & 113.69 & 110.64 & 109.12 \\
\hline DAY 12 & FEB 22.5 & 119.33 & 116.28 & 113.23 & 110.19 & 108.66 \\
\hline & + FEB 23 & 118.87 & 115.82 & 112.78 & 109.73 & 108.20 \\
\hline DAY 13 & FEB 23.5 & 97.99 & 94.95 & 91.90 & 88.85 & 87.33 \\
\hline & FEB 24 & 77.11 & 74.07 & 71.02 & 67.97 & 66.45 \\
\hline DAY 14 & FEB 24.5 & 56.24 & 53.19 & 50.14 & 47.09 & 45.57 \\
\hline & - FEB 25 & 35.36 & 32.31 & 29.26 & 26.21 & 24.69 \\
\hline
\end{tabular}

- heasured data point + value ouring simulation 
NODE NUKBER

\begin{tabular}{|c|c|c|c|c|c|}
\hline \\
\hline \multirow{2}{*}{ DAY } & DATE & \multirow[t]{2}{*}{407} & \multirow[t]{2}{*}{421} & \multirow[t]{2}{*}{433} & \multirow[t]{2}{*}{443} \\
\hline & --- & & & & \\
\hline & - FEB II & 0.00 & 0.00 & 0.00 & 0.00 \\
\hline \multirow[t]{2}{*}{ DAY 1} & FEB 11.5 & + & + & + & + \\
\hline & I FEB 12 & 0.00 & 0.00 & 0.00 & 0.00 \\
\hline \multirow[t]{2}{*}{ DAY 2} & FEB 12.5 & + & + & & \\
\hline & + FEB 13 & 0.00 & 0.00 & 0.00 & 0.00 \\
\hline \multirow[t]{2}{*}{ DAY 3} & FEB 13.5 & + & + & + & + \\
\hline & FEB 14 & 0.71 & 0.71 & 0.71 & 0.71 \\
\hline \multirow[t]{2}{*}{ DAY 4} & FEB 14.5 & 1.68 & 1.68 & 1.68 & 1.68 \\
\hline & FEB 15 & 2.64 & 2.64 & 2.64 & 2.64 \\
\hline \multirow[t]{2}{*}{ DAY 5} & FEB15.5 & 3.61 & 3.61 & 3.61 & 3.61 \\
\hline & FEB 16 & 4.57 & 4.37 & 4.57 & 4.57 \\
\hline \multirow[t]{2}{*}{ DAY 6} & FEB 16.5 & 21.49 & 21.49 & 21.49 & 21.49 \\
\hline & FEB 17 & 38.40 & 38.40 & 38.40 & 38.40 \\
\hline \multirow[t]{2}{*}{ DAY 7} & FEB 17.5 & 55.32 & 35.32 & 55.32 & 53.32 \\
\hline & - FEB 18 & 72.24 & 72.24 & 72.24 & 72.24 \\
\hline \multirow[t]{2}{*}{ DAY 8} & FE8 18.5 & 139.75 & 139.75 & 139.75 & 139.75 \\
\hline & - FEB 19 & 207.26 & 207.26 & 207.26 & 207.26 \\
\hline \multirow[t]{2}{*}{ DAY 9} & FEB 19.5 & 207.26 & 207.26 & 207.26 & 207.26 \\
\hline & - FEB 20 & 207.26 & 207.26 & 207.26 & 207.26 \\
\hline \multirow[t]{2}{*}{ DAY 10} & FEB 20.5 & 157.12 & 157.12 & 157.12 & 157.12 \\
\hline & - FEB 21 & 106.98 & 106.98 & 106.98 & 106.98 \\
\hline \multirow[t]{2}{*}{ DAY 11} & FEB 21.5 & 106.53 & 106.53 & 106.53 & 106.53 \\
\hline & FEB 22 & 106.07 & 106.07 & 106.07 & 106.07 \\
\hline \multirow[t]{2}{*}{ DAY 12} & FEB 22.5 & 105.61 & 105.61 & 105.61 & 105.61 \\
\hline & - FEB 23 & 105.16 & 105.16 & 105.16 & 105.16 \\
\hline \multirow[t]{2}{*}{ DAY IJ } & FEB 23.5 & 84.28 & 94.28 & 84.28 & 84.28 \\
\hline & FEB 24 & 63.40 & 63.40 & 63.40 & 63.40 \\
\hline \multirow[t]{2}{*}{ DAY 14} & FEB 24.5 & 42.52 & 42.52 & 42.52 & 42.52 \\
\hline & - FEB 25 & 21.64 & 21.64 & 21.64 & 21.64 \\
\hline
\end{tabular}




\section{APPENDIX D}

Computer Input File used for the February 1986 Storm Simulation 
Table 3. Input data for the February 1986 storm simulation.

\begin{tabular}{|c|c|c|c|c|c|c|c|}
\hline FERRUARY & 1986 STORK & A SIMULATI & ON INPUT $F$ & ILE.. . & & & \\
\hline $443 \quad 14$ & 414 & 50 & $30 \quad 1$ & 15 & & & \\
\hline 0 & 0 & 0 & 0 & 0 & & & \\
\hline 11 & 17 & 13 & 23 & 22 & & & \\
\hline 15 & & & & & & & \\
\hline 12 & 34 & 45 & 78 & $39 \quad 100$ & $111 \quad 122$ & $132 \quad 142$ & 152 \\
\hline $\begin{array}{rr}15 & -1 \\
162 & 172\end{array}$ & & & & & & & \\
\hline $\begin{array}{rr}162 & 172 \\
9 & -1\end{array}$ & 183 & $209 \quad 223$ & $237 \quad 251$ & $264 \quad 277$ & $288 \quad 298$ & $308 \quad 318$ & 328 \\
\hline $338 \quad 348$ & $358 \quad 368$ & $380 \quad 394$ & $408 \quad 422$ & 434 & & & \\
\hline $\begin{array}{l}0.5 \\
1.0\end{array}$ & 0.5 & 1.0 & 0.5 & 0.1 & & & \\
\hline $\begin{array}{r}1.0 \\
1.6000\end{array}$ & 1.0 & & & & & & \\
\hline $\begin{array}{r}1.6000 \\
120.0\end{array}$ & 1.6000 & 0.442 & 0.0 & & & & \\
\hline 120.0 & 120.0 & 0.305 & 0.0 & & & & \\
\hline 7.0 & 7.0 & 0.400 & 0.0 & & & & \\
\hline 65.0 & 65.0 & 0.14 & 0.0 & & & & \\
\hline 1.0368 & 1.0368 & 0.495 & 0.0 & & & & \\
\hline 0.2 & 0.0 & 0.235 & 0.00575 & 0.25 & 0.0161 & 0.28 & 0.0517 \\
\hline 0.3 & 0.0895 & 0.325 & 0.155 & 0.35 & 0.245 & 0.375 & 0.379 \\
\hline 0.4 & 0.815 & 0.425 & 0.977 & 0.442 & 1.0 & & \\
\hline 0.03 & 96000.0 & 0.04 & 54000.0 & 0.06 & 24000.0 & 0.0904 & 10000.0 \\
\hline 0.15 & 3000.0 & 0.1912 & 1300.0 & $0.2 \mathrm{i} 3$ & 790.0 & 0.2367 & 486.0 \\
\hline 0.2488 & 380.0 & 0.2874 & 231.0 & 0.3097 & 184.0 & 0.3636 & 87.0 \\
\hline 0.3803 & 57.0 & 0.3965 & 36.0 & $0.4 !$ & 21.0 & 0.4183 & 7.6 \\
\hline 0.4338 & 2.6 & 0.442 & 0.0 & & & & \\
\hline 0.085 & 0.0337 & 0.09 & 0.0346 & 0.1 & 0.0385 & 0.11 & 0.04425 \\
\hline 0.12 & 0.0576 & 0.13 & 0.077 & 0.14 & 0.09625 & 0.15 & 0.12 \\
\hline 0.16 & 0.154 & 0.17 & 0.189 & 0.18 & 0.2305 & 0.19 & 0.2755 \\
\hline 0.2 & 0.346 & 0.21 & 0.404 & 0.22 & 0.5 & 0.23 & 0.596 \\
\hline 0.24 & 0.7225 & 0.25 & 0.855 & 0.305 & 1.00 & & \\
\hline 0.084 & 38.0 & 0.088 & 36.0 & 0.092 & 34.0 & 0.096 & 32.0 \\
\hline 0.104 & 30.0 & 0.11 & 28.0 & 0.117 & 26.0 & 0.125 & 24.0 \\
\hline 0.14 & 22.0 & 0.155 & 20.0 & 0.179 & 18.0 & 0.2 & 16.0 \\
\hline 0.217 & 14.0 & 0.23 & 12.0 & 0.243 & 10.0 & 0.2525 & 8.0 \\
\hline 0.305 & 0.0 & & & & & & \\
\hline 0.19 & 0.00 & 0.22 & 0.003 & 0.2504 & 0.0129 & 0.2765 & 0.0286 \\
\hline 0.3 & 0.0715 & 0.32 & 0.129 & 0.33 & 0.171 & 0.349 & 0.286 \\
\hline 0.36 & 0.12 & 0.37 & 0.54 & 0.38 & 0.677 & 0.39 & 0.818 \\
\hline 0.4 & 1.0 & & & & & & \\
\hline 0.19 & 550.0 & 0.192 & 516.0 & 0.195 & 455.0 & 0.2 & 400.0 \\
\hline 0.21 & 315.0 & 0.23 & 222.0 & 0.27 & 138.0 & 0.3 & 100.0 \\
\hline 0.32 & 80.0 & 0.34 & 57.0 & 0.37 & 31.0 & 0.393 & 10.0 \\
\hline 0.4 & 0.0 & & & & & & \\
\hline 0.062 & 0.0002121 & 0.075 & 0.00125 & 0.1 & 0.006061 & 0.125 & 0.01515 \\
\hline 0.15 & 0.03076 & 0.175 & 0.05682 & 0.2 & 0.09848 & 0.225 & 0.1591 \\
\hline 0.25 & 0.25 & 0.275 & 0.3591 & 0.3 & 0.4879 & 0.325 & 0.6439 \\
\hline 0.35 & 0.7803 & 0.375 & 0.9469 & 0.4 & 0.98 & 0.44 & 1.00 \\
\hline
\end{tabular}




\begin{tabular}{|c|c|c|c|c|c|c|c|}
\hline 0.02 & 2500.0 & 0.04 & 550.0 & 0.06 & 245.0 & 0.08 & 150.0 \\
\hline 0.1 & 92.5 & 0.12 & 65.5 & 0.14 & 50.0 & 0.16 & 41.5 \\
\hline 0.18 & 34.5 & 0.2 & 29.3 & 0.22 & 25.5 & 0.24 & 23.0 \\
\hline 0.26 & 20.6 & 0.28 & 18.8 & 0.3 & 16.5 & 0.32 & 14.0 \\
\hline 0.34 & 12.2 & 0.36 & 10.5 & 0.37 & 9.0 & 0.38 & 7.75 \\
\hline 0.39 & 4.0 & 0.4 & 1.0 & 0.44 & 0.0 & & \\
\hline 0.238 & 0.0009821 & 0.244 & 0.00138 & 0.257 & 0.00252 & 0.27 & 0.00414 \\
\hline 0.283 & 0.006091 & 0.296 & 0.008778 & 0.308 & 0.01348 & 0.321 & 0.01902 \\
\hline 0.334 & 0.03 & 0.347 & 0.04 & 0.36 & 0.055 & 0.373 & 0.07 \\
\hline 0.386 & 0.08943 & 0.398 & 0.1041 & 0.411 & 0.1276 & 0.424 & 0.1658 \\
\hline 0.437 & 0.2154 & 0.45 & 0.2789 & 0.463 & 0.3764 & 0.476 & 0.5398 \\
\hline 0.489 & 0.813 & 0.495 & 1.00 & & & & \\
\hline 0.238 & 586.0 & 0.244 & 494.0 & 0.257 & 400.0 & 0.27 & 316.0 \\
\hline 0.283 & 252.0 & 0.296 & 199.0 & 0.308 & 161.0 & 0.321 & 129.0 \\
\hline 0.334 & 100.0 & 0.347 & 82.0 & 0.36 & 73.0 & 0.373 & 64.0 \\
\hline 0.386 & 56.0 & 0.398 & 49.0 & 0.411 & 43.0 & 0.424 & 36.0 \\
\hline 0.437 & 33.0 & 0.45 & 27.0 & 0.463 & 22.0 & 0.476 & 16.0 \\
\hline 0.489 & 8.0 & 0.495 & 0.00 & & & & \\
\hline 1 & $\begin{array}{ll}0 & 0.0\end{array}$ & 0.00 & -10.00 & 0.0 & & & \\
\hline 2 & 0.0 & 143.25 & -130.0 & 0.0 & & & \\
\hline 3 & 0.0 & 271.27 & -120.0 & 0.0 & & & \\
\hline 4 & 0.0 & 497.68 & -120.0 & 0.0 & & & \\
\hline 5 & 0.0 & 701.04 & -100.0 & 0.0 & & & \\
\hline 6 & 0.0 & 914.40 & -100.0 & 0.0 & & & \\
\hline 7 & 0.0 & 1127.76 & 0.0 & 0.0 & & & \\
\hline 8 & 0.0 & 1371.60 & 0.0 & 0.0 & & & \\
\hline 9 & 0.0 & 1463.04 & 0.0 & 0.0 & & & \\
\hline 10 & 0.0 & 1581.91 & 0.0 & 0.0 & & & \\
\hline$\$ 1$ & 0.0 & 1588.01 & 52.58 & 0.0 & & & \\
\hline 12 & $\begin{array}{ll}0 & 152.4\end{array}$ & 0.00 & -10.00 & 0.0 & & & \\
\hline 13 & $\begin{array}{ll}0 & 152.4\end{array}$ & 143.26 & -130.0 & 0.0 & & & \\
\hline 14 & $\begin{array}{ll}0 & 152.4\end{array}$ & 274.32 & -120.0 & 0.0 & & & \\
\hline 15 & $\begin{array}{ll}0 & 152.4\end{array}$ & 487.68 & -120.0 & 0.0 & & & \\
\hline 16 & $0 \quad 152.4$ & 701.04 & -100.0 & 0.0 & & & \\
\hline 17 & $\begin{array}{ll}0 & 152.4\end{array}$ & 914.40 & -100.0 & 0.0 & & & \\
\hline 18 & $\begin{array}{ll}0 & 152.4\end{array}$ & 1127.76 & 0.0 & 0.0 & & & \\
\hline 19 & 152.4 & 1371.60 & 0.0 & 0.0 & & & \\
\hline 20 & 152.4 & 1463.04 & 0.0 & 0.0 & & & \\
\hline 21 & 152.4 & 1581.91 & 0.0 & 0.0 & & & \\
\hline 22 & 152.4 & 1588.01 & 52.58 & 0.0 & & & \\
\hline 23 & 304.8 & 0.00 & -10.00 & 0.0 & & & \\
\hline 24 & $0 \quad 304.8$ & 143.26 & -130.0 & 0.0 & & & \\
\hline 25 & 0304.8 & 277.37 & -120.0 & 0.0 & & & \\
\hline 26 & 0304.8 & 197.68 & -120.0 & 0.0 & & & \\
\hline 27 & 0304.8 & 701.04 & -100.0 & 0.0 & & & \\
\hline 28 & $0 \quad 304.8$ & 914.40 & -100.0 & 0.0 & & & \\
\hline 29 & $\begin{array}{ll}0 & 304.8\end{array}$ & 1127.76 & 0.0 & 0.0 & & & \\
\hline 30 & 0304.8 & 1371.60 & 0.0 & 0.0 & & & \\
\hline
\end{tabular}




\begin{tabular}{|c|c|c|c|c|c|}
\hline 31 & 0 & 304.8 & 1463.04 & 0.0 & 0.0 \\
\hline 32 & 0 & 304.8 & 1581.91 & 0.0 & 0.0 \\
\hline 33 & 1 & 304.8 & 1588.01 & 52.58 & 0.0 \\
\hline 34 & 0 & 457.2 & 0.00 & -10.00 & 0.0 \\
\hline 35 & 0 & 457.2 & 143.26 & -130.0 & 0.0 \\
\hline 36 & 0 & 457.2 & 265.42 & -120.0 & 0.0 \\
\hline 37 & 0 & 457.2 & 487.68 & -120.0 & 0.0 \\
\hline 38 & 0 & 457.2 & 701.04 & -100.0 & 0.0 \\
\hline 39 & 0 & 457.2 & 914.40 & -100.0 & 0.0 \\
\hline 40 & 0 & 457.2 & 1127.76 & 0.0 & 0.0 \\
\hline 41 & 0 & 457.2 & 1371.60 & 0.0 & 0.0 \\
\hline 42 & 0 & 457.2 & 1463.04 & 0.0 & 0.0 \\
\hline 43 & 0 & 457.2 & 1581.91 & 0.0 & 0.0 \\
\hline 44 & 1 & 457.2 & 1588.01 & 52.58 & 0.0 \\
\hline 45 & 0 & 609.6 & 0.00 & -10.00 & 0.0 \\
\hline 16 & 0 & 609.6 & 143.26 & -130.0 & 0.0 \\
\hline 47 & 0 & 609.6 & 265.12 & -120.0 & 0.0 \\
\hline 48 & 0 & 609.6 & 487.68 & -120.0 & 0.0 \\
\hline 49 & 0 & 609.6 & 701.04 & -100.0 & 0.0 \\
\hline 50 & 0 & 609.6 & 914.40 & -100.0 & 0.0 \\
\hline 51 & 0 & 609.6 & 1127.76 & 0.0 & 0.0 \\
\hline 52 & 0 & 609.6 & 1371.60 & 0.0 & 0.0 \\
\hline 53 & 0 & 609.6 & 1466.09 & 0.0 & 0.0 \\
\hline 54 & 0 & 609.6 & 1581.91 & 0.0 & 0.0 \\
\hline 55 & 1 & 609.6 & 1588.01 & 52.58 & 0.0 \\
\hline 56 & 0 & 762.0 & 0.00 & -10.00 & 0.0 \\
\hline 57 & 0 & 762.0 & 144.78 & -130.0 & 0.0 \\
\hline 58 & 0 & 762.0 & 286.51 & -120.0 & 0.0 \\
\hline 59 & 0 & 762.0 & 492.25 & -120.0 & 0.0 \\
\hline 60 & 0 & 762.0 & 701.04 & -100.0 & 0.0 \\
\hline $6 !$ & 0 & 762.0 & 914,40 & -100.0 & 0.0 \\
\hline 62 & 0 & 762.0 & 1130.81 & 0.0 & 0.0 \\
\hline 63 & 0 & 762.0 & 1371.60 & 0.0 & 0.0 \\
\hline 64 & 0 & 762.0 & 1470.66 & 0.0 & 0.0 \\
\hline 65 & 0 & 762.0 & 1581.91 & 0.0 & 0.0 \\
\hline 66 & $i$ & 762.0 & 1588.01 & 52.58 & 0.0 \\
\hline 67 & 0 & 914.4 & 0.00 & -10.00 & 0.0 \\
\hline 68 & 0 & 914.4 & 149.35 & -130.0 & 0.0 \\
\hline 69 & 0 & 914.4 & 295.66 & -120.0 & 0.0 \\
\hline 70 & 0 & 914.4 & 496.82 & -120.0 & 0.0 \\
\hline 71 & 0 & 914.4 & 701.04 & -100.0 & 0.0 \\
\hline 72 & 0 & 914.4 & 914.40 & -100.0 & 0.0 \\
\hline 73 & 0 & 914.4 & 1133.86 & -100.0 & 0.0 \\
\hline 74 & 0 & 914.4 & 1371.60 & 0.0 & 0.0 \\
\hline 75 & 0 & 914.4 & 1475.23 & 0.0 & 0.0 \\
\hline 76 & 0 & 914.4 & 1581.91 & 0.0 & 0.0 \\
\hline 77 & 1 & 914.4 & 1588.01 & 52.58 & 0.0 \\
\hline 78 & 0 & 1066.8 & 0.00 & -10.00 & 0.0 \\
\hline
\end{tabular}




\begin{tabular}{|c|c|c|c|c|}
\hline 79 & 01066.8 & 152.40 & -130.0 & 0.0 \\
\hline 80 & 01066.8 & 304.65 & -120.0 & 0.0 \\
\hline 81 & 01066.8 & 501.40 & -120.0 & 0.0 \\
\hline 82 & 01066.8 & 701.04 & -100.0 & 0.0 \\
\hline 83 & 01066.8 & 914.40 & -100.0 & 0.0 \\
\hline 84 & 01066.8 & 1139.95 & -100.0 & 0.0 \\
\hline 85 & 01066.8 & 1371.60 & 0.0 & 0.0 \\
\hline $\begin{array}{l}86 \\
87\end{array}$ & $\begin{array}{ll}0 & 1066.8 \\
0 & 1066.8\end{array}$ & $\begin{array}{l}1479.80 \\
1581.91\end{array}$ & $\begin{array}{l}0.0 \\
0.0\end{array}$ & $\begin{array}{l}0.0 \\
0.0\end{array}$ \\
\hline 88 & 11066.8 & 1588.01 & 52.58 & 0.0 \\
\hline 89 & 01219.2 & 0.00 & -10.00 & 0.0 \\
\hline 90 & 01219.2 & 152.10 & -130.0 & 0.0 \\
\hline 91 & 01219.2 & 304.80 & -120.0 & 0.0 \\
\hline 92 & 01219.2 & 509.02 & -120.0 & 0.0 \\
\hline 93 & O 1219.2 & 707.14 & -100.0 & 0.0 \\
\hline 94 & 01219.2 & 914.40 & -100.0 & 0.0 \\
\hline 95 & 01219.2 & 1146.05 & -100.0 & 0.0 \\
\hline 96 & 01219.2 & 1371.60 & 0.0 & 0.0 \\
\hline 97 & 01219.2 & 1484.38 & 0.0 & 0.0 \\
\hline 98 & 01219.2 & 1581.91 & 0.0 & 0.0 \\
\hline 99 & 11219.2 & 1588.01 & 52.58 & 0.0 \\
\hline 100 & 01371.6 & 0.00 & -10.00 & 0.0 \\
\hline 101 & 01371.6 & 152.40 & -130.0 & 0.0 \\
\hline 102 & 01371.6 & 304.80 & -120.0 & 0.0 \\
\hline 103 & 01371.6 & 515.11 & -120.0 & 0.0 \\
\hline 104 & 01371.6 & 707.14 & -100.0 & 0.0 \\
\hline 105 & 01371.6 & 914.40 & -100.0 & 0.0 \\
\hline 106 & 01371.6 & 1152.14 & -100.0 & 0.0 \\
\hline 107 & 01371.6 & 1374.65 & 0.0 & 0.0 \\
\hline 108 & 01371.6 & 1488.95 & 0.0 & 0.0 \\
\hline 109 & 01371.6 & 1581.91 & 0.0 & 0.0 \\
\hline 110 & 11371.6 & 1588.01 & 52.58 & 0.0 \\
\hline 111 & 01524.0 & 0.00 & -10.00 & 0.0 \\
\hline 112 & 01524.0 & 152.40 & -130.0 & 0.0 \\
\hline 113 & 01524.0 & 307.85 & -120.0 & 0.0 \\
\hline 114 & 01524.0 & 518.16 & -120.0 & 0.0 \\
\hline 115 & 01524.0 & 716.28 & -100.0 & 0.0 \\
\hline 116 & 01524.0 & 914.40 & -100.0 & 0.0 \\
\hline 117 & 01524.0 & 1158.24 & -100.0 & 0.0 \\
\hline 118 & 01524.0 & 1377.70 & 0.0 & 0.0 \\
\hline 119 & 01524.0 & 1492.00 & 0.0 & 0.0 \\
\hline 120 & 01524.0 & 1581.91 & 0.0 & 0.0 \\
\hline 121 & 11524.0 & 1588.01 & 52.58 & 0.0 \\
\hline 122 & 01676.4 & 0.00 & -10.00 & 0.0 \\
\hline 123 & 01676.4 & 152.40 & -130.0 & 0.8 \\
\hline 124 & 01676.4 & 320.04 & -120.0 & 0.8 \\
\hline 125 & 01676.4 & 524.26 & -120.0 & 0.0 \\
\hline 126 & 01676.4 & 725.42 & -100.0 & 0.0 \\
\hline
\end{tabular}




\begin{tabular}{|c|c|c|c|c|}
\hline 127 & 01676.4 & 914.40 & -100.0 & 0.0 \\
\hline 128 & 01676.4 & 1161.29 & -100.0 & 0.0 \\
\hline 129 & 01676.4 & 1380.75 & 0.0 & 0.0 \\
\hline 130 & 01676.4 & 1493.52 & 0.0 & 0.0 \\
\hline 131 & 11676.4 & 1591.06 & 49.53 & 0.0 \\
\hline 132 & 01828.8 & 0.00 & -10.00 & 0.0 \\
\hline 133 & $0 \quad 1828.8$ & 156.97 & -132.0 & 0.0 \\
\hline 134 & 01828.8 & 323.09 & -120.0 & 0.0 \\
\hline 135 & 01828.8 & 530.35 & -120.0 & 0.0 \\
\hline 136 & 01828.8 & 728.47 & -100.0 & 0.0 \\
\hline 137 & 01828.8 & 914.40 & -100.0 & 0.0 \\
\hline 138 & 01829.8 & 1170.43 & -100.0 & 0.0 \\
\hline 139 & O 1828.8 & 1383.79 & 0.0 & 0.0 \\
\hline 140 & 01828.8 & 1499.62 & 0.0 & 0.0 \\
\hline $14 !$ & 11828.8 & 1597.15 & 43.43 & 0.0 \\
\hline 142 & 02133.6 & 0.00 & -10.00 & 0.0 \\
\hline 143 & 02133.6 & 161.54 & -134.0 & 0.0 \\
\hline 144 & 02133.6 & 335.28 & -120.0 & 0.0 \\
\hline 145 & 02133.6 & 536.45 & -120.0 & 0.0 \\
\hline 146 & 02133.6 & 731.52 & -100.0 & 0.0 \\
\hline 147 & 02133.6 & 914.40 & -100.0 & 0.0 \\
\hline 148 & 02133.6 & 1382.62 & -100.0 & 0.0 \\
\hline 149 & 02133.6 & 1392.94 & 0.0 & 0.0 \\
\hline 150 & 02133.6 & 1505.71 & 0.0 & 0.0 \\
\hline 151 & 12133.6 & 1603.25 & 37.34 & 0.0 \\
\hline 152 & 02438.4 & 0.00 & -10.00 & 0.0 \\
\hline 153 & 02438.4 & 167.64 & -140.0 & 0.0 \\
\hline 154 & 02439.4 & 335.28 & -120.0 & 0.0 \\
\hline 155 & 02438.4 & 542.54 & -120.0 & 0.0 \\
\hline 156 & 02438.4 & 731.52 & -100.0 & 0.0 \\
\hline 157 & 02438.4 & 914.40 & -100.0 & 0.0 \\
\hline 158 & 02438.4 & 1188.72 & -100.0 & 0.0 \\
\hline 159 & O 2438.4 & 1402.08 & -95.00 & 0.0 \\
\hline 160 & 02438.4 & 1511.81 & 0.0 & 0.0 \\
\hline 161 & 12438.4 & 1612.39 & 28.19 & 0.0 \\
\hline 162 & 02743.2 & 0.00 & -10.00 & 0.0 \\
\hline 163 & O 2743.2 & 173.74 & -146.0 & 0.0 \\
\hline 164 & 02743.2 & 350.52 & -120.0 & 0.0 \\
\hline 165 & 02743.2 & 551.69 & -120.0 & 0.0 \\
\hline 166 & O 2743.2 & 731.52 & -100.0 & 0.0 \\
\hline 167 & O 2743.2 & 914.40 & -100.0 & 0.0 \\
\hline 168 & O 2743.2 & 1194.82 & -100.0 & 0.0 \\
\hline 169 & 02743.2 & 1411.22 & -95.00 & 0.0 \\
\hline 170 & 02743.2 & 1517.90 & 0.0 & 0.0 \\
\hline 171 & 12743.2 & 1621.54 & 19.05 & 0.0 \\
\hline 172 & 03048.0 & 0.00 & -10.00 & 0.0 \\
\hline 173 & 03048.0 & 179.83 & -150.0 & 0.0 \\
\hline 174 & 03048.0 & 365.76 & -120.0 & 0.0 \\
\hline
\end{tabular}




\begin{tabular}{|c|c|c|c|c|}
\hline 175 & 03048.0 & 566.93 & -120.0 & 0.0 \\
\hline 176 & 03048.0 & 734.57 & -100.0 & 0.0 \\
\hline 177 & 03048.0 & 914.40 & -100.0 & 0.0 \\
\hline 178 & 03048.0 & 1005.84 & -60.00 & 0.0 \\
\hline 179 & 03048.0 & 1207.01 & -150.0 & 0.0 \\
\hline 180 & 03048.0 & 1424.94 & -95.00 & 0.0 \\
\hline 181 & 03048.0 & 1524.00 & 0.0 & 0.0 \\
\hline 182 & 13048.0 & 1629.16 & 11.43 & 0.0 \\
\hline 183 & 03200.4 & 0.00 & -10.00 & 0.0 \\
\hline 184 & 03200.4 & 182.88 & -150.0 & 0.0 \\
\hline 185 & 03200.4 & 371.86 & -120.0 & 0.0 \\
\hline 186 & 03200.4 & 487.68 & -120.0 & 0.0 \\
\hline 187 & 03200.4 & 573.02 & -120.0 & 0.0 \\
\hline 188 & 03200.4 & 737.62 & -100.0 & 0.0 \\
\hline 189 & 03200.4 & 914.40 & -60.00 & 0.0 \\
\hline 190 & 03200.4 & 1005.84 & -60.00 & 0.0 \\
\hline 191 & 03200.4 & 1097.28 & -60.00 & 0.0 \\
\hline 192 & 03200.4 & 1213.10 & -150.0 & 0.0 \\
\hline 193 & 03200.4 & 1429.51 & -95.00 & 0.0 \\
\hline 194 & 03200.4 & 1527.05 & 0.0 & 0.0 \\
\hline 195 & 13200.4 & 1633.73 & 6.86 & 0.0 \\
\hline 196 & 03474.7 & 0.00 & -10.00 & 0.0 \\
\hline 197 & 03474.7 & 182.88 & -150.0 & 0.0 \\
\hline 198 & 03474.7 & 372.77 & -120.0 & 0.0 \\
\hline 199 & 03474.7 & 187.68 & -90.00 & 0.0 \\
\hline 200 & 03429.0 & 579.12 & -120.0 & 0.0 \\
\hline 201 & $0 \quad 3352.8$ & 740.66 & -85.00 & 0.0 \\
\hline 202 & 03352.8 & 914.40 & -60.00 & 0.0 \\
\hline 203 & o 3352.8 & 1005.84 & -60.00 & 0.0 \\
\hline 204 & o 3352.8 & 1097.28 & -60.00 & 0.0 \\
\hline 205 & 03352.8 & 1219.20 & -150.0 & 0.0 \\
\hline 206 & 03352.8 & 1432.56 & -95.00 & 0.0 \\
\hline 207 & 03352.8 & 1530.10 & 00.0 & 0.0 \\
\hline 208 & 13352.8 & 1611.35 & 0.00 & 0.0 \\
\hline 209 & o 3535.7 & 0.00 & -10.00 & 0.0 \\
\hline 210 & 03535.7 & 182.88 & -150.0 & 0.0 \\
\hline 211 & 03535.7 & 377.95 & -120.0 & 0.0 \\
\hline 212 & o 3535.7 & 457.20 & -100.0 & 0.0 \\
\hline 213 & 03535.7 & 518.16 & -80.00 & 0.0 \\
\hline 214 & 03514.3 & 583.69 & -120.0 & 0.0 \\
\hline 215 & 03505.2 & 743.71 & -85.00 & 0.0 \\
\hline 216 & 03503.2 & 914.40 & -60.00 & 0.0 \\
\hline 217 & 03505.2 & 1005.84 & -60.00 & 0.0 \\
\hline 218 & 03505.2 & 1097.28 & -60.00 & 0.0 \\
\hline 219 & 03505.2 & 1222.25 & -150.0 & 0.0 \\
\hline 220 & 03505.2 & 1435.61 & -95.00 & 0.0 \\
\hline $22 !$ & 03505.2 & 1533.14 & -95.00 & 0.0 \\
\hline 222 & 13505.2 & 1645.92 & 00.0 & 0.0 \\
\hline
\end{tabular}




\begin{tabular}{|c|c|c|c|c|}
\hline 223 & 03657.6 & 0.00 & -10.00 & 0.0 \\
\hline 224 & 03657.6 & 182.88 & -150.0 & 0.0 \\
\hline 225 & 03657.6 & 381.00 & -120.0 & 0.0 \\
\hline 226 & 03657.6 & 457.20 & -100.0 & 0.0 \\
\hline 227 & 03657.6 & 518.16 & -80.00 & 0.0 \\
\hline 228 & 03657.6 & 588.26 & -120.0 & 0.0 \\
\hline 22 & 03657.6 & 746.76 & -85.00 & 0.0 \\
\hline 230 & 03657.6 & 914.40 & -60.00 & 0.0 \\
\hline 31 & 03657.6 & 1005.84 & -60.00 & 0.0 \\
\hline 232 & 03657.6 & 1097.28 & -60.00 & 0.0 \\
\hline 233 & 03657.6 & 1225.30 & -150.0 & 0.0 \\
\hline 234 & 03657.6 & 1435.61 & -95.00 & 0.0 \\
\hline 235 & 03657.6 & 1536.19 & -95.00 & 0.0 \\
\hline 23 & 13657.6 & 1648.97 & 00.0 & 0.0 \\
\hline 23 & 03779.5 & 0.00 & -10.00 & 0.0 \\
\hline 238 & 03779.5 & 188.98 & -155.0 & 0.0 \\
\hline 239 & 03779.5 & 390.14 & -122.0 & 0.0 \\
\hline 240 & 037779.5 & 457.20 & -100.0 & 0.0 \\
\hline 241 & 03779.5 & 518.16 & -80.00 & 0.0 \\
\hline 242 & 03788.7 & 594.36 & -120.0 & 0.0 \\
\hline 243 & 03910.0 & 752.86 & -85.00 & 0.0 \\
\hline 244 & 03810.0 & 914.40 & -60.00 & 0.0 \\
\hline 245 & 03810.0 & 1005.84 & -60.00 & 0.0 \\
\hline 246 & 03810.0 & 1097.28 & -60.00 & 0.0 \\
\hline 247 & 03810.0 & 1222.25 & -150.0 & 0.0 \\
\hline 248 & 03810.0 & 1437.13 & -95.00 & 0.0 \\
\hline 249 & 03810.0 & 1539.24 & -95.00 & 0.0 \\
\hline 250 & 13810.0 & 1648.97 & 00.0 & 0.0 \\
\hline 251 & 03840.5 & 0.00 & -10.00 & 0.0 \\
\hline 252 & 03840.5 & 195.07 & -155.0 & 0.0 \\
\hline 253 & 03840.5 & 393.19 & -122.0 & 0.0 \\
\hline 254 & 03840.5 & 487.68 & -90.00 & 0.0 \\
\hline 255 & 03886.2 & 600.46 & -120.0 & 0.0 \\
\hline 256 & 03962.1 & 757.43 & -85.00 & 0.0 \\
\hline 257 & 03962.4 & 922.02 & -60.00 & 0.0 \\
\hline 258 & 03962.4 & 1005.84 & -60.00 & 0.0 \\
\hline 259 & 03962.4 & 1097.28 & -60.00 & 0.0 \\
\hline 260 & 03962.4 & 1219.20 & -150.0 & 0.0 \\
\hline 261 & 03962.4 & 1438.66 & -95.00 & 0.0 \\
\hline 262 & 03962.4 & 1542.29 & -95.00 & 0.0 \\
\hline 263 & 13962.4 & 1650.49 & 00.0 & 0.0 \\
\hline 264 & 04114.8 & 0.00 & -10.00 & 0.0 \\
\hline 265 & 01114.8 & 213.36 & -165.0 & 0.0 \\
\hline 266 & 04114.8 & 408.43 & -124.0 & 0.0 \\
\hline 267 & 01114.8 & 487.68 & -120.0 & 0.0 \\
\hline 268 & 04114.8 & 609.60 & -120.0 & 0.0 \\
\hline 269 & 04114.8 & 760.48 & -85.00 & 0.0 \\
\hline 270 & 04114.8 & 929.64 & -60.00 & 0.0 \\
\hline
\end{tabular}




\begin{tabular}{|c|c|c|c|c|}
\hline 271 & 04114.8 & 1005.84 & -60.00 & 0.0 \\
\hline 272 & 04114.8 & 1097.28 & -60.00 & 0.0 \\
\hline 273 & 04114.8 & 1219.20 & -150.0 & 0.0 \\
\hline 274 & 04114.8 & 1440.18 & -95.00 & 0.0 \\
\hline 275 & 04114.8 & 1545.34 & -95.00 & 0.0 \\
\hline 276 & 14114.8 & 1652.02 & 00.0 & 0.0 \\
\hline 277 & 04267.2 & 0.00 & -10.00 & 0.0 \\
\hline 278 & 04267.2 & 219.46 & -165.0 & 0.0 \\
\hline 279 & 04267.2 & 426.72 & -124.0 & 0.0 \\
\hline 280 & 04267.2 & 612.65 & -120.0 & 0.0 \\
\hline 281 & 04267.2 & 762.00 & -85.00 & 0.0 \\
\hline 282 & 04267.2 & 937.26 & -90.00 & 0.0 \\
\hline 283 & 04267.2 & 1005.84 & -60.00 & 0.0 \\
\hline 284 & 04267.2 & 1219.20 & -150.0 & 0.0 \\
\hline 285 & 04267.2 & 1441.70 & -95.00 & 0.0 \\
\hline 286 & $0 \$ 267.2$ & 1548.38 & -95.00 & 0.0 \\
\hline 287 & 14267.2 & 1653.54 & 00.0 & 0.0 \\
\hline 288 & 04572.0 & 0.00 & -10.00 & 0.0 \\
\hline 289 & 04572.0 & 237.74 & -165.0 & 0.0 \\
\hline 290 & 04572.0 & 451.10 & -126.0 & 0.0 \\
\hline 291 & 04572.0 & 624.84 & -120.0 & 0.0 \\
\hline 292 & 04572.0 & 762.00 & -100.0 & 0.0 \\
\hline 293 & 04572.0 & 944.88 & -100.0 & 0.0 \\
\hline 294 & 04572.0 & 1219.20 & -100.0 & 0.0 \\
\hline 295 & 04572.0 & 1446.28 & -95.00 & 0.0 \\
\hline 296 & 04572.0 & 1551.43 & -95.00 & 0.0 \\
\hline 297 & 14572.0 & 1656.59 & 00.0 & 0.0 \\
\hline 298 & 04876.8 & 0.00 & -10.00 & 0.0 \\
\hline 299 & 04876.8 & 243.84 & -180.0 & 0.0 \\
\hline 300 & 04976.8 & 172.14 & -126.0 & 0.0 \\
\hline 301 & 04876.8 & 640.08 & -120.0 & 0.0 \\
\hline 302 & 04876.8 & 768.10 & -100.0 & 0.0 \\
\hline 303 & 04876.8 & 947.93 & -100.0 & 0.0 \\
\hline 304 & 01976.8 & 1219.20 & -100.0 & 0.0 \\
\hline 305 & 04876.8 & 1450.85 & -95.00 & 0.0 \\
\hline 306 & 04876.8 & 1554.48 & -95.00 & 0.0 \\
\hline 307 & 14876.8 & 1659.64 & 00.0 & 0.0 \\
\hline 308 & 05181.6 & 0.00 & -10.00 & 0.0 \\
\hline 309 & 05181.6 & 259.08 & -180.0 & 0.0 \\
\hline 310 & 05181.6 & 499.87 & -126.0 & 0.0 \\
\hline 311 & 05181.6 & 649.22 & -120.0 & 0.0 \\
\hline 312 & 05181.6 & 780.29 & -100.0 & 0.0 \\
\hline 313 & 05181.6 & 950.98 & -100.0 & 0.0 \\
\hline 314 & 05181.6 & 1219.20 & -100.0 & 0.0 \\
\hline 315 & 05181.6 & 1456.94 & -95.00 & 0.0 \\
\hline 316 & 05181.6 & 1557.53 & -95.00 & 0.0 \\
\hline 317 & 15181.6 & 1662.68 & 00.0 & 0.0 \\
\hline 318 & 05486.4 & 0.00 & -10.00 & 0.0 \\
\hline
\end{tabular}




\begin{tabular}{|c|c|c|c|c|}
\hline 319 & 05486.4 & 274.32 & -180.0 & 0.0 \\
\hline 320 & 05486.4 & 518.16 & -126.0 & 0.0 \\
\hline 321 & 05486.4 & 659.89 & -120.0 & 0.0 \\
\hline 322 & o 5486.4 & 792.48 & -100.0 & 0.0 \\
\hline 223 & 05486.4 & 954.02 & -100.0 & 0.0 \\
\hline 324 & 05486.4 & 1219.20 & -100.0 & 0.0 \\
\hline 325 & 05486.4 & 1463.04 & -95.00 & 0.0 \\
\hline 326 & 05486.4 & 1560.58 & -95.00 & 0.0 \\
\hline 327 & 15486.4 & 1665.73 & 00.0 & 0.0 \\
\hline 328 & 05791.2 & 0.00 & -10.00 & 0.0 \\
\hline 329 & 05791.2 & 289.56 & -180.0 & 0.0 \\
\hline 330 & 05791.2 & 548.64 & -126.0 & 0.0 \\
\hline 331 & 05791.2 & 670.56 & -120.0 & 0.0 \\
\hline 332 & 05791.2 & 792.48 & -100.0 & 0.0 \\
\hline 333 & 05791.2 & 957.07 & -100.0 & 0.0 \\
\hline 334 & 05791.2 & 1219.20 & -100.0 & 0.0 \\
\hline 335 & 05791.2 & 1466.09 & -95.00 & 0.0 \\
\hline 336 & 05791.2 & 1563.62 & -95.00 & 0.0 \\
\hline 337 & 15791.2 & 1668.78 & 00.0 & 0.0 \\
\hline 338 & 06096.0 & 0.00 & -10.00 & 0.0 \\
\hline 339 & 06096.0 & 304.80 & -180.0 & 0.0 \\
\hline 340 & 06096.0 & 569.98 & -126.0 & 0.0 \\
\hline 341 & 06096.0 & 685.80 & -120.0 & 0.0 \\
\hline 342 & 06096.0 & 795.53 & -100.0 & 0.0 \\
\hline 343 & 06096.0 & 960.12 & -100.0 & 0.0 \\
\hline 344 & 06096.0 & 1219.20 & -100.0 & 0.0 \\
\hline 345 & 06096.0 & 1469.14 & -95.00 & 0.0 \\
\hline 346 & 06096.0 & 1568.20 & -95.00 , & 0.0 \\
\hline 347 & 16096.0 & 1671.83 & 00.0 & 0.0 \\
\hline 348 & 06400.8 & 0.00 & -10.00 & 0.0 \\
\hline 349 & 06400.8 & 320.04 & -180.0 & 0.0 \\
\hline 350 & 06400.8 & 591.31 & -126.0 & 0.0 \\
\hline 351 & 06400.8 & 701.04 & -120.0 & 0.0 \\
\hline 352 & 06400.8 & 804.67 & -100.0 & 0.0 \\
\hline 353 & 06400.8 & 963.17 & -100.0 & 0.0 \\
\hline 354 & 06400.8 & 1219.20 & -100.0 & 0.0 \\
\hline 355 & 06400.8 & 1472.18 & -95.00 & 0.0 \\
\hline 356 & 06400.8 & 1572.77 & -95.00 & 0.0 \\
\hline 357 & 16400.8 & 1674.88 & 00.0 & 0.0 \\
\hline 358 & 06705.6 & 0.00 & -10.00 & 0.0 \\
\hline 359 & 06705.6 & 335.28 & -180.0 & 0.0 \\
\hline 360 & 06705.6 & 615.70 & -126.0 & 0.0 \\
\hline 361 & 06705.6 & 716.28 & -120.0 & 0.0 \\
\hline 362 & 06705.6 & 816.86 & -100.0 & 0.0 \\
\hline 363 & 06705.6 & 966.22 & -100.0 & 0.0 \\
\hline 364 & 06705.6 & 1219.20 & -100.0 & 0.0 \\
\hline 365 & 06705.6 & 1475.23 & -95.00 & 0.0 \\
\hline 366 & 06705.6 & 1577.34 & -95.00 & 0.0 \\
\hline
\end{tabular}




\begin{tabular}{|c|c|c|c|c|}
\hline 367 & 16705.6 & 1677.92 & 00.0 & 0.0 \\
\hline 368 & 07010.4 & 0.00 & -10.00 & 0.0 \\
\hline 369 & 07010.4 & 152.40 & -121.0 & 0.0 \\
\hline 370 & 07010.4 & 353.57 & -70.00 & 0.0 \\
\hline 371 & 07010.4 & 518.16 & -120.0 & 0.0 \\
\hline 372 & 07010.4 & 680.08 & -126.0 & 0.0 \\
\hline 373 & 07010.4 & 731.52 & -120.0 & 0.0 \\
\hline 374 & 07010.4 & 822.96 & -100.0 & 0.0 \\
\hline 375 & 07010.4 & 969.26 & -100.0 & 0.0 \\
\hline 376 & 07010.4 & 1219.20 & -100.0 & 0.0 \\
\hline 377 & 07010.4 & 1478.28 & -95.00 & 0.0 \\
\hline 378 & 07010.4 & 1580.39 & -95.00 & 0.0 \\
\hline 379 & 17010.4 & 1680.97 & 00.0 & 0.0 \\
\hline 380 & 07162.8 & 0.00 & -10.00 & 0.0 \\
\hline 381 & 07162.8 & 152.40 & -121.0 & 0.0 \\
\hline 382 & 07162.8 & 304.80 & -70.00 & 0.0 \\
\hline 383 & 07162.8 & 365.76 & -70.00 & 0.0 \\
\hline 384 & 07162.8 & 426.72 & -70.00 & 0.0 \\
\hline 385 & 07162.8 & 518.16 & -120.0 & 0.0 \\
\hline 386 & 07162.8 & 649.22 & -126.0 & 0.0 \\
\hline 387 & 07162.8 & 736.09 & -120.0 & 0.0 \\
\hline 388 & 07162.8 & 822.96 & -100.0 & 0.0 \\
\hline 389 & 07162.8 & 972.31 & -100.0 & 0.0 \\
\hline 390 & 07162.8 & 1219.20 & -100.0 & 0.0 \\
\hline 391 & 07162.8 & 1481.33 & -95.00 & 0.0 \\
\hline 392 & 07162.8 & 1581.91 & -95.00 & 0.0 \\
\hline 393 & 17162.8 & 1692.50 & 00.0 & 0.0 \\
\hline 394 & 07376.2 & 0.00 & -10.00 & 0.0 \\
\hline 395 & 07376.2 & 152.40 & -121.0 & 0.0 \\
\hline 396 & 07376.2 & 304.80 & -70.00 & 0.0 \\
\hline 397 & 07376.2 & 365.76 & -70.00 & 0.0 \\
\hline 398 & 07376.2 & 426.72 & -70.00 & 0.0 \\
\hline 399 & 07376.2 & 518.16 & -120.0 & 0.0 \\
\hline 100 & 07376.2 & 670.56 & -126.0 & 0.0 \\
\hline 401 & 07376.2 & 746.76 & -120.0 & 0.0 \\
\hline 402 & 07376.2 & 822.96 & -100.0 & 0.0 \\
\hline 403 & 07376.2 & 975.36 & -100.0 & 0.0 \\
\hline 404 & 07376.2 & 1219.20 & -100.0 & 0.0 \\
\hline 405 & 07376.2 & 1497.42 & -95.00 & 0.0 \\
\hline 106 & 07376.2 & 1584.96 & -95.00 & 0.0 \\
\hline 107 & 17376.2 & 1685.51 & 00.0 & 0.0 \\
\hline 408 & 07559.0 & 0.00 & -10.00 & 0.0 \\
\hline 409 & 07559.0 & 152.40 & -121.0 & 0.0 \\
\hline 410 & 07559.0 & 304.80 & -70.00 & 0.0 \\
\hline 411 & 07559.0 & 365.76 & -70.00 & 0.0 \\
\hline 412 & 07559.0 & 126.72 & -70.00 & 0.0 \\
\hline 413 & 07559.0 & 518.16 & -120.0 & 0.0 \\
\hline 414 & O 7559.0 & 655.32 & -126.0 & 0.0 \\
\hline
\end{tabular}




\begin{tabular}{|c|c|c|c|c|}
\hline 415 & 07559.0 & 746.76 & -120.0 & 0.0 \\
\hline 116 & 07559.0 & 822.96 & -100.0 & 0.0 \\
\hline 417 & 07559.0 & 975.36 & -100.0 & 0.0 \\
\hline 418 & 07559.0 & 1219.20 & -100.0 & 0.0 \\
\hline 419 & o 7559.0 & 1487.42 & -95.00 & 0.0 \\
\hline 120 & o 7559.0 & 1584.96 & -95.00 & 0.0 \\
\hline 421 & 17559.0 & 1685.54 & 00.0 & 0.0 \\
\hline 422 & 07711.4 & 0.00 & -10.00 & 0.0 \\
\hline 423 & 07711.4 & 152.40 & -121.0 & 0.0 \\
\hline 424 & 07711.4 & 365.76 & -70.00 & 0.0 \\
\hline 125 & 07711.4 & 518.16 & -120.0 & 0.0 \\
\hline $42 \mathrm{~b}$ & 07711.4 & 680.08 & -126.0 & 0.0 \\
\hline 427 & 07711.4 & 731.52 & -120.0 & 0.0 \\
\hline 428 & 07711.4 & 822.96 & -100.0 & 0.0 \\
\hline 429 & 07711.4 & 975.36 & -100.0 & 0.0 \\
\hline 430 & 07711.4 & 1219.20 & -100.0 & 0.0 \\
\hline 431 & 07711.4 & 1487.42 & -95.00 & 0.0 \\
\hline 432 & o 7711.4 & $1584.9 b$ & -95.00 & 0.0 \\
\hline 433 & 17711.4 & 1685.54 & 00.0 & 0.0 \\
\hline 434 & 07924.8 & 0.00 & -10.00 & 0.0 \\
\hline 435 & 07924.8 & 365.76 & -180.0 & 0.0 \\
\hline 436 & 07924.8 & 680.08 & -126.0 & 0.0 \\
\hline 437 & 07924.8 & 731.52 & -120.0 & 0.0 \\
\hline 438 & 07924.8 & 822.96 & -100.0 & 0.0 \\
\hline 439 & 07924.8 & 975.36 & -100.0 & 0.0 \\
\hline 440 & 07924.8 & 1219.20 & -100.0 & 0.0 \\
\hline 441 & 07924.8 & 1487.12 & -95.00 & 0.0 \\
\hline 442 & 07924.8 & 1584.96 & -95.00 & 0.0 \\
\hline 443 & 17924.8 & 1685.54 & 00.0 & 0.0 \\
\hline 1 & $1 \quad 12$ & $13 \quad 2$ & 3 & \\
\hline 2 & 213 & 14 & 3 & \\
\hline 3 & 314 & 15 & 4 & \\
\hline 4 & 15 & 16 & 4 & \\
\hline 5 & 16 & 17 & 3 & \\
\hline 6 & 17 & 18 & 3 & \\
\hline 7 & 18 & 19 & 3 & \\
\hline 8 & 19 & 20 & 2 & \\
\hline 9 & 20 & 21 & 2 & \\
\hline 10 & 21 & 22 & 1 & \\
\hline 11 & 12 & 24 & 3 & \\
\hline 12 & 24 & 25 & 3 & \\
\hline 13 & 14 & 26 & 4 & \\
\hline 14 & $15 \quad 26$ & 16 & 4 & \\
\hline 15 & 27 & 17 & 3 & \\
\hline 16 & 28 & 18 & 3 & \\
\hline 17 & 18 & 19 & 3 & \\
\hline 18 & 19 & 20 & 2 & \\
\hline 19 & 20 & $32 \quad 21$ & 2 & \\
\hline
\end{tabular}




$\begin{array}{llllll}20 & 21 & 32 & 33 & 22 & 1 \\ 21 & 23 & 34 & 35 & 24 & 3 \\ 22 & 24 & 35 & 36 & 25 & 3 \\ 23 & 25 & 36 & 37 & 26 & 4 \\ 24 & 26 & 37 & 38 & 27 & 4 \\ 25 & 27 & 38 & 39 & 28 & 3 \\ 26 & 28 & 39 & 40 & 29 & 3 \\ 27 & 29 & 40 & 41 & 30 & 3 \\ 28 & 30 & 41 & 42 & 31 & 2 \\ 29 & 31 & 42 & 43 & 32 & 2 \\ 30 & 32 & 43 & 44 & 33 & 1 \\ 31 & 34 & 45 & 46 & 35 & 3 \\ 32 & 35 & 46 & 47 & 36 & 3 \\ 33 & 36 & 47 & 48 & 37 & 4 \\ 34 & 37 & 48 & 49 & 38 & 1 \\ 35 & 38 & 49 & 50 & 39 & 3 \\ 36 & 39 & 50 & 51 & 40 & 3 \\ 37 & 40 & 51 & 52 & 41 & 3 \\ 38 & 41 & 52 & 53 & 42 & 2 \\ 39 & 42 & 53 & 54 & 43 & 2 \\ 40 & 43 & 54 & 55 & 41 & 1 \\ 41 & 45 & 56 & 57 & 46 & 3 \\ 42 & 46 & 57 & 58 & 47 & 3 \\ 43 & 47 & 59 & 59 & 48 & 1 \\ 44 & 48 & 59 & 60 & 49 & 4 \\ 45 & 49 & 60 & 61 & 50 & 3 \\ 46 & 50 & 61 & 62 & 51 & 3 \\ 47 & 51 & 62 & 63 & 52 & 3 \\ 48 & 52 & 63 & 64 & 53 & 2 \\ 49 & 53 & 64 & 65 & 54 & 2 \\ 50 & 54 & 65 & 66 & 55 & 1 \\ 51 & 56 & 67 & 68 & 57 & 3 \\ 52 & 57 & 68 & 69 & 58 & 3 \\ 53 & 58 & 69 & 70 & 59 & 4 \\ 54 & 59 & 70 & 71 & 60 & 4 \\ 55 & 60 & 71 & 72 & 61 & 3 \\ 56 & 61 & 72 & 73 & 62 & 3 \\ 57 & 62 & 73 & 74 & 63 & 3 \\ 58 & 63 & 74 & 75 & 64 & 2 \\ 59 & 64 & 75 & 76 & 65 & 2 \\ 60 & 65 & 76 & 77 & 66 & 1 \\ 61 & 67 & 78 & 79 & 68 & 3 \\ 62 & 68 & 79 & 80 & 69 & 3 \\ 63 & 69 & 80 & 81 & 70 & 4 \\ 64 & 70 & 81 & 82 & 71 & 4 \\ 65 & 71 & 82 & 83 & 72 & 3 \\ 66 & 72 & 83 & 84 & 73 & 3 \\ 67 & 73 & 84 & 85 & 74 & 3\end{array}$




$\begin{array}{cccccc}68 & 71 & 85 & 96 & 75 & 2 \\ 69 & 75 & 86 & 97 & 76 & 2 \\ 70 & 76 & 87 & 88 & 77 & 1 \\ 71 & 78 & 89 & 90 & 79 & 3 \\ 72 & 79 & 90 & 91 & 80 & 3 \\ 73 & 80 & 91 & 92 & 81 & 4 \\ 74 & 91 & 92 & 93 & 82 & 4 \\ 75 & 92 & 93 & 94 & 83 & 3 \\ 76 & 83 & 94 & 95 & 84 & 3 \\ 77 & 84 & 95 & 96 & 85 & 3 \\ 78 & 85 & 96 & 97 & 86 & 2 \\ 79 & 86 & 97 & 98 & 87 & 2 \\ 80 & 87 & 98 & 99 & 88 & 1 \\ 81 & 89 & 100 & 101 & 90 & 3 \\ 82 & 90 & 101 & 102 & 91 & 3 \\ 83 & 91 & 102 & 103 & 92 & 1 \\ 94 & 92 & 103 & 104 & 93 & 1 \\ 85 & 93 & 104 & 105 & 91 & 3 \\ 86 & 94 & 105 & 106 & 95 & 3 \\ 87 & 95 & 106 & 107 & 96 & 3 \\ 88 & 96 & 107 & 108 & 97 & 2 \\ 89 & 97 & 108 & 109 & 98 & 2 \\ 90 & 98 & 109 & 110 & 99 & 1 \\ 91 & 100 & 111 & 112 & 101 & 3 \\ 92 & 101 & 112 & 113 & 102 & 3 \\ 93 & 102 & 113 & 114 & 103 & 4 \\ 94 & 103 & 114 & 115 & 104 & 4 \\ 95 & 104 & 115 & 116 & 105 & 3 \\ 96 & 105 & 116 & 117 & 106 & 3 \\ 97 & 106 & 117 & 118 & 107 & 3 \\ 98 & 107 & 119 & 119 & 108 & 2 \\ 99 & 108 & 119 & 120 & 109 & 2 \\ 100 & 109 & 120 & 121 & 110 & 1 \\ 101 & 111 & 122 & 123 & 112 & 3 \\ 102 & 112 & 123 & 124 & 113 & 3 \\ 103 & 113 & 124 & 125 & 114 & 1 \\ 104 & 114 & 125 & 126 & 115 & 1 \\ 105 & 115 & 126 & 127 & 116 & 3 \\ 106 & 116 & 127 & 129 & 117 & 3 \\ 107 & 117 & 128 & 129 & 118 & 3 \\ 108 & 118 & 129 & 130 & 119 & 2 \\ 109 & 119 & 130 & 120 & 120 & 2 \\ 110 & 120 & 130 & 131 & 131 & 2 \\ 111 & 120 & 131 & 121 & 121 & 2 \\ 112 & 122 & 132 & 133 & 123 & 3 \\ 113 & 123 & 133 & 134 & 124 & 3 \\ 114 & 124 & 134 & 135 & 125 & 1 \\ 115 & 125 & 135 & 136 & 126 & 1 \\ 9 & & & & \end{array}$




$\begin{array}{llllll}116 & 126 & 136 & 137 & 127 & 3 \\ 117 & 127 & 137 & 138 & 128 & 3 \\ 118 & 128 & 138 & 139 & 129 & 3 \\ 119 & 129 & 139 & 140 & 130 & 2 \\ 120 & 130 & 140 & 141 & 131 & 2 \\ 121 & 132 & 142 & 143 & 133 & 3 \\ 122 & 133 & 143 & 144 & 134 & 3 \\ 123 & 134 & 144 & 145 & 135 & 1 \\ 124 & 135 & 145 & 146 & 136 & 1 \\ 125 & 136 & 146 & 147 & 137 & 3 \\ 126 & 137 & 147 & 148 & 138 & 3 \\ 127 & 138 & 148 & 149 & 139 & 3 \\ 128 & 139 & 149 & 150 & 140 & 2 \\ 129 & 140 & 150 & 151 & 141 & 2 \\ 130 & 142 & 152 & 153 & 143 & 3 \\ 131 & 143 & 153 & 154 & 144 & 3 \\ 132 & 144 & 154 & 155 & 145 & 4 \\ 133 & 145 & 155 & 156 & 146 & 4 \\ 134 & 146 & 156 & 157 & 147 & 3 \\ 135 & 147 & 157 & 158 & 149 & 3 \\ 136 & 148 & 158 & 159 & 149 & 3 \\ 137 & 149 & 159 & 160 & 150 & 2 \\ 138 & 150 & 160 & 161 & 151 & 2 \\ 139 & 152 & 162 & 163 & 153 & 3 \\ 140 & 153 & 163 & 164 & 154 & 3 \\ 141 & 154 & 164 & 165 & 155 & 4 \\ 142 & 155 & 165 & 166 & 156 & 4 \\ 143 & 156 & 166 & 167 & 157 & 3 \\ 144 & 157 & 167 & 168 & 158 & 3 \\ 145 & 158 & 168 & 169 & 159 & 3 \\ 146 & 159 & 169 & 170 & 160 & 2 \\ 147 & 160 & 170 & 171 & 161 & 2 \\ 148 & 162 & 172 & 173 & 163 & 3 \\ 149 & 163 & 173 & 174 & 164 & 3 \\ 150 & 164 & 174 & 175 & 165 & 4 \\ 151 & 165 & 175 & 176 & 166 & 1 \\ 152 & 166 & 176 & 177 & 167 & 3 \\ 153 & 167 & 177 & 178 & 178 & 3 \\ 154 & 167 & 178 & 168 & 168 & 3 \\ 155 & 168 & 178 & 179 & 179 & 3 \\ 156 & 168 & 179 & 180 & 169 & 3 \\ 157 & 169 & 180 & 181 & 170 & 2 \\ 158 & 170 & 181 & 192 & 171 & 2 \\ 159 & 172 & 183 & 184 & 173 & 3 \\ 160 & 173 & 184 & 185 & 174 & 3 \\ 161 & 174 & 185 & 186 & 186 & 4 \\ 162 & 174 & 186 & 175 & 175 & 4 \\ 163 & 175 & 186 & 187 & 187 & 1 \\ & & & & & \end{array}$




$\begin{array}{llllll}164 & 175 & 187 & 198 & 176 & 4 \\ 165 & 176 & 188 & 199 & 177 & 3 \\ 166 & 177 & 189 & 178 & 178 & 3 \\ 167 & 178 & 189 & 190 & 190 & 4 \\ 168 & 178 & 190 & 191 & 191 & 4 \\ 169 & 178 & 191 & 192 & 179 & 3 \\ 170 & 179 & 192 & 193 & 180 & 3 \\ 171 & 180 & 193 & 194 & 181 & 2 \\ 172 & 181 & 194 & 195 & 182 & 2 \\ 173 & 183 & 196 & 197 & 184 & 3 \\ 174 & 184 & 197 & 198 & 185 & 3 \\ 175 & 185 & 199 & 199 & 186 & 1 \\ 176 & 186 & 199 & 200 & 187 & 4 \\ 177 & 187 & 200 & 201 & 188 & 4 \\ 178 & 188 & 201 & 202 & 189 & 3 \\ 179 & 189 & 202 & 203 & 190 & 4 \\ 180 & 190 & 203 & 204 & 191 & 4 \\ 181 & 191 & 204 & 205 & 192 & 3 \\ 182 & 192 & 205 & 206 & 193 & 3 \\ 183 & 193 & 206 & 207 & 194 & 2 \\ 184 & 194 & 207 & 208 & 195 & 2 \\ 185 & 196 & 209 & 210 & 197 & 3 \\ 186 & 197 & 210 & 211 & 198 & 3 \\ 187 & 198 & 211 & 212 & 199 & 4 \\ 188 & 199 & 212 & 213 & 213 & 5 \\ 189 & 199 & 213 & 214 & 200 & 4 \\ 190 & 200 & 214 & 215 & 201 & 4 \\ 191 & 201 & 215 & 216 & 202 & 3 \\ 192 & 202 & 216 & 217 & 203 & 4 \\ 193 & 203 & 217 & 218 & 204 & 4 \\ 194 & 204 & 219 & 219 & 205 & 3 \\ 195 & 205 & 219 & 220 & 206 & 3 \\ 196 & 206 & 220 & 221 & 207 & 2 \\ 197 & 207 & 221 & 222 & 208 & 2 \\ 198 & 209 & 223 & 224 & 210 & 3 \\ 199 & 210 & 224 & 225 & 211 & 3 \\ 200 & 211 & 225 & 226 & 212 & 4 \\ 201 & 212 & 226 & 227 & 213 & 5 \\ 202 & 213 & 227 & 228 & 214 & 4 \\ 203 & 214 & 228 & 229 & 215 & 4 \\ 204 & 215 & 229 & 230 & 216 & 3 \\ 205 & 216 & 230 & 231 & 217 & 1 \\ 206 & 217 & 231 & 232 & 219 & 4 \\ 207 & 218 & 232 & 233 & 219 & 3 \\ 208 & 219 & 233 & 234 & 220 & 3 \\ 209 & 220 & 234 & 235 & 221 & 2 \\ 210 & 221 & 235 & 236 & 222 & 2 \\ 211 & 223 & 237 & 238 & 224 & 3\end{array}$




$\begin{array}{llllll}212 & 224 & 238 & 239 & 225 & 3 \\ 213 & 225 & 239 & 240 & 226 & 4 \\ 214 & 226 & 240 & 241 & 227 & 5 \\ 215 & 227 & 241 & 242 & 228 & 4 \\ 216 & 228 & 242 & 243 & 229 & 4 \\ 217 & 229 & 243 & 244 & 230 & 3 \\ 218 & 230 & 244 & 245 & 231 & 4 \\ 219 & 231 & 245 & 246 & 232 & 4 \\ 220 & 232 & 246 & 247 & 233 & 3 \\ 221 & 233 & 247 & 248 & 234 & 3 \\ 222 & 234 & 248 & 249 & 235 & 2 \\ 223 & 235 & 249 & 250 & 236 & 2 \\ 224 & 237 & 251 & 252 & 239 & 3 \\ 225 & 238 & 252 & 253 & 239 & 3 \\ 226 & 239 & 253 & 254 & 240 & 4 \\ 227 & 240 & 254 & 241 & 241 & 5 \\ 228 & 241 & 254 & 255 & 242 & 4 \\ 229 & 242 & 255 & 256 & 243 & 4 \\ 230 & 243 & 256 & 257 & 244 & 3 \\ 231 & 244 & 257 & 258 & 245 & 4 \\ 232 & 245 & 258 & 259 & 246 & 4 \\ 233 & 246 & 259 & 260 & 247 & 3 \\ 234 & 247 & 260 & 261 & 249 & 3 \\ 235 & 248 & 261 & 262 & 249 & 2 \\ 236 & 249 & 262 & 263 & 250 & 2 \\ 237 & 251 & 264 & 265 & 252 & 3 \\ 238 & 252 & 265 & 266 & 253 & 3 \\ 239 & 253 & 266 & 267 & 254 & 4 \\ 240 & 254 & 267 & 268 & 255 & 4 \\ 241 & 255 & 268 & 269 & 256 & 4 \\ 242 & 256 & 269 & 270 & 257 & 3 \\ 243 & 257 & 270 & 271 & 259 & 4 \\ 244 & 258 & 271 & 272 & 259 & 4 \\ 245 & 259 & 272 & 273 & 260 & 3 \\ 246 & 260 & 273 & 274 & 261 & 3 \\ 247 & 261 & 274 & 275 & 262 & 2 \\ 248 & 262 & 275 & 276 & 263 & 2 \\ 249 & 264 & 277 & 278 & 265 & 3 \\ 250 & 265 & 278 & 279 & 266 & 3 \\ 251 & 266 & 279 & 267 & 267 & 4 \\ 252 & 267 & 279 & 280 & 280 & 4 \\ 253 & 267 & 280 & 268 & 268 & 4 \\ 254 & 268 & 280 & 281 & 269 & 4 \\ 255 & 269 & 281 & 282 & 270 & 3 \\ 256 & 270 & 282 & 283 & 283 & 3 \\ 257 & 270 & 293 & 271 & 271 & 1 \\ 258 & 271 & 283 & 272 & 272 & 4 \\ 259 & 272 & 283 & 284 & 273 & 3\end{array}$




$\begin{array}{llllll}260 & 273 & 284 & 285 & 274 & 3 \\ 261 & 274 & 285 & 286 & 275 & 2 \\ 262 & 275 & 286 & 287 & 276 & 2 \\ 263 & 277 & 289 & 289 & 278 & 3 \\ 264 & 278 & 289 & 290 & 279 & 3 \\ 265 & 279 & 290 & 291 & 280 & 4 \\ 266 & 280 & 291 & 292 & 281 & 4 \\ 267 & 281 & 292 & 293 & 282 & 3 \\ 268 & 282 & 293 & 283 & 283 & 3 \\ 269 & 293 & 293 & 294 & 294 & 3 \\ 270 & 283 & 294 & 284 & 284 & 3 \\ 271 & 284 & 294 & 295 & 285 & 3 \\ 272 & 285 & 295 & 296 & 286 & 2 \\ 273 & 286 & 296 & 297 & 287 & 2 \\ 274 & 288 & 298 & 299 & 289 & 3 \\ 275 & 289 & 299 & 300 & 290 & 3 \\ 276 & 290 & 300 & 301 & 291 & 4 \\ 277 & 291 & 301 & 302 & 292 & 1 \\ 279 & 292 & 302 & 303 & 293 & 3 \\ 279 & 293 & 303 & 304 & 294 & 3 \\ 280 & 294 & 304 & 305 & 295 & 3 \\ 281 & 295 & 305 & 306 & 296 & 2 \\ 282 & 296 & 306 & 307 & 297 & 2 \\ 283 & 298 & 308 & 309 & 299 & 3 \\ 284 & 299 & 309 & 310 & 300 & 3 \\ 285 & 300 & 310 & 311 & 301 & 4 \\ 286 & 301 & 311 & 312 & 302 & 4 \\ 287 & 302 & 312 & 313 & 303 & 3 \\ 288 & 303 & 313 & 314 & 304 & 3 \\ 289 & 304 & 314 & 315 & 305 & 3 \\ 290 & 305 & 315 & 316 & 306 & 2 \\ 291 & 306 & 316 & 317 & 307 & 2 \\ 292 & 308 & 318 & 319 & 309 & 3 \\ 293 & 309 & 319 & 320 & 310 & 3 \\ 294 & 310 & 320 & 321 & 311 & 4 \\ 295 & 311 & 321 & 322 & 312 & 1 \\ 296 & 312 & 322 & 323 & 313 & 3 \\ 297 & 313 & 323 & 324 & 314 & 3 \\ 298 & 314 & 324 & 325 & 315 & 3 \\ 299 & 315 & 325 & 326 & 316 & 2 \\ 300 & 316 & 326 & 327 & 317 & 2 \\ 301 & 318 & 328 & 329 & 319 & 3 \\ 302 & 319 & 329 & 330 & 320 & 3 \\ 303 & 320 & 330 & 331 & 321 & 1 \\ 304 & 321 & 331 & 332 & 322 & 4 \\ 305 & 322 & 332 & 333 & 323 & 3 \\ 306 & 323 & 333 & 334 & 324 & 3 \\ 307 & 324 & 334 & 335 & 325 & 3\end{array}$




$\begin{array}{llllll}308 & 325 & 335 & 336 & 326 & 2 \\ 309 & 326 & 336 & 337 & 327 & 2 \\ 310 & 328 & 338 & 339 & 329 & 3 \\ 311 & 329 & 339 & 340 & 330 & 3 \\ 312 & 330 & 340 & 341 & 331 & 4 \\ 313 & 331 & 341 & 342 & 332 & 4 \\ 314 & 332 & 342 & 343 & 333 & 3 \\ 315 & 333 & 343 & 344 & 334 & 3 \\ 316 & 334 & 344 & 345 & 335 & 3 \\ 317 & 335 & 345 & 346 & 336 & 2 \\ 319 & 336 & 346 & 347 & 337 & 2 \\ 319 & 338 & 348 & 349 & 339 & 3 \\ 320 & 339 & 349 & 350 & 340 & 3 \\ 321 & 340 & 350 & 351 & 341 & 1 \\ 322 & 341 & 351 & 352 & 342 & 1 \\ 323 & 342 & 352 & 353 & 343 & 3 \\ 324 & 343 & 353 & 354 & 344 & 3 \\ 325 & 344 & 354 & 355 & 345 & 3 \\ 326 & 345 & 355 & 356 & 346 & 2 \\ 327 & 346 & 356 & 357 & 347 & 2 \\ 328 & 348 & 358 & 359 & 349 & 3 \\ 329 & 349 & 359 & 360 & 350 & 3 \\ 330 & 350 & 360 & 361 & 351 & 4 \\ 331 & 351 & 361 & 362 & 352 & 4 \\ 332 & 352 & 362 & 363 & 353 & 3 \\ 333 & 353 & 363 & 364 & 354 & 3 \\ 334 & 354 & 364 & 365 & 355 & 3 \\ 335 & 355 & 365 & 366 & 356 & 2 \\ 336 & 356 & 366 & 367 & 357 & 2 \\ 337 & 359 & 368 & 369 & 369 & 3 \\ 339 & 358 & 369 & 359 & 359 & 3 \\ 339 & 359 & 369 & 370 & 370 & 3 \\ 340 & 359 & 370 & 371 & 371 & 3 \\ 341 & 359 & 371 & 360 & 360 & 3 \\ 342 & 360 & 371 & 372 & 372 & 3 \\ 343 & 360 & 372 & 373 & 361 & 4 \\ 344 & 361 & 373 & 374 & 362 & 4 \\ 345 & 362 & 374 & 375 & 363 & 3 \\ 346 & 363 & 375 & 376 & 354 & 3 \\ 347 & 364 & 376 & 377 & 365 & 3 \\ 318 & 365 & 377 & 378 & 366 & 2 \\ 349 & 366 & 378 & 379 & 367 & 2 \\ 350 & 368 & 380 & 381 & 369 & 3 \\ 351 & 369 & 381 & 382 & 370 & 3 \\ 352 & 370 & 382 & 383 & 383 & 4 \\ 353 & 370 & 383 & 384 & 384 & 4 \\ 354 & 370 & 384 & 385 & 371 & 3 \\ 355 & 371 & 385 & 386 & 372 & 3\end{array}$




$\begin{array}{llllll}356 & 372 & 386 & 387 & 373 & 4 \\ 357 & 373 & 387 & 388 & 374 & 4 \\ 358 & 374 & 388 & 389 & 375 & 3 \\ 359 & 375 & 389 & 390 & 376 & 3 \\ 360 & 376 & 390 & 391 & 377 & 3 \\ 361 & 377 & 391 & 392 & 378 & 2 \\ 362 & 378 & 392 & 393 & 379 & 2 \\ 363 & 380 & 394 & 395 & 381 & 3 \\ 364 & 381 & 395 & 396 & 382 & 3 \\ 365 & 382 & 396 & 397 & 383 & 4 \\ 366 & 383 & 397 & 398 & 384 & 4 \\ 367 & 384 & 398 & 399 & 385 & 3 \\ 368 & 385 & 399 & 400 & 386 & 3 \\ 369 & 386 & 400 & 401 & 387 & 4 \\ 370 & 387 & 401 & 402 & 388 & 4 \\ 371 & 388 & 402 & 403 & 389 & 3 \\ 372 & 389 & 403 & 404 & 390 & 3 \\ 373 & 390 & 404 & 405 & 391 & 3 \\ 374 & 391 & 405 & 406 & 392 & 2 \\ 375 & 392 & 406 & 407 & 393 & 2 \\ 376 & 394 & 408 & 409 & 395 & 3 \\ 377 & 395 & 409 & 410 & 396 & 3 \\ 378 & 396 & 410 & 411 & 397 & 4 \\ 379 & 397 & 411 & 412 & 398 & 4 \\ 380 & 398 & 412 & 413 & 399 & 3 \\ 381 & 399 & 413 & 414 & 400 & 3 \\ 382 & 400 & 414 & 415 & 401 & 4 \\ 383 & 401 & 415 & 416 & 402 & 4 \\ 381 & 402 & 416 & 417 & 403 & 3 \\ 385 & 403 & 417 & 418 & 404 & 3 \\ 386 & 404 & 418 & 419 & 405 & 3 \\ 387 & 405 & 419 & 420 & 406 & 2 \\ 388 & 406 & 420 & 421 & 407 & 2 \\ 389 & 408 & 422 & 423 & 409 & 3 \\ 390 & 409 & 423 & 424 & 410 & 3 \\ 391 & 410 & 424 & 411 & 411 & 4 \\ 392 & 411 & 421 & 412 & 412 & 4 \\ 393 & 412 & 424 & 425 & 413 & 3 \\ 394 & 413 & 425 & 426 & 414 & 3 \\ 395 & 414 & 426 & 427 & 415 & 4 \\ 396 & 415 & 427 & 428 & 416 & 4 \\ 397 & 416 & 428 & 429 & 417 & 3 \\ 398 & 417 & 129 & 430 & 418 & 3 \\ 399 & 418 & 430 & 431 & 419 & 3 \\ 400 & 419 & 431 & 432 & 420 & 2 \\ 401 & 420 & 432 & 433 & 421 & 2 \\ 402 & 422 & 434 & 423 & 423 & 3 \\ 403 & 423 & 434 & 435 & 435 & 3\end{array}$




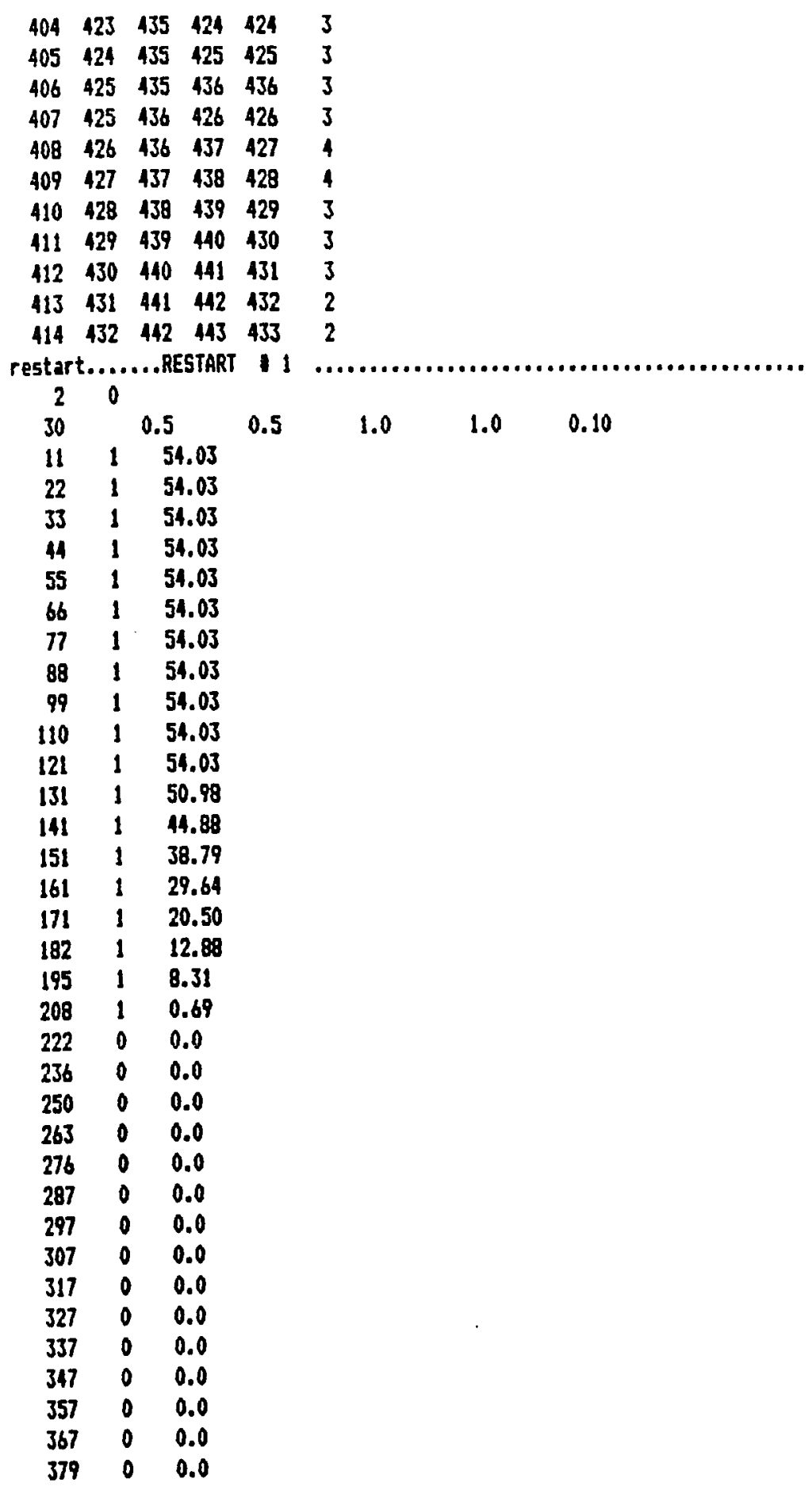




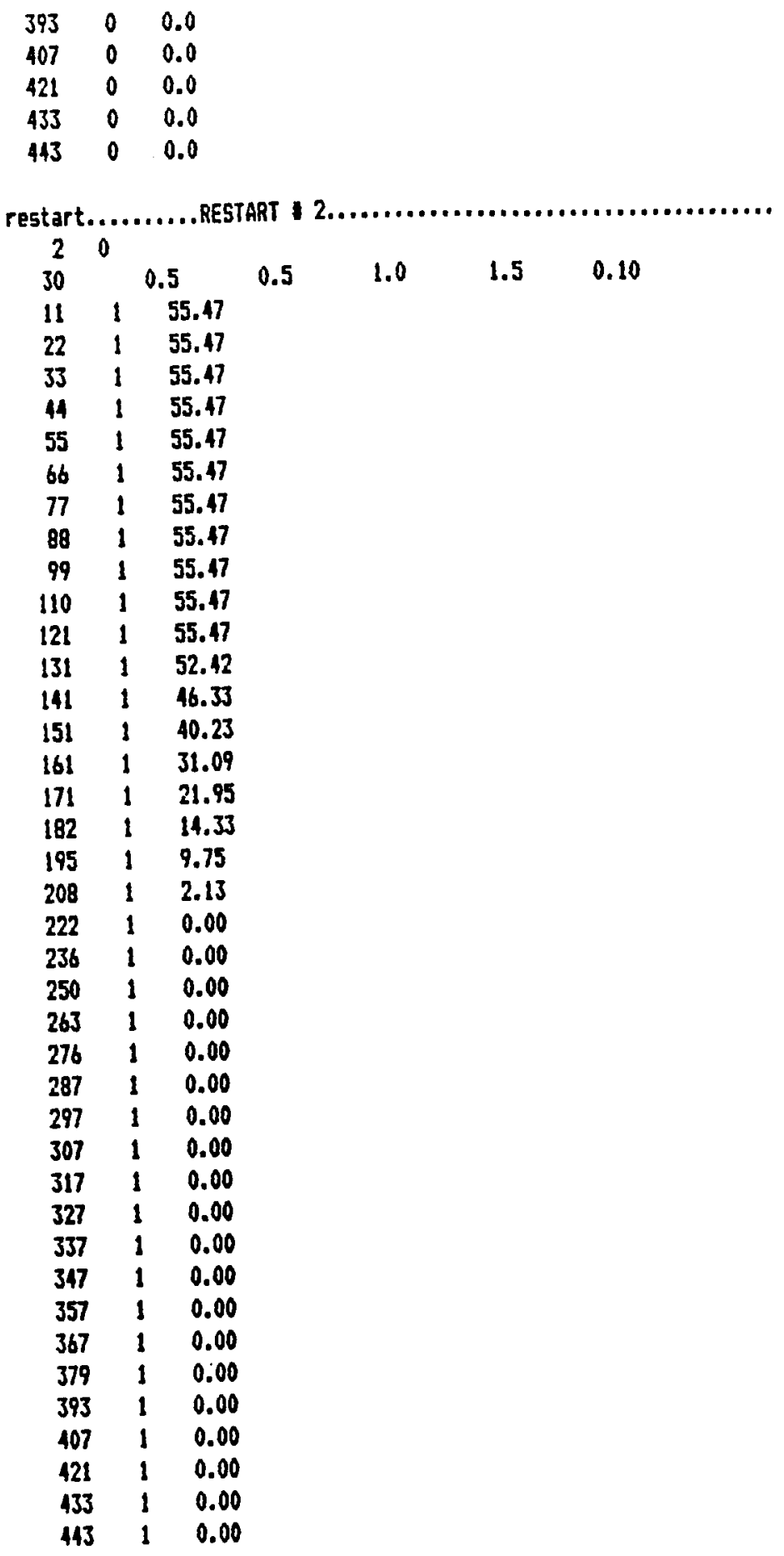




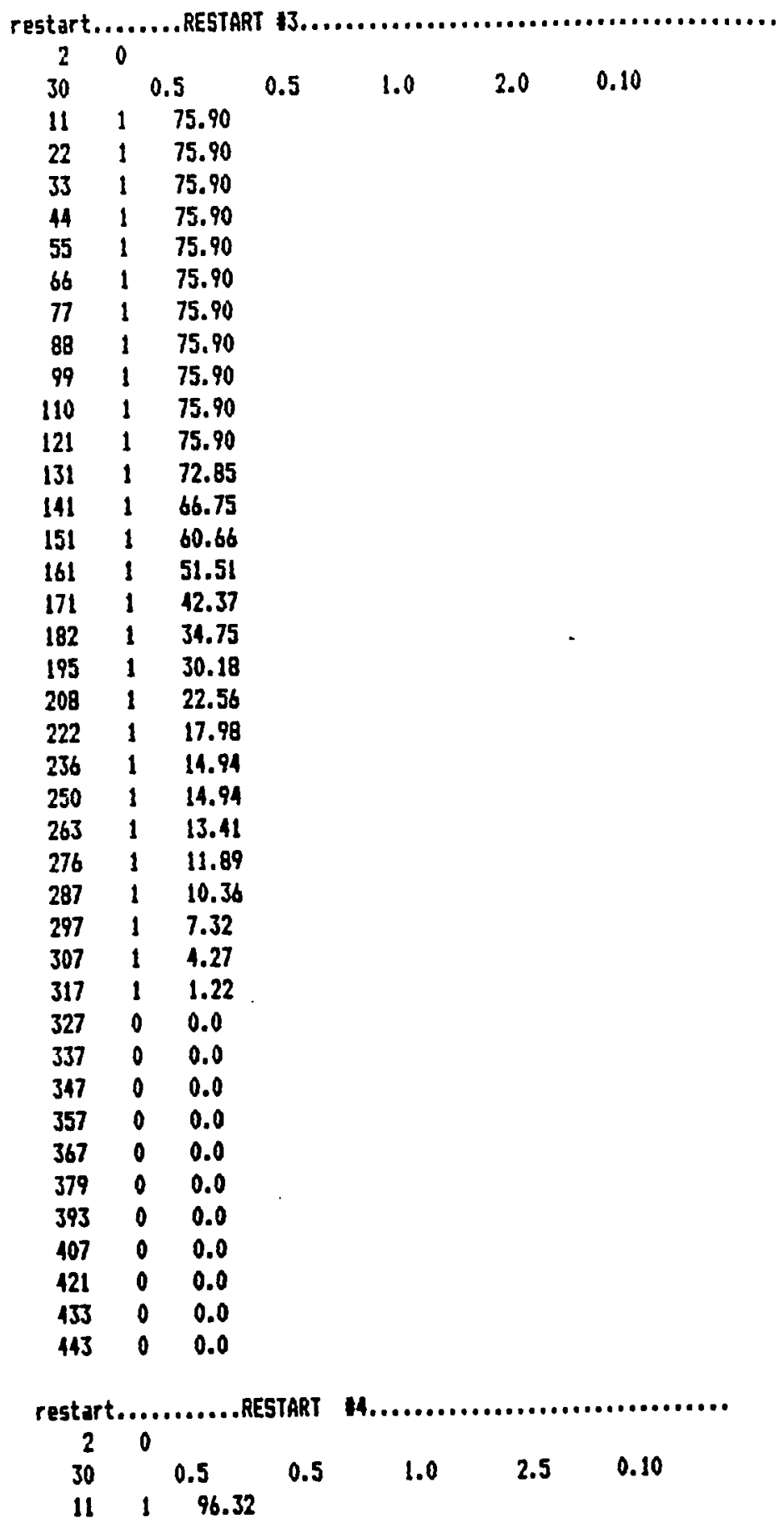




$\begin{array}{lll}22 & 1 & 96.32 \\ 33 & 1 & 96.32 \\ 44 & 1 & 96.32 \\ 55 & 1 & 96.32 \\ 66 & 1 & 96.32 \\ 77 & 1 & 96.32 \\ 88 & 1 & 96.32 \\ 99 & 1 & 96.32 \\ 110 & 1 & 96.32 \\ 121 & 1 & 96.32 \\ 131 & 1 & 93.27 \\ 141 & 1 & 87.17 \\ 151 & 1 & 81.08 \\ 161 & 1 & 71.93 \\ 171 & 1 & 62.79 \\ 182 & 1 & 55.17 \\ 195 & 1 & 50.60 \\ 208 & 1 & 42.98 \\ 222 & 1 & 38.40 \\ 236 & 1 & 35.36 \\ 250 & 1 & 35.36 \\ 263 & 1 & 33.83 \\ 276 & 1 & 32.31 \\ 287 & 1 & 30.78 \\ 297 & 1 & 27.74 \\ 307 & 1 & 24.69 \\ 317 & 1 & 21.64 \\ 327 & 1 & 18.59 \\ 337 & 1 & 15.54 \\ 347 & 1 & 12.50 \\ 357 & 1 & 9.45 \\ 367 & 1 & 6.40 \\ 379 & 1 & 3.35 \\ 393 & 1 & 1.83 \\ 407 & 1 & 0.0 \\ 421 & 1 & 0.0 \\ 433 & 1 & 0.0 \\ 443 & 1 & 0.0\end{array}$

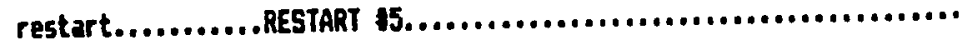

$\begin{array}{lll}2 & 0 & \\ 30 & & 0.5 \\ 11 & 1 & 97.28 \\ 22 & 1 & 97.28 \\ 33 & 1 & 97.28 \\ 41 & 1 & 97.28 \\ 55 & 1 & 97.28 \\ 66 & 1 & 97.28\end{array}$




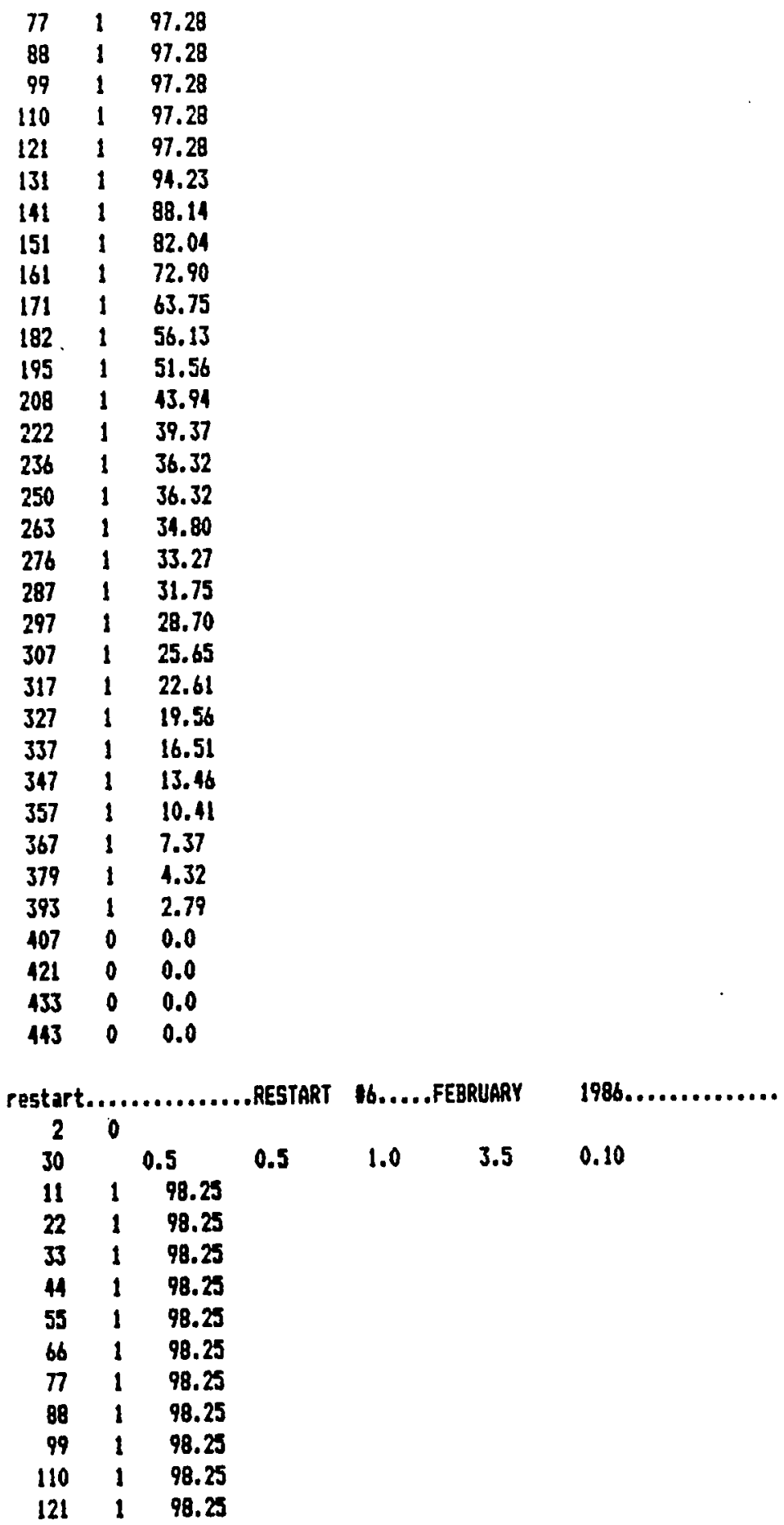




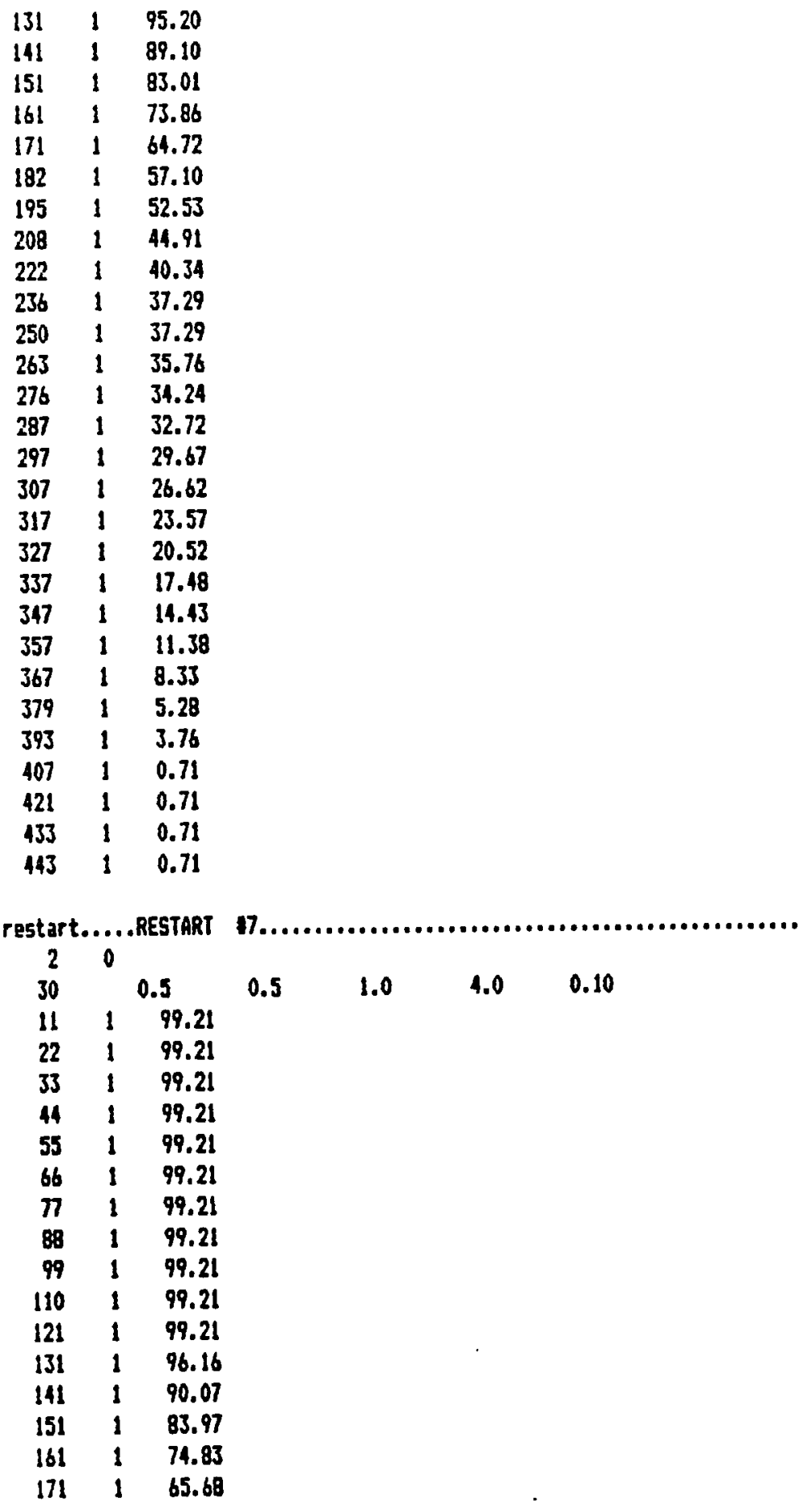




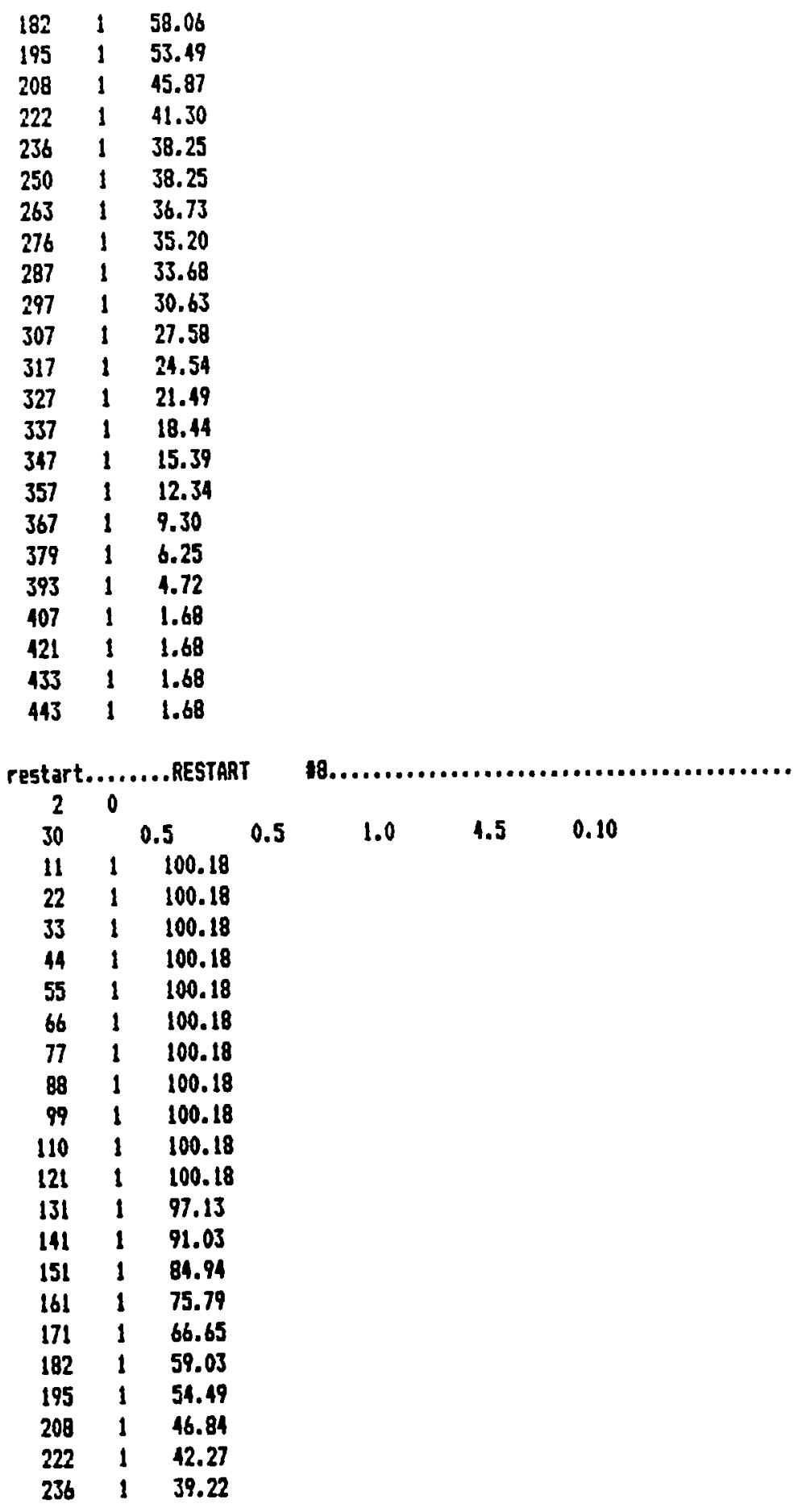




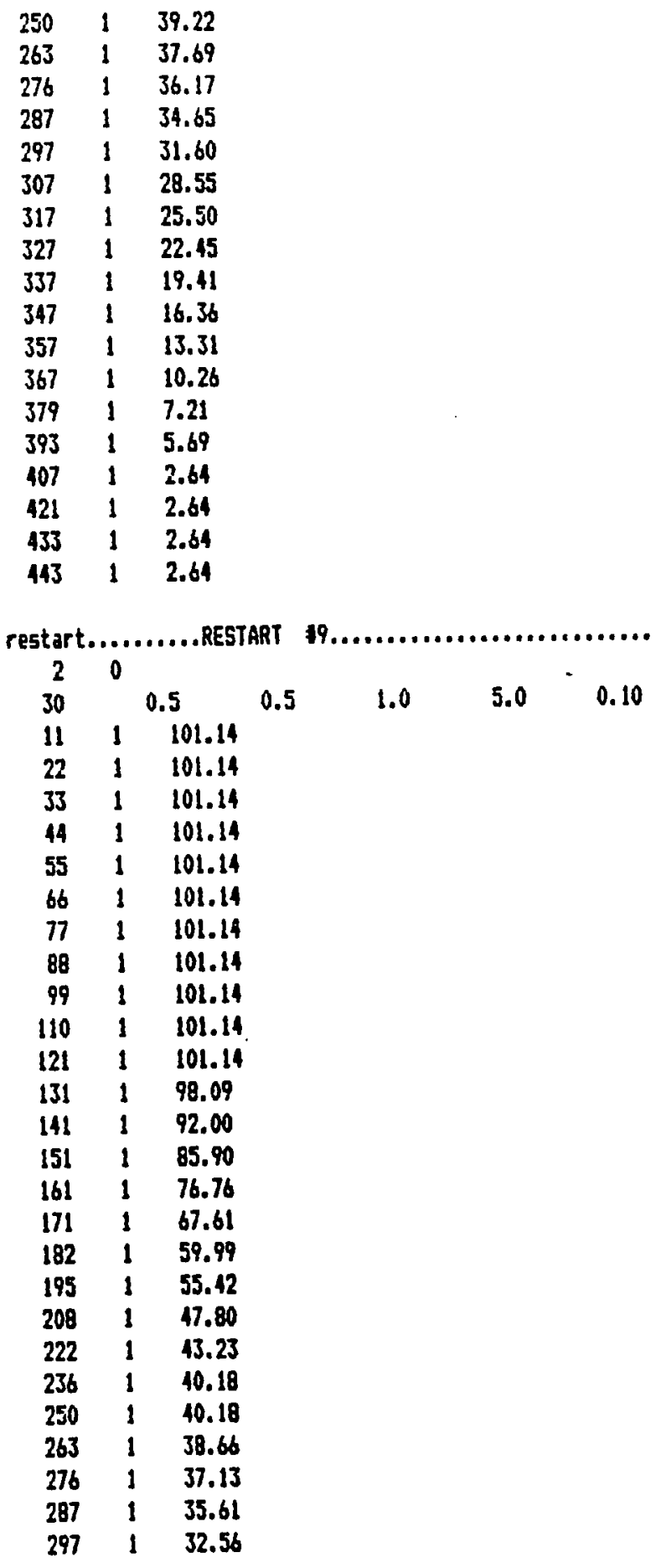




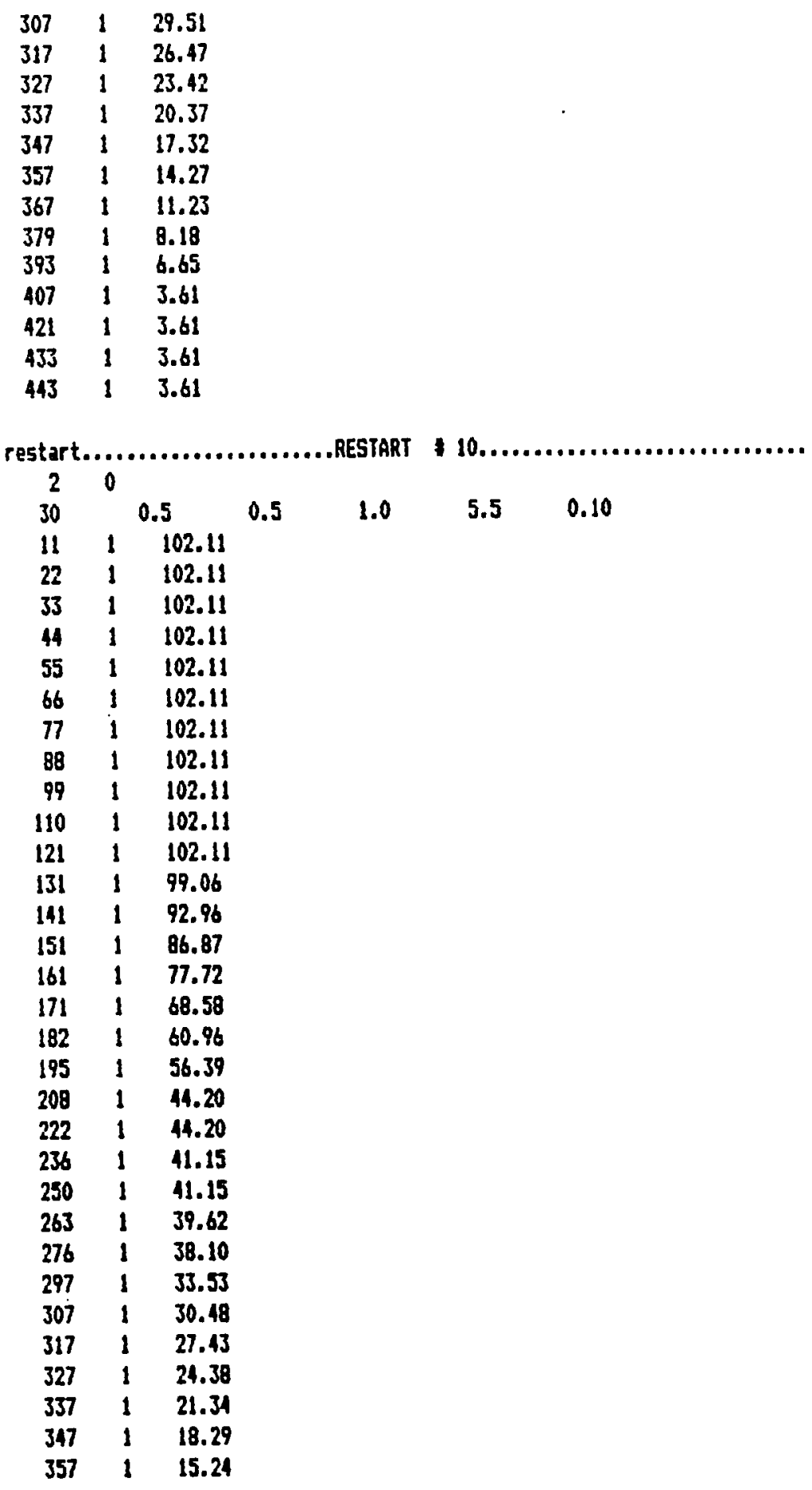




$\begin{array}{lll}367 & 1 & 12.19 \\ 379 & 1 & 9.14 \\ 393 & 1 & 7.62 \\ 407 & 1 & 4.57 \\ 421 & 1 & 4.57 \\ 433 & 1 & 4.57 \\ 443 & 1 & 4.57\end{array}$

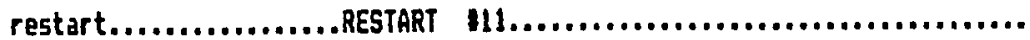

\begin{tabular}{|c|c|c|c|c|c|c|}
\hline 30 & 0 & .5 & 0.5 & 1.0 & 6.0 & 0.10 \\
\hline 11 & 1 & 119.02 & & & & \\
\hline 22 & 1 & 119.02 & & & & \\
\hline 33 & 1 & 119.02 & & & & \\
\hline 44 & 1 & 119.02 & & & & \\
\hline 55 & 1 & 119.02 & & & & \\
\hline 66 & 1 & 119.02 & & & & \\
\hline 77 & 1 & 119.02 & & & & \\
\hline 89 & 1 & 119.02 & & & & \\
\hline 99 & 1 & 119.02 & & & & \\
\hline 110 & 1 & 119.02 & & & & \\
\hline 121 & 1 & 119.02 & & & & \\
\hline 131 & 1 & 115.97 & & & & \\
\hline 141 & 1 & $\begin{array}{l}109.88 \\
103.78\end{array}$ & & & & \\
\hline $\begin{array}{l}151 \\
161\end{array}$ & $\begin{array}{l}1 \\
1\end{array}$ & 94.64 & & & & \\
\hline 171 & 1 & 85.50 & & & & \\
\hline 182 & 1 & 77.88 & & & & \\
\hline 195 & 1 & 73.30 & & & & \\
\hline 208 & 1 & 65.68 & & & & \\
\hline 222 & 1 & 61.11 & & & & \\
\hline 236 & 1 & 58.06 & & & & \\
\hline 250 & 1 & 58.06 & & & & \\
\hline 263 & 1 & 56.54 & & & & \\
\hline 276 & 1 & 55.02 & & & & \\
\hline 287 & 1 & 53.49 & & & & \\
\hline 297 & 1 & 50.44 & & & & \\
\hline 307 & 1 & 17.40 & & & & \\
\hline 317 & 1 & 44.35 & & & & \\
\hline 327 & 1 & 41.30 & & & & \\
\hline 337 & 1 & 38.25 & & & & \\
\hline $\begin{array}{l}347 \\
357\end{array}$ & 1 & 35.20 & & & & \\
\hline $\begin{array}{l}357 \\
367\end{array}$ & 1 & 29.11 & & & & \\
\hline 379 & 1 & 26.06 & & & & \\
\hline 393 & 1 & 24.54 & & & & \\
\hline 407 & 1 & 21.49 & & & & \\
\hline 121 & 1 & 21.49 & & & & \\
\hline
\end{tabular}




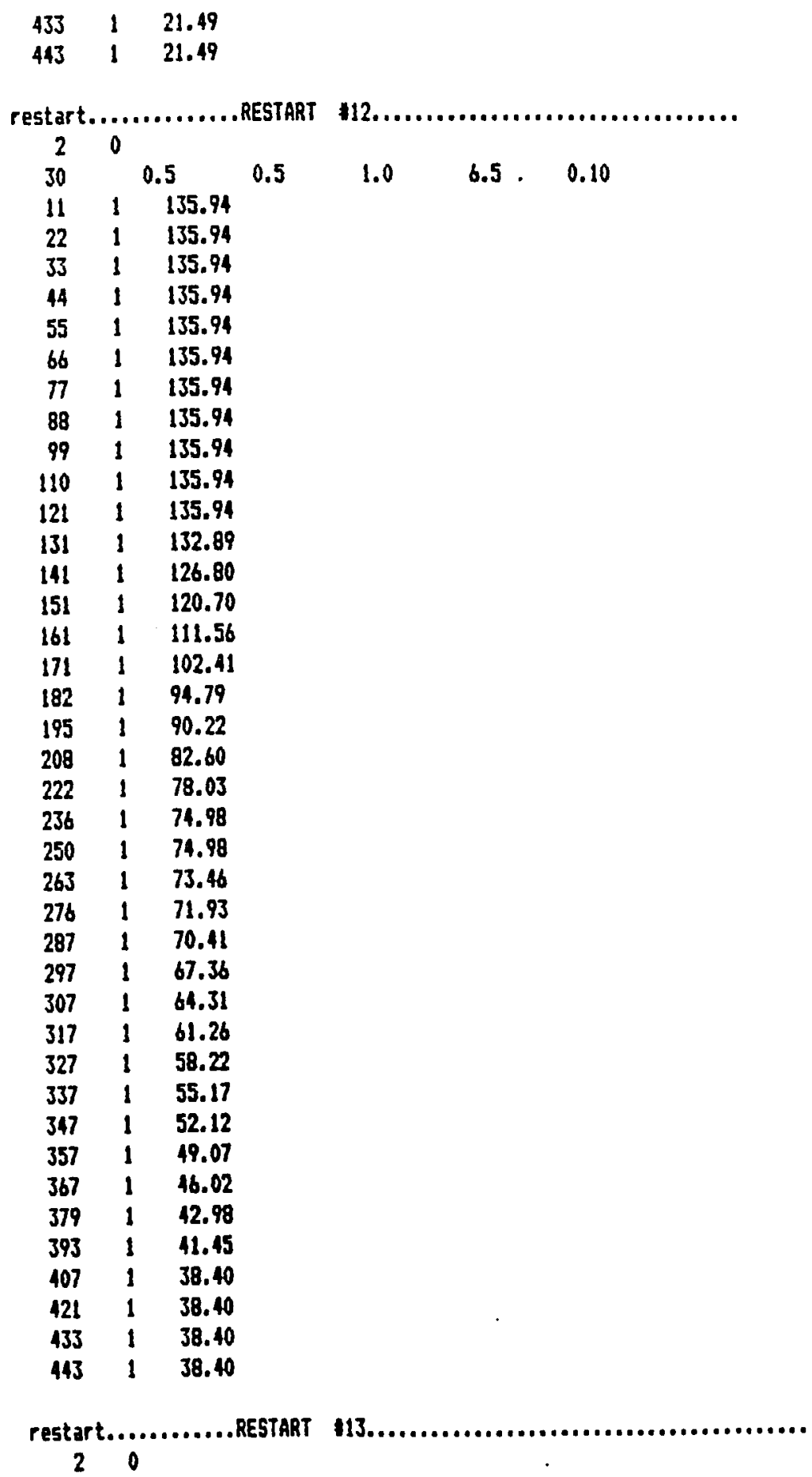




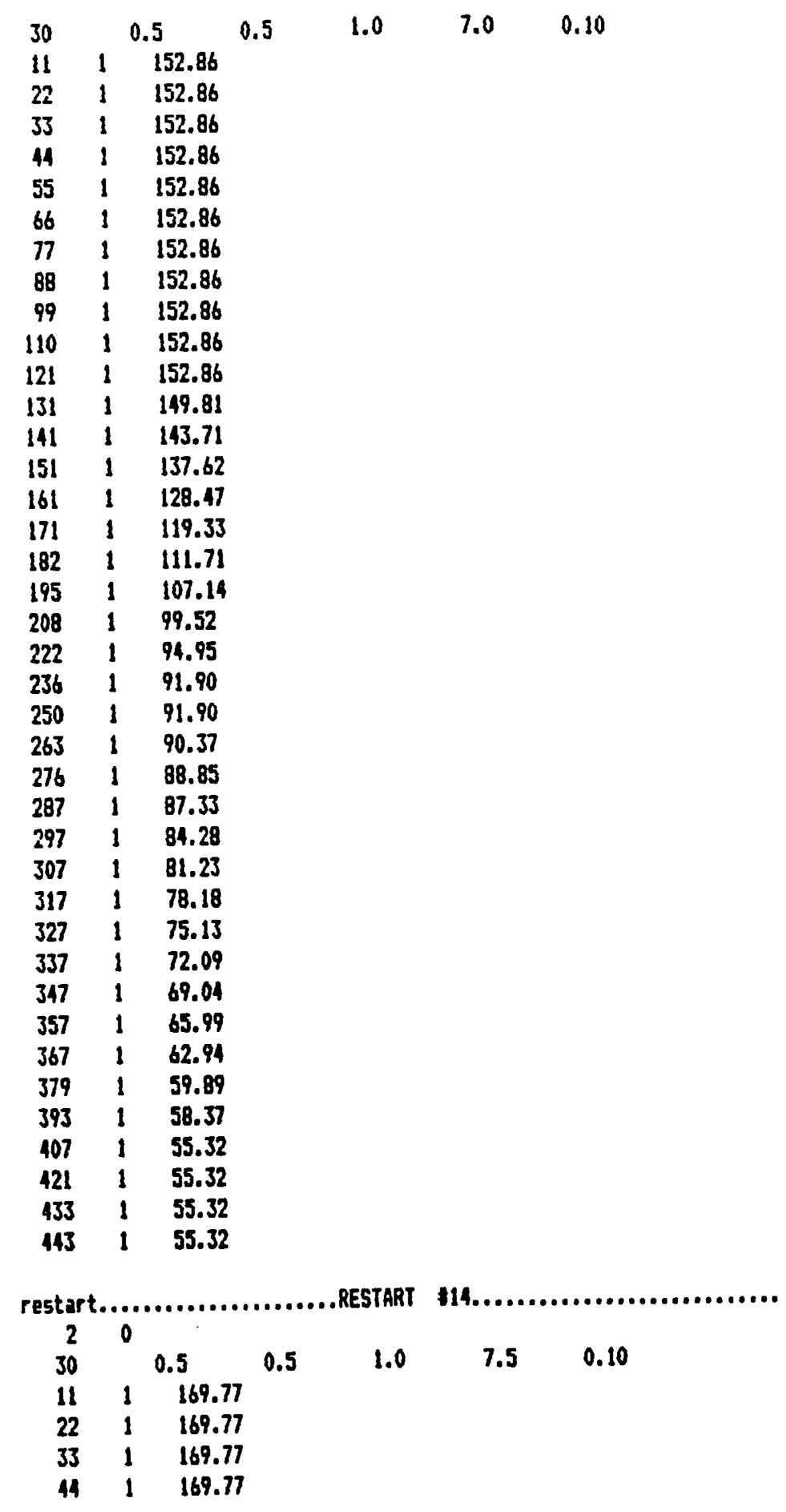




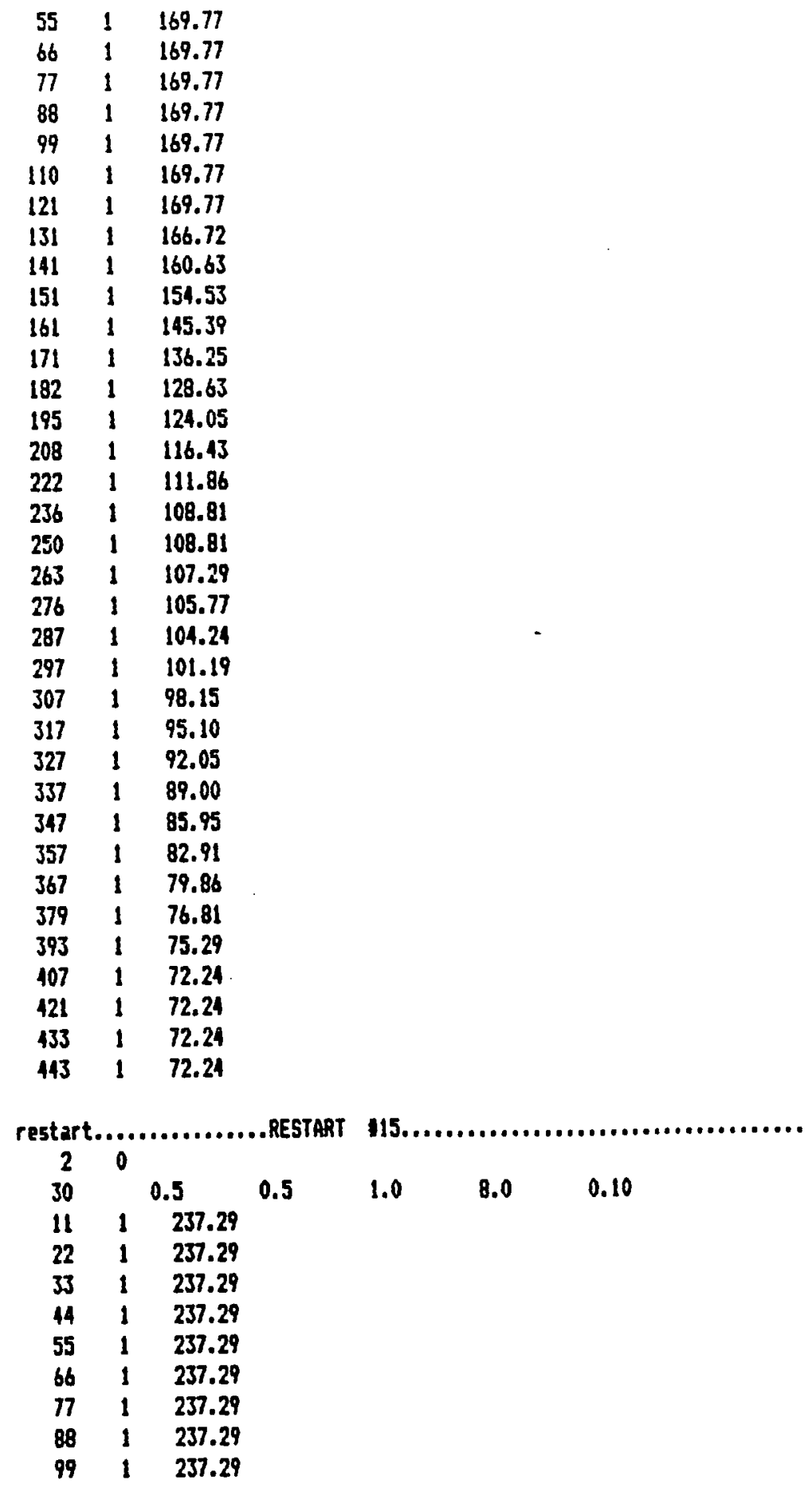




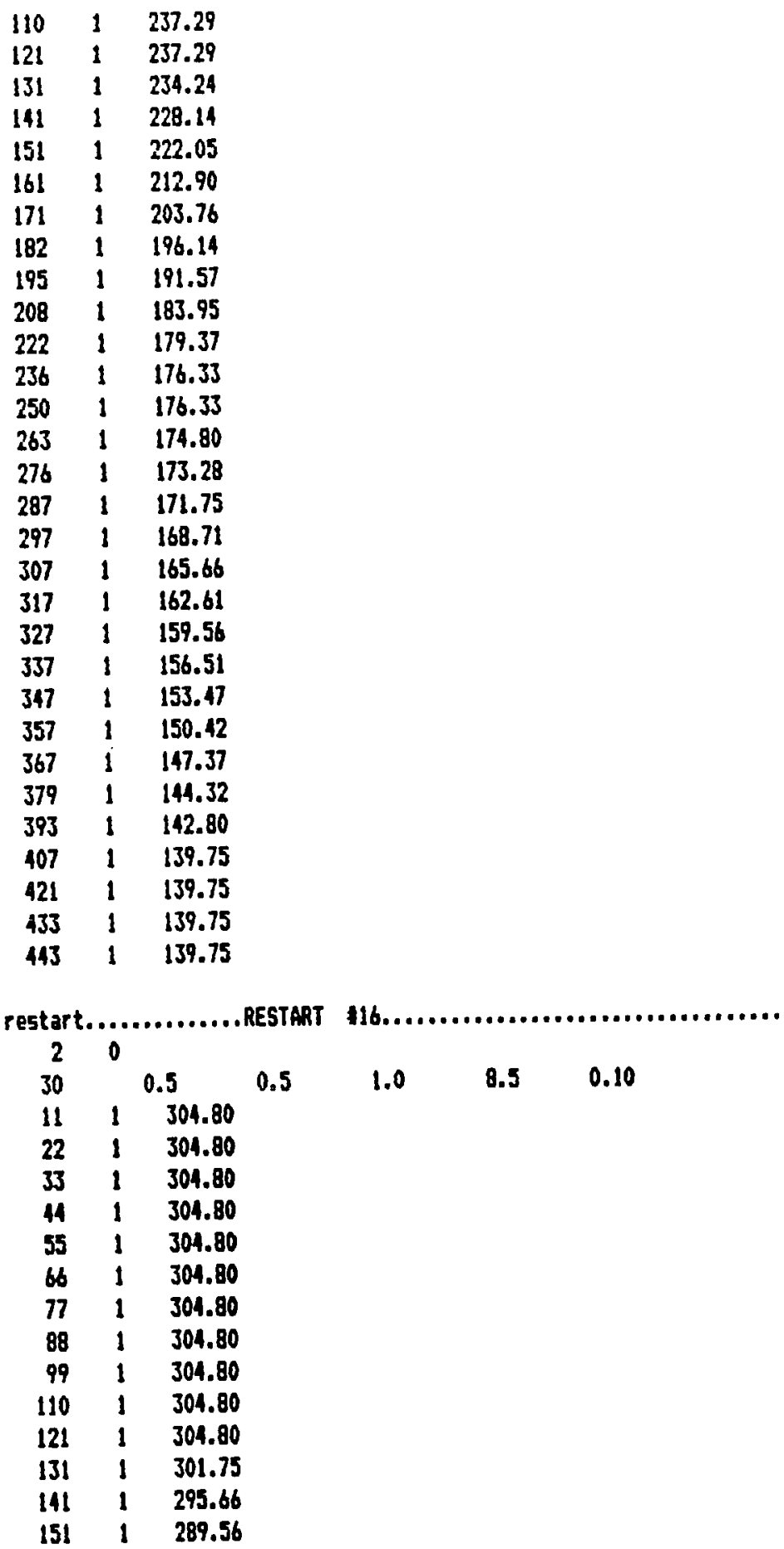




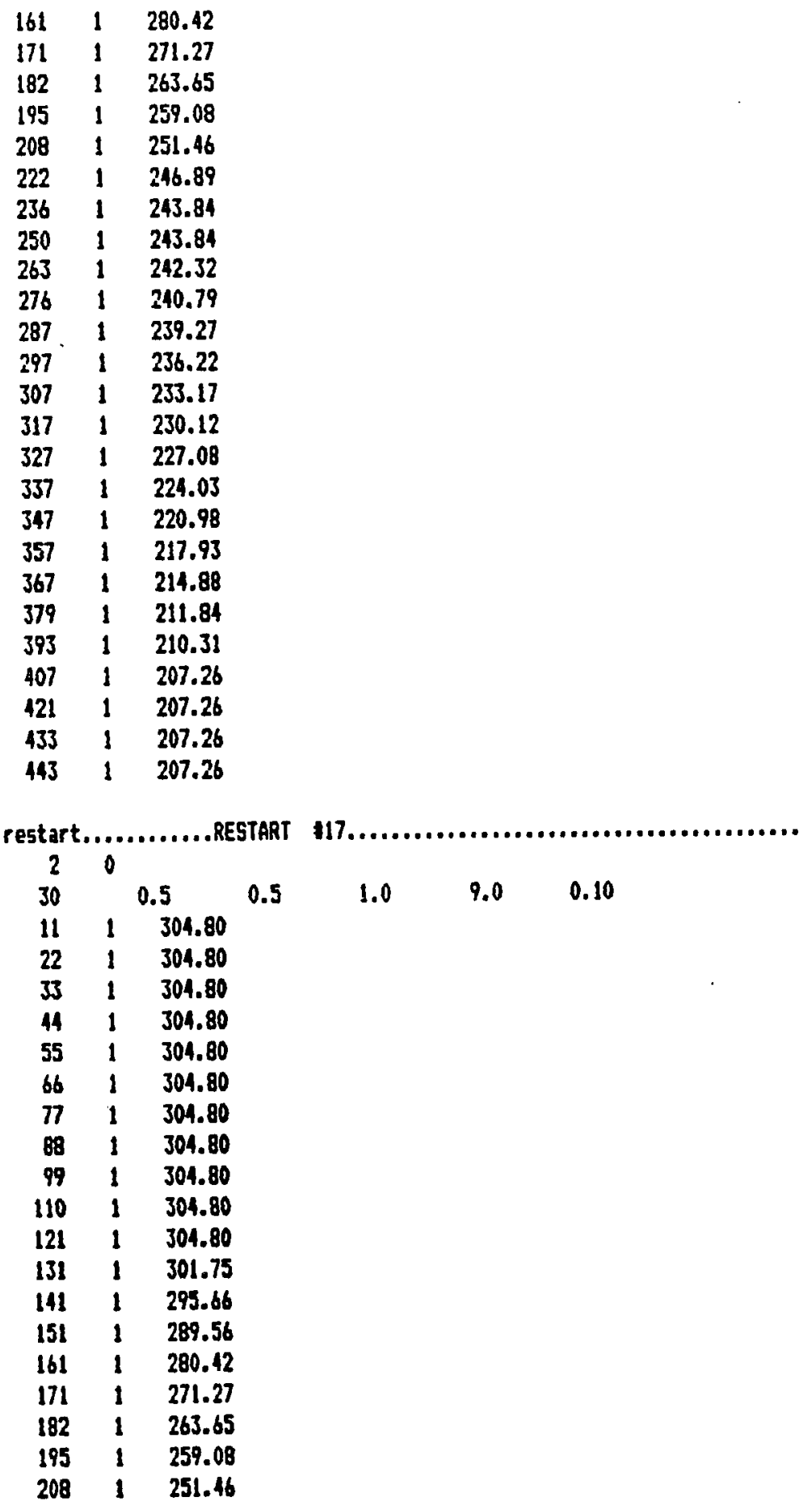




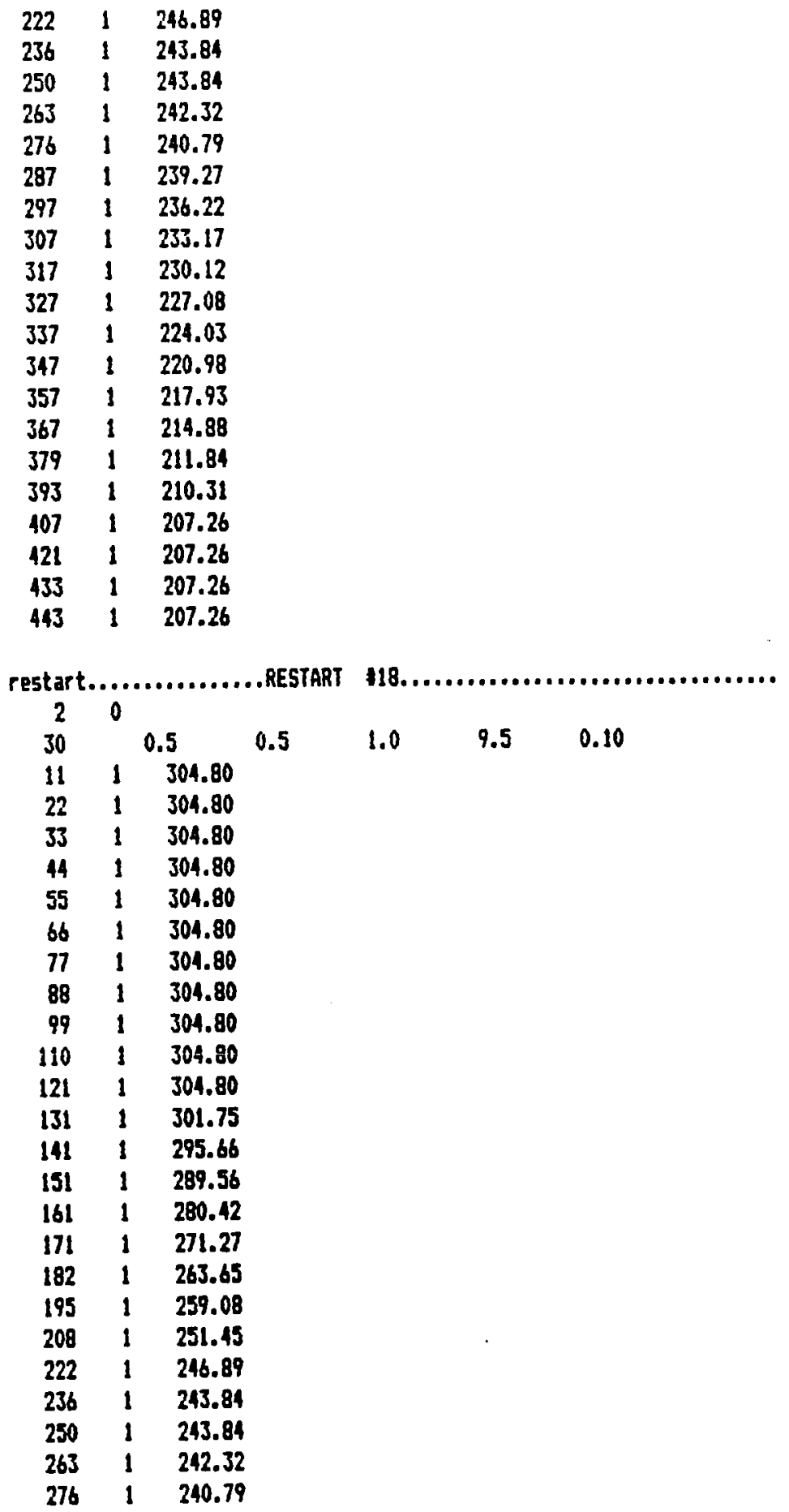




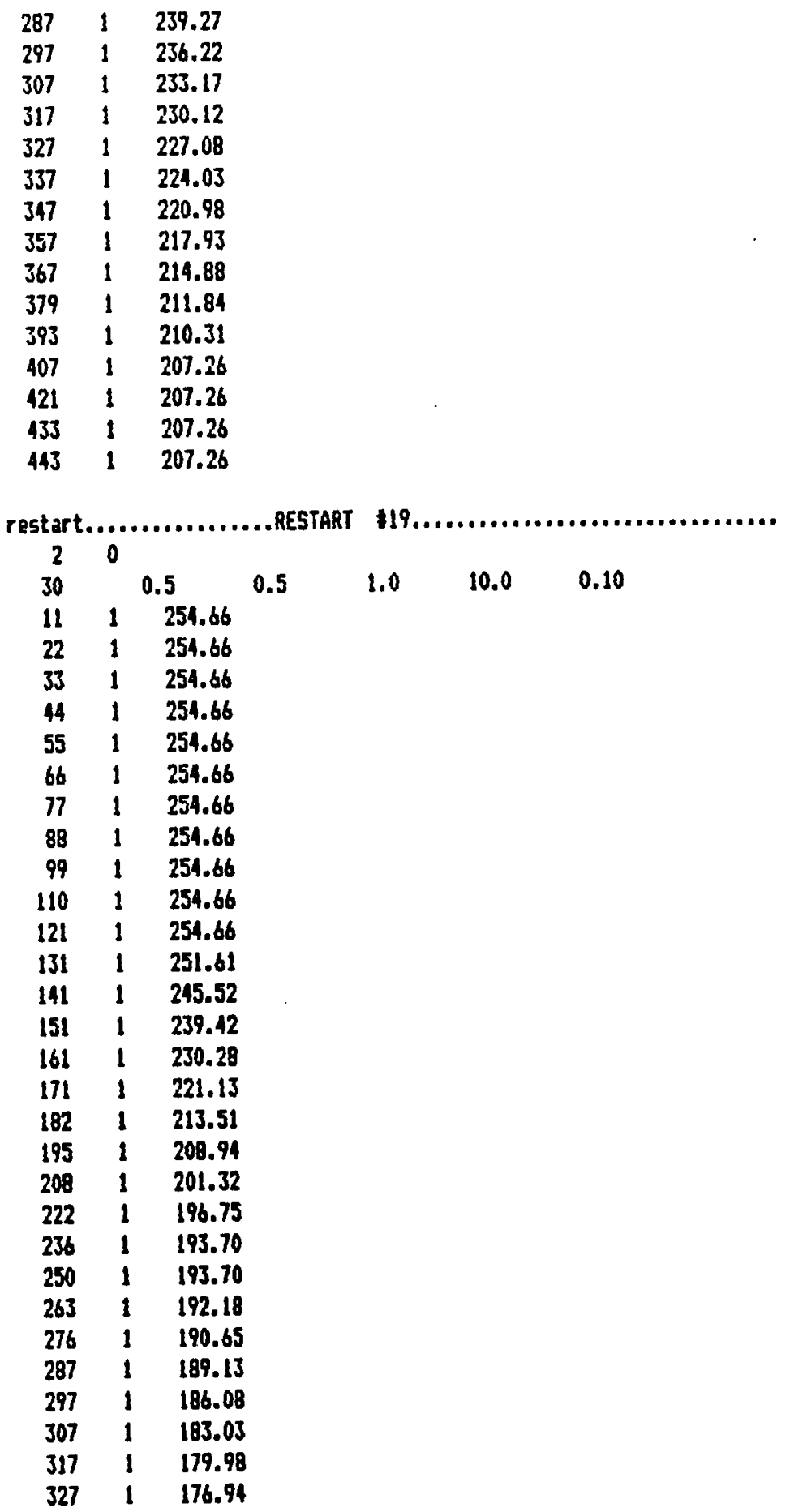




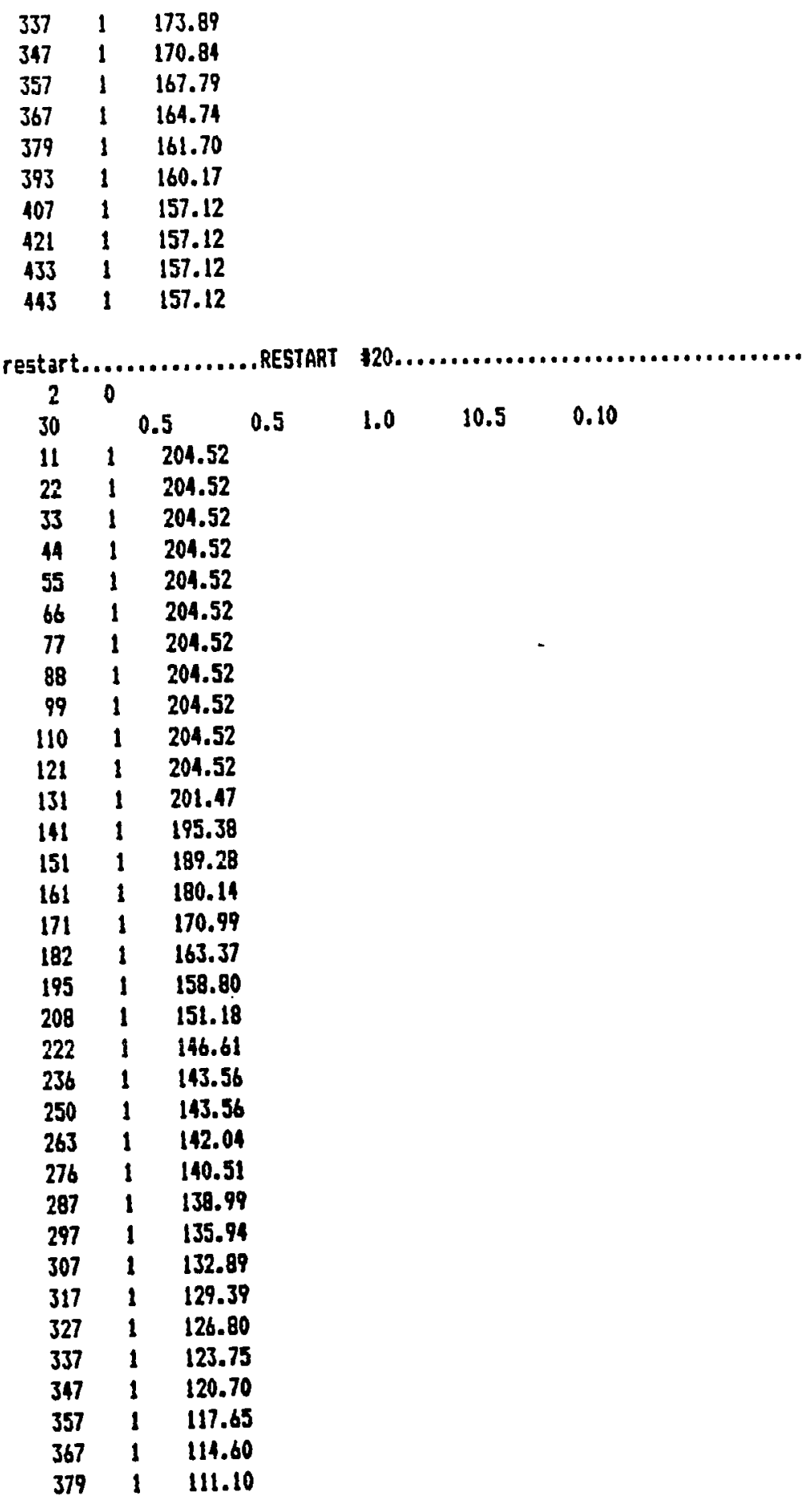




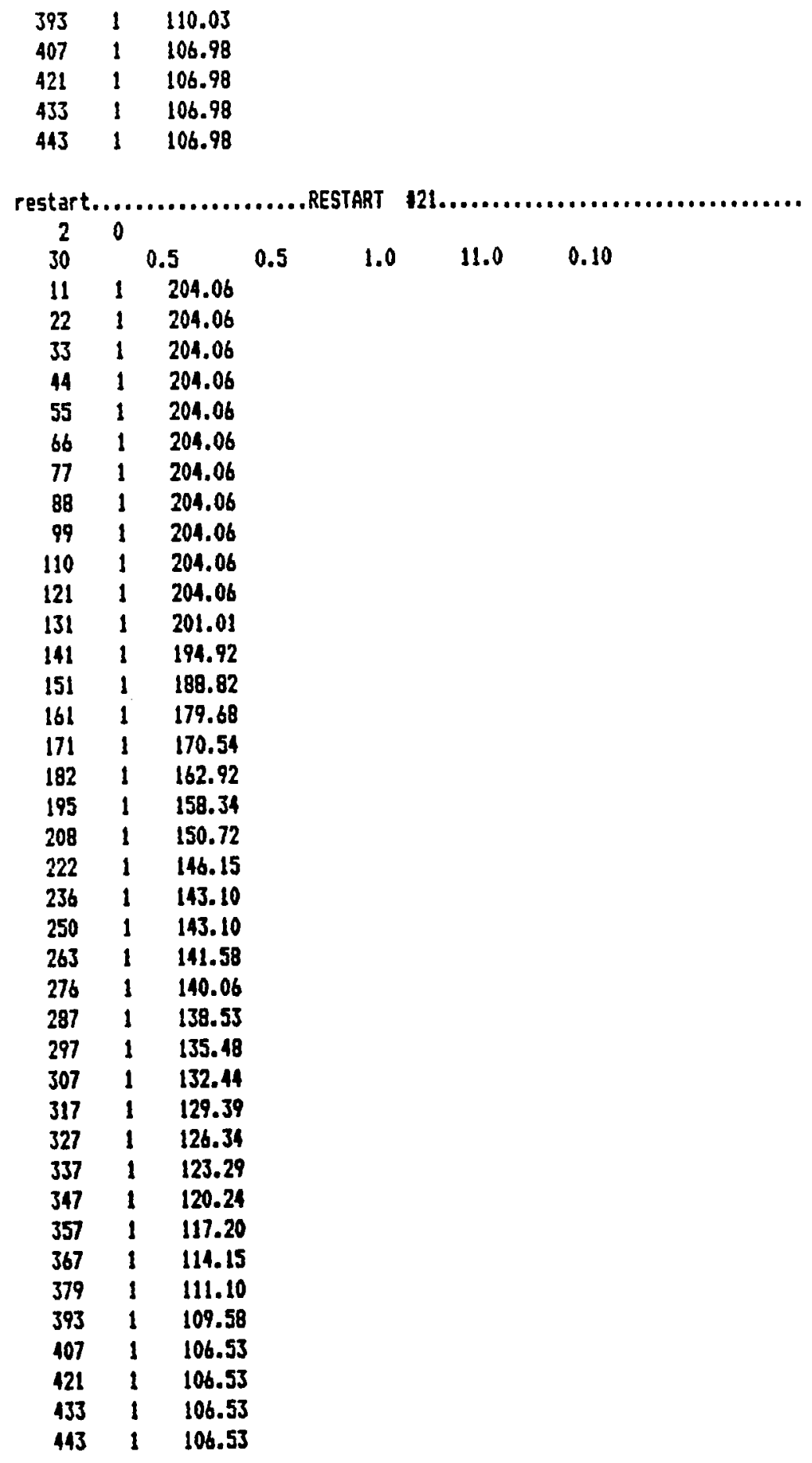




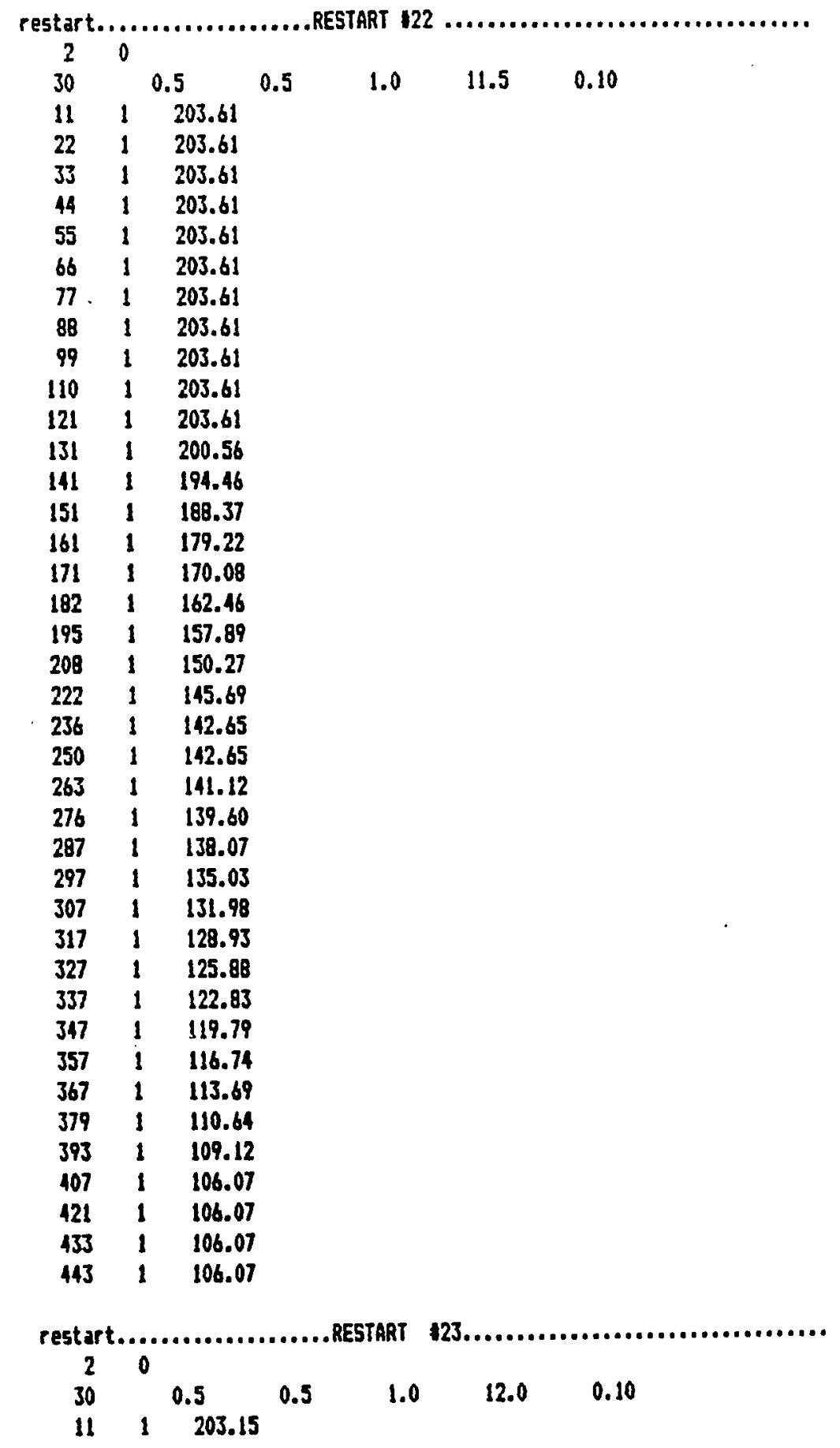




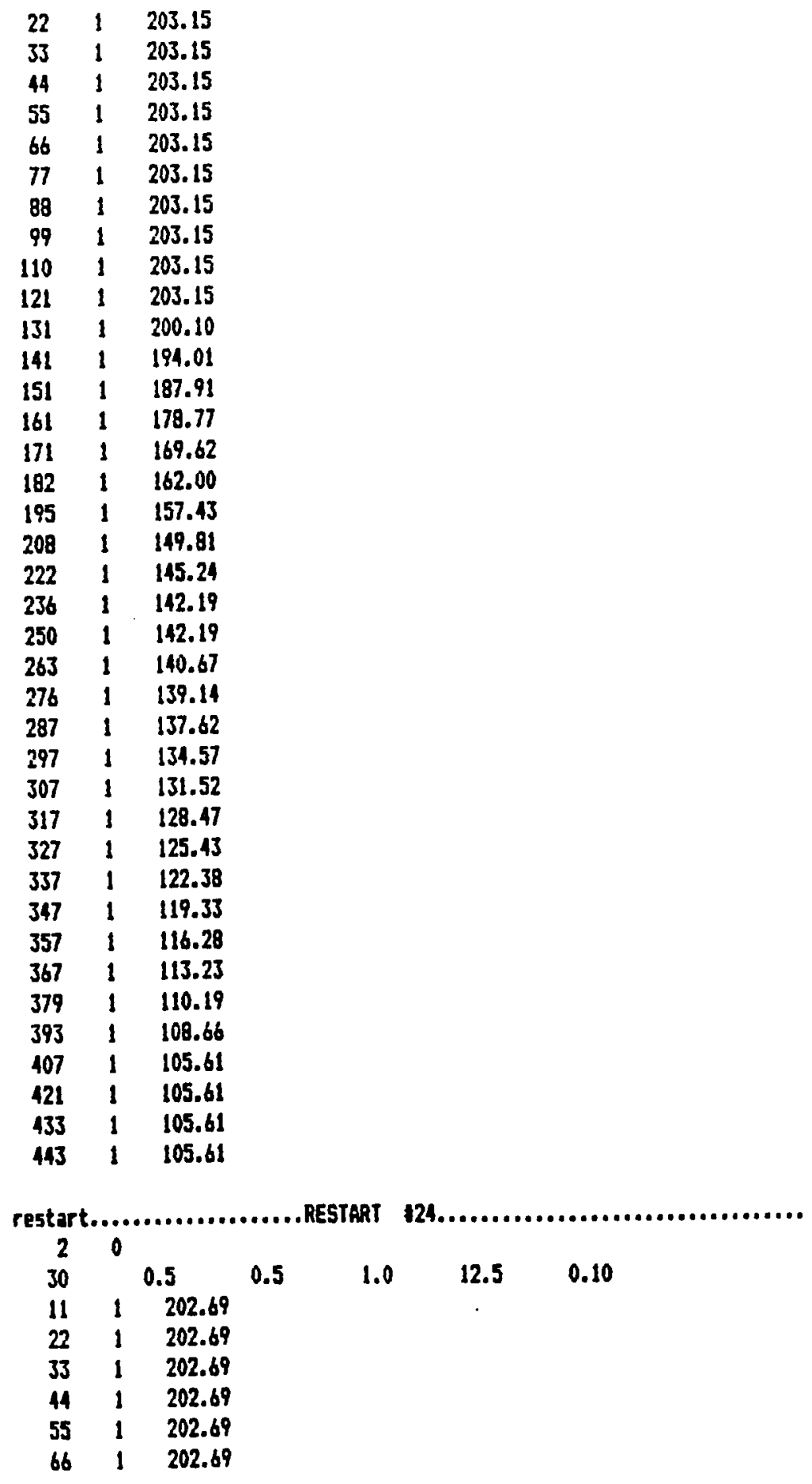




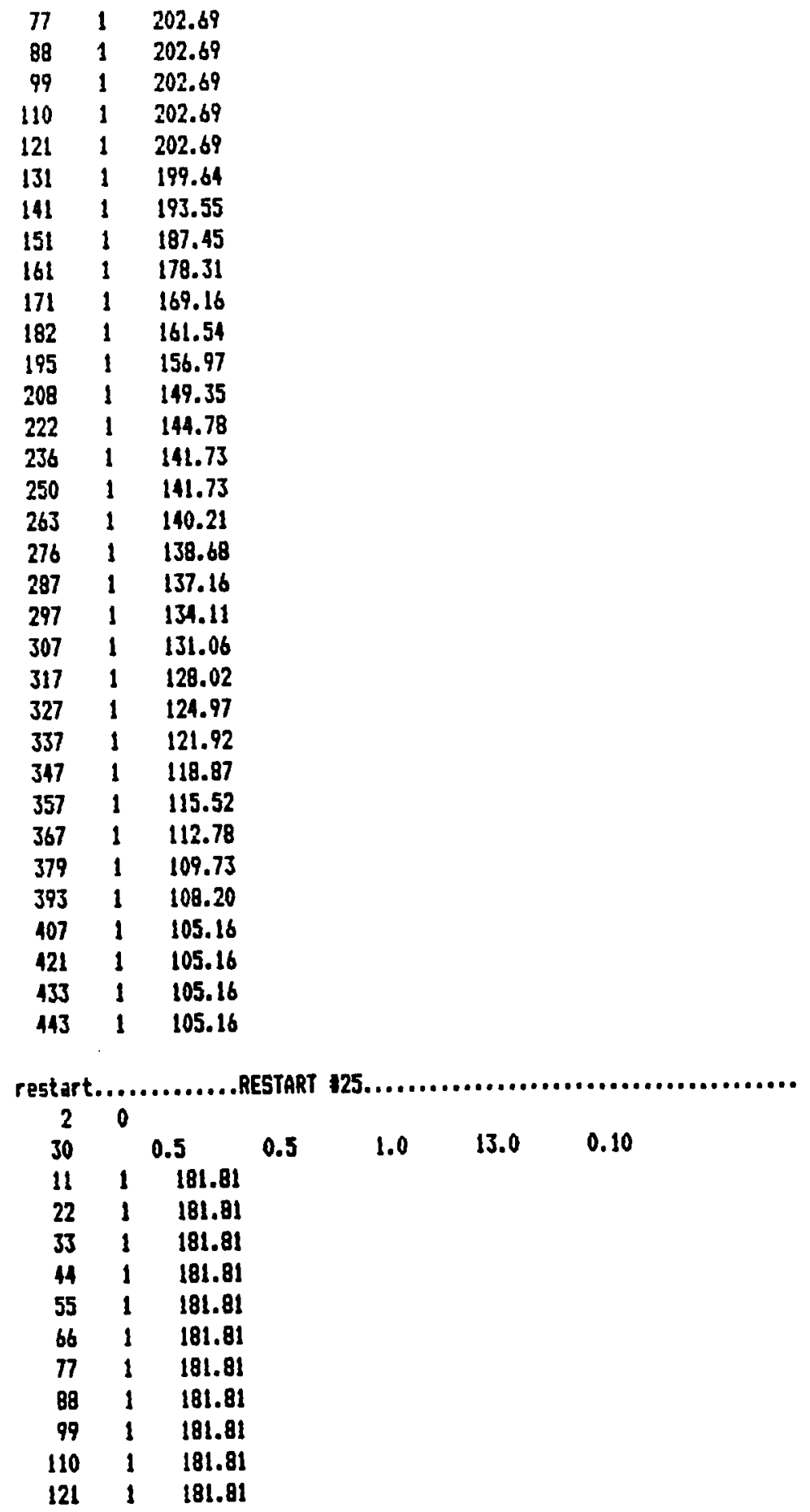




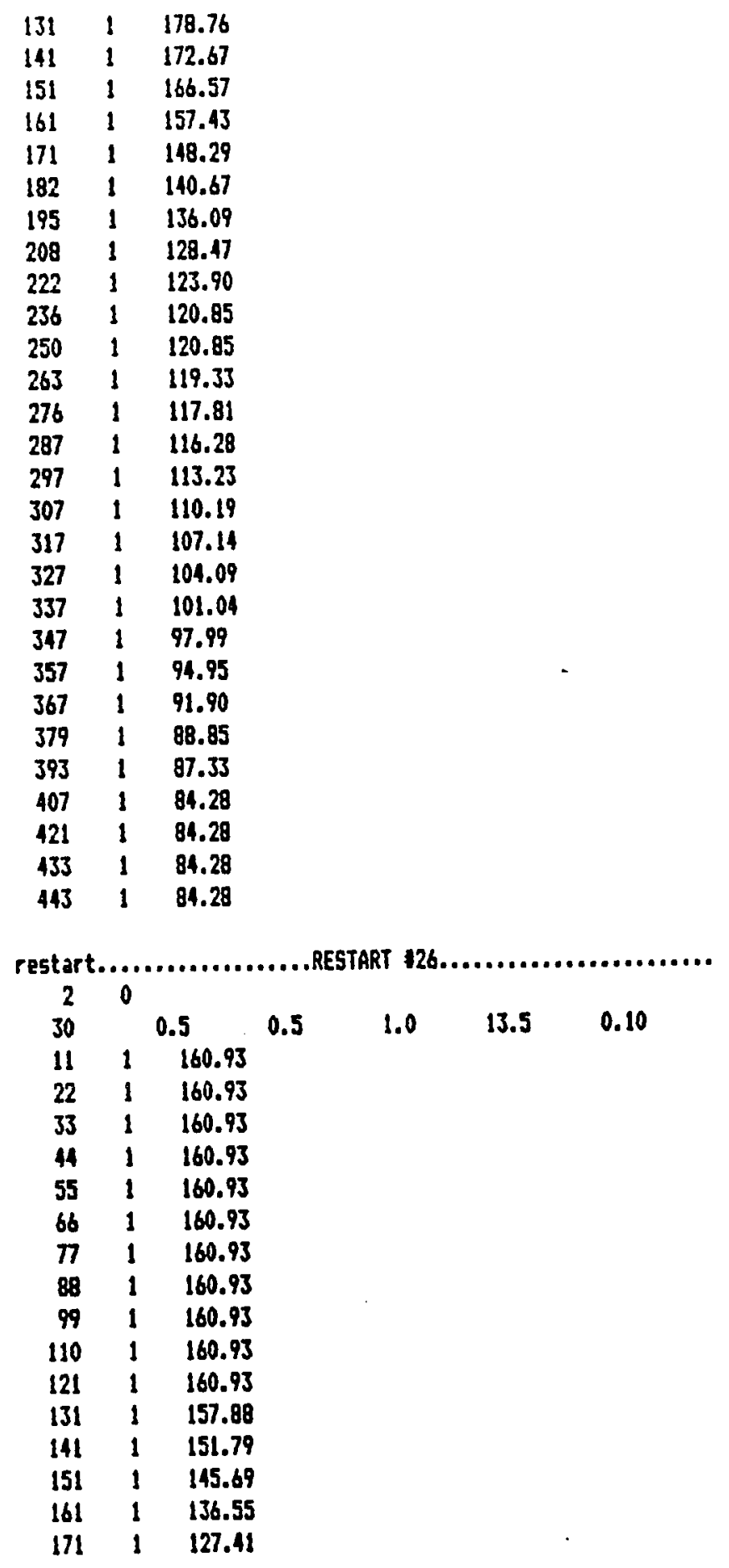




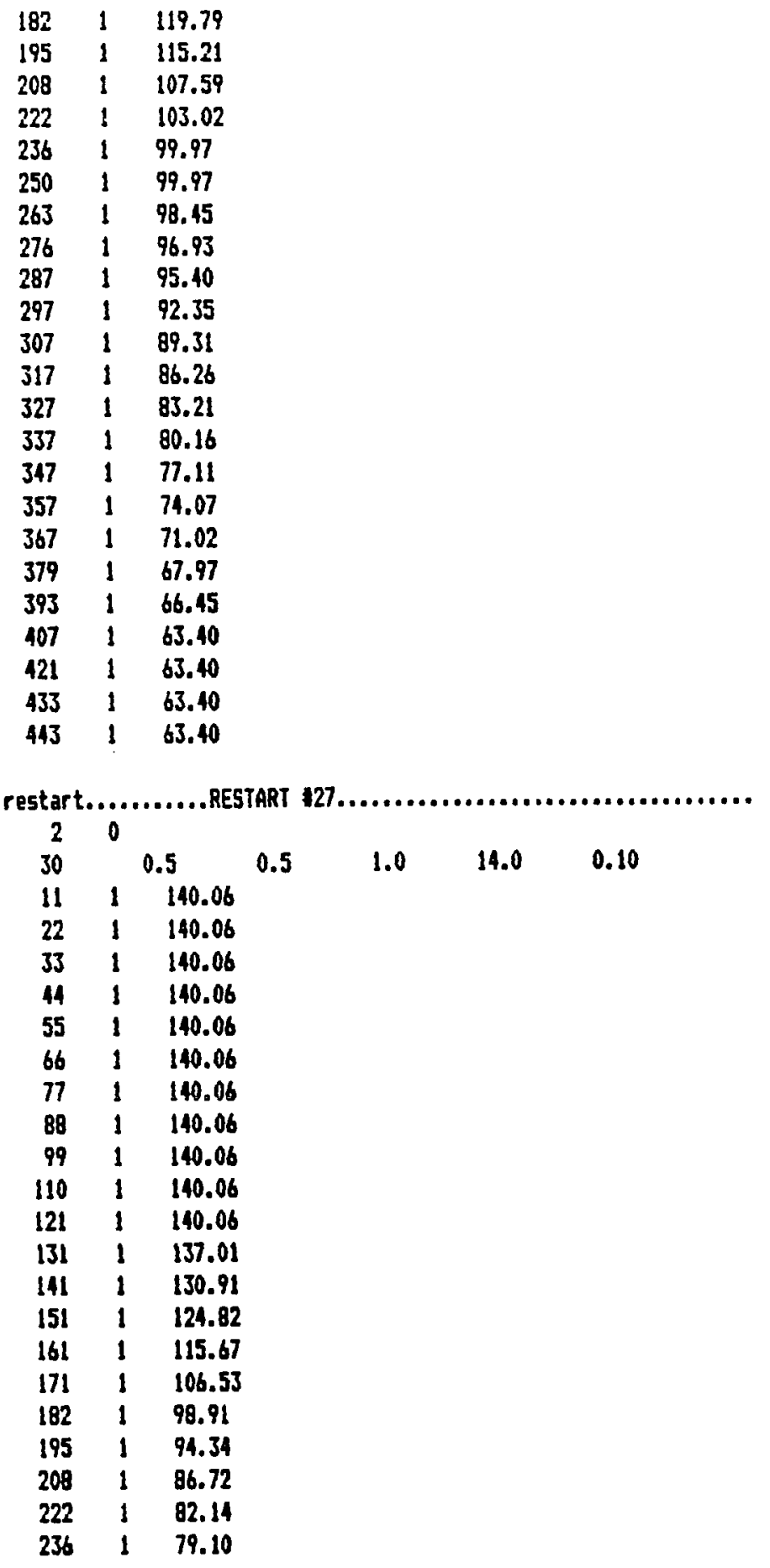




$\begin{array}{lll}250 & 1 & 79.10 \\ 263 & 1 & 77.57 \\ 276 & 1 & 76.05 \\ 287 & 1 & 74.52 \\ 297 & 1 & 71.48 \\ 307 & 1 & 68.43 \\ 317 & 1 & 65.38 \\ 327 & 1 & 62.33 \\ 337 & 1 & 59.28 \\ 347 & 1 & 56.24 \\ 357 & 1 & 53.19 \\ 367 & 1 & 50.14 \\ 379 & 1 & 47.09 \\ 393 & 1 & 45.57 \\ 407 & 1 & 42.52 \\ 421 & 1 & 42.52 \\ 433 & 1 & 42.52 \\ 443 & 1 & 42.52 \\ & & \\ \text { end } & & \end{array}$




\section{APPENDIX E}

Relative Moisture Content Plots 


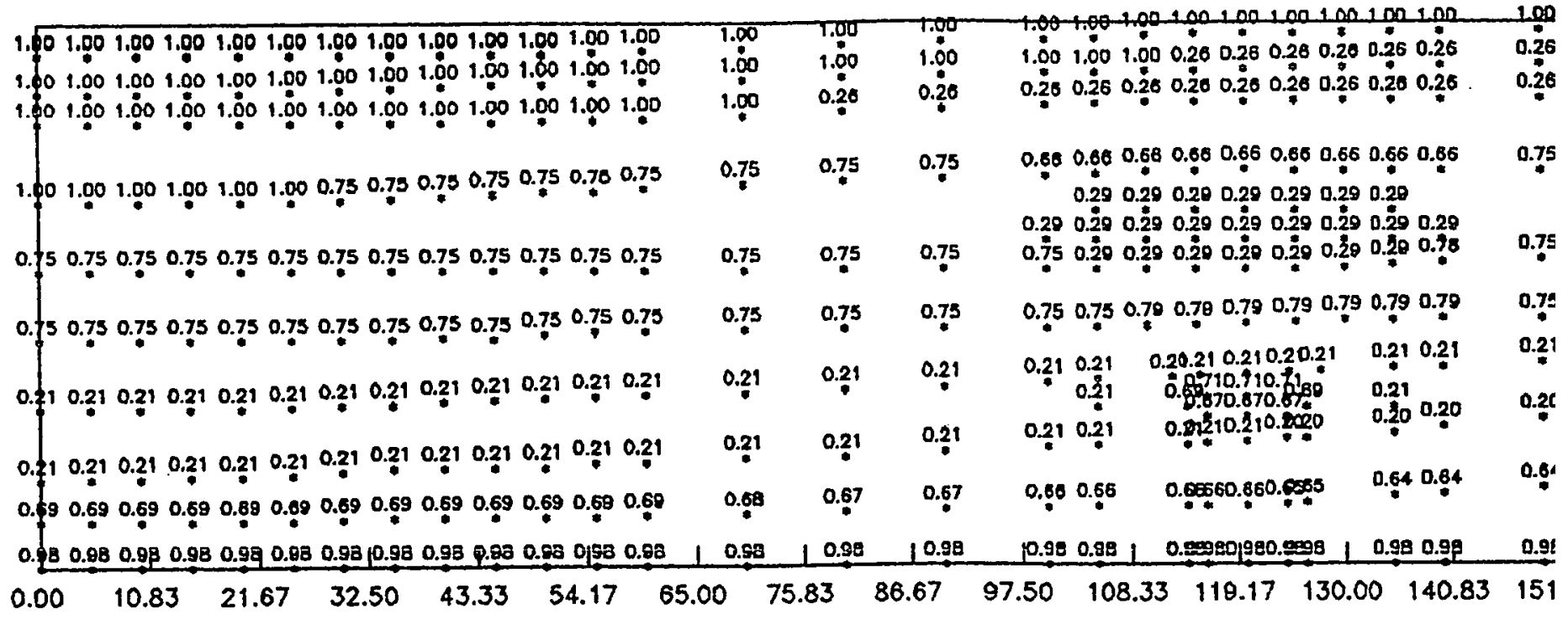

Figure 70. Initial relative moisture content plot of the February 1986 storm. X and $Y$ coordinates are in feet. 
$=$ 
$=$ 


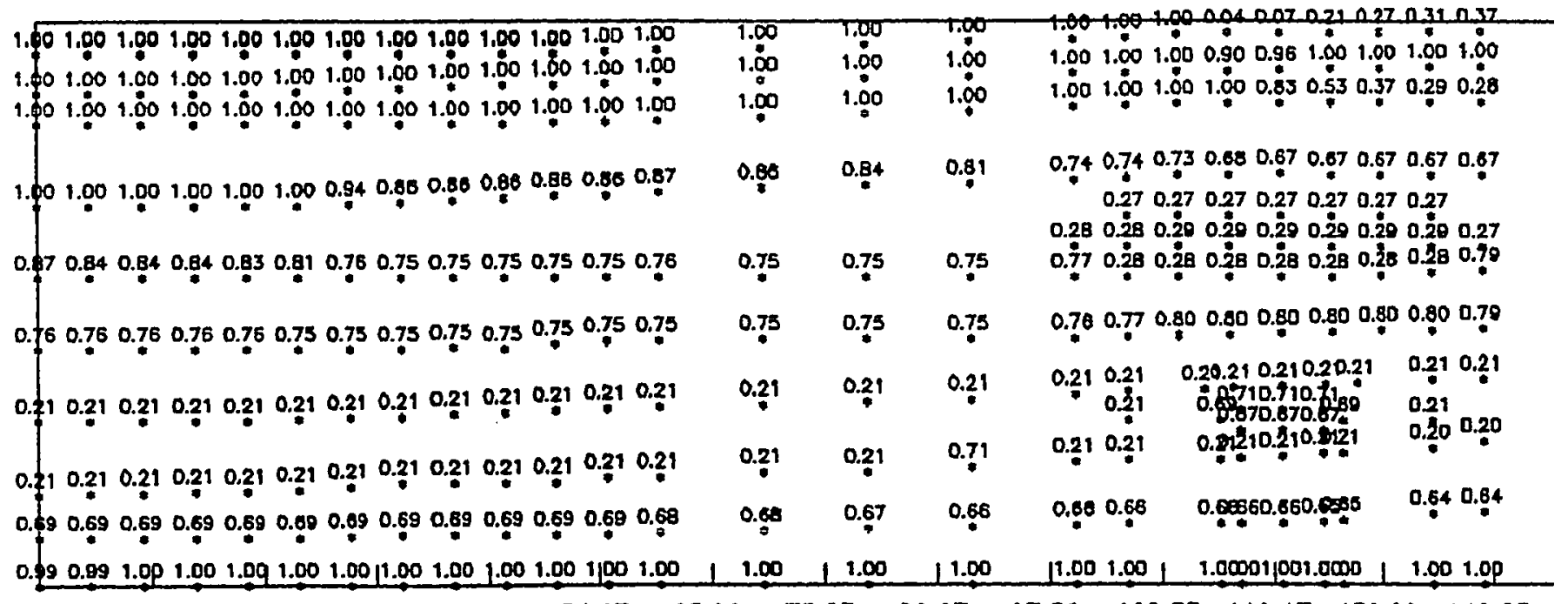

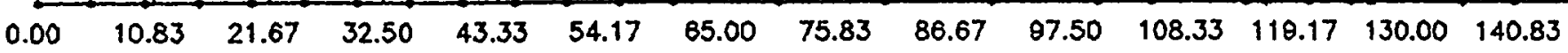

Figure 71. Relative moisture content plot of the February 1986 storm after 1 day of simulation. $\mathrm{X}$ and $\mathrm{Y}$ coordinates are in feet. 


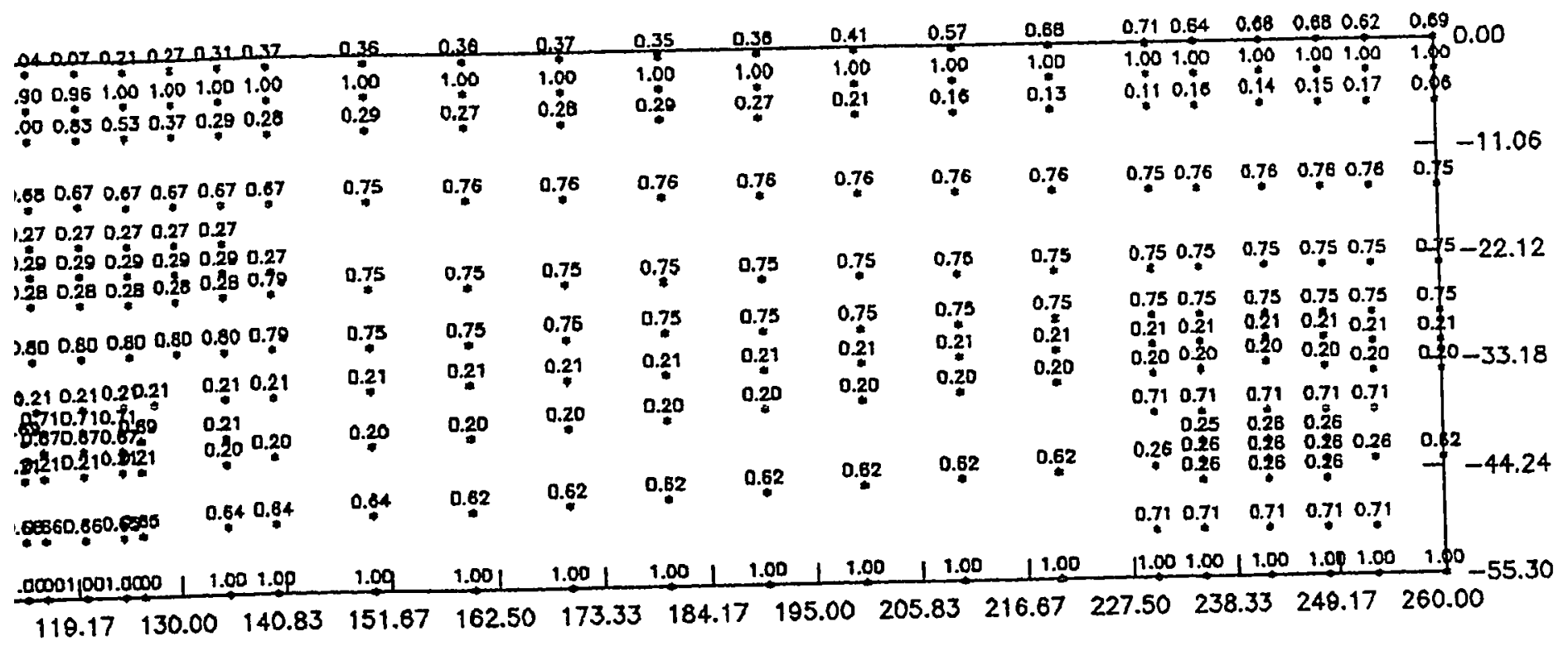




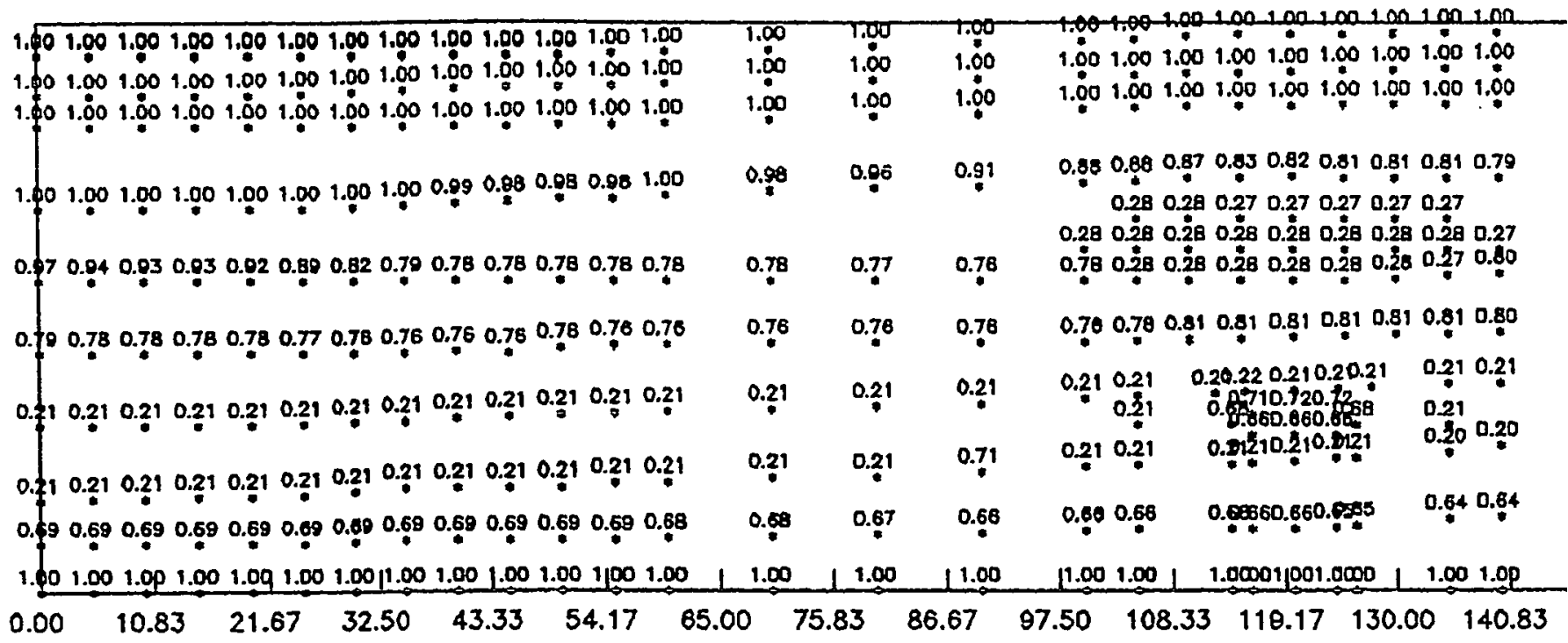

Figure 72. Relative moisture content plot of the February 1986 storm after 2 days of simulation. $\mathrm{X}$ and $\mathrm{Y}$ coordinates are in feet. 
$=$ 


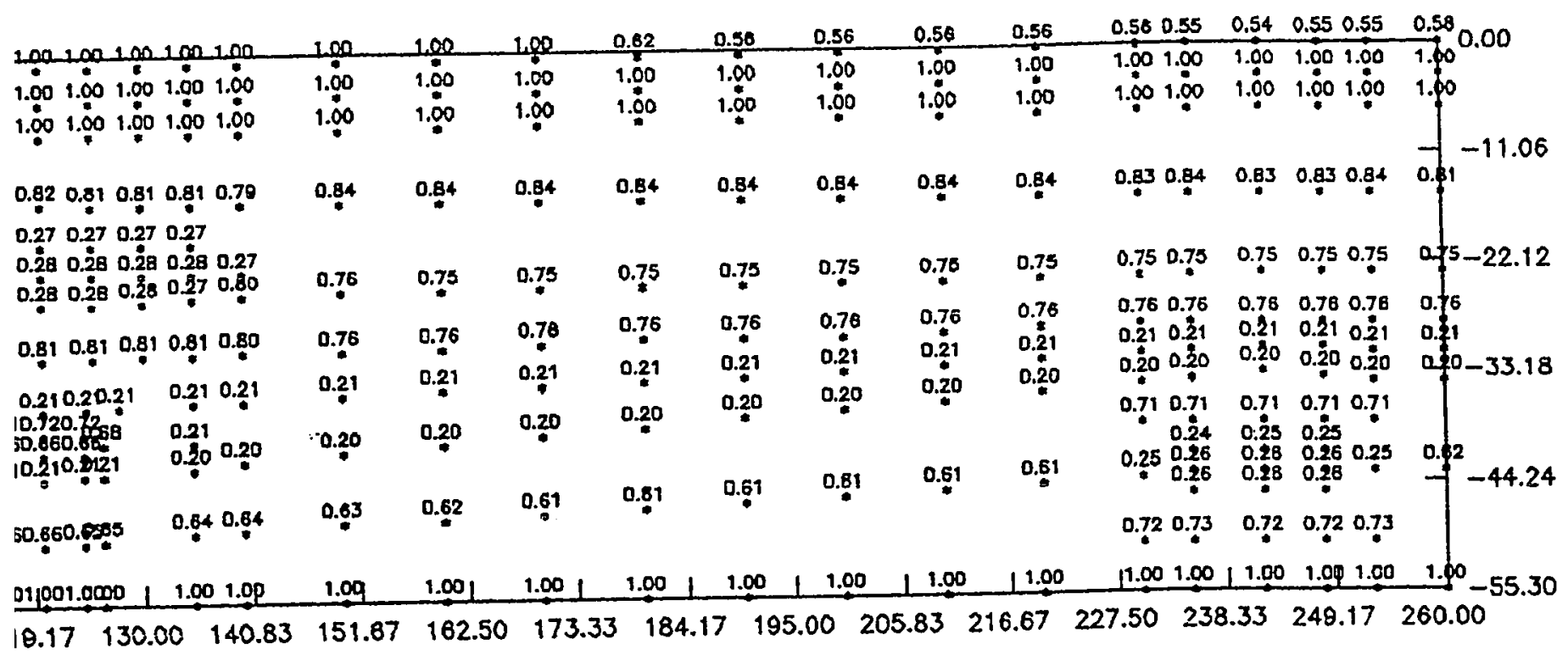




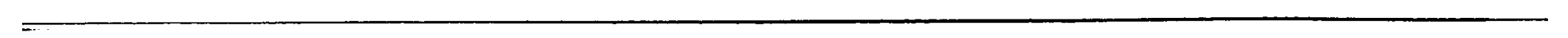




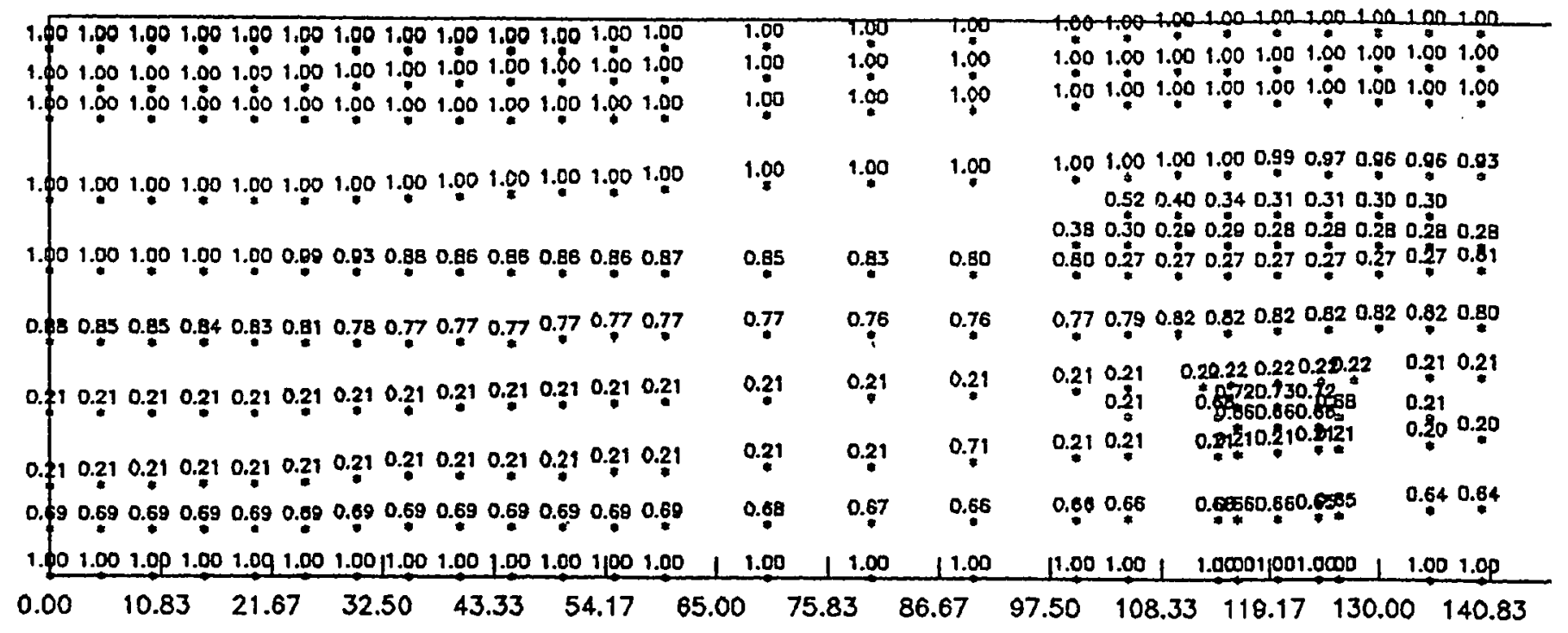

Figure 73. Relative moisture content plot of the February 1986 storm after 3 days of simulation. $\mathrm{X}$ and $\mathrm{Y}$ coordinates are in feet. 
$=$ 


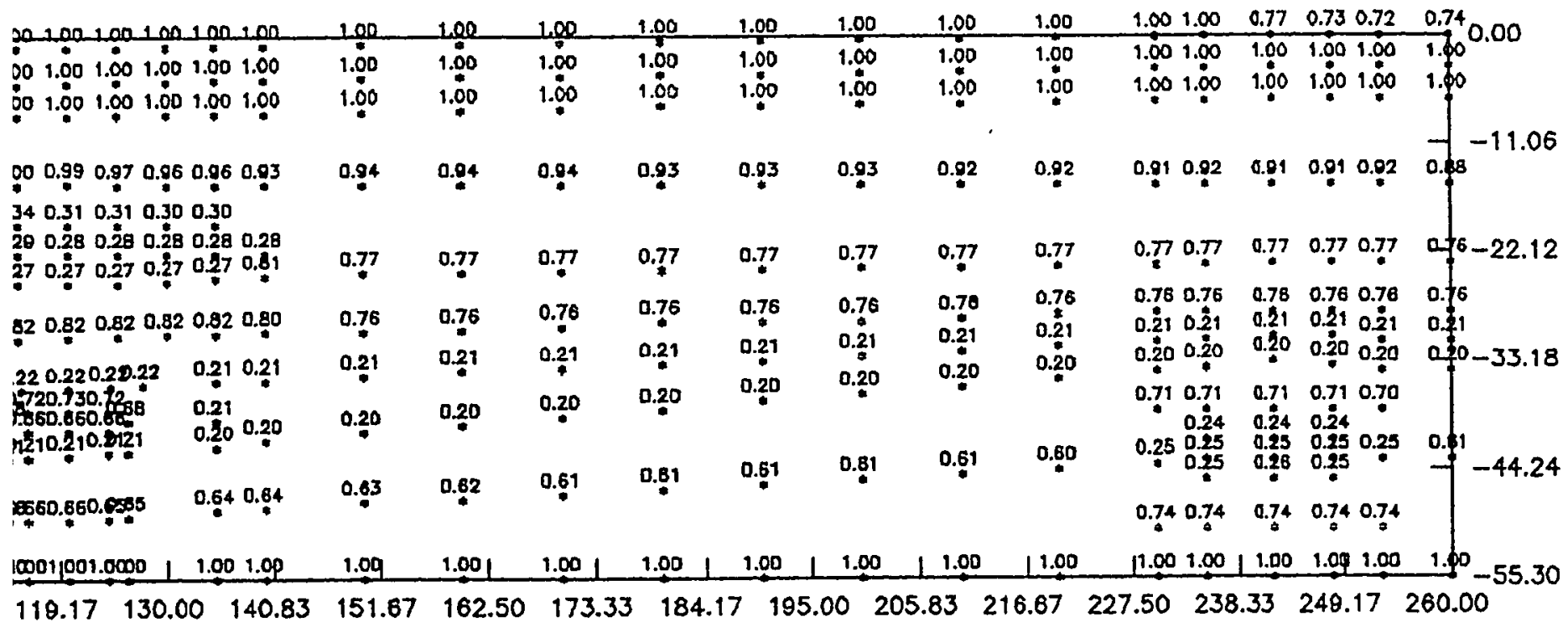




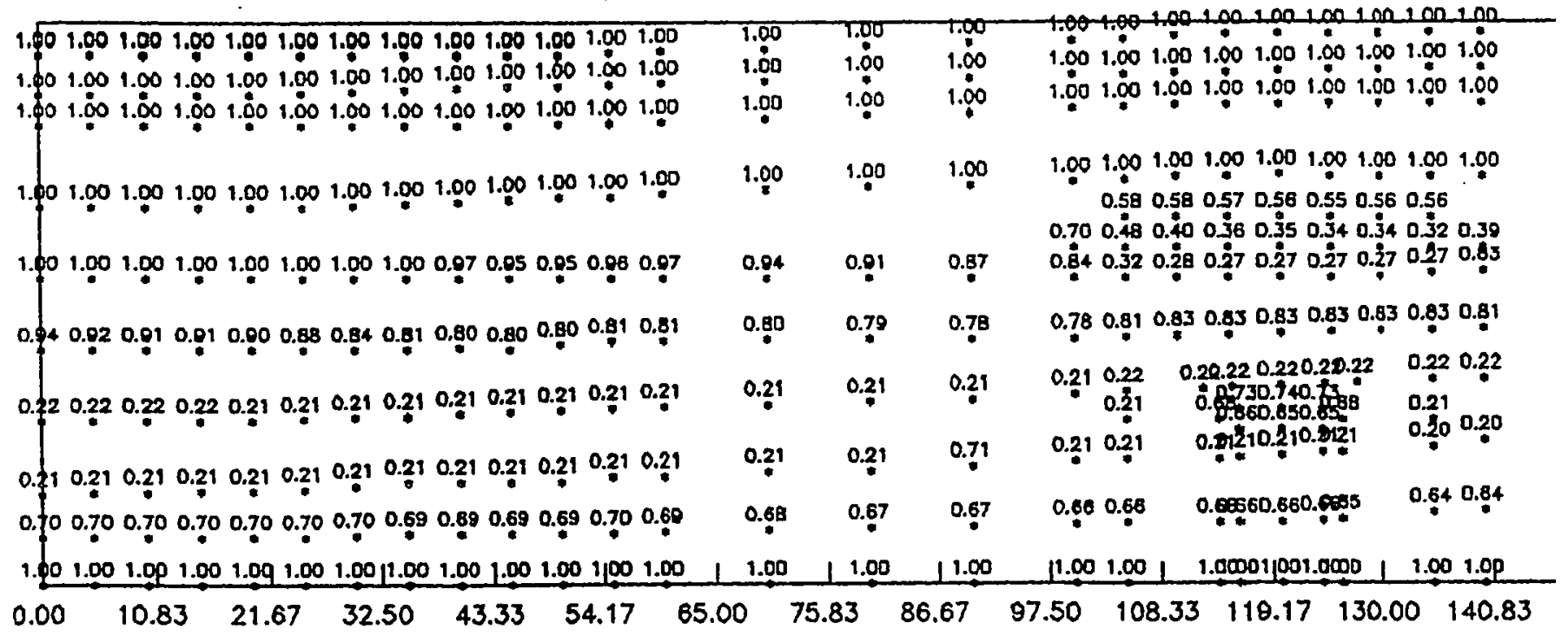

Figure 74. Relative moisture content plot of the February 1986 storm after 4 days of simulation. $\mathrm{X}$ and $\mathrm{Y}$ coordinates are in feet. 
$=$ 


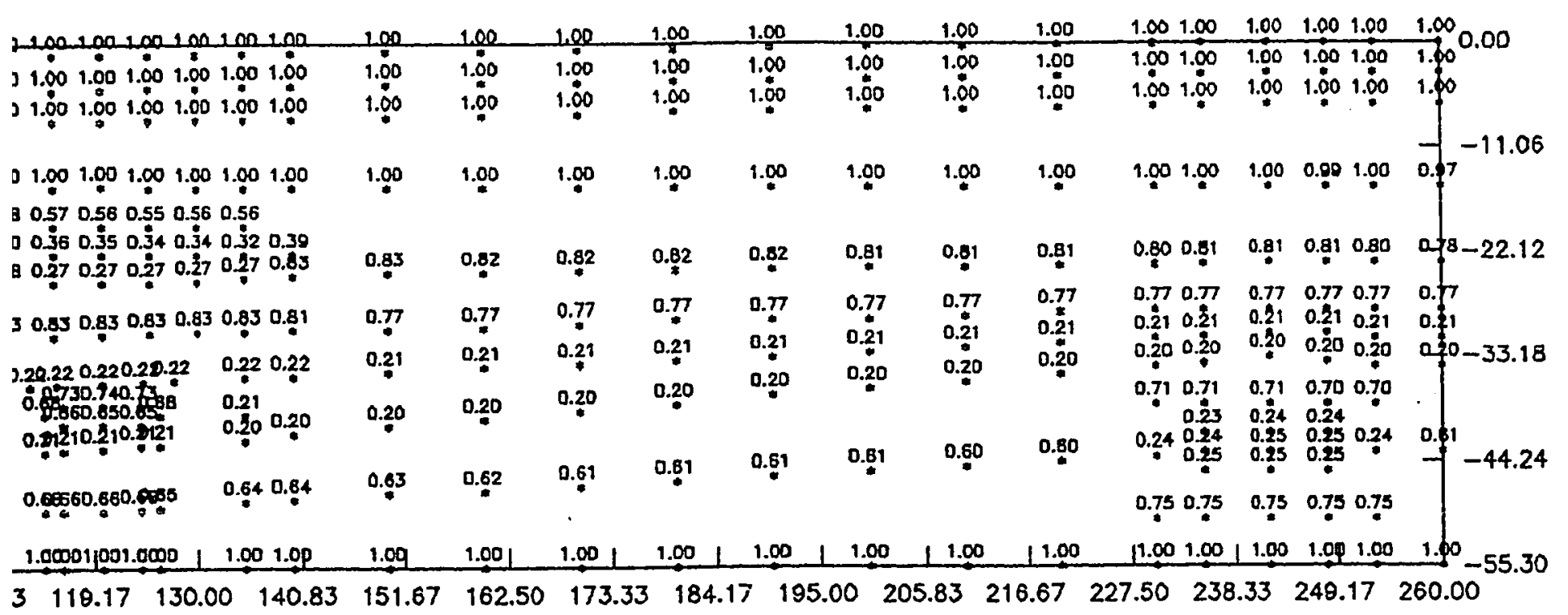


$=$ 


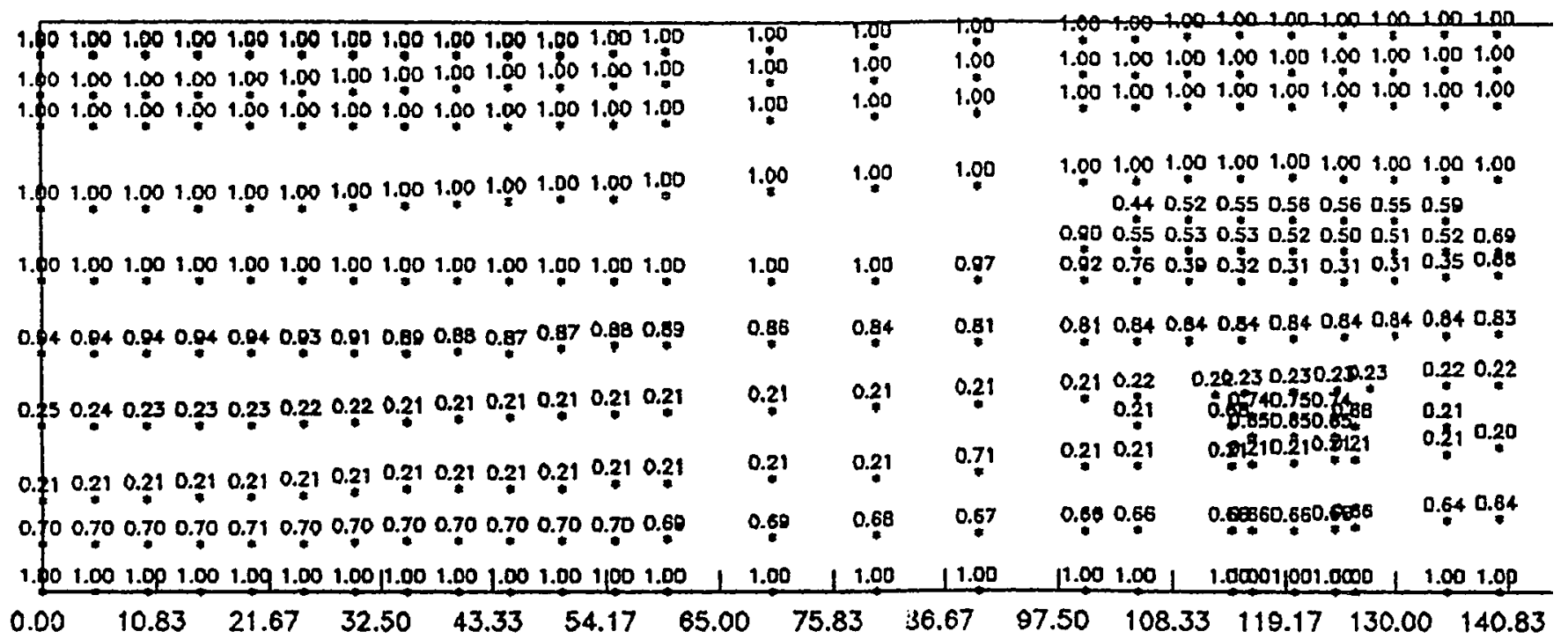

Figure 75. Relative moisture content plot of the February 1986 storm after 5 days of simulation. $\mathrm{X}$ and $\mathrm{Y}$ coordinates are in feet. 
$=$ 


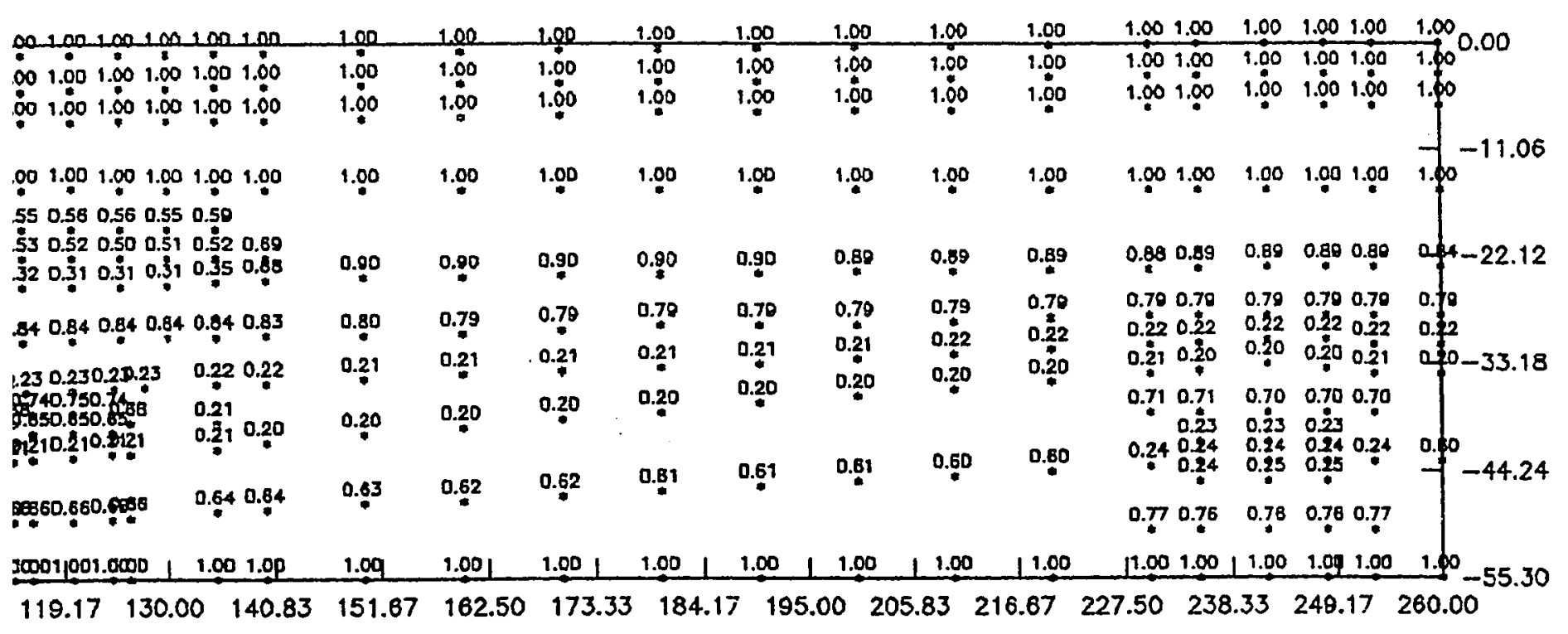




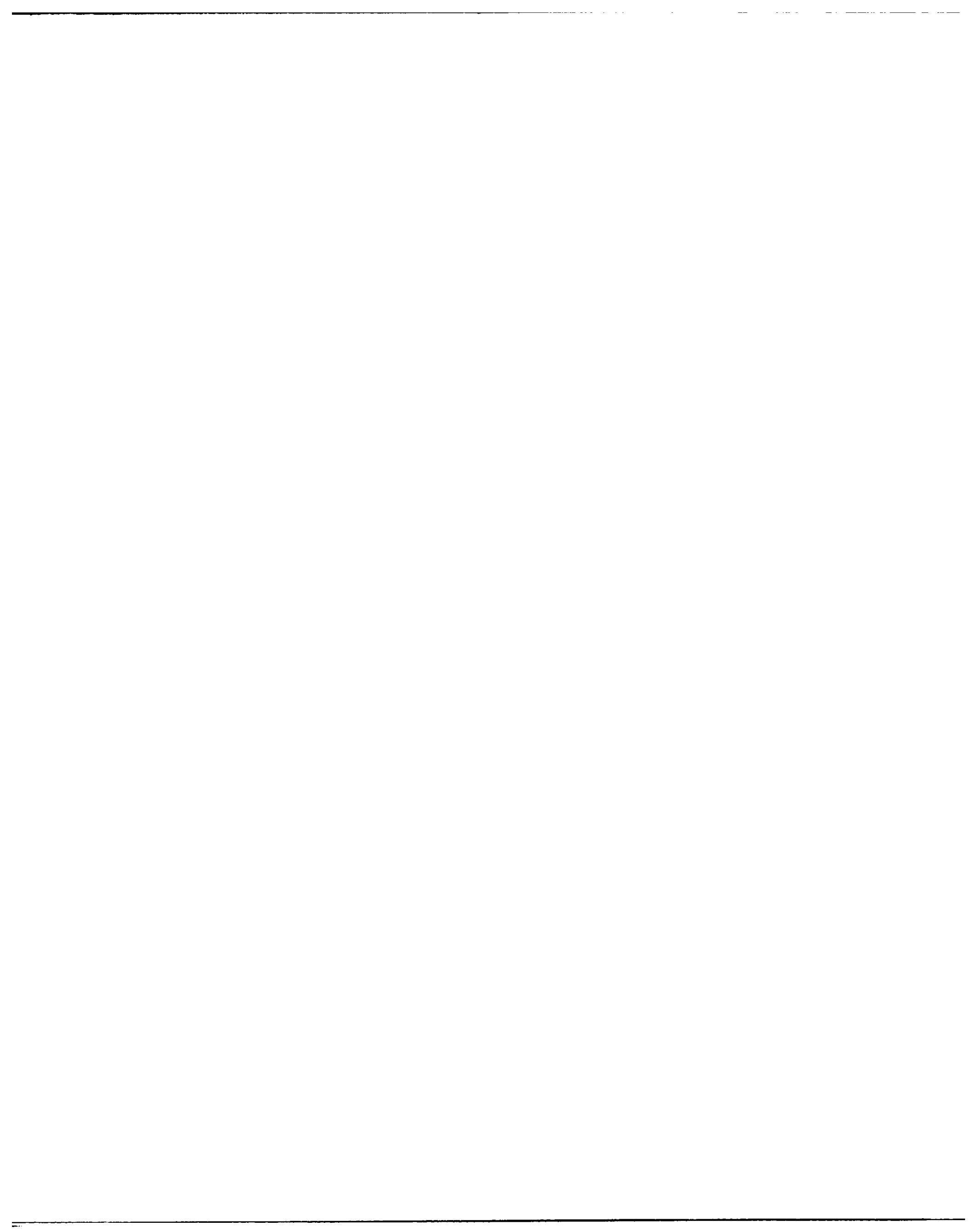




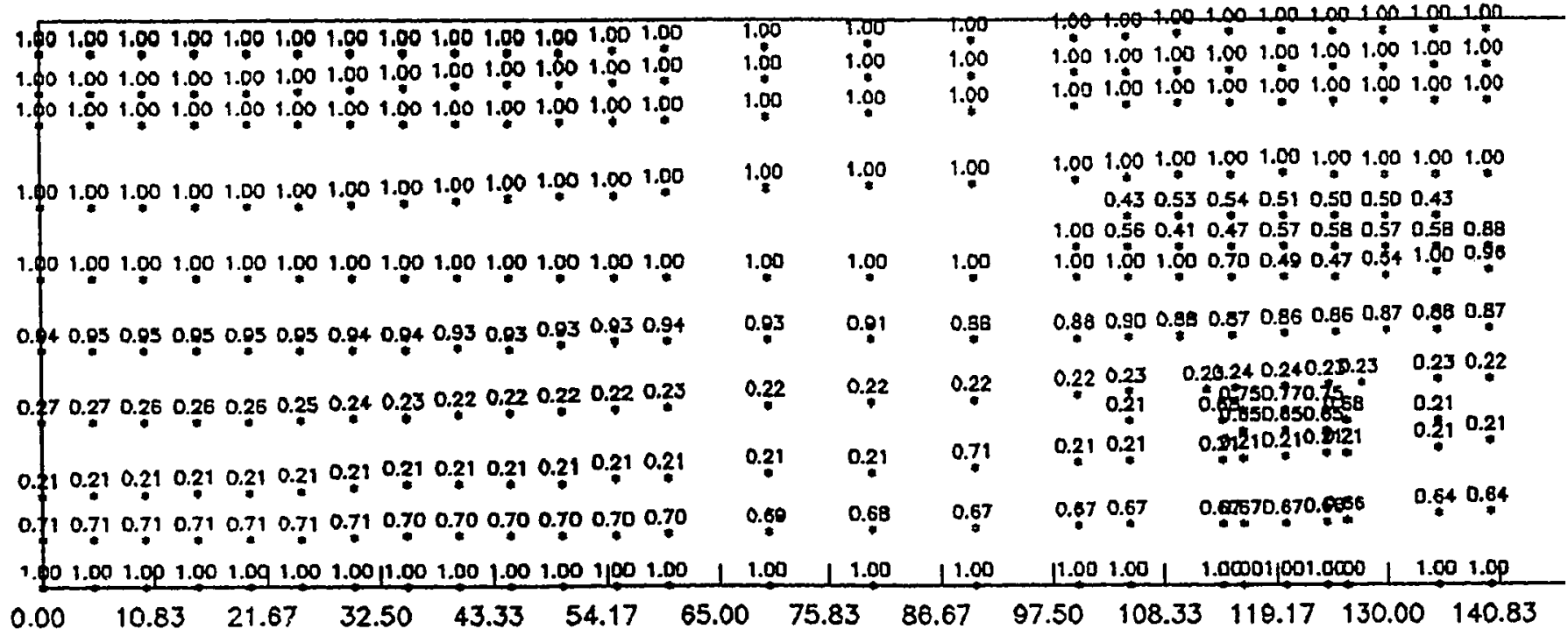

Figure 76. Relative moisture content plot of the February 1986 storm after 6 days of simulation. $\mathrm{X}$ and $\mathrm{Y}$ coordinates are in feet. 
$=$ 


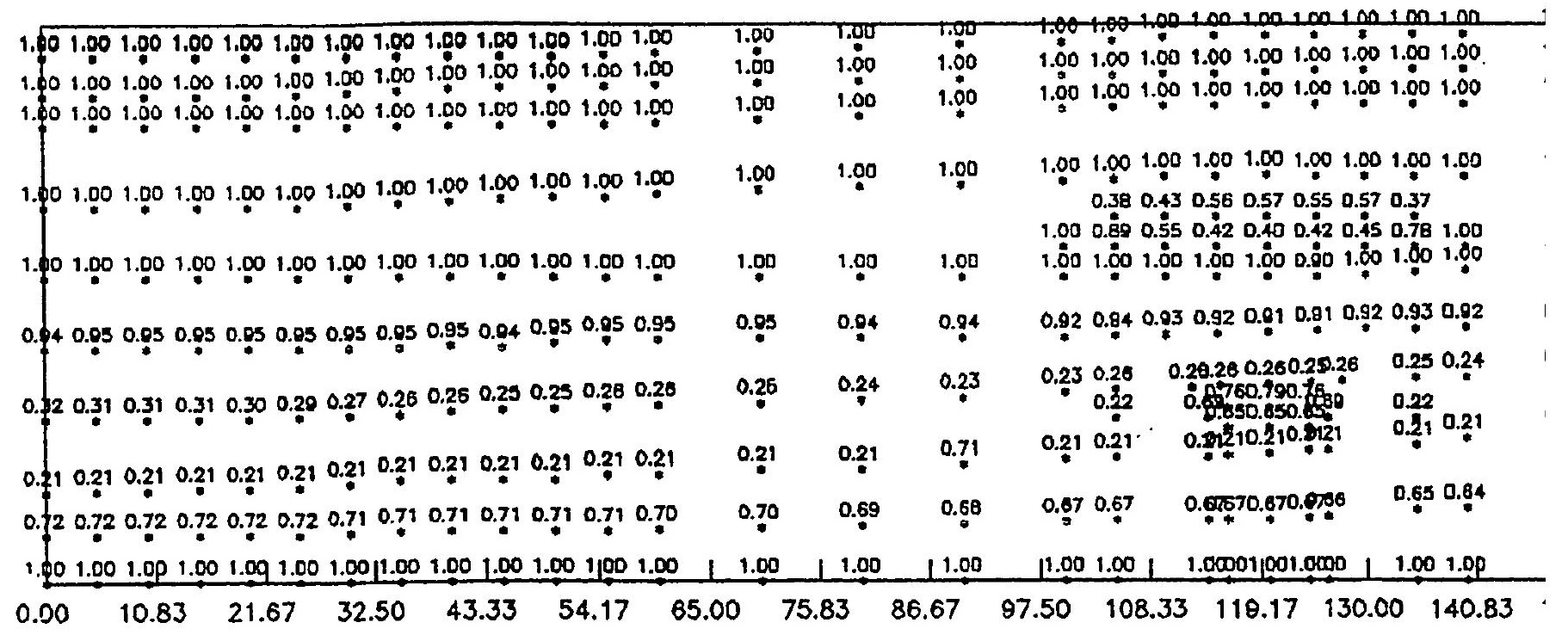

Figure 77. Relative moisture content plot of the February 1986 storm after 7 days of simulation. $\mathrm{X}$ and $\mathrm{Y}$ coordinates are in feet. 
 


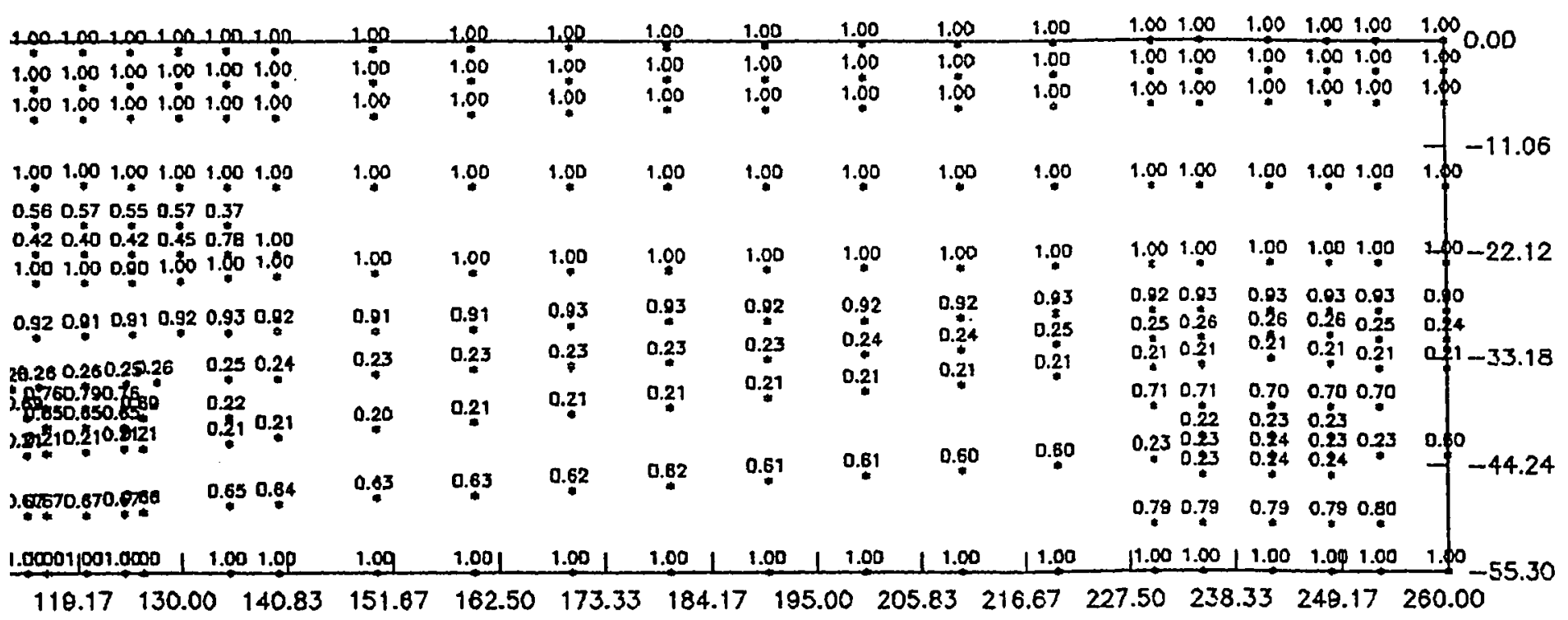




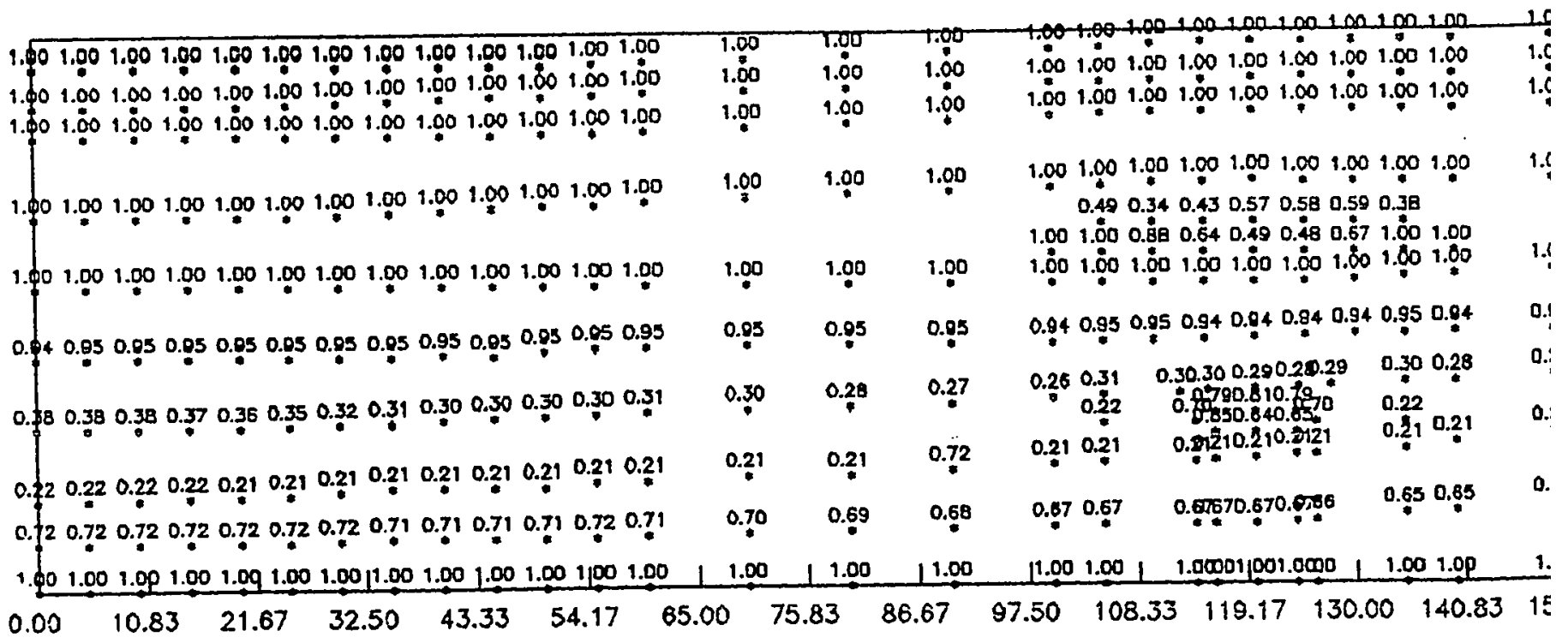

Figure 78. Relative moisture content plot of the February 1986 storm after 8 days of simulation. $\mathrm{X}$ and $\mathrm{Y}$ coordinates are in feet. 


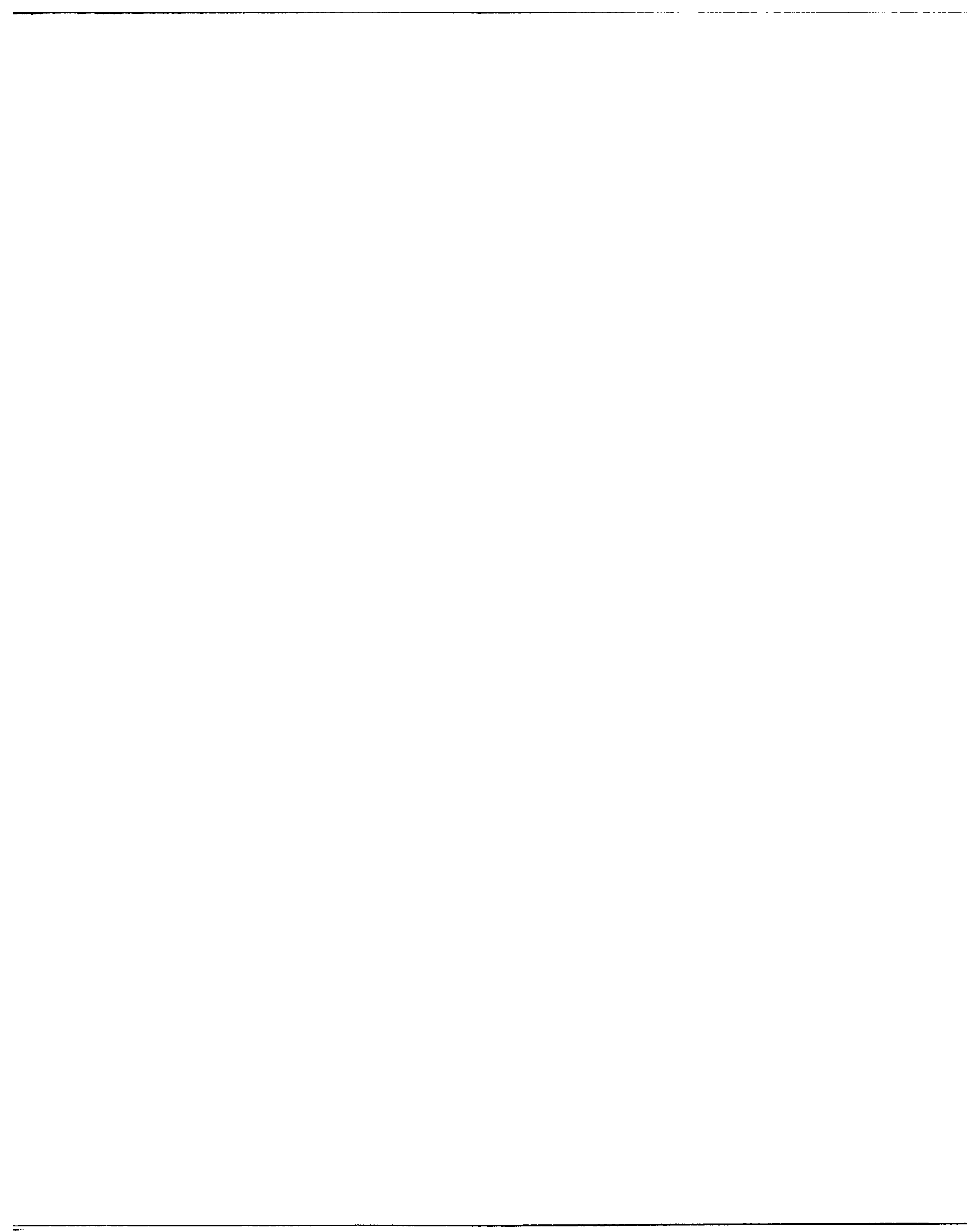




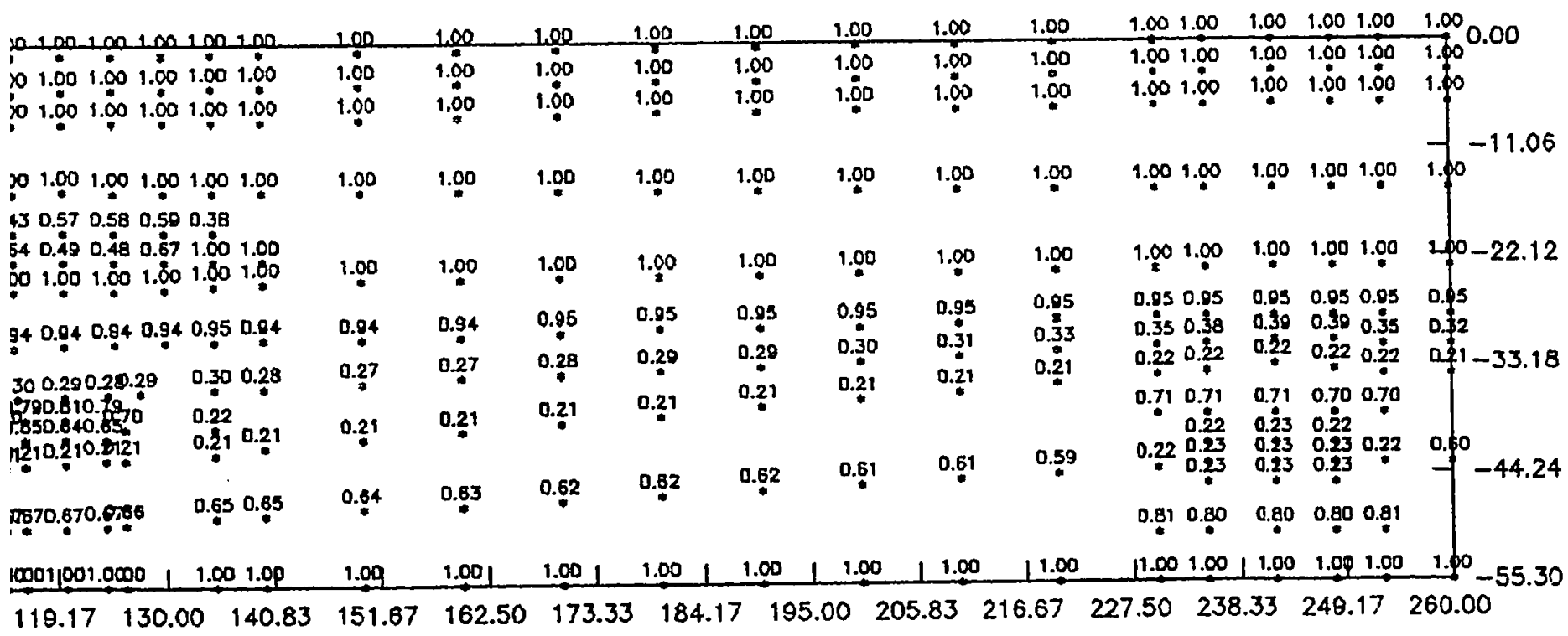




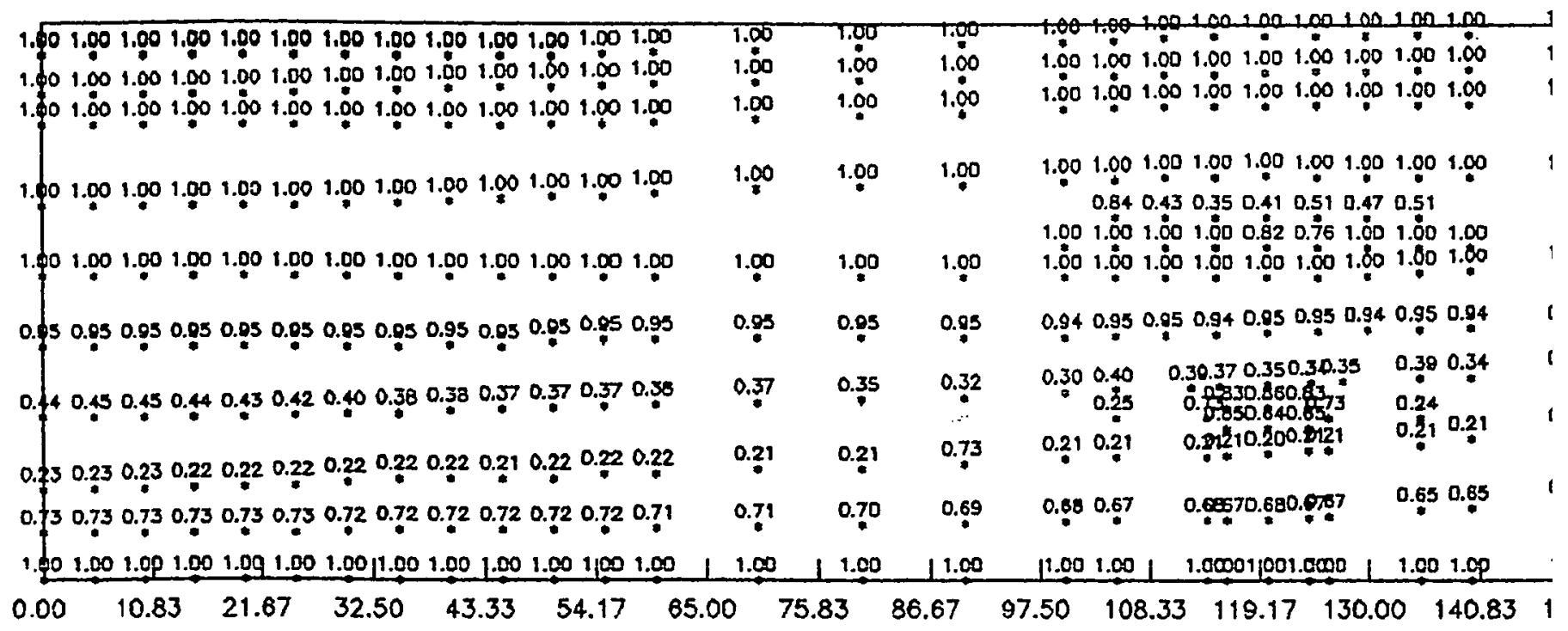

Figure 79. Relative moisture content plot of the February 1986 storm after 9 days of simulation. $\mathrm{X}$ and $\mathrm{Y}$ coordinates are in feet. 
$=$ 


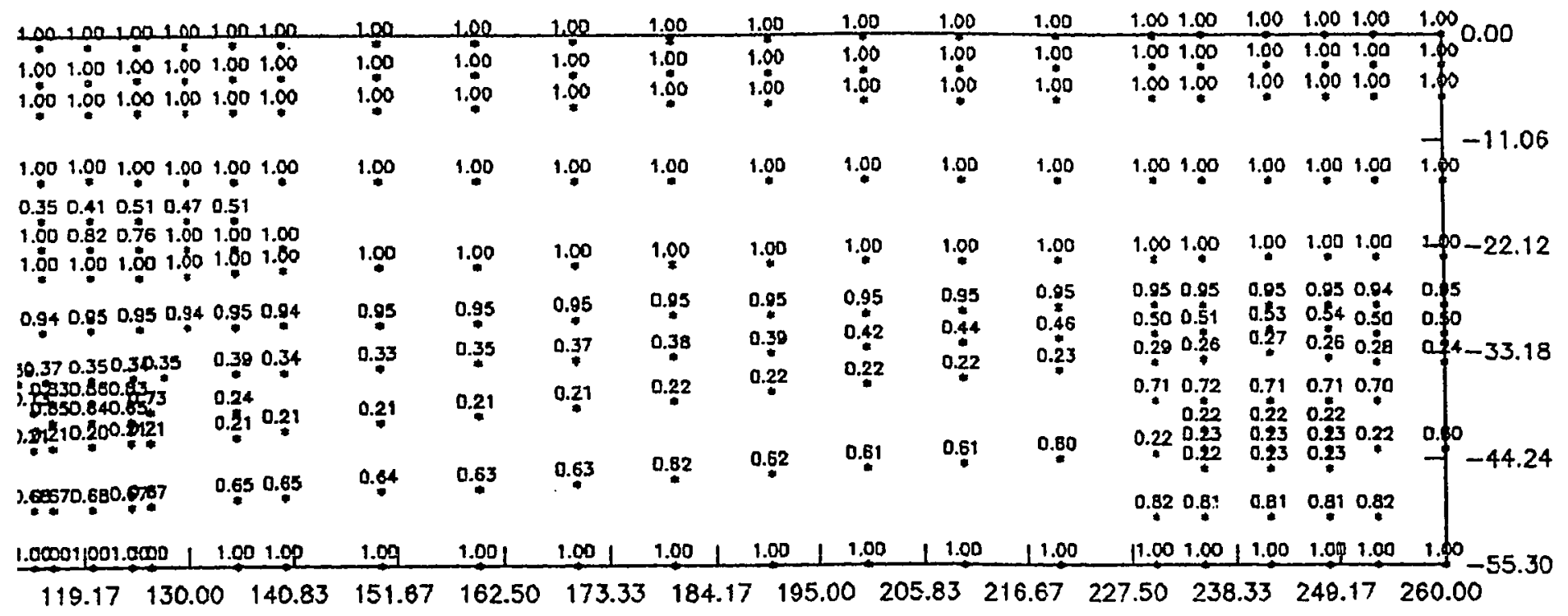




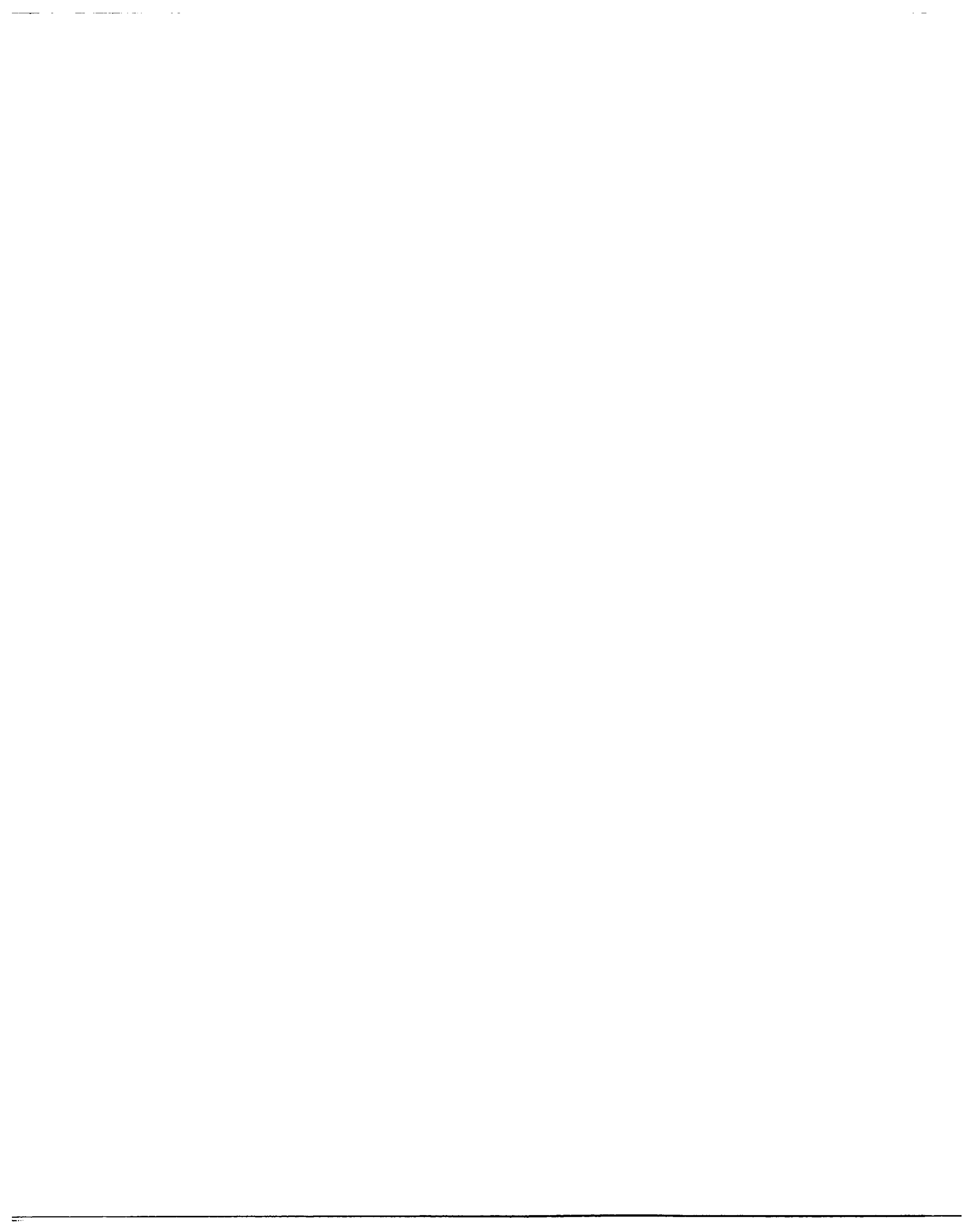




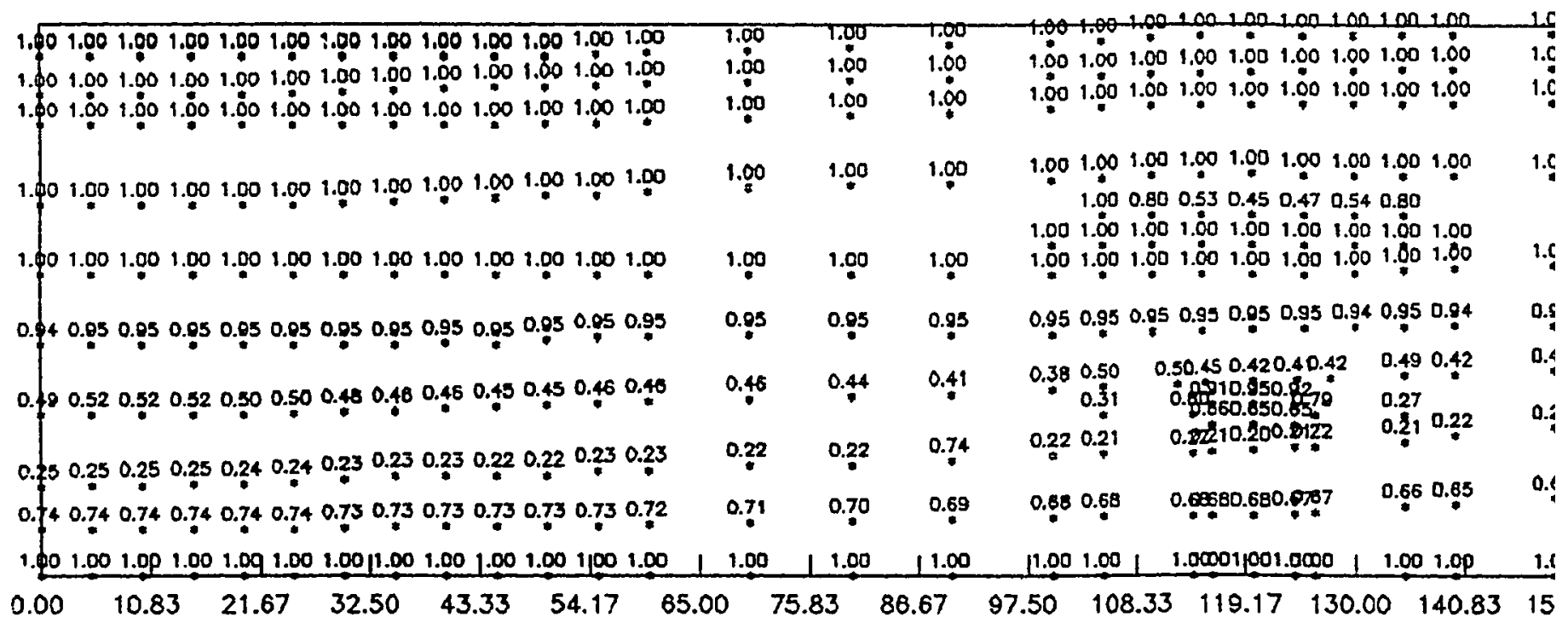

Figure 80. Relative moisture content plot of the February 1986 storm after 10 days of simulation. $\mathrm{X}$ and $\mathrm{Y}$ coordinates are in feet. 
$-$

$=$ 
$=$ 


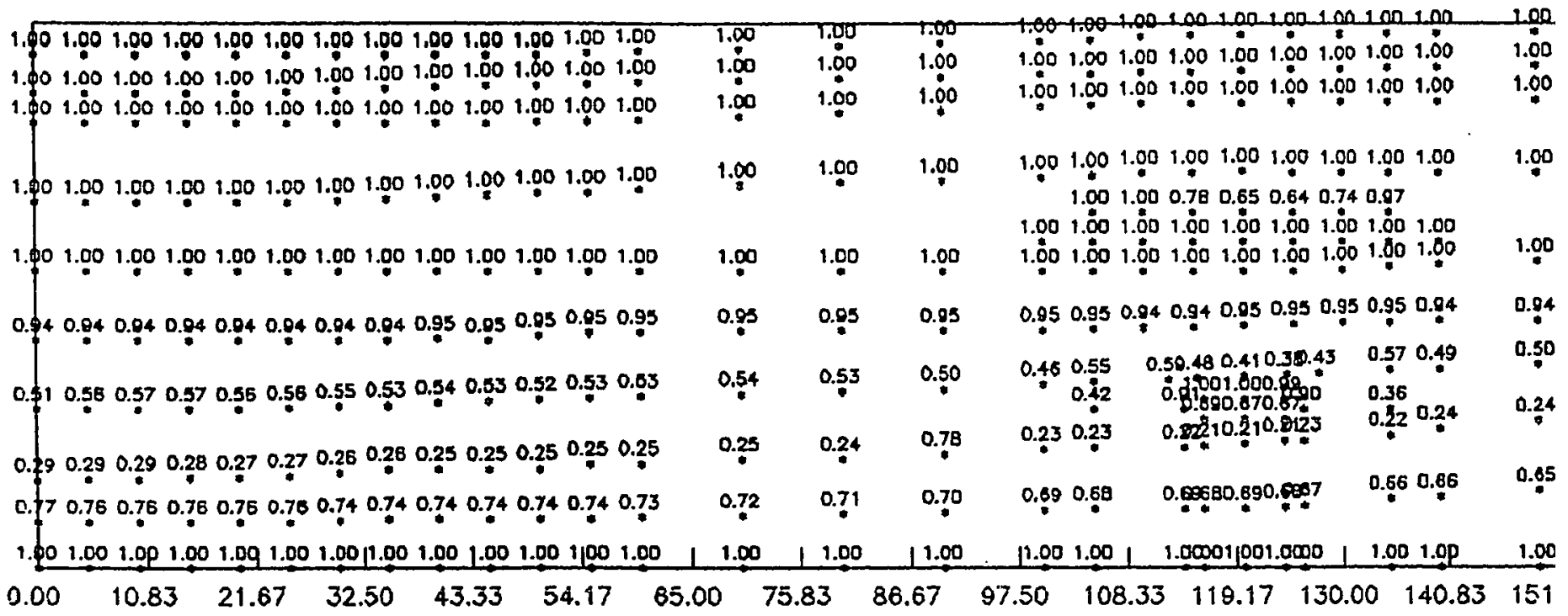

Figure 81. Relative moisture content plot of the February 1986 storm after 11 days of simulation. $\mathrm{X}$ and $\mathrm{Y}$ coordinates are in feet. 
$=$ 
$=$ 


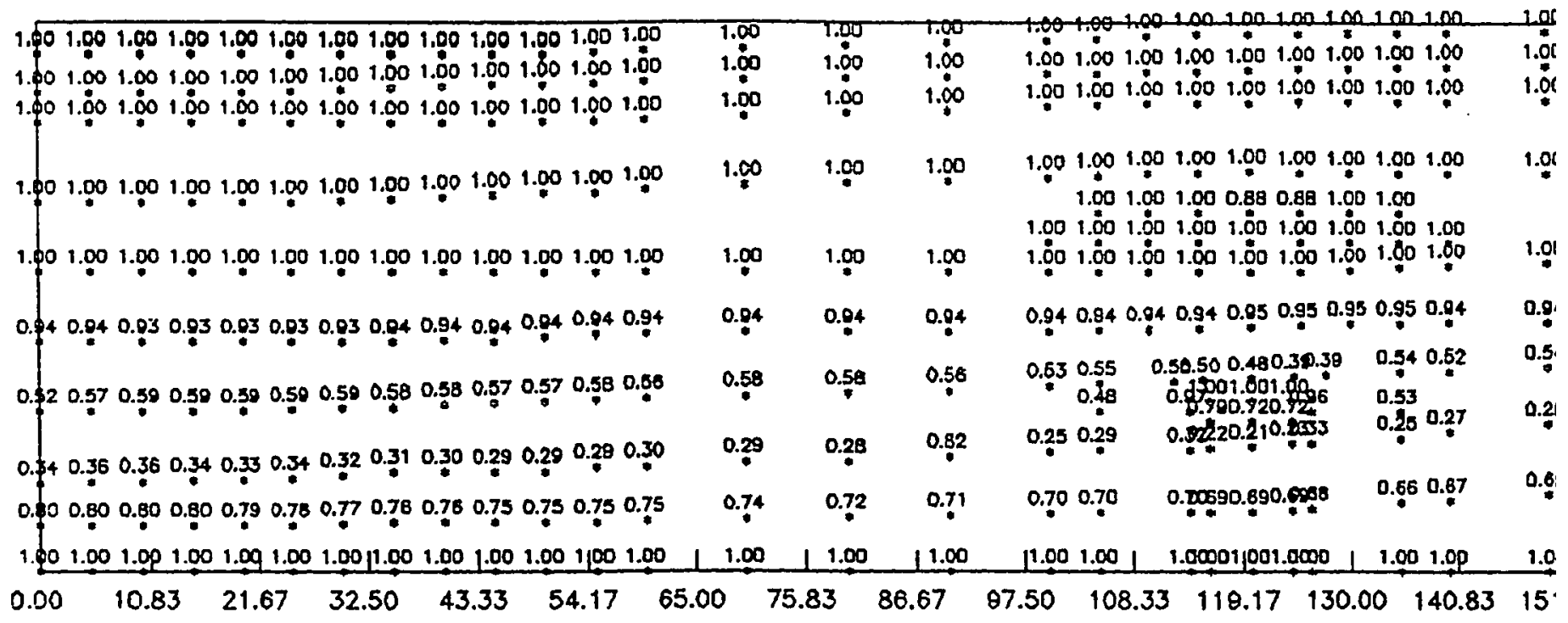

Figure 82. Relative moisture content plot of the February 1986 storm after 12 days of simulation. $\mathrm{X}$ and $\mathrm{Y}$ coordinates are in feet. 
$=$ 
$=$ 


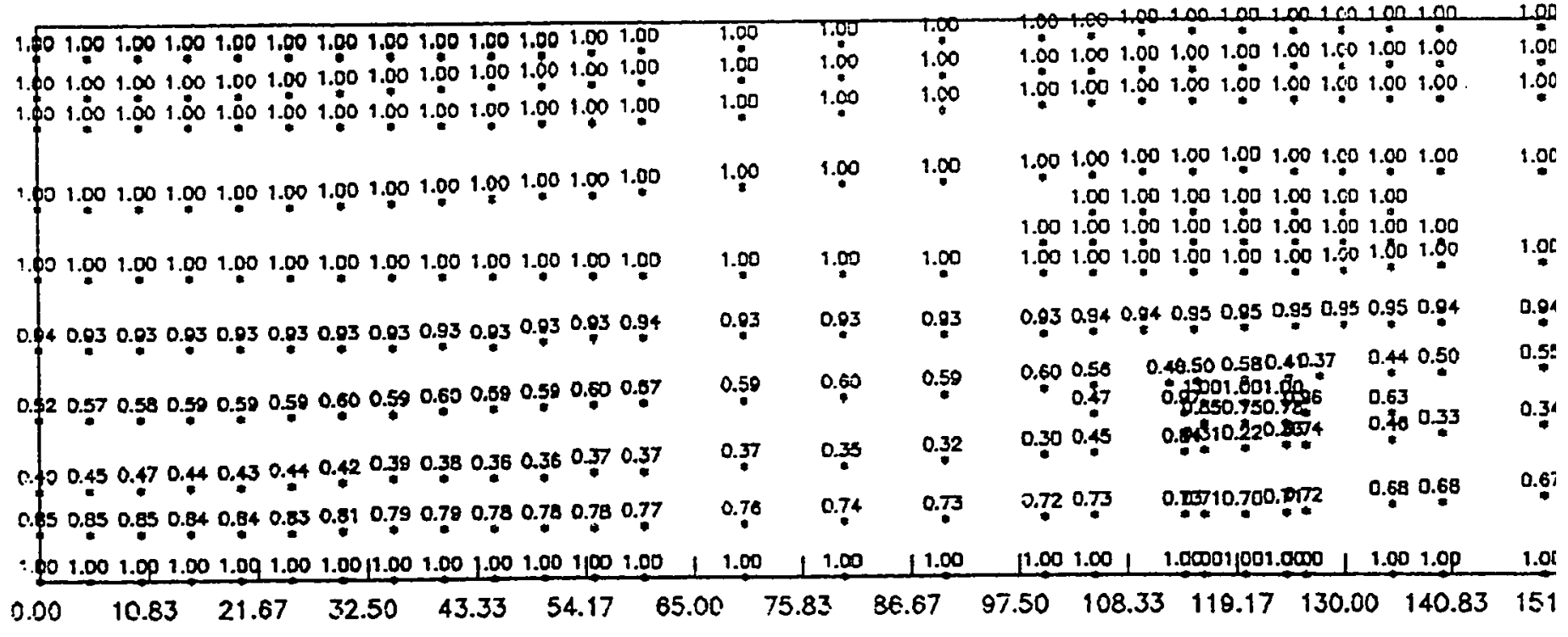

Figure 83. Relative moisture content plot of the February 1986 storm after 13 days of simulation. $\mathrm{X}$ and $\mathrm{Y}$ coordinates are in feet. 
$=$ 


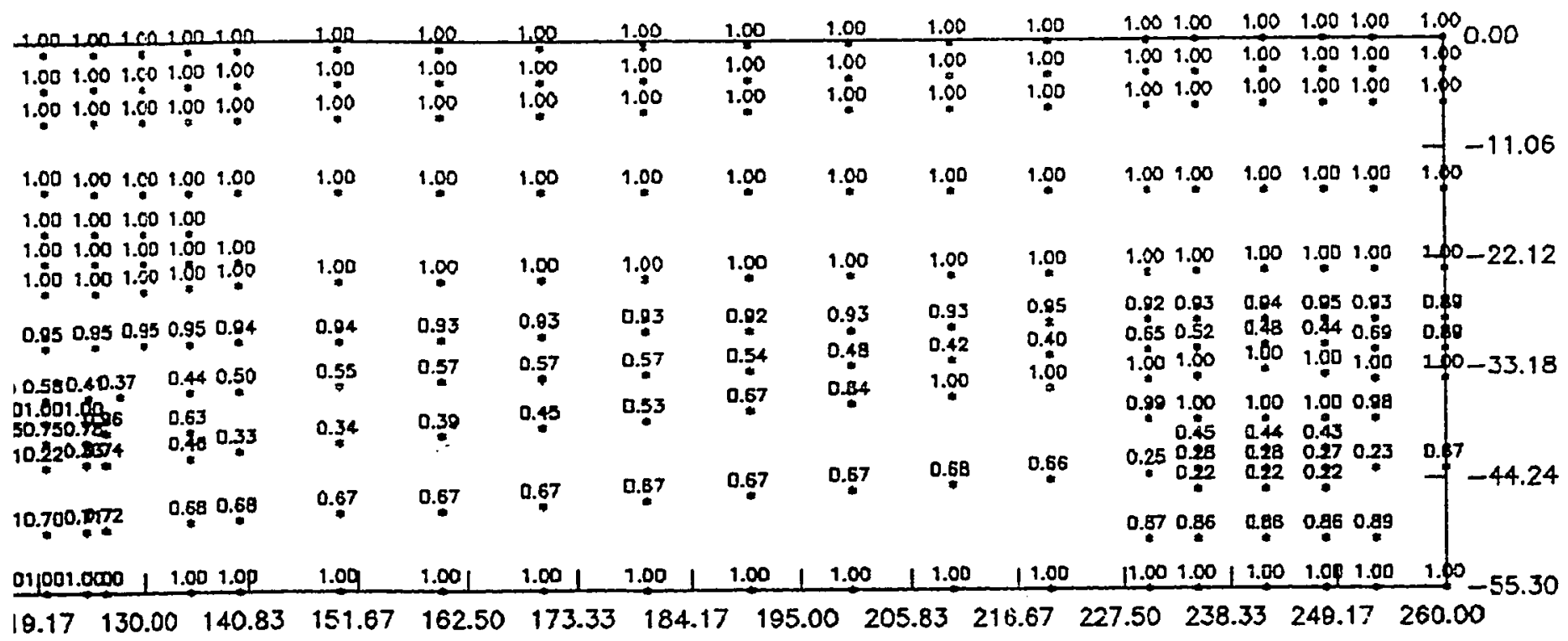




$$
\text { }
$$




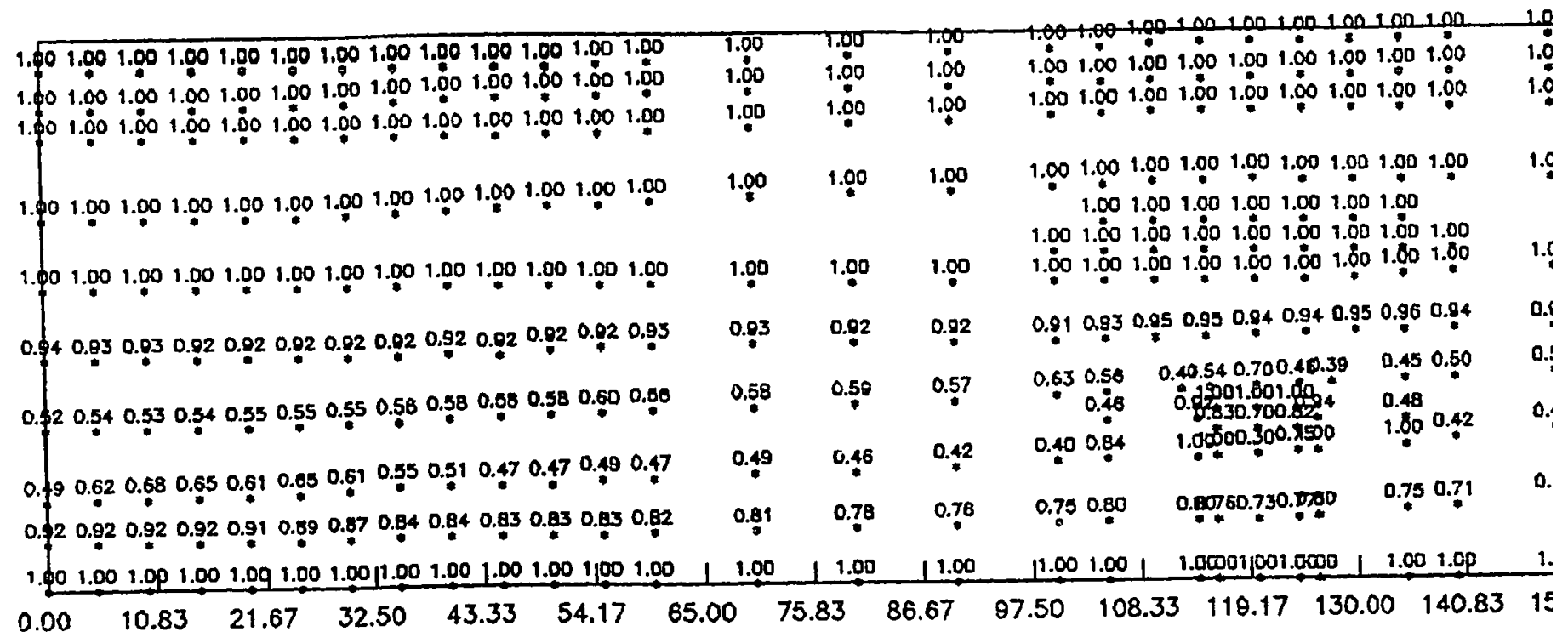

Figure 84. Relative moisture content plot of the February 1986 storm after 14 days of simulation. $\mathrm{X}$ and $\mathrm{Y}$ coordinates are in feet. 


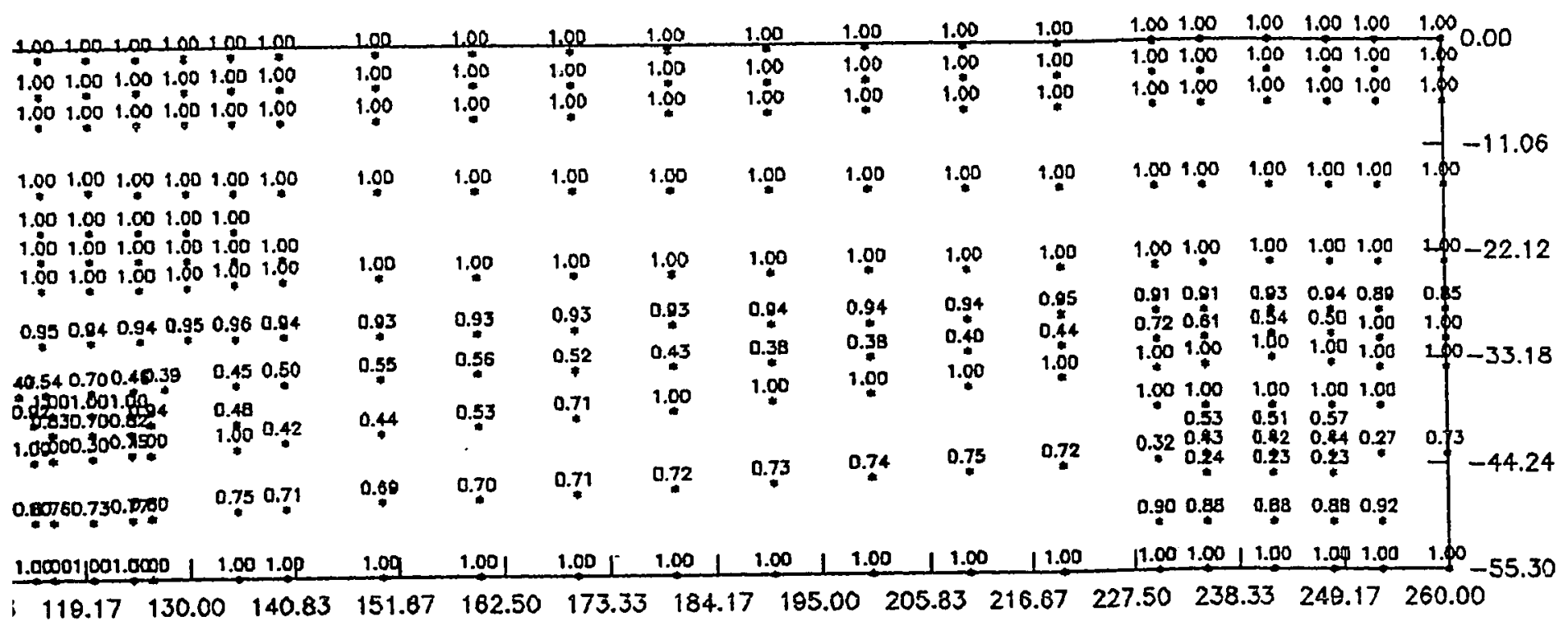


APPENDIX F

Table Comparing Saturated Hydraulic Conductivities 
Table 4. Table comparing the saturated hydraulic conductivities used in the model with those generated from field data and acceptable ranges of expected hydraulic conductivity values for each material.

Comparison of Saturated Hydraulic Conductivity Values of Soils Used in the Computer Model.

\begin{tabular}{clllll}
\hline Material & Description & A & B & C & D \\
\hline 1 & Clayey silt & N/A & $<3$ & $0.001-1$ & 1.6 \\
2 & Silty gravel & N/A & 60 & $100-10000$ & 120 \\
3 & Silt & N/A & N/A & $0.001-10$ & 7 \\
4 & Sand & 680 & N/A & $1-10000$ & 65 \\
5 & Clay & N/A & N/A & $0.000001-0.01$ & 1.04 \\
\hline
\end{tabular}

$A=$ Hydraulic Conductivity from Permeameter Test (cm/day)

$\mathrm{B}=$ Hydraulic Conductivity from Infiltrometer Test (cm/day)

$\mathrm{C}=$ Range of Hydraulic Conductivity Values from Freeze and Cherry (1979) (cm/day)

D = Model Saturated Hydraulic Conductivity Input (cm/day) 